Pedro Lozada Ayala

\title{
DYNAMIC SYSTEM PERFORMANCE ANALYSIS OF A NOVEL GRID CONNECTION TOPOLOGY FOR OFFSHORE WIND FARMS USING MMC-HVDC TRANSMISSION
}

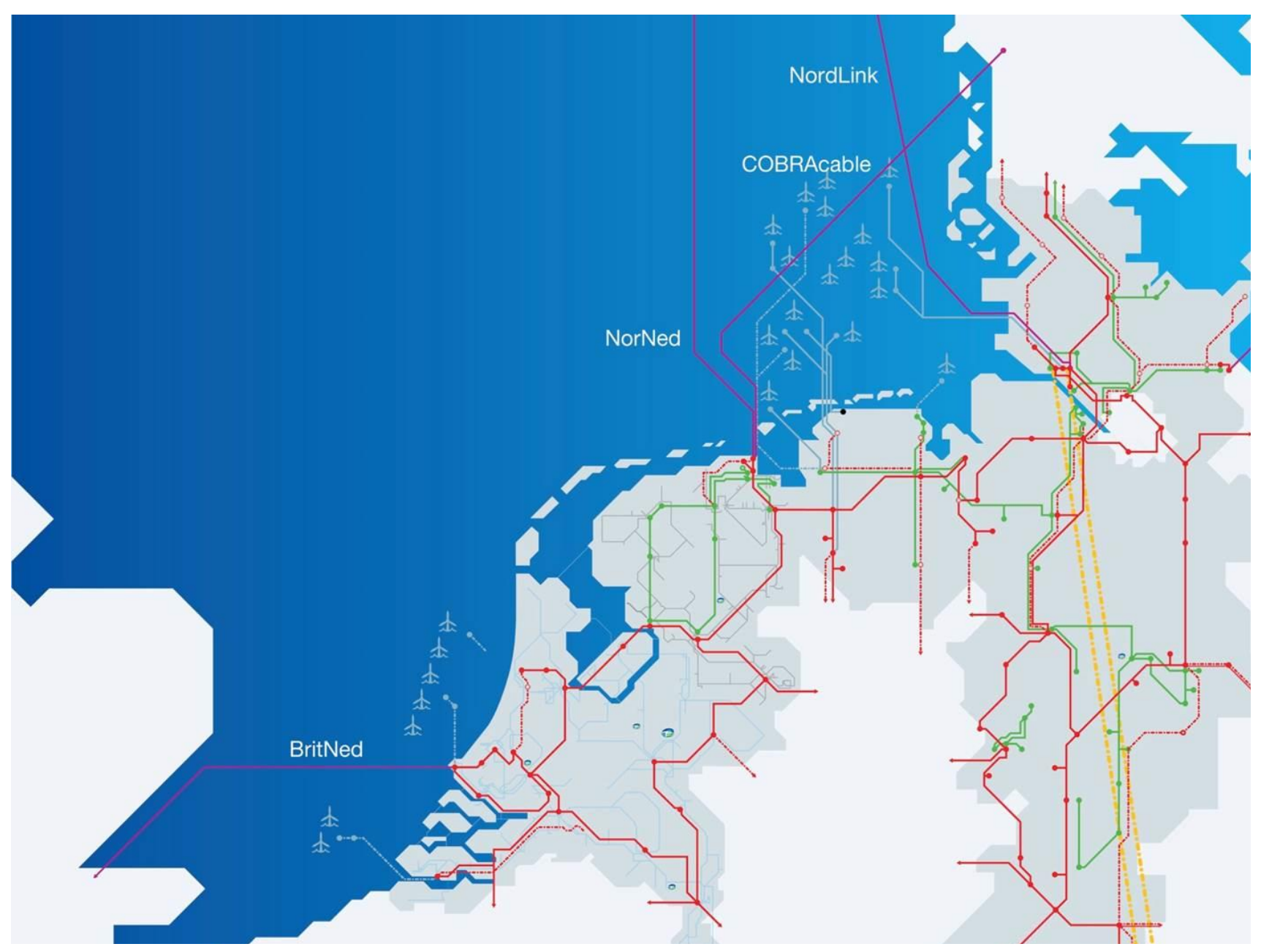

TंUDelft AIEPG =- 



\title{
DYNAMIC SYSTEM PERFORMANCE ANALYSIS OF A NOVEL GRID CONNECTION TOPOLOGY FOR OFFSHORE WIND FARMS USING MMC-HVDC TRANSMISSION
}

\author{
By
}

\section{Pedro Lozada Ayala}

Thesis submitted in partial fulfilment of the requirements for the degree of

\section{Master of Science}

in

\section{Electrical Engineering}

to be defended publicly on Wednesday August 29, 2018 at 09:00 am.

\section{Committee members:}

Supervisor:

Thesis committee:
Dr.ir. J.L. Rueda Torres

Prof.ir. M.A.M.M. van der Meijden

Dr. Jianning Dong

Ir. C.G.A. Koreman
TU Delft

TU Delft - TenneT TSO B.V.

TU Delft

TenneT TSO B.V.

Track Electrical Sustainable Energy

Intelligent Electrical Power Grids (IEPG) Group

Department of Electrical Sustainable Energy

Faculty of Electrical Engineering, Mathematics and Computer Science

Delft University of Technology

An electronic version of this thesis is available at http://repository.tudelft.nl/. 


\section{Preface}

This report is the result of my research project at TenneT TSO B.V., where I could immerse myself into the deep waters of offshore wind energy. The thesis is part of my two-year master program which I pursue at TU Delft.

The topic itself was one of the motivations to do this study as it offered me the possibility to gain theoretical knowledge about the integration of offshore wind energy into the power system. The second reason to work on this subject was the great opportunity to join TenneT and get practical understanding from the experiences of a leading TSO in Europe facing many challenges of the energy transition.

Over this period, I was able to become familiar with the plans for the offshore wind roll-out the Dutch government has planned for the next years; investigate the dynamic performance of a new topology to connect offshore wind farms to the onshore high-voltage power grid; and interact in a professional working environment as an international student/engineer with the colleagues at TenneT in the Netherlands and Germany.

I would like to express my deep gratitude to my supervisor Kees Koreman for the opportunity to work in this very interesting topic and the rest of the colleagues of Asset Management Offshore (AMO) in the Netherlands. Moreover, I want to thank the engineers from the different HVDC divisions at TenneT Germany and particularly Jose Alfredo Campos for very generously sharing his knowledge on power system simulation in PSCAD and MMC-HVDC technology. His patience and kindness are greatly appreciated. I am also grateful to Juan Carlos García Alonso from Manitoba Hydro International for his valuable contributions to the EMT model I developed in PSCAD. Technical discussions were very helpful to find the solutions to some of my problems while performing simulations. I owe special thanks to my supervisors and juries professors Jose Rueda Torres and Mart van der Meijden at TU Delft for their enthusiastic encouragements, guidance, and feedback during this work.

Finally, I would like to thank my family to whom this thesis is dedicated, for their love and support throughout these years. 


\section{Abstract}

Recent projections estimate that the Netherlands needs circa $33 \mathrm{GW}$ of offshore wind capacity in the North Sea to meet the goals of the Paris Agreement. To this end, the Dutch government has very ambitious plans to create new wind sites far from shore and integrate that power generation to the high-voltage power grid in the next years. Due to the challenges of connecting future massive amounts of offshore wind power into the grid TenneT operates it becomes urgent to investigate new alternatives for this purpose. A grid topology with transmission capacities above $1 \mathrm{GW}$ connecting offshore wind farms at distances close to 100 $\mathrm{km}$ in a standardized, modular, and cost-efficient manner is the focus of this thesis.

With eight point-to-point HVDC links in operation in Germany and more expected in near future, TenneT TSO is analysing new offshore grid connection concepts to achieve a reliable and secure operation of the infrastructure connecting wind energy both in Germany and the Netherlands. A solution is presented in this thesis report in which new wind farms are connected with 66-kV cables to a centralised platform with a connection capacity of $1050 \mathrm{MW}$. This platform will utilise HVDC technology based on VSC conversion techniques and MMC topology. It is expected that the $66-\mathrm{kV}$ cables will not be connected to a single busbar through paralleled converter transformer, but that this will be done with at least three converter transformers connected to each other on the valve side but not connected on the 66-kV side.

A dynamic performance study of a test network with the novel connection topology developed in PSCAD has been done. Each component of the system was studied to obtain a complete overview and understanding of the overall behaviour. All the associated control loops for the MMC terminals and wind turbines were modelled in detail. Through several simulations based on eight cases and scenarios the performance of the offshore 66-kV ac grid and the MMCHVDC link using the control schemes of MMC converters as in a typical grid connection topology for OWFs was assessed. 


\section{Abbreviations}

The following abbreviations have been used in this document:

BTB Back to Back

CCSC Circulating Current Suppression Control

EMT Electromagnetic Transient

GSC Grid Side Converter

HVAC High Voltage Alternating Current

HVDC High Voltage Direct Current

IGBT Insulated Gate Bipolar Transistor

LCC Line Commutated Converter

MMC Modular Multilevel Converter

MSC Machine Side Converter

OWF Offshore Wind Farm

PCC Point of Common Coupling

PI Proportional Integral

PLL $\quad$ Phase Locked Loop

PMW Pulse Width Modulation

SCR Short Circuit Ratio

VCO Voltage Controlled Oscillator

VSC Voltage Source Converter

WPP Wind Power Plant

WECS Wind Energy Conversion Systems

WTG Wind Turbine Generator 


\section{Contents}

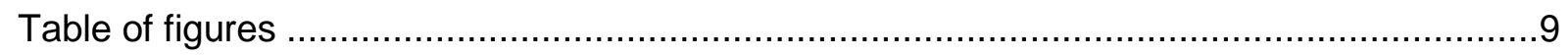

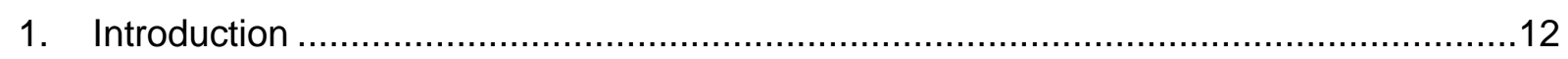

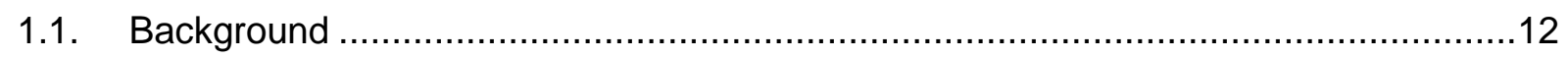

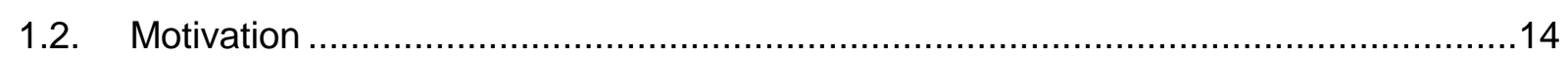

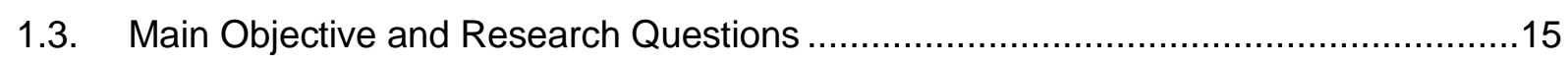

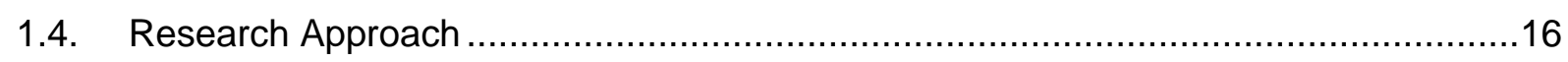

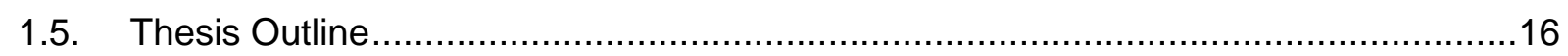

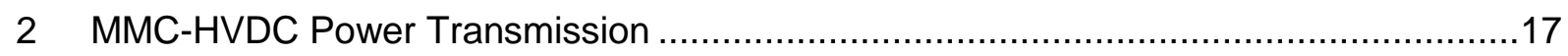

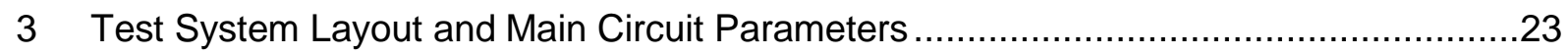

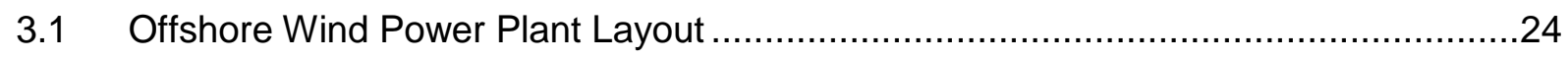

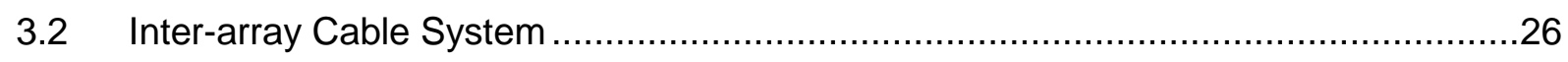

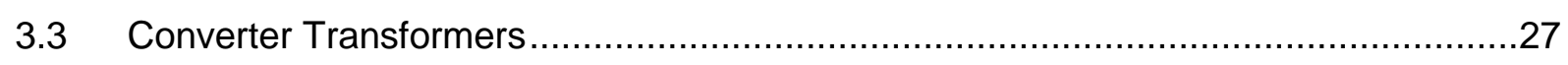

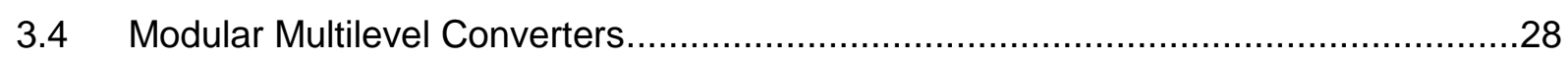

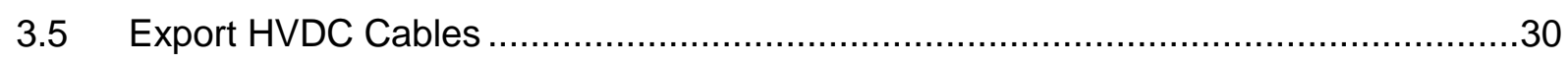

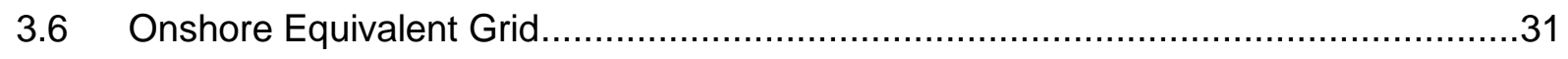

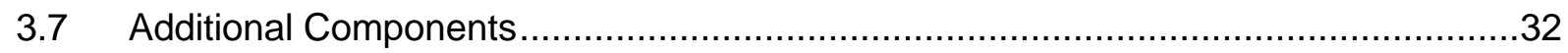

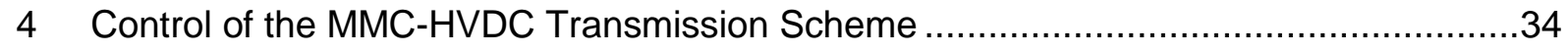

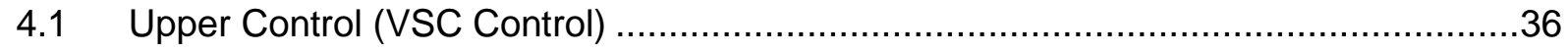

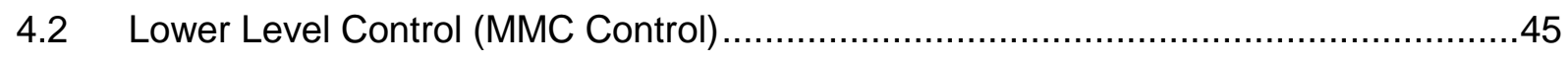

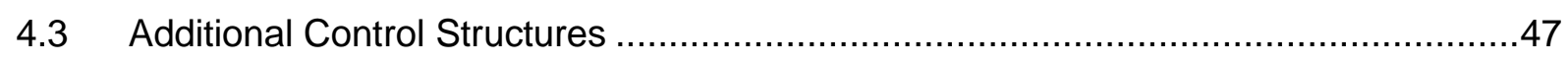

5 Operation of the MMC-HVDC Transmission Scheme ...........................................50

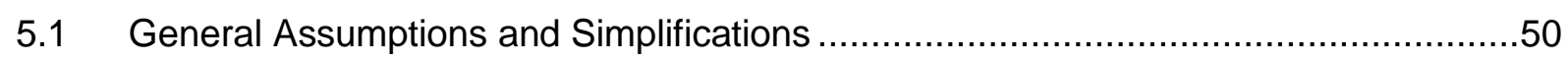

5.2 Topology with a Leader-Follower Configuration for the Offshore Transformers..........51

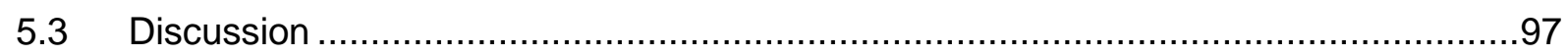

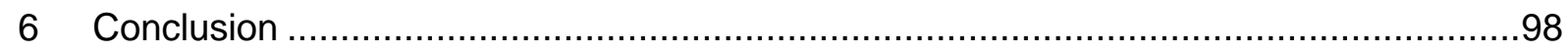

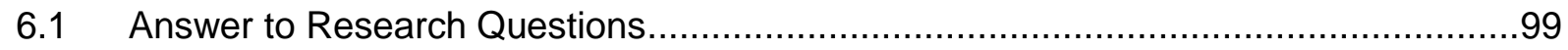

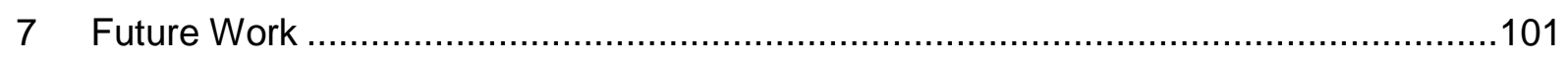

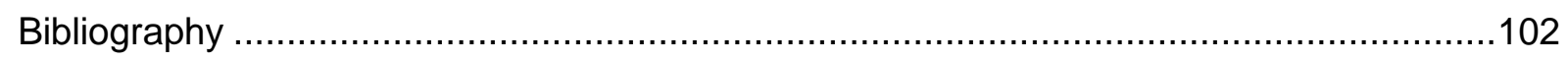




\section{Table of figures}

Figure 1. Offshore wind sites in the Netherlands to de developed until 2030................... 13

Figure 2. Single busbar and converter transformer connection..................................... 14

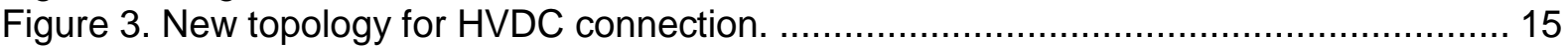

Figure 4. States and current paths of a half-bridge submodule...................................... 18

Figure 5. Half-bridge string and possible voltage levels.............................................. 19

Figure 6. Three-phase MMC with half-bridge submodules............................................ 19

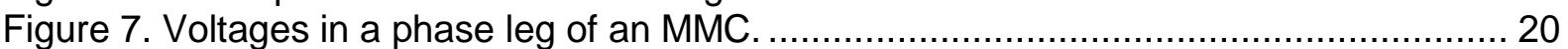

Figure 8. A schematic diagram of a VSC-HVDC Link for an OWF.................................. 21

Figure 9. Control scheme for an OWF connected via an HVDC link to the onshore grid...... 21

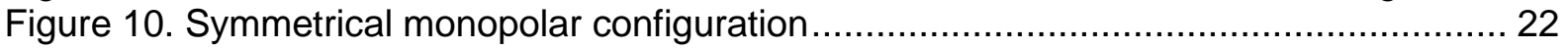

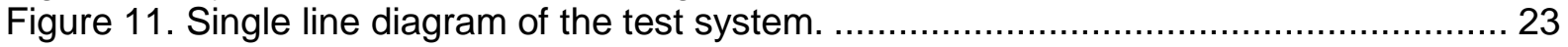

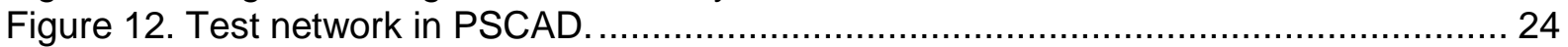

Figure 13. PSCAD representation of an OWF equivalent model...................................... 25

Figure 14. Overview of the PSCAD type 4 wind turbine module. ...................................... 25

Figure 15. Simplified diagram of a type 4 WECS configuration with two-level BTB VSCs.... 26

Figure 16. PSCAD representation of the HVDC link for the test system. ........................... 28

Figure 17. MMC Equivalent circuit based on detailed equivalent modeling ......................... 30

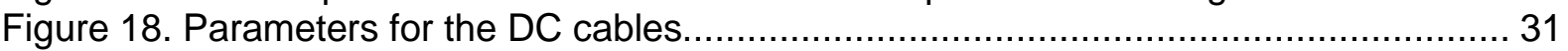

Figure 19. Single-line diagram with the PIR and grounding reference. ........................... 32

Figure 20. PSCAD model with the PIR and grounding reference.................................... 33

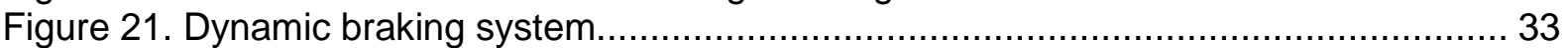

Figure 22. Two-bus system representation of the operation principle of an MMC unit. ........ 34

Figure 23. Control hierarchy for an MMC-HVDC multi-terminal converter............................ 35

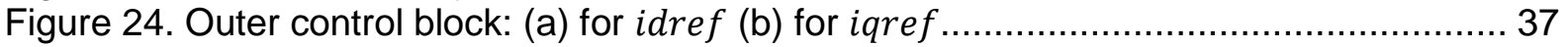

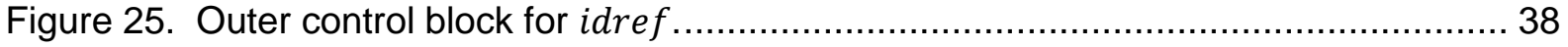

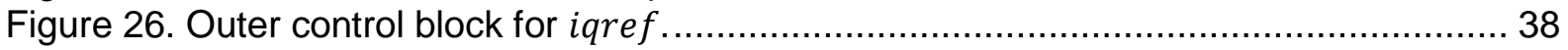

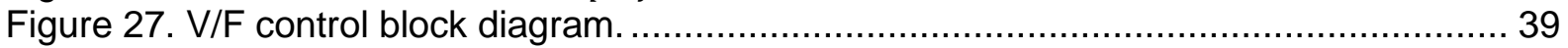

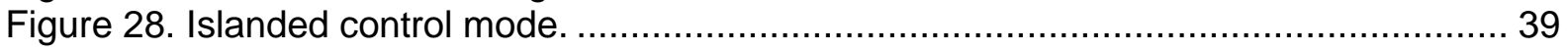

Figure 29. Typical monopole configuration of an MMC station........................................ 40

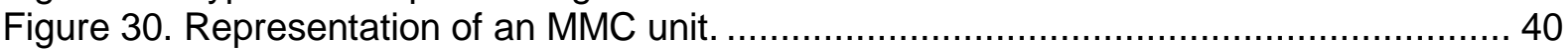

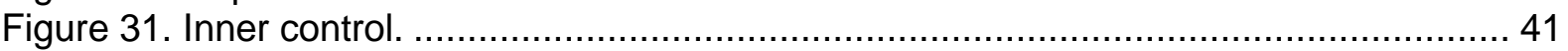

Figure 32. Equivalent phase inductance for a typical MMC unit................................... 42

Figure 33. Equivalent phase inductance considering a virtual PCC. ............................. 43

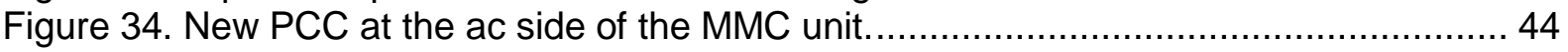

Figure 35. Arm inductances for one phase in the MMC topology................................. 44

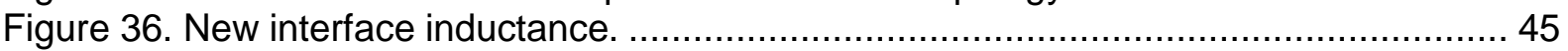

Figure 37. Equivalent circuit for the converter operation........................................... 45

Figure 38. Circulating current control (where j = a,b,c; $p$ : positive, n: negative). ................ 46

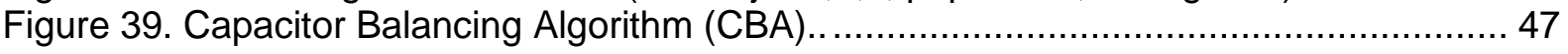

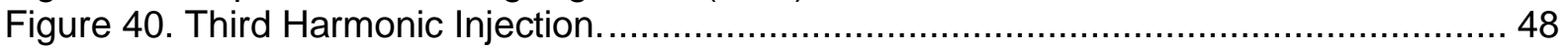

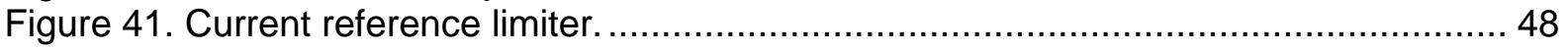

Figure 42. Control block for the current reference limiter. ............................................. 49

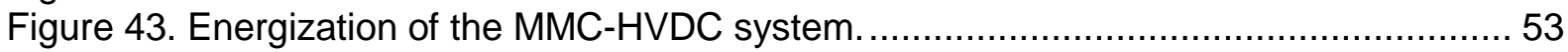

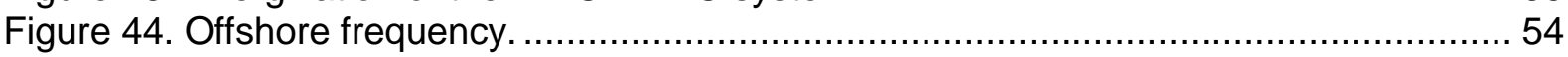

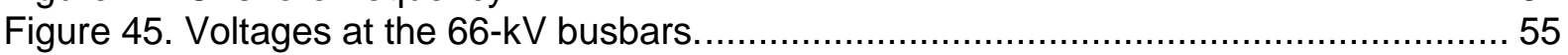

Figure 46. Active power production by the OWFs and total power flowing through the HVDC

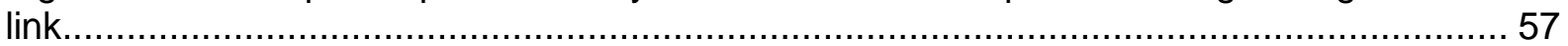

Figure 47. Wind speed profiles during energization state. ............................................ 58

Figure 48. The dc voltage and currents during the initialization of the OWFs.................... 59

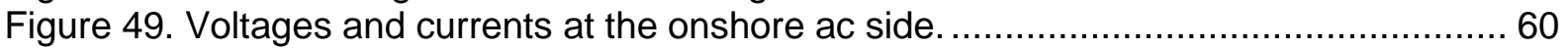

Figure 50. Currents at the onshore ac side for the complete sequence. .............................6 60 


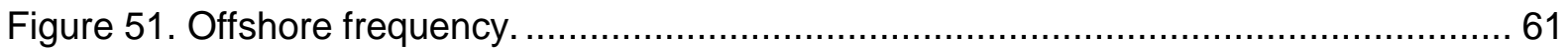

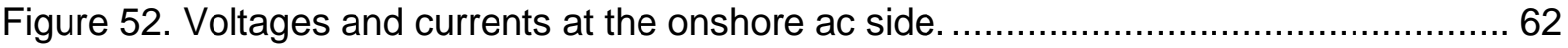

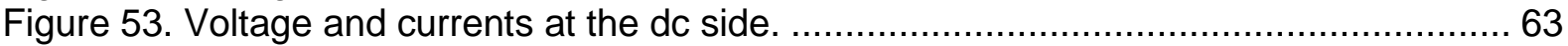

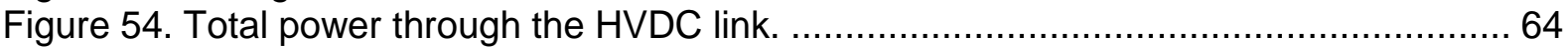

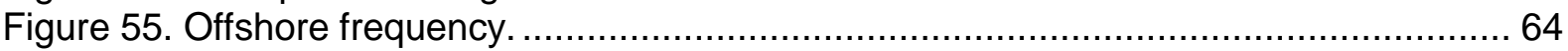

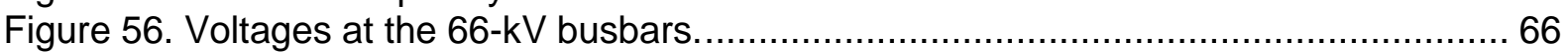

Figure 57. Changes in the power generation after the shutdown of OWF $1 \ldots \ldots \ldots \ldots \ldots \ldots \ldots . \ldots 6$

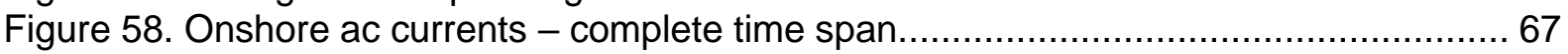

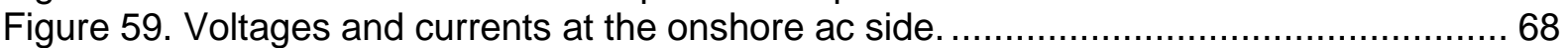

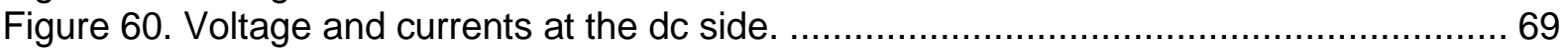

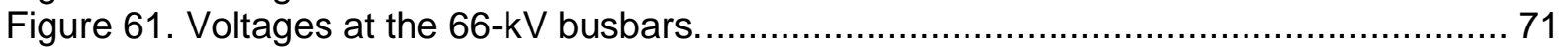

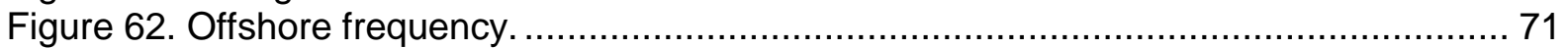

Figure 63. Active power through the HVDC link - disconnection of OWF 2 ........................ 72

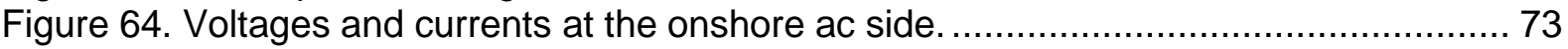

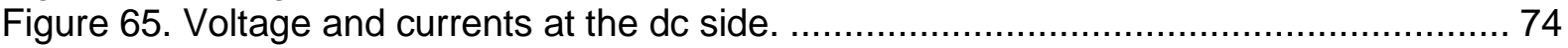

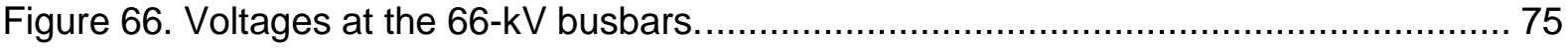

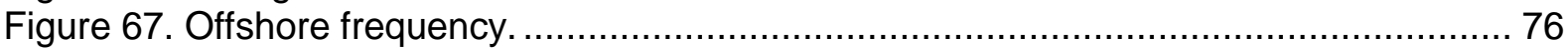

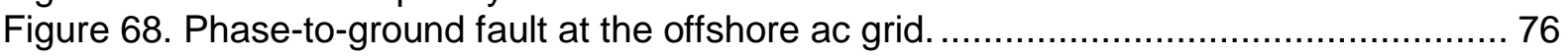

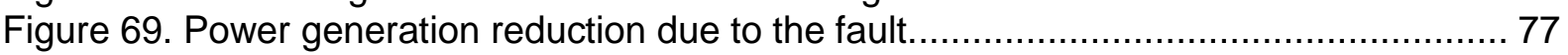

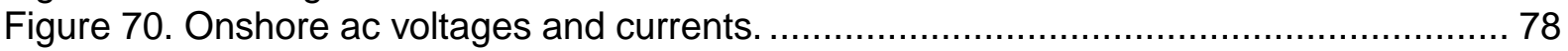

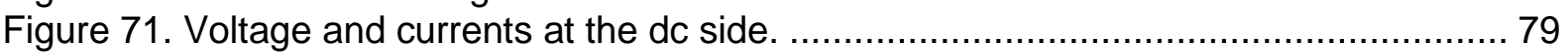

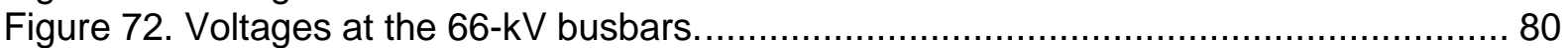

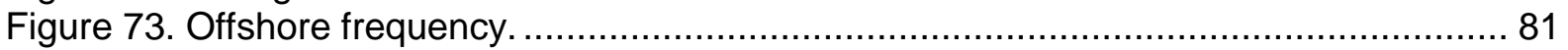

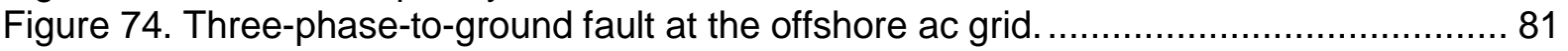

Figure 75. Reduction in the power generation due to the fault......................................... 82

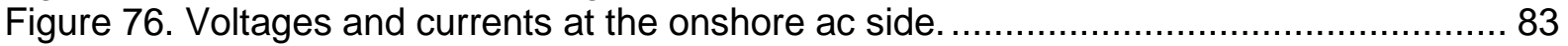

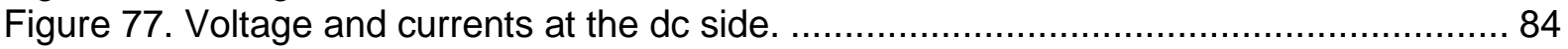

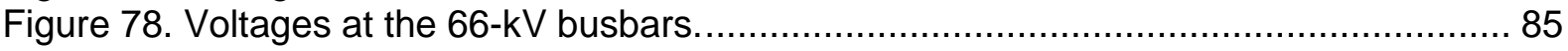

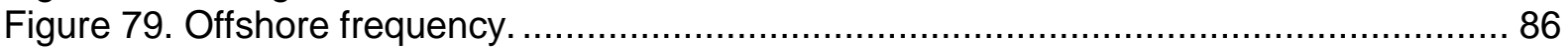

Figure 80. Single phase-to-ground fault at the $380-k V$ grid. ........................................ 86

Figure 81. Power reduction due to the fault at the onshore side. ................................... 87

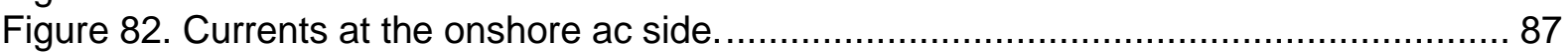

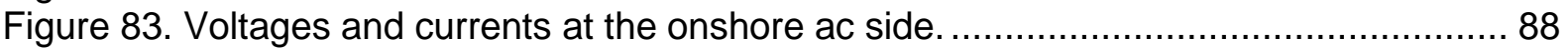

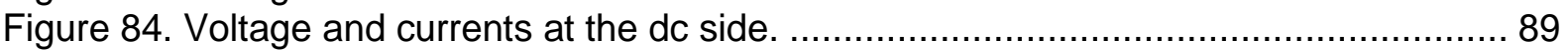

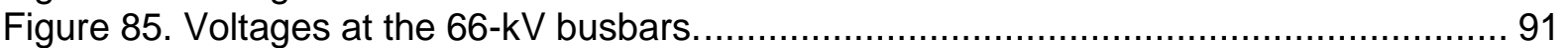

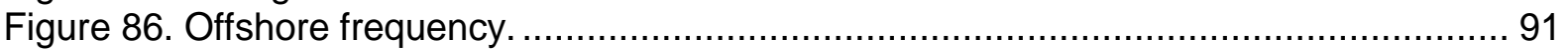

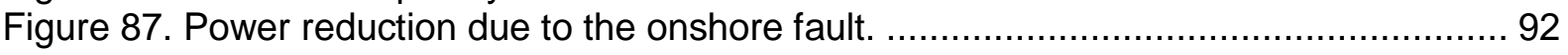

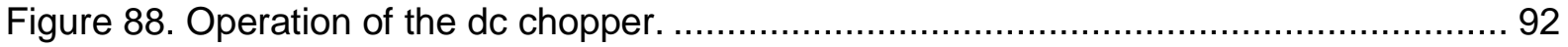

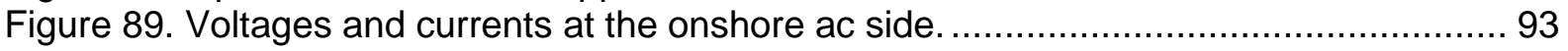

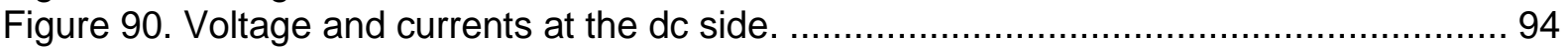

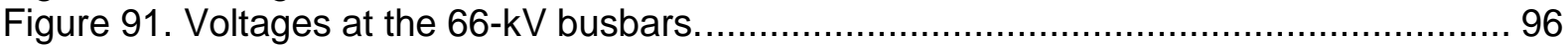

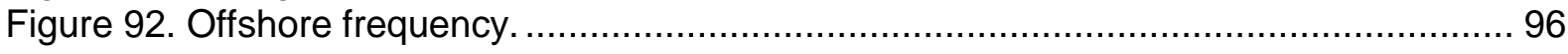




\section{Introduction}

\subsection{Background}

Europe, as the rest of the world, is in a process of transitioning from a fossil fuel-based energy economy to a sustainable, low-carbon model based on renewable energy sources. The European ambitions were defined with the 20-20-20 targets by 2020 in 2007 [1] which include reduction of greenhouse gas emissions by $20 \%$ compared to the 1990 levels; increase share of the final-form consumption of renewable energy by $20 \%$; and improvements in energy efficiency by $20 \%$. National targets have been set by each country and even higher levels of penetration of clean energies are expected in some cases. In particular, the German and Dutch governments are driving this transformation through the so-called Energiewende and Energieakkoord, respectively. These plans aim for a sustainable and reliable electricity system in the long term.

The Dutch government decided to establish a regulatory framework to facilitate the energy transition through the Offshore Wind Energy Law ("Wet Windenergie op Zee"), of July 2015. New wind farms were designated along with site data and the governmental subsidy scheme. Later in April 2016 TenneT TSO was appointed as the offshore grid operator in the Netherlands, which implies that it will develop at least 3,500 MW of offshore connections until 2023.

A recent study [2] predicts that the energy mix in 2045 for ten North Sea countries would be composed of approximately $230 \mathrm{GW}$ of offshore wind energy, with $180 \mathrm{GW}$ of that capacity generated in the North Sea. If this is true, a sustained connection of wind farms to the European power grid will happen in the next 30 years. For the Dutch situation, $33 \mathrm{GW}$ of offshore capacity in the North Sea is required to meet the goals of the Paris Agreement.

In 2017 a total of $15.6 \mathrm{GW}$ of new wind power capacity was installed in the EU, with 3,148 MW being offshore, twice as much as in 2016. Cumulatively, there are now $168.7 \mathrm{GW}$ of wind power capacity in the European Union, $153 \mathrm{GW}$ onshore and $15.8 \mathrm{GW}$ offshore, making wind energy second only to gas in the European market [3]. The average water depth of offshore wind farms with grid connections in Europe during 2017 was $27.5 \mathrm{~m}$ and the average distance to shore was $41 \mathrm{~km}$ [4]. At the end of the year, the Netherlands launched a landmark zerosubsidy offshore wind tender to build the 700 MW Hollandse Kust Zuid project. This new model is certainly a significant change as the bidders will rely exclusively on wholesale electricity prices without financial aid from the government what can help keep the energy transition affordable.

On March 27, 2018, the Dutch government announced the 'Routekaart windenergie op zee 2030' which includes plans for additional wind farms with a total capacity of at least 7,000 MW [5]. One of the new wind sites is the area known as IJmuiden Ver, shown in Figure 1. This section is located approximately $80 \mathrm{~km}$ off the Dutch coast and approximately $4 \mathrm{GW}$ are expected to be produced in this region [5]. Due to the longer distances compared to the near shore wind farms being developed until 2023, one of the solutions to integrate all the wind power is to use high voltage direct current (HVDC) transmission instead of the standardized high voltage alternating current (HVAC) transmission concept.

HVDC is seen as having several advantages over HVAC transmission [6]: 1) HVDC lines involve lower capital costs (bipolar lines vs. three phase lines) and lower energy losses in long distance power transmission. 2) They have power transmission and stabilization capabilities between unsynchronized $A C$ networks, as well as the ability to prevent the transmission of faults between connected AC grids in terms of a "firewall." 3) The HVDC power flow is fully 
controllable, rapid, and accurate. Moreover, the low voltage ride-through capability of VSC HVDC makes it more suitable for renewable energy integration. 4) For a fixed corridor, overhead HVDC transmission systems provide increased capacity. 5) For cable schemes, the lengths are not limited by charging currents and no reactive compensation (for the cable itself) is required at the end stations and/or at intermediate points, as in the case of AC transmission systems.

Voltage source converter (VSC) based HVDC (VSC-HVDC) is the latest transmission technology for connecting distant offshore wind farms (OWFs) which need long distance cable connection. Among the topologies of VSCs, the modular multilevel converter (MMC) topology has become one of the optimal solutions for offshore wind power integration to the transmission network offering advantages such as [7]: the ability to continuously transfer any power level in both directions; ease of integration with wind turbine generators (WTGs) in islanded grids with very low fault current levels; no need for harmonic filters and additional reactive power resources; improved performance during onshore ac disturbances; decoupled control of the active and reactive powers; interconnection capability to weak or passive ac networks; black-start capability; feasibility of building compact converter stations; ability to use XLPE cables since the operating voltage polarity is unchanged and independent of the direction of the power flow; and implementation of future multi-terminal grids.

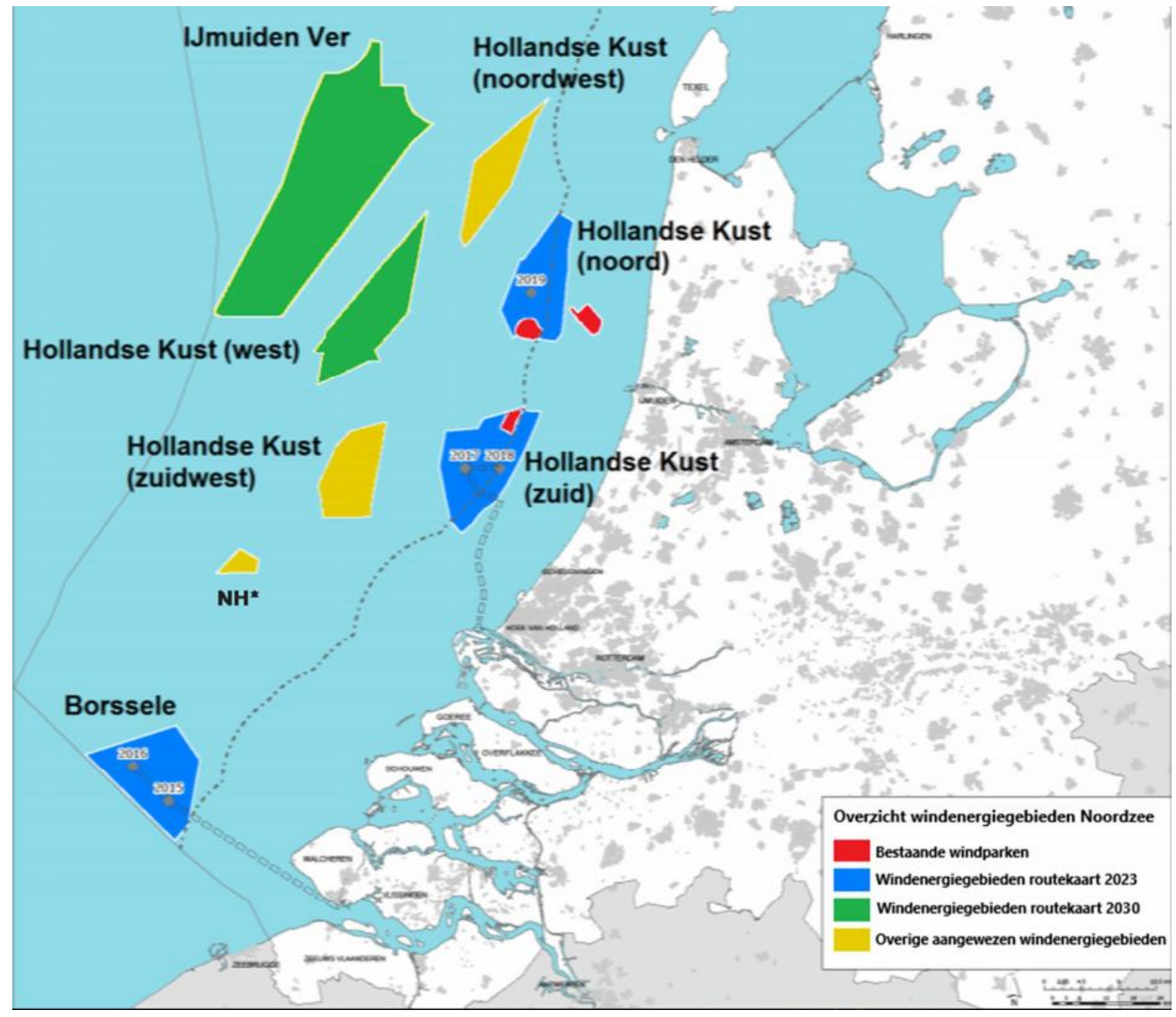

Figure 1. Offshore wind sites in the Netherlands to de developed until 2030. Source [5].

The first application of VSC-HVDC transmission for the grid connection of an OWF has been in operation by TenneT since December 2010. The BorWin1 project connects the wind park BARD Offshore 1 in the North Sea through an HVDC link with a capacity of $400 \mathrm{MW}$ to an onshore substation in Germany. TenneT is one of the leading TSOs in Europe regarding interconnection of OWFs. In Germany there are currently eight MMC-HVDC schemes for the export of energy from offshore wind farms in the North Sea to the onshore grid [8] being the most common voltage $\pm 320 \mathrm{kV}$ and capacities varying between $576 \mathrm{MW}$ and $916 \mathrm{MW}$. 
For future projects, the rated voltage of the inter-array cable system will increase from 33 to $66 \mathrm{kV}$. This will represent that up to twice as much power can be transported, less array cabling is needed, substantial capital cost savings and the elimination of the ac collector substation platforms as the wind farm's 66-kV array cables are directly connected to the primary side of the offshore HVDC converter transformer. Additionally, the control of VSC-HVDC converters that connect an OWF to the onshore ac system must be designed to start the operation of the offshore converter station and energize cables and transformers. This can be accomplished only by the VSC technology [7].

The strong drive to decarbonise the energy system in Europe will continue to increase the share of renewable energies and to that end innovative solution are to be found by the transmission system operators (TSOs). Wind is one of the key energy sources to mitigate climate change. The new connection topology for far-offshore wind farms presented in this thesis is part of those efforts made by TenneT TSO to make the energy transition happen guaranteeing sufficient reliability and security of supply.

\subsection{Motivation}

With eight point-to-point HVDC links in operation in Germany and more expected in near future, TenneT TSO is analysing new offshore grid connection concepts to achieve a reliable and secure operation of the infrastructure connecting wind energy both in Germany and the Netherlands. One of the possible solutions is to connect the new wind farms with 66-kV cables to a centralised platform with a connection capacity of $1050 \mathrm{MW}$. This platform will utilise HVDC technology based on VSC conversion techniques and MMC topology. It is expected that the $66-\mathrm{kV}$ cables will not be connected to a single busbar through paralleled converter transformer as in Figure 2, but that this will be done with at least three converter transformers connected to each other on the valve side but not connected on the 66-kV side, as depicted in Figure 3.

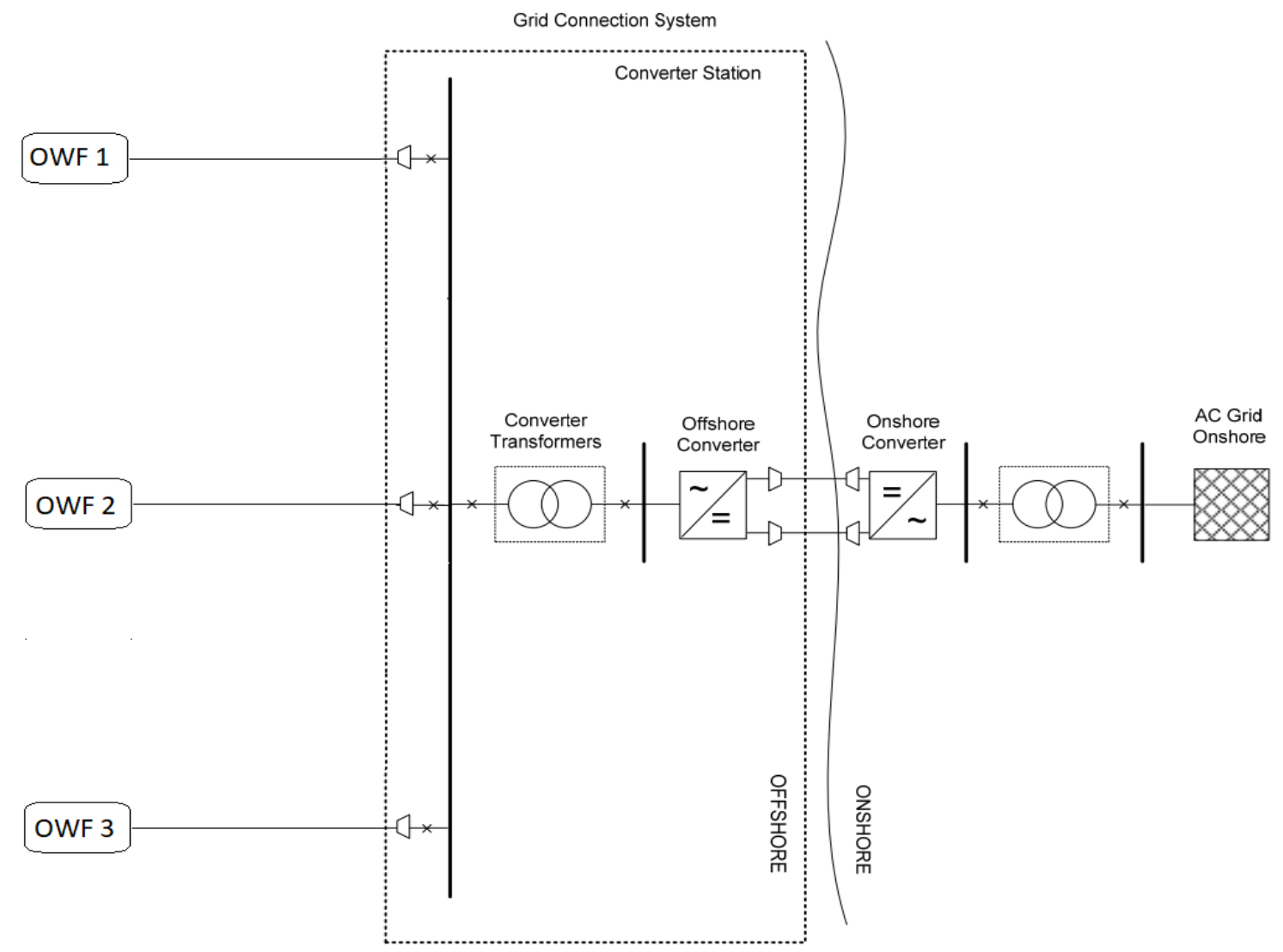

Figure 2. Single busbar and converter transformer connection. 
Due to the challenges of connecting future massive amounts of offshore wind power into the grid TenneT operates it becomes urgent to investigate new possible grid topologies able to integrate transmission capacities above $1 \mathrm{GW}$ connecting OWFs at distances close to $100 \mathrm{~km}$ in a standardized, modular, and cost-efficient manner. After 2030, the wind sites designated by the Dutch government will certainly be at further distances offshore and with more capacity compared to the recently announced ones.

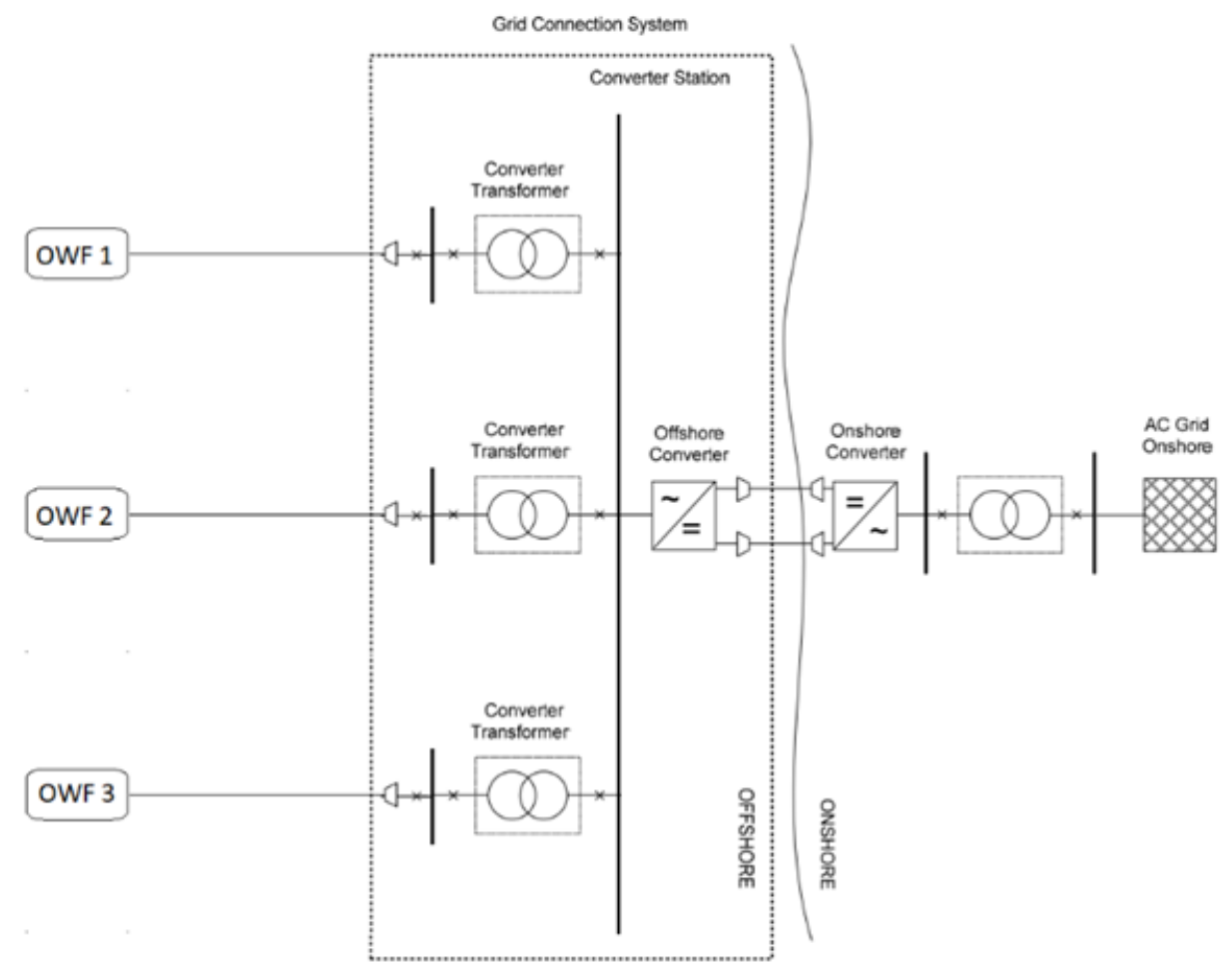

Figure 3. New topology for HVDC connection.

With the new topology it is possible to avoid the so-called collector platform that uses a transformer to step up the voltage as the cables are rated at $66 \mathrm{kV}$ and are then connected to the converter station (rectifier). This represents saves on CAPEX and OPEX. The tender model of offshore wind sites with different parties involved creates a scenario in which different grid connection points must be available to connect the wind turbine clusters.

\subsection{Main Objective and Research Questions}

The main research objective of this thesis is to assess the performance of the offshore $66-\mathrm{kV}$ ac grid using the control schemes of MMC converters as in a typical grid connection topology for OWFs. The formulated research questions to answer in the context of this thesis are:

What are the necessary assumptions and simplifications to perform simulations in the software tool PSCAD/EMTDC for the desired point-to-point MMC-HVDC link and the rest of the test network?

What are the associated limitations of control structures currently implemented in MMC-HVDC transmission links if multiple transformers are connected as intended in the new topology?

What are the necessary modifications of control structures currently implemented in MMCHVDC transmission links considering the new topology of big-transmission-capacity and longtransmission-distance OWFs proposed in this research? 


\subsection{Research Approach}

The research approach for this thesis started with a literature review of MMC-HVDC technology applied to the interconnection of offshore wind farms to the high voltage transmission grid. It was important to understand the different characteristics of the equipment involved in HVDC transmission, and the control schemes and modes normally used for the application to be studied.

The next step was to get acquainted with the simulation of this type of networks in the software tool PSCAD/EMTDC. To achieve the main goal proposed, time domain dynamic simulations were performed to understand the behaviour of the test network. To this end, an EMT-type model was developed in PSCAD. It represents three OWFs connected to the onshore highvoltage system through an MMC-HVDC scheme. Each component of the system was studied to obtain a complete overview and understanding of the overall behaviour. All the associated control loops for the MMC terminals and wind turbines were modelled in detail. Required tuning of controllers were done by trial and error.

Finally, evaluation of the results of the simulations based on eight test cases and scenarios is presented to demostrate the dynamic performance of the topolgy investigated.

\subsection{Thesis Outline}

The organization of the thesis is as follows:

Chapter 1 describes the milestones in the energy transition in the Netherlands during the last years and gives an overview of the application of HVDC transmission for connecting OWFs to the onshore grid.

Chapter 2 introduces the topology of the modular multilevel converter, its operation and MMCHVDC technology applied to the interconnection of OWFs as the background theory for the research topic.

Chapter 3 presents the layout and modelling of each of the main elements of the test network being studied. Main circuit parameters for the system components are derived and discussed. Recommended models from literature are compared to the actual PSCAD implementations.

The control hierarchy of the complete integrated system is given in chapter 4 . The control structures are explained and the PSCAD representations are also shown. The control modes are chosen based on the application of offshore wind power for the upper and lower levels of the MMC stations.

The operation of the test network and several tests cases regarding the new topology for connecting OWFs are discussed in chapter 5 . The dynamic system performance of the test network is analysed in each situation.

Finally, chapter 6 summarizes the conclusions of this thesis and chapter 7 lists some of the areas for future research. 


\section{MMC-HVDC Power Transmission}

High voltage direct current (HVDC) technology has been in use since 1954 when the first commercial link from the mainland of Sweden to the island of Gotland was commissioned. The initial developments in power electronics for conversion between alternating current (ac) and direct current (dc) were based on mercury valve arc technology, which were replaced by thyristor valves because of the superiority of the thyristor technology. This type of converter switches is one of the components of the current source converters (CSC) that operate by natural commutation. A relatively strong ac system with a sufficiently high short-circuit power is necessary [9].

New power semiconductors with turn-off capability, allowing for forced current commutation, made possible a new type of converter called voltage source converters (VSC) which can operate independently from the ac grid as the valves can be switched on and off by external low-voltage control signals. These converters offer increased controllability and improved harmonic performance. VSC-HVDC transmission can function when it is connected to an ac system with a very low short-circuit ratio, or even to passive an ac system without any generation or short-circuit power. The first application of VSCs to HVDC transmission was announced in 1997 and since then a considerable number of projects have been commissioned. Among the advantages of VSC transmission compared to CSC transmission, also known as line commutated converter (LCC) transmission, are the following: robustness against the ac system faults as there are no commutation failures, flexibility of power flow reversal, independent control of reactive power and active power at both ends of the link, and black start capability [9].

From the beginning the prevailing VSC topology was the two-level converter which can be used for HVDC applications directly connecting semiconductor elements in a series to create valves capable of withstanding high voltages. However, this topology tends to be complex since several problems need to be solved to ensure the operation and fault tolerance of such a valve. Other topologies of VSCs emerged to offer better prospects for cost-effective power conversion in HVDC transmission schemes. Multilevel converter topologies do not require direct series connection for increasing the operating voltage. Additionally, the harmonic properties are much improved, so that the requirements on voltage and current distortion can be met without excessive switching losses [10]. Of all the multilevel converter topologies, the modular multilevel converter (MMC) will be explained in detail in this chapter of the thesis as it will be implemented in the converter units for the point-to-point HVDC transmission link under study in this research.

MMCs are the state-of-the-art topology for VSC-HVDC transmission [11], [12]. The first commercial MMC-based HVDC transmission link was the Trans Bay Cable link installed in The USA in 2010 [13]. The main component of this type of converter is the switching submodule also referred to as power submodule or power cell. There are two alternatives for the submodules: half-bridge and full-bridge submodules. The focus here will be in the half-bridge submodule which consists of one two-level phase leg parallel to a dc capacitor that will maintain a direct voltage, shown in Figure 4 [14]. The external terminals of the power cell are formed by the phase leg midpoint and one of the dc capacitor terminals. Two possible switching states are possible: insertion and bypass. In the first state, the valve in series with the submodule capacitor is conducting, implying that the voltage at the terminal equals the capacitor voltage. For the bypass state, the switch in the valve parallel to the external terminal is conducting and the terminal voltage is zero. The output voltage of the power cell can be described in terms of a switching functions as:

$$
v=s V_{c}
$$


The switching function will be 0 in the bypass state and 1 when the submodule is inserted. There is a third state labeled blocking in which both switches are open, i.e. not conducting. In this state the voltage at the terminals will depend on the direction of the current since only the diodes may conduct. In one direction the voltage of the capacitor will be present and in the other the voltage will be zero. This state is not used in normal operation, only during start-up and certain fault conditions. Possible states of a half-bridge submodule and the currents paths are depicted in Figure 4.

The power semiconductor devices inside the submodules are insulated-gate bipolar transistors (IGBT) with turn-off capability, but other devices can also be implemented. There are two IGBTs in each submodule. The design of the power cells also includes antiparallel diodes across the IGBTs which means that the converter voltage cannot rise above the dc voltage. There are additional protection elements in each submodule in case of internal or external faults as a high-speed bypass switch and a thyristor which are normally connected in parallel to the IGBT2 switch.

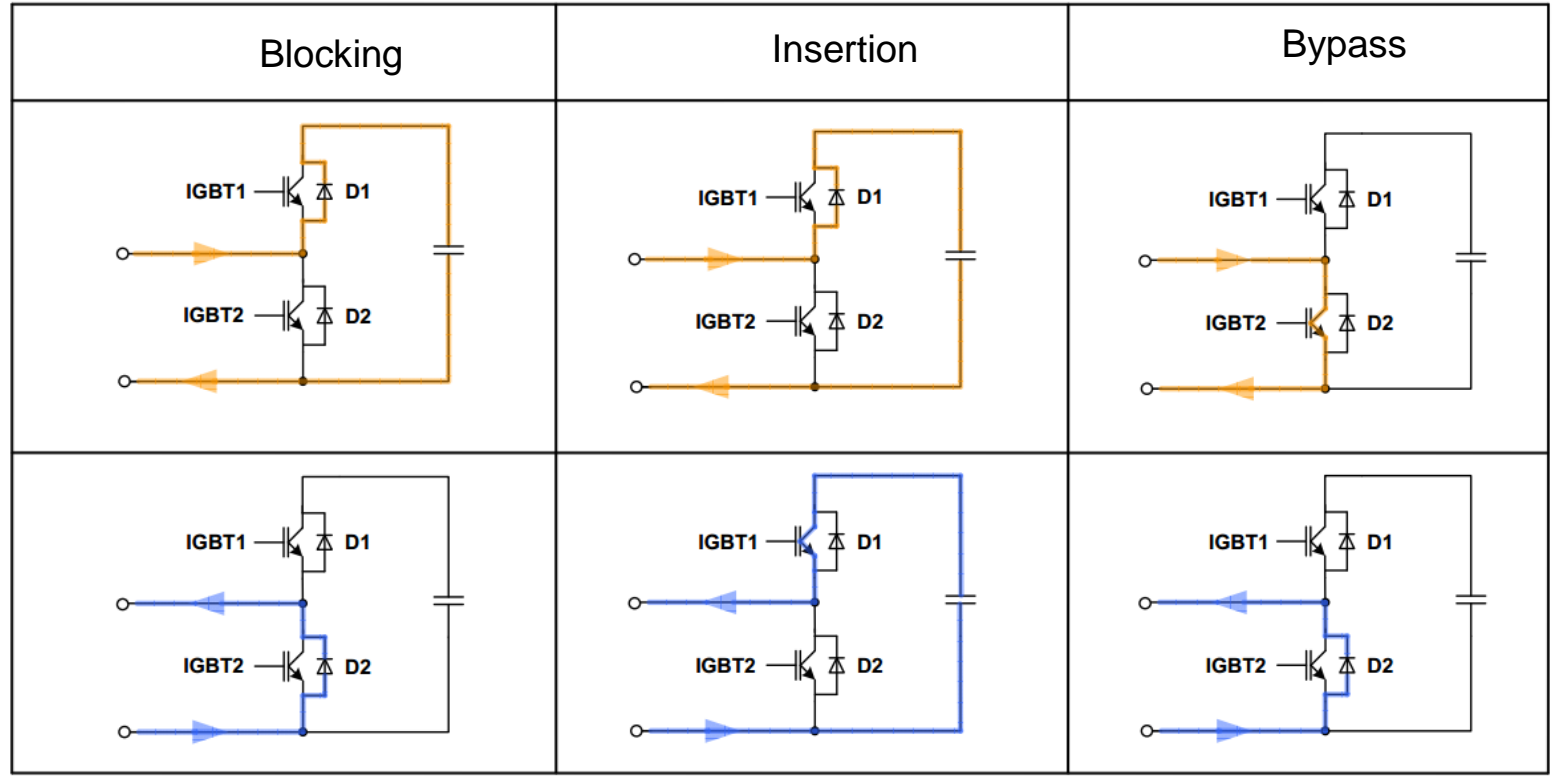

Figure 4. States and current paths of a half-bridge submodule. Source [14].

To handle high voltages a series connection of the submodules is needed. At the same time, the submodule string allows for a larger number of levels the terminal voltage can assume. A string of half-bridge submodules is presented in Figure 5 [10] along with the output voltage it can produce. A string of $\mathrm{N}$ half-bridge submodules can take values between zero and $\mathrm{NVc}$ for a total number of $\mathrm{N}+1$ levels. The half-bridge power module can only provide a unipolar voltage and is therefore only suited to producing a voltage with a dc component.

The submodules and the submodule strings can be considered as controllable voltage sources, if there is no net power exchange with a string over time, and the energy balance between the submodules is maintained. The capacitor has to be of significant size as it should maintain an approximately constant direct voltage while carrying significant currents at low harmonic order, usually fundamental and second. A schematic of a three-phase MMC for ac/dc conversion is illustrated in Figure 6 [15]. 

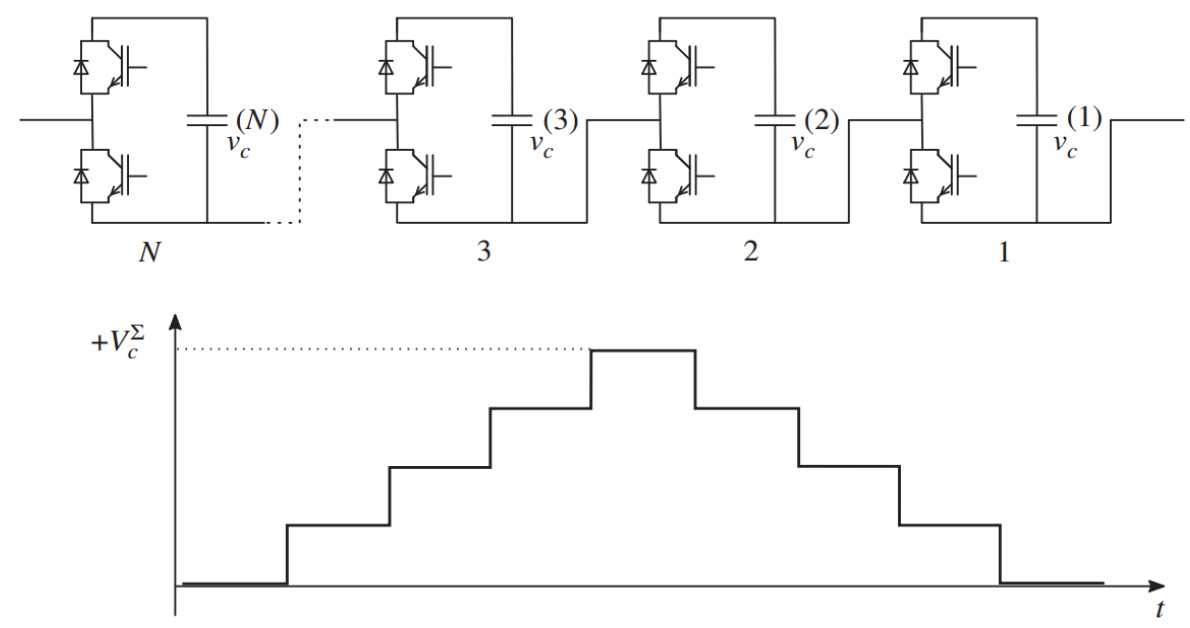

Figure 5. Half-bridge string and possible voltage levels. Source [10].

The circuit structure of the MMC consists of three phase legs where each leg has two phase arms and each arm is composed of a submodule string and an arm inductance. The midpoints of the phase legs form the ac terminal of the converter. The arm reactors are there to avoid direct parallel connection of the voltage sources implemented by the submodule strings. The operation of the converter is based on controlling the six submodule strings so that the combination of voltages they provide results in the desired voltages on the dc and ac sides of the converter. To synthesize the dc voltage, the sum of the voltages of all inserted submodules in the top and bottom converter arms of each phase leg is maintained approximately equal to the desired pole-to-pole dc-side voltage. Simultaneously, the output ac voltage is produced by the difference between all the active submodules in the top and bottom converter arms. Therefore, for the ac terminal to create a sine wave, only individual submodules need to change state in the top and bottom converter arms at any one time, minimizing the number of semiconductor switching events and practically eliminating the need for filtering on the ac and dc output terminals [15]. Figure 7 shows how the top and bottom submodule string voltages of a phase leg change during one fundamental cycle [10]. The peak ac-side phase voltage may never exceed half of the dc-side pole-to-pole voltage. The sum capacitor voltage of the submodule string in each arm is set equal to the dc-side voltage.

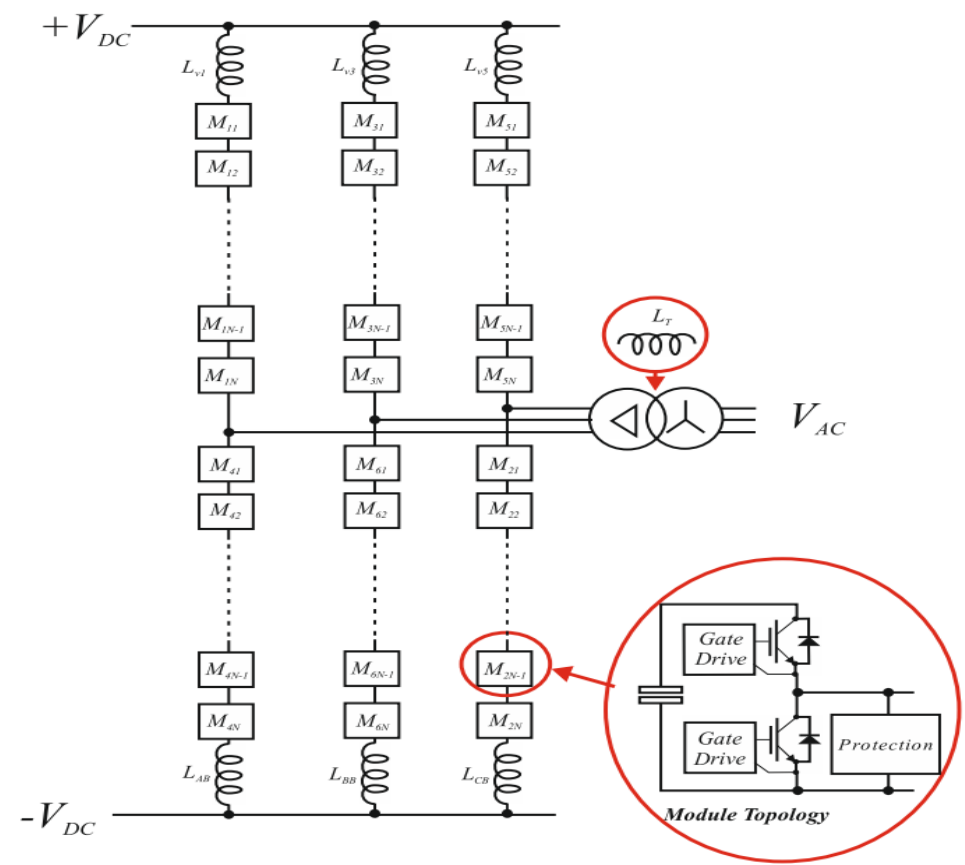

Figure 6. Three-phase MMC with half-bridge submodules. Source [15]. 
The frequency of operation of the individual submodules is very low, typically in the region of $150 \mathrm{~Hz}$, compared to the switching frequency of the two-level converter what significantly reduces the switching losses as well as the electrical noise in terms of both radiated and conducted electromagnetic compatibility [15].

Some of the main benefits of the MMC topology are [14]: highly modular design which allows for excellent scalability; fine adjustment of the ac voltage and a dc voltage with very small ripple as under normal operation conditions the switching process per converter leg only involves one submodule at a time; very little radiant or conducted high-frequency interference; lower switching losses compared to 2 or 3-level topology due to the much lower switching frequency of the individual semiconductors; the use of industrially proven standard components, such as medium voltage capacitors which are very robust and highly reliable; and the use of standard ac transformers.

MMC-type VSC-based HVDC transmission technology is nowadays the best option to connect OWFs. In fact, TenneT TSO has been one of the pioneers in this field. In Germany there are currently four MMC-HVDC schemes for the export of energy from offshore wind farms to the mainland ac network [8]. The first links connecting OWFs to the onshore ac grid using MMCHVDC technology were BorWin2 and HelWin1 in January 2015 [8]. Different manufactures offer solutions based on MMC topologies such as the Siemens' HVDC PLUS [16] and GE's HVDC MaxSine [17].

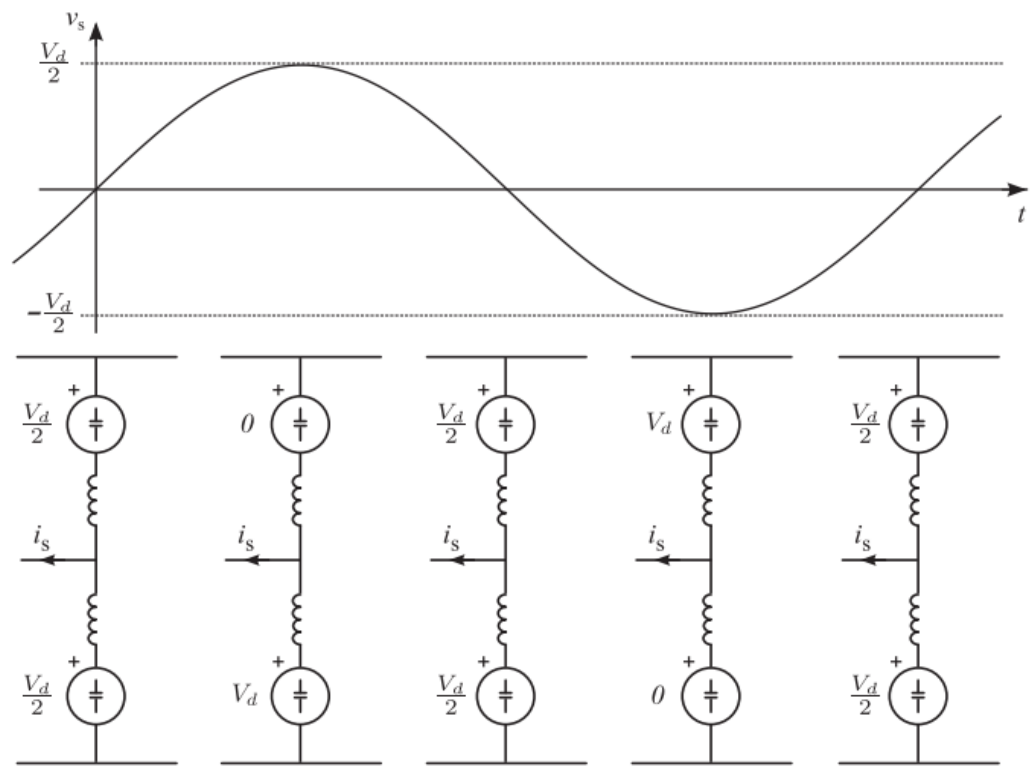

Figure 7. Voltages in a phase leg of an MMC. Source [10].

The components of a typical design of an offshore MMC-HVDC transmission scheme are presented in Figure 8 [7] and are the following: wind turbine generators, collector grid (interarray cables), ac collector substation platforms, converter transformers, dc pole reactors, arm reactors, converter valve hall (MMC units), ac and dc switchyards, auxiliary systems, export dc cables, dc chopper, pre-insertion resistor, grounding system, control system, and protection system. 


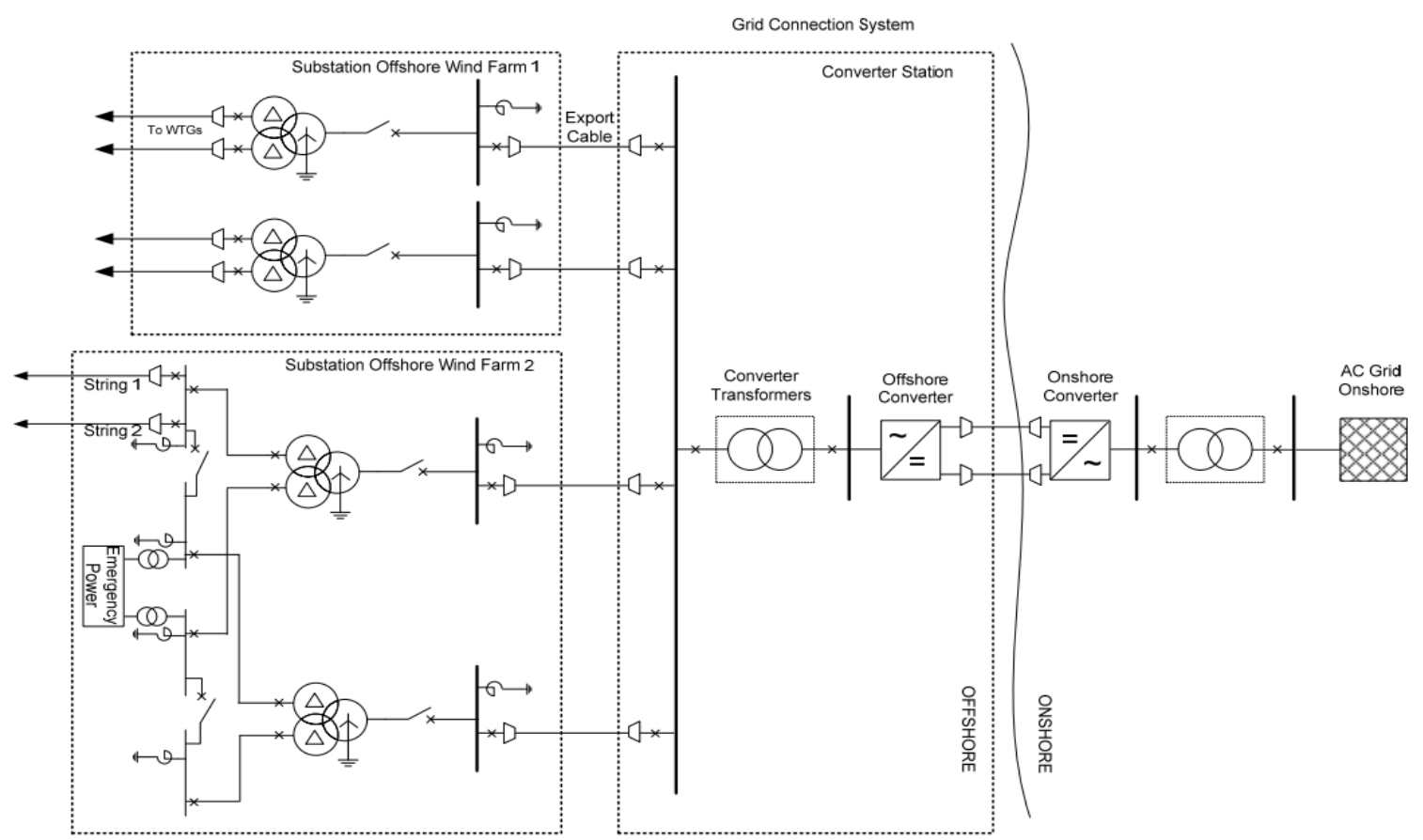

Figure 8. A schematic diagram of a VSC-HVDC Link for an OWF. Source [7].

A very general control integration scheme including communication requirements is illustrated in Figure 9 [7]. The specific control hierarchy of the MMC-HVDC scheme under study in this thesis will be explained in detail in chapter 4 .

The HVDC systems can be developed in monopolar or bipolar configurations, or a combination of the two like this [18]: asymmetric monopolar system with earth return, asymmetric monopole system with metallic return, symmetrical monopolar configuration, and bipolar configuration. For MMC-HVDC systems the most commonly used configuration is the symmetrical monopolar configuration, shown in Figure 10 [19].

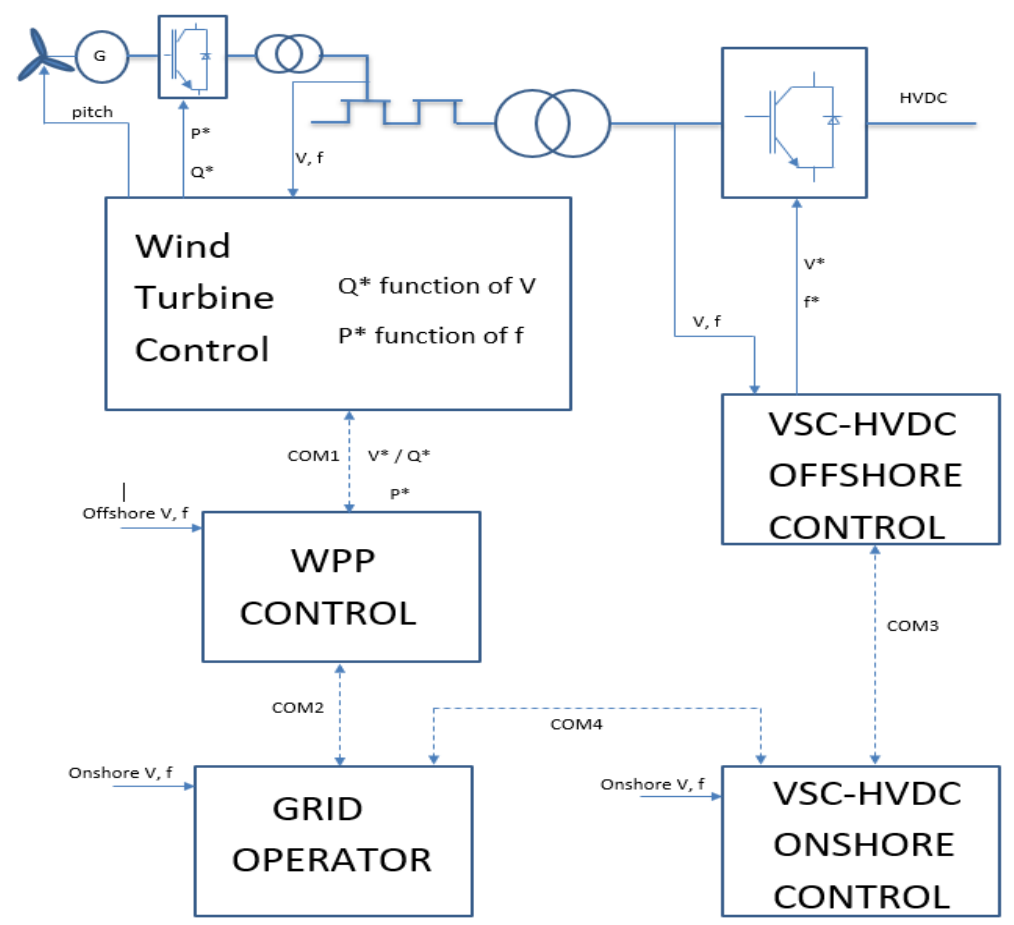

Figure 9. Control scheme for an OWF connected via an HVDC link to the onshore grid. Inspired based on original illustration in [7]. 
The dc-side converters are connected between two high voltage conductors of the same magnitude but of opposite polarity. The earth reference can be provided with various methods including the connection of the dc capacitors' midpoint, high impedance reactors on the ac side of the converters, and high resistances from both dc buses to earth. No current will flow through the earth under normal operating conditions. Although in this configuration two conductors of opposite polarity carry power, they cannot operate independently, i.e. one conductor cannot transmit power using earth as the return path. Both conductors are fully rated for the current duty and fully insulated. As the dc voltage is symmetrical, the transformer connection experiences no steady-state dc voltage stress.

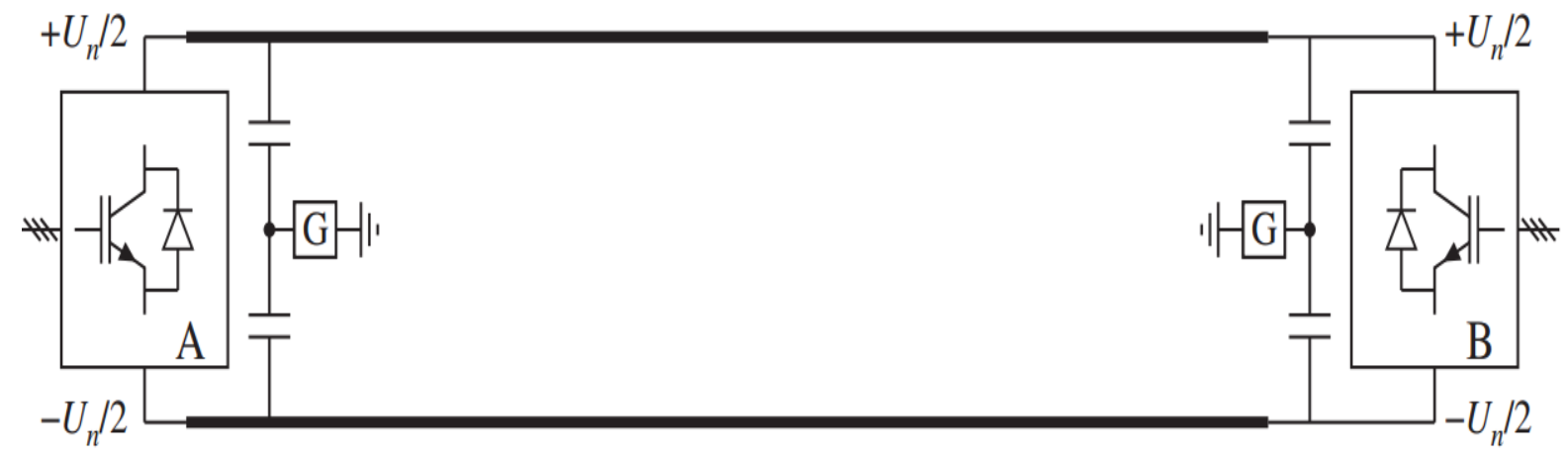

Figure 10. Symmetrical monopolar configuration. Source [19].

Among the advantages of MMC-HVDC technology are [7]: ability to continuously transfer any power level (zero to maximum rating) in both directions, thereby facilitating WPP start up, and operation at low wind speeds; ease of integration with wind turbine generators (WTGs) in islanded grids with very low fault current levels; normally, no need for harmonic filters and additional reactive power resources; improved performance during onshore ac disturbances, because the VSC converters are self-commuted - commutation failures will not occur in case of ac grid disturbances; decoupled control of the active and reactive powers; interconnection capability to weak or passive ac networks; black-start capability; feasibility of building compact converter stations resulting in lower costs and risks for the off-shore platform; ability to use XLPE cables since the operating voltage polarity is unchanged and independent of the direction of the power flow; and implementation of future multi-terminal grids.

Future HVDC projects for the integration of offshore wind energy are expected to be based on the MMC topology. Even the concept of a supergrid for massive integration of remote sources of renewable energy has been already presented in [20] and [21] where it is considered that one of the building blocks will be the MMC-HVDC technology. Other potential applications of MMC-HVDC systems include interconnections of asynchronous systems and electrification of remote islands and oil and gas stations. 


\section{Test System Layout and Main Circuit Parameters}

The test network designed consists of three identical OWFs of nominal capacity of $350 \mathrm{MW}$ using type 4 wind turbines, which are connected to the offshore ac/dc converter station through three different three-phase transformers. These converter transformers are connected to each other on the valve side, but not connected on the low-voltage side, i.e. are not in parallel. The power produced by the WTs is transported to the onshore grid via a point-to-point HVDC link. On the onshore end, a dc/ac converter is connected to an equivalent point of the $380-\mathrm{kV}$ ac transmission system. The single line diagram of the system under study is presented in Figure 11.

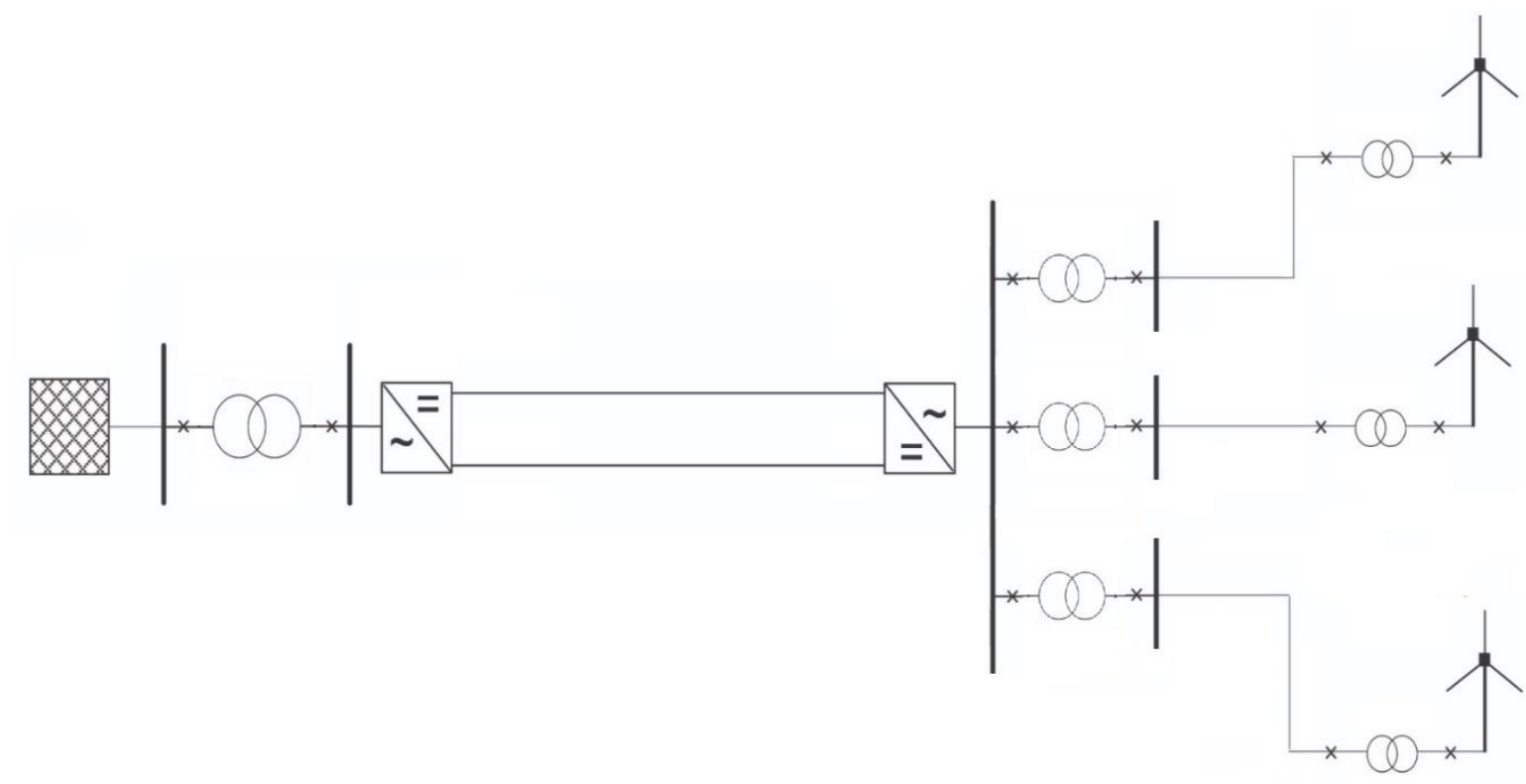

Figure 11. Single line diagram of the test system.

In this chapter, the different components of the system are described. Some of the parameters were assumed based on the system ratings, while others were calculated. The total transmission capacity of the HVDC link is $1050 \mathrm{MW}$.

The test network comprises the following main components:

- Three OWFs.

- Inter-array cable system.

- Three converter transformers at the offshore end.

- The ac/dc and dc/ac MMC units.

- Export HVDC cables.

- Phase reactors.

- Filters.

- Onshore grid.

The PSCAD single line diagram is illustrated in Figure 12. 


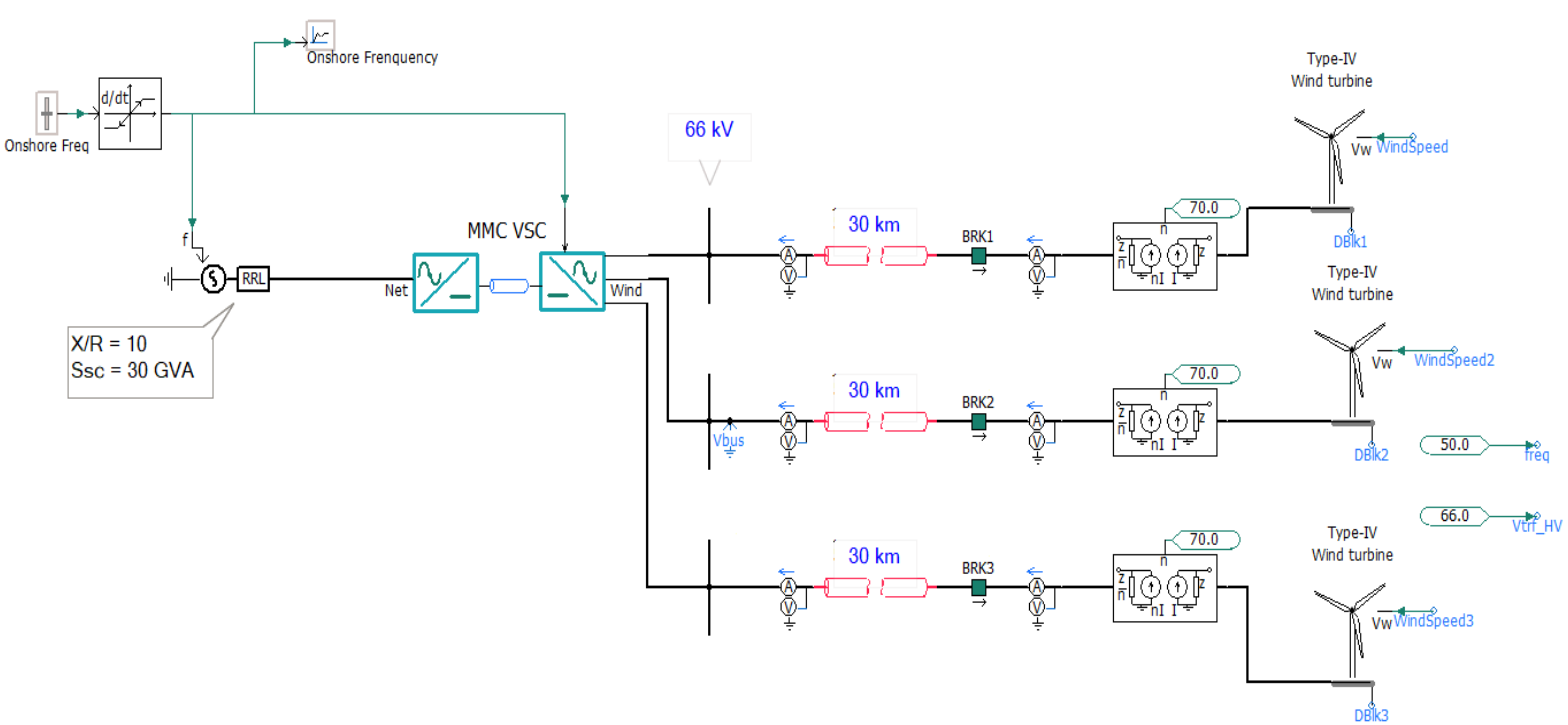

Figure 12. Test network in PSCAD.

\subsection{Offshore Wind Power Plant Layout}

The $1050 \mathrm{~W}$ offshore wind power plant is divided into three offshore wind farms rated at 350 MW. It is projected that each cluster could have between 32 and 36 WTGs installed on four radial feeders. Wind turbines deployed offshore are expected to grow up to $11 \mathrm{MW}$ in European sites by 2030 [22]. All WTGs are assumed to be Type 4 wind turbines. Four WTG feeder strings are connected to the same collector bus at the low-voltage side of one converter transformer in parallel combination. The parameters for modelling the $11 \mathrm{MW}$ wind turbines were not publicly available at the moment. Therefore, a standard model of a $5 \mathrm{MW}$ type 4 wind turbine was used. To represent an aggregated $350 \mathrm{MW}$ OWF 70 wind turbines were implemented. Each OWFs is located at a distance of $30 \mathrm{~km}$ from the offshore MMC station.

A PSCAD module representing an aggregated offshore wind farm is used in the simulation, as seen in Figure 13. The type 4 wind turbine module uses an average converter model and a scaling component. The average model provides enough detail for the objective of this thesis. The total power of each wind farm is $350 \mathrm{MW}$. Three OWFs are implemented for a total power production of $1050 \mathrm{MW}$. This full aggregated model represents a cluster of wind turbines. There are also three independent control blocks to generate the incoming wind speeds in every wind park. According to [23], the wind speed at the reference height of $128 \mathrm{~m}$ in the wind site IJmuiden Ver, where the offshore WPPs are expected to be located, is $11.9 \mathrm{~m} / \mathrm{s}$. The cut-in and cut-out speeds considered were 4 and $25 \mathrm{~m} / \mathrm{s}$ respectively. The overview of the type 4 wind turbine which is a general module available in the PSCAD Knowledge Library is shown in Figure 14. 

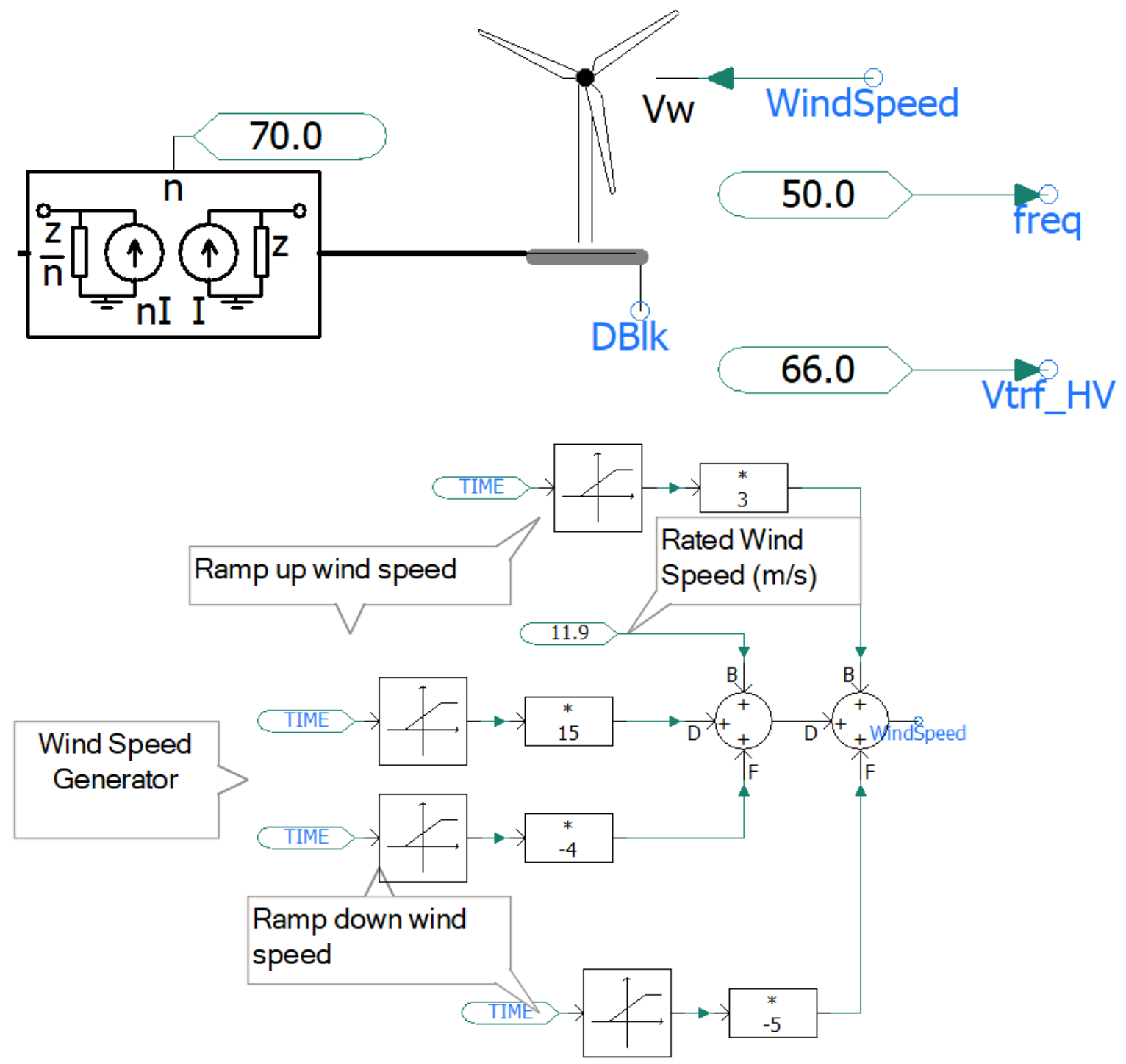

Figure 13. PSCAD representation of an OWF equivalent model.

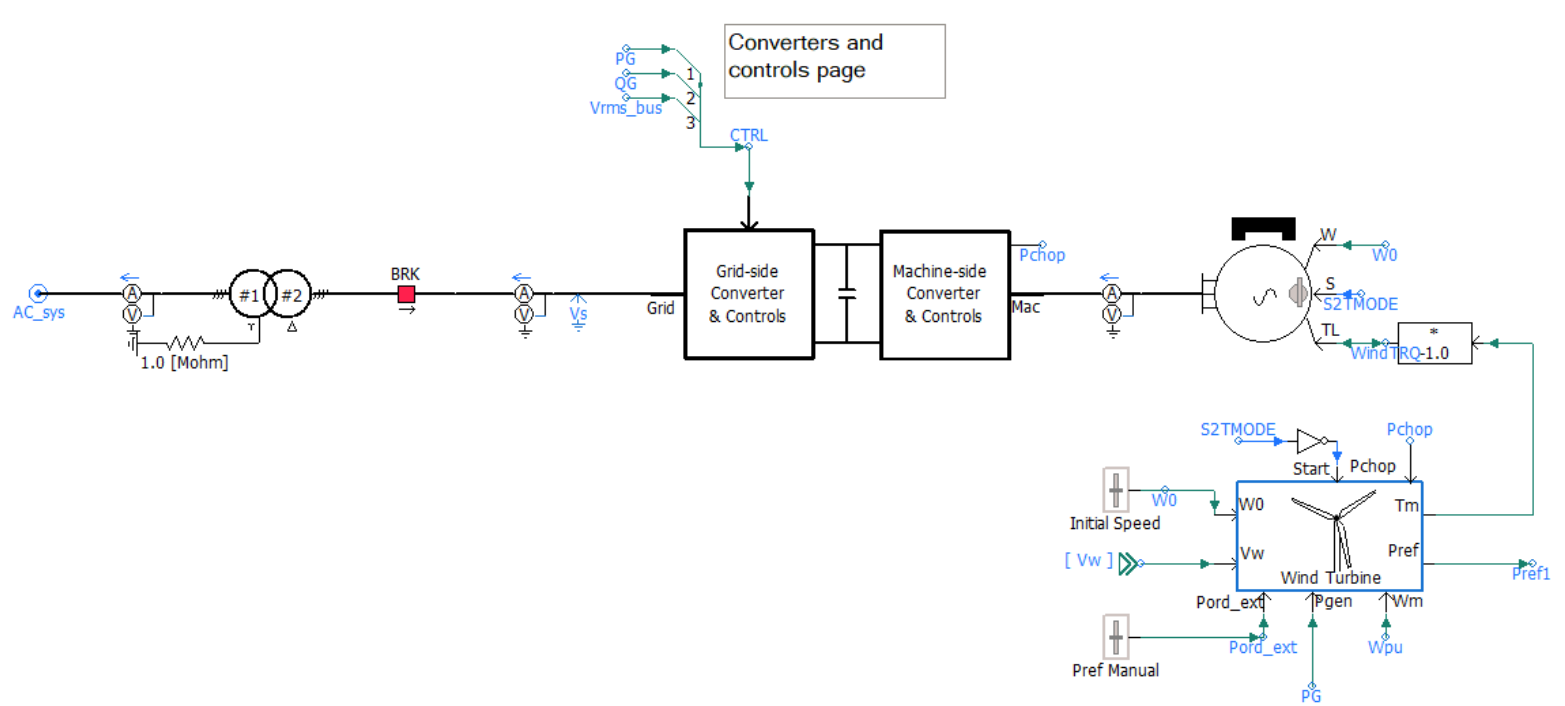

Figure 14. Overview of the PSCAD type 4 wind turbine module. 
The GSC is controlled to maintain the dc link voltage balance, by evacuating the excess power to the offshore $66 \mathrm{kV}$ grid, and the grid reactive power, while the MSC controls the generator torque and speed. Both two-level VSCs are equipped with an L-C-L filter to minimize the impact on the ac network and the machine, respectively, due to the considerable amount of harmonics produced by the converters. A simplified diagram of a type 4 WECS is presented in Figure 15 [24]. The control of the converters inside the type 4 WECS is based on standard structures which were already available in the PSCAD library modules that were used to simulate the test network under study in this thesis.

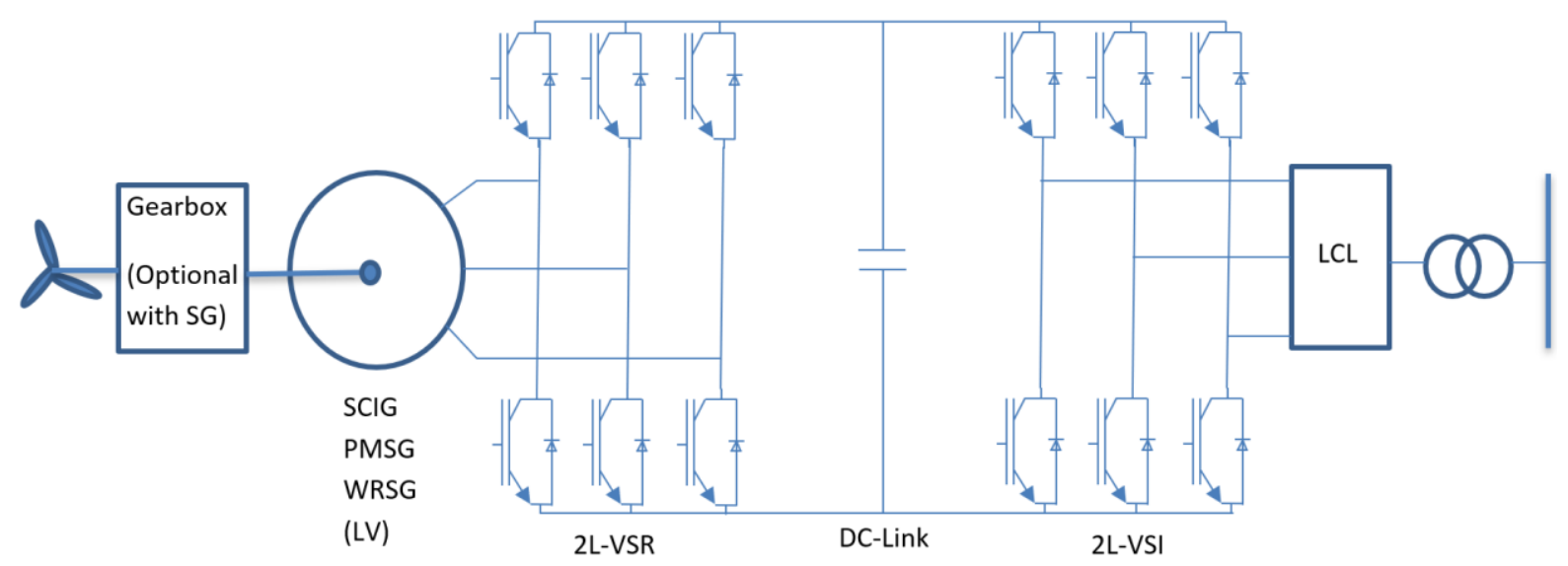

Figure 15. Simplified diagram of a type 4 WECS configuration with two-level BTB VSCs. Inspired based on original illustration in [24].

\subsection{Inter-array Cable System}

The inter-array cable system is rated at $66 \mathrm{kV}$. These cables will collect the output of the WTGs and route it to the offshore ac/dc converter where the voltage will be stepped up for the efficient onward transmission of power to the onshore transmission system. Among the advantages of a cable system operated at $66 \mathrm{kV}$ instead of $33 \mathrm{kV}$ are: possibly up to twice as much power can be transported, less array cabling, and substantial capital cost savings, in terms of both cable purchase and installation [25]. Another great benefit is the elimination of the ac collector substation platforms as the wind farm's $66-\mathrm{kV}$ array cables are directly connected to the primary side of the offshore HVDC converter transformer. Removing the intermediate ac substation platform will result in significant investment savings (CAPEX) and will reduce overall maintenance costs (OPEX), as there are fewer components to fail [10].

Standard cable elements from the PSCAD library were used. The parameters for the cable system are based on data from TenneT projects. The inter-array cable system was modelled using the Bergeron model in PSCAD [26].

An important aspect to be analysed for the inter-array cable system is the reactive power that must be compensated. Capacitance of HVAC submarine cables is higher than that of overhead transmission lines and therefore has to be properly compensated. The submarine ac cable generates a considerable reactive current due to its high capacitance which reduces its active current-carrying capacity and increases the its losses. A compensation device can solve these problems and improve the security and stability of system.

In the PSCAD model, the cable has a fixed inductive reactive power compensation at the wind farm side. The capacitive reactive power generated in the submarine cable rated at $66 \mathrm{kV}$, worst-case estimation, is [25]: 


$$
Q_{c}=3\left(\frac{U_{c}^{2}}{X_{c}}\right)=3\left(\frac{U_{r}}{\sqrt{3}}\right)^{2} \cdot \omega \cdot C=U_{r}^{2} \cdot \omega \cdot C=66^{2} \cdot 2 \pi \cdot 50 \cdot(0.38)=520 \quad \frac{k V A r}{k m}
$$

Where $\mathrm{Ur}$ is in $\mathrm{kV}, \omega$ is in $\mathrm{rad} / \mathrm{s}$ and $\mathrm{C}$ is in $\mu \mathrm{F} / \mathrm{km}$. For a total length of the cable array of 30 $\mathrm{km}$, the total charging power is 15.6 MVAr. For four cables carrying the power from one OWF, the total reactive power to compensate adds up to $62.4 \mathrm{MVAr}$ for a wind farm of $350 \mathrm{MW}$. Grid codes define the P-Q capability for a grid connection point. The wind farm developer will decide if compensation is needed.

\subsection{Converter Transformers}

Converter transformers have several functions among of which the most important are [9]:

- Provide a reactance between the ac system and VSC unit.

- Adapt a standard ac system voltage to a value matching the VSC ac output voltage and allow optimal utilisation of VSC valve ratings.

- Prevent zero sequence currents from flowing between the ac system and VSC unit.

An MMC can be fed by the delta side of a star-delta transformer, which isolates the ground currents on the ac and dc sides in case of faults in the ac or dc transmission system. The neutral point of the ac side of the converter is not actually available and can be considered isolated from the dc side ground point [27]. No special transformers are required for the MMCHVDC technology [28]. Therefore, conventional transformers are used from the PSCAD library to model these elements.

\subsubsection{Converter transformers at the offshore end}

There are three offshore converter transformers which connect the wind farms with 66-kV cables to a centralised platform (power hub) where the offshore end of the HVDC link is located. The 66-kV cables will not be connected to a single busbar and converter transformer as done in current standard topologies but will be connected to three transformers not in parallel. These transformers are connected to each other on the valve side but not connected on the $66-\mathrm{kV}$ side. The transformers have identical nominal voltage ratio of $333 / 66 \mathrm{kV}$ to connect the VSC station to the offshore grid at $66 \mathrm{kV}$. The nominal capacity of each transformers is 400 MVA. The leakage reactance is assumed to be $14 \%$, typically the optimum reactance value [15].

\subsubsection{Converter transformers at the onshore end}

For this new connection concept with a nominal capacity of $1050 \mathrm{MW}$, the onshore side transformer could be either a bank of three single phase transformers or a three-phase transformer. Considerations regarding availability and reliability of the connection could suggest another option of two identical three-phase transformers each with $75 \%$ of the total capacity for the offshore HVDC platform [10], similar to standard current concepts [29], which may also reduce the cost as already available commercial equipment is used.

The nominal voltage ratio of the three-phase transformer modelled in the test network is $380 / 333 \mathrm{kV}$ as it interfaces the $\pm 320 \mathrm{kV}$ MMC-VSC station with the $380-\mathrm{kV}$ onshore grid. The leakage reactance is assumed to be $18 \%$, and the losses are $0.5 \%$ no load loss and $0.5 \%$ full load copper loss. The parameters of the converter transformer have been taken from the MMCHVDC system that interconnects the 400-kV systems of France and Spain (INELFE) [30]. The 
secondary winding of each transformer is connected in delta to block the zero-sequence voltages generated by the MMC.

\subsection{Modular Multilevel Converters}

Voltage source converter using modular multilevel converter topology is today the state-of-theart HVDC technology and future projects are believed to use this type of converters based on all its advantages as explained in detail in the previous chapter. The converters have a design based on series-connected half-bridge submodules. The converter stations are connected following a symmetrical monopole configuration with rated DC voltage of $\pm 320 \mathrm{kV}$ (positive negative pole) and AC voltage of $333 \mathrm{kV}$, as the real HVDC link presented in [30].

It has been reported that some on-going HVDC projects using MMC topology are planned to use more than 400 submodules per multivalve arm [31] and this same trend is likely to continue in the future. However, to model a converter with this large number of submodules will require huge computational effort. Reference [32] indicates that good results can be achieved if the amount of simulated power submodules inside the MMC are higher than 25 when using carrier phase-shifted, multilevel sinusoidal PWM method for generating output voltage waveforms in terms of total harmonics content. This same reference shows that for converters using 48 levels, the output voltage waveform is essentially sinusoidal and closely follows the reference waveform.

The amount of power submodules per arm inside the MMC of the test network is 300 . The PSCAD representation of the HVDC link based on MMC is presented in Figure 16. These modules are available from the PSCAD Knowledge Library.

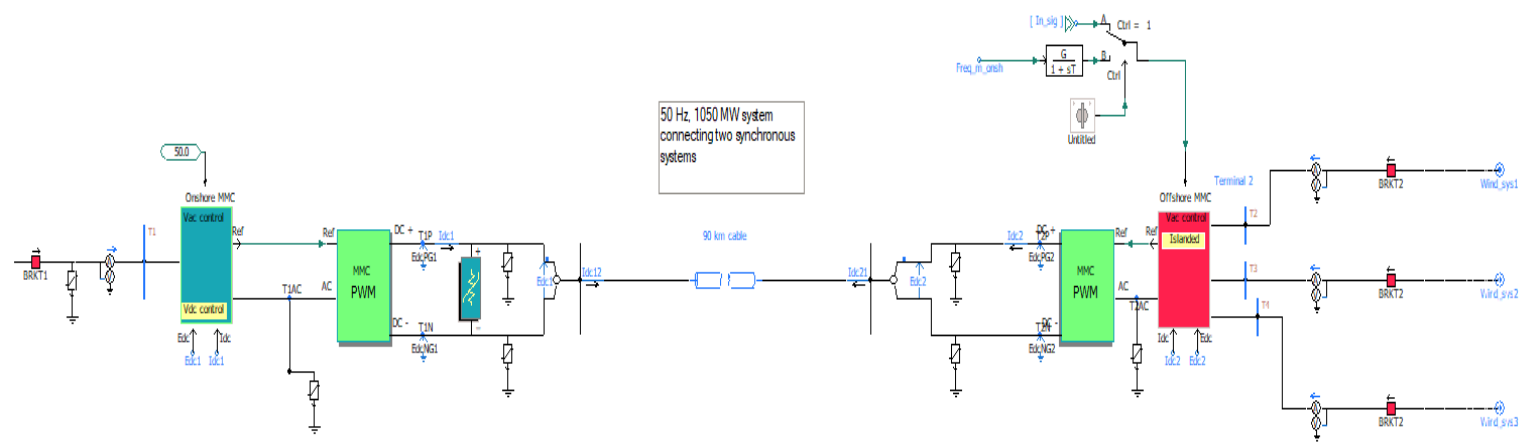

Figure 16. PSCAD representation of the HVDC link for the test system.

The values of the parameters for the MMC are mainly based on formulas given in [31]. The arm reactor helps control and balance circulating currents in the phase arms and limiting fault currents and has a value of 0.15 p.u on the system impedance base:

$$
L_{\text {arm }}=L_{p u} * \frac{Z_{\text {ref }}}{\omega_{\text {ref }}}=0.15 * \frac{333^{2} / 1107}{2 \pi(50)}=48 \mathrm{mH}
$$

According to [10], this dimensioning is based on one method to handle dc-side short-circuits, where the submodules are not equipped with bypass thyristors or separate additional power modules entirely equipped with diodes. For the point-to-point HVDC link, the method to clear a fault on the dc side requires opening the slow-acting ac circuit breakers at both ends. During this time, the magnitude of the fault current must be limited by the arm inductors to protect the anti-parallel diodes that conduct the fault current.

The arm inductors have two functions [14]: first, suppression of the balancing currents flowing through the individual phase units of the converter as a result of the inequality of the three 
generated phase unit voltages that connected in parallel on the dc side. The reactors could suppress these balancing currents to a very low level and make them manageable by means of appropriate control methods. The second purpose is to limit the current rise rate of the MMC to only a few tens of amperes per microsecond for the worst case, a dc terminal short circuit fault. The arm inductors are in series with the distributed energy storage capacitors, so the effects of faults arising inside or outside of the converter can be reduced by the arm inductor substantially.

Literature on the value of the capacitance of the submodules inside the MMC recommends that the individual capacitance of each half-bridge cell is selected so that the ripple of the submodules voltages is kept within a range of $\pm 10 \%$. To achieve this, the total stored energy in all submodule capacitors of the converter $\left(E_{M M C}\right)$ should be in the range of $30-40 \mathrm{~kJ} / \mathrm{MVA}$ [30]:

$$
C=\frac{2 S E_{M M C}}{\left(6 N_{\text {arm }} v_{C}^{2}\right)}=\frac{2(1107)(40)}{6(300)\left(2.14^{2}\right)}=10.7 \mathrm{mF}
$$

Where $v_{C}$ is the average submodule capacitor voltage in $\mathrm{kV}, \mathrm{S}$ is the rated apparent power of the link in MVA, considering \pm 350 MVAr of reactive power capability, and $N_{\text {arm }}$ is the number of submodules per arm. There are IGBT power modules with a voltage rating of $4.5 \mathrm{kV}$ available today in the market and are part of projects already in operation within the TenneT's grid [33].

The detailed equivalent model of the MMC available in PSCAD, named type 4 in [31], assumes that IGBTs and diodes can be treated as two-state resistive devices. With this approach, each arm is replaced by a Norton equivalent circuit. An MMC unit based on the detailed equivalent model is represented in Figure 17 [31]. The switch "on" and "off" resistance values are selected as $500 \mu \Omega$ and $100 \mathrm{M} \Omega$, respectively.

A detailed equivalent model is used to perform electromagnetic-transients (EMT) studies where the very fast behavior of the power electronics and control circuits are of interest. Transient models are focused on the HVDC system and include a detailed representation of the converter power electronics and the implemented control structures. The behavior of the rectifier station can be better studied if the network dynamics are simulated in detail through EMT simulations. The time range of interest is from milliseconds to several seconds. The response of the assessed system depends on the controls. For the controls to correctly operate, the measurements during a fault has to be done very quickly and accurately so it is possible to detect the variation of the voltage values and act upon the signals as required.

The controls highly depend on the measured values. An EMT model accurately represents the response of fast controls. To really know if the voltage can be controlled during fault periods, EMT simulations are necessary. The scope of the an EMT study is in the evaluation of the performance of the projected HVDC transmission scheme. The type 4 model has a very accurate steady-state and dynamic response for ac faults when compared to a detailed nonlinear IGBT-based model and average value models [34]. The representation of the ac network in this model is limited to an equivalent voltage source determining the short-circuit power of the ac system. 


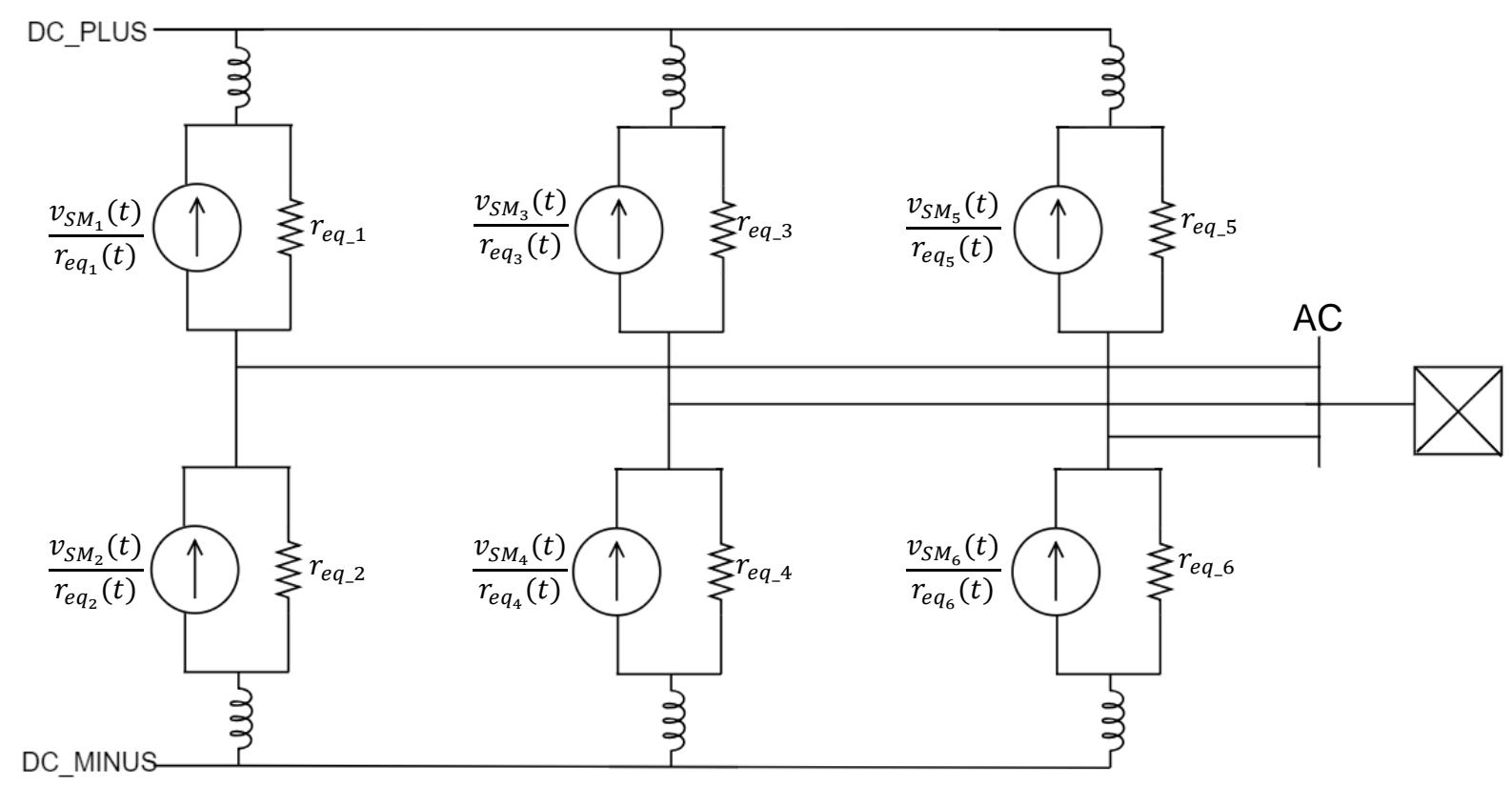

Figure 17. MMC Equivalent circuit based on detailed equivalent modeling. Inspired based on original illustration in [31].

\subsection{Export HVDC Cables}

For VSC-based HVDC power transmission, extruded dc cables have been successfully applied in many projects at up to $320 \mathrm{kV}$ voltage rating and up to $1000 \mathrm{MW}$ power rating [35]. The major insulation material is cross-linked polyethylene (XLPE). Some of the benefits of extruded cables are that they can withstand a higher operational temperature (up to $90^{\circ} \mathrm{C}$ ) allowing for more power to be carried for a given conductor cross section than massimpregnated (MI) cables; the cables are generally mechanically robust and the weight is smaller; the installation is simpler and faster due to the easier jointing process; extruded cables can avoid the environmental problem caused by oil leakage, and are recyclable [6]. A very important characteristic of the VSC HVDC technology that has led to increase the applications for extruded HVDC cables is non-voltage reversal feature. The same pole voltage polarity is always maintained, whereas the current flow direction is reversed to change the direction of the power flow from one converter station to the other.

The cable representation in PSCAD uses a frequency dependant phase model [26]. The distance between cables is $50 \mathrm{~cm}$ (wide spacing). For submarine cables resistivity of the return path is close to resistivity of sea water: $\rho=0.2 \Omega \cdot \mathrm{m}$ and the depth measured from the center of the cable and the ground surface is $1.5 \mathrm{~m}$ (but $50 \mathrm{~m}$ deep in the water) [31]. Nominal power rating of $1050 \mathrm{MW}$ at $\pm 320 \mathrm{kV}$ dc voltage requires a current flow of $1.64 \mathrm{kA}$. The cable parameters used in the PSCAD model are based on the parameters given in the CIGRE DC Grid test system [31] for the 400-kV cable: 


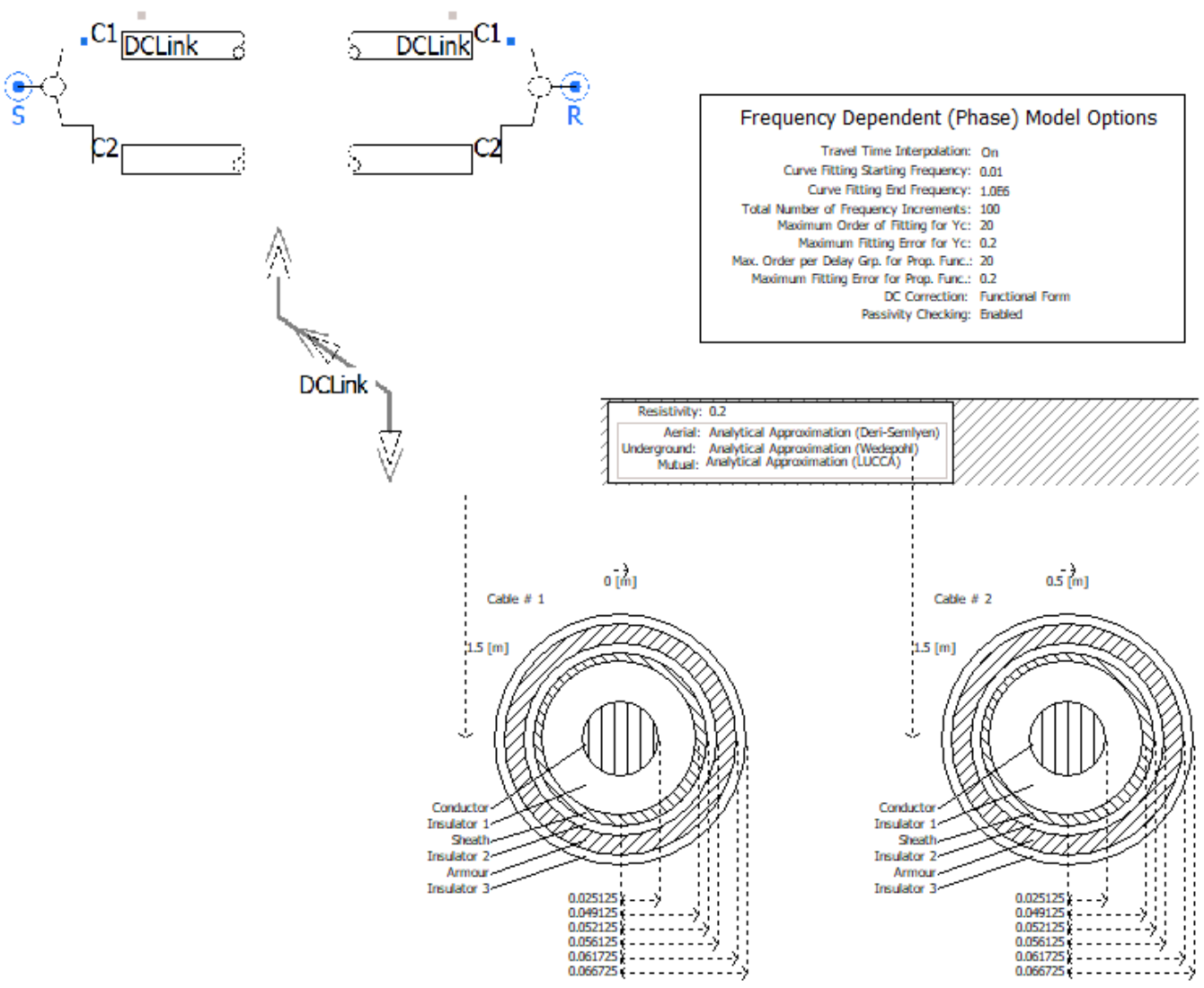

Figure 18. Parameters for the DC cables.

\subsection{Onshore Equivalent Grid}

The onshore transmission grid is represented by a Thevenin's equivalent of a 380-kV voltage source with series impedance. The grid impedance is estimated based on the short circuit power at the point of grid connection. The resistive and inductive parts of the impedance are determined from the grid angle. Assuming a strong grid at the PCC of the HVDC link, and following the reference parameters presented in [31] for the CIGRE DC Grid test system, short circuit power $=30 \mathrm{GVA}$ and $\mathrm{X} / \mathrm{R}=10$, the equivalent parameters are calculated as follows:

$$
\begin{aligned}
& Z_{t h}=\frac{V_{a c}^{2}}{s_{s c}}=4.813 \angle 84.3^{\circ} \Omega \\
& R_{\text {grid }}=Z_{t h} * \cos 84.3^{\circ}=0.478 \Omega \\
& X_{\text {grid }}=Z_{t h} * \operatorname{sen} 84.3^{\circ}=4.789 \Omega \\
& \omega=2 \pi f=314.16 \mathrm{rad} / \mathrm{s} \\
& L_{\text {grid }}=\frac{X_{\text {grid }}}{\omega}=15.245 \mathrm{mH}
\end{aligned}
$$




\subsection{Additional Components}

The pre-insertion resistor has a value in the order of magnitude of $\mathrm{k} \Omega$ and is project specific. For the INELFE project, the value referenced in [36] is $5 \mathrm{k} \Omega$. A circuit breaker with a preinsertion resistor is required to be installed at the MMC station to suppress the inrush current due to the saturation of the converter transformer and avoid severe voltage dips at the PCC during the energization of the MMC station [37], see Figure 19 and Figure 20. For the start-up sequence of the converter in the PSCAD simulation a value of $100 \Omega$ was implemented [38] as it allows for a faster simulation. There will not be a pre-insertion resistor at the offshore MMC station as the operation strategy considered in this case will not consider the case in which the OWFs have black start capability and the system is energized from offshore.

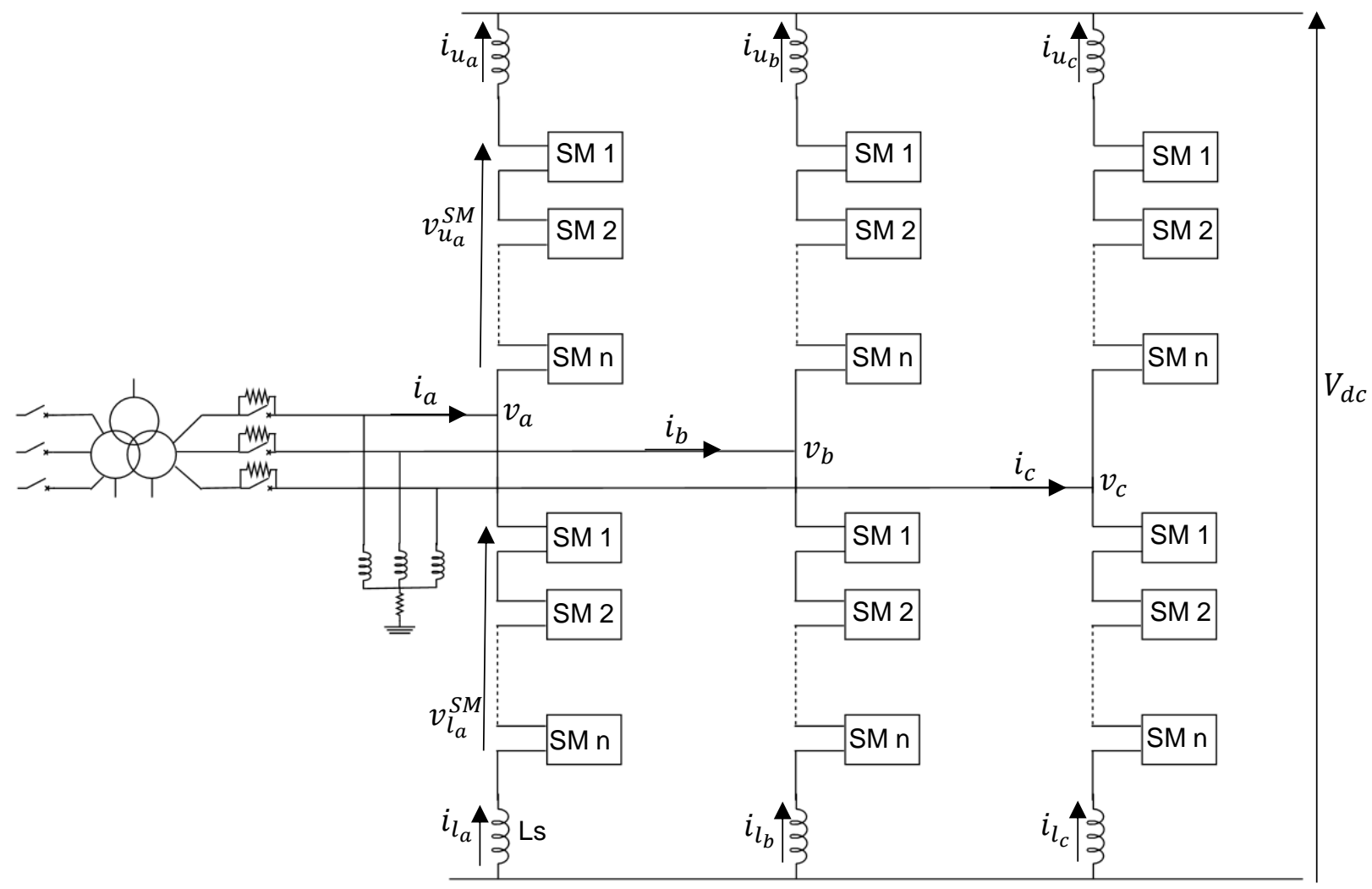

Figure 19. Single-line diagram with the PIR and grounding reference. Inspired based on original illustration in [31].

The grounding reference for the symmetrical monopole configuration used here is obtained by a special grounding device, a star-point reactor which is installed between the converter transformer secondary side and ac side of the converter arms to provide a reference to ground in one station and provides the zero-potential point for the dc side of the converter. It is normally placed at the onshore station. The star-point reactor consists of three star-connected inductors with their neutral connected to the ground through a resistor. In this way, this device provides a low impedance path to the ground for dc from the ac side of the converter without requiring dc current flowing through the transformer windings [10]. The values of the star-point reactor parameters in the PSCAD model are $5000 \mathrm{H}$ and $5000 \Omega$, respectively based on [31]. The representation is shown in Figure 19 and Figure 20.

The dynamic braking system (DBS), also referred to as dc chopper is a common element in the HVDC topology connecting OWFs. The main function of the onshore DBS is to regulate the dc voltage by dissipating the surplus energy in the system which can arise when the MMCs are not able to export all the wind power on the system. This situation happens when there are onshore network faults and the offshore wind turbines keep generating power to the HVDC 
link. The excess of power is dissipated by the dc chopper during temporary onshore faults, normally loner than the onshore auto-recloser deadtime [10], which enables an undisturbed operation of the OWFs during onshore faults. The dc chopper is installed between the positive and negative poles and is represented as a power electronic switch (IGBT) connected in series with a resistor as illustrated in Figure 21 [39] and Figure 16. The basic control strategy for a DBS is to turn on the IGBT valve once the dc voltage has exceeded a threshold and turn it off once the dc voltage has returned below a specific value [40]. Normally, the dc chopper must provide: independent control based on local voltage measurement; low or no degree of dependency on communication systems; robustness, reliability, and ease of maintenance; and coordinated control with the converter station controller (if applicable) [7]. For the power of $1050 \mathrm{MW}$ the resistor of the DBS has a value close to $500 \Omega$.

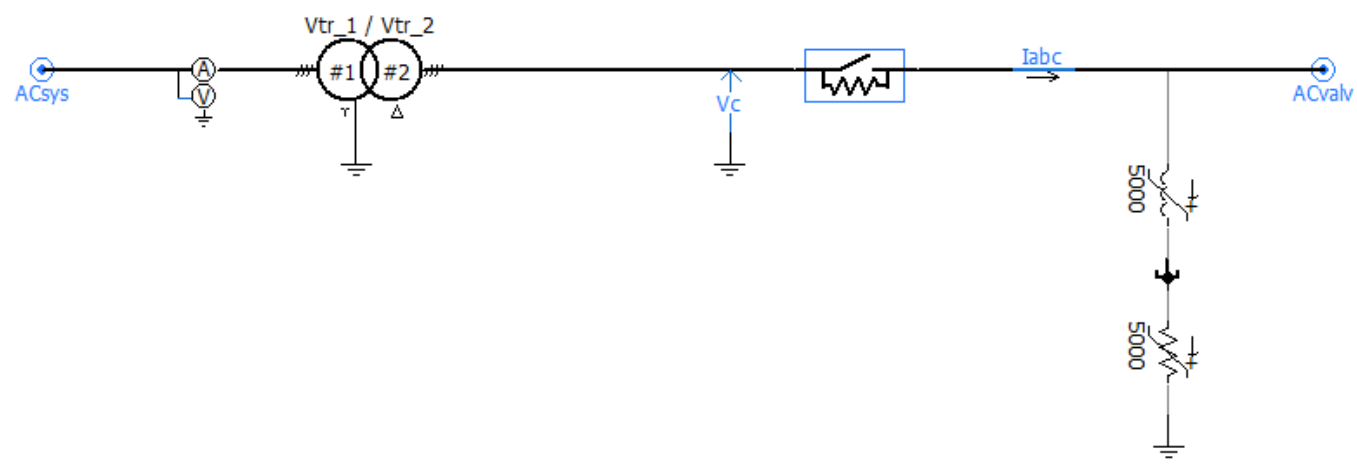

Figure 20. PSCAD model with the PIR and grounding reference.

Surge arresters are part of the equipment installed to protect the components of the HVDC transmission scheme from any abnormal overvoltages such as temporary and transient voltages. An appropriate insulation coordination is required to determine the maximum overvoltages to which the high voltage equipment will be exposed, establish the required voltage withstand capabilities and define the characteristics of the protective device, i.e. the surge arresters [41]. The values of the surge arresters in the PSCAD model were selected based on the guide given in [42].

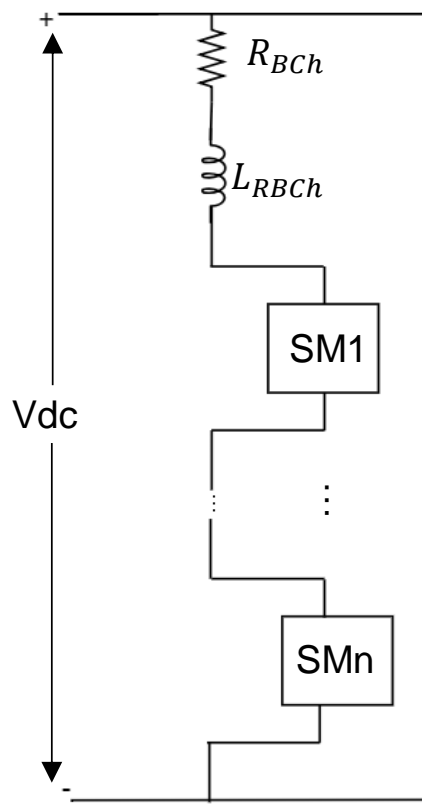

Figure 21. Dynamic braking system. Inspired based on original illustration in [39]. 


\section{Control of the MMC-HVDC Transmission Scheme}

The principle of operation of grid-connected converters considers a series inductive interface separating the MMC from the ac system, as in Figure 6. One of the main advantages of MMCHVDC technology is that active and reactive power can be controlled independently, as explained in chapter 2 . The reactive power can be controlled separately in each MMC by the required ac voltage or set manually. The active power flow can be controlled by the dc voltage, the variation of frequency at the ac side or set manually. By adjusting the magnitude and phase of the voltage waveform at the output terminals of the MMC with respect to the ac grid voltage, the current flowing through the interface inductance is controlled to match a desired active and reactive power transfer between the two systems.

If the magnitude of the synthesized voltage is greater than the magnitude of the ac system voltage, reactive power will be transferred into the ac system. If the magnitude of the synthesized voltage is lower than the magnitude of the ac system, the MMC will be absorbing reactive power. Controlling the phase angle of the output voltage of the MMC can regulate the active power transfer with ac grid, action possible by shifting the phase of the synthesized voltage with respect to the phase locked loop (PLL) that is synchronized to the ac system voltage. The interaction of the MMC with the ac grid can be summarized through the following diagrams [43]:

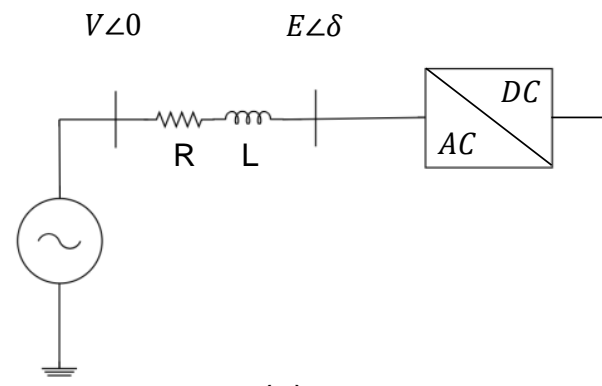

(a)

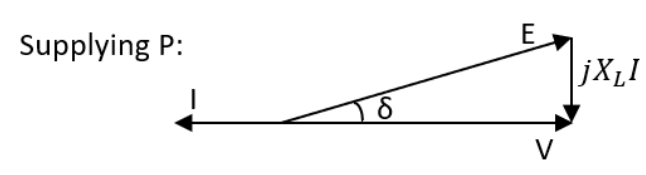

Absorbing P:

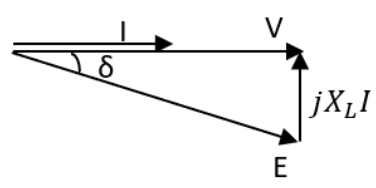

Supplying Q:

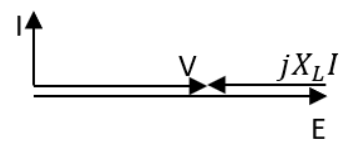

Absorbing Q:

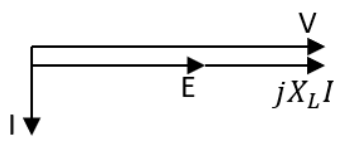

(b)

Figure 22. Two-bus system representation of the operation principle of an MMC unit. Inspired based on original illustration in [43]. 
The equations which describe the transferred power between the ac grid and the MMC station, neglecting the resistive component of the interface, are [43]:

$$
\begin{gathered}
I=\frac{V \angle 0-E \angle \delta}{j X_{L}} \\
P=-\frac{E V}{X_{L}} \sin \delta \\
Q=\frac{V^{2}-E V \cos \delta}{X_{L}}
\end{gathered}
$$

The control levels of an MMC-HVDC station are classified into three levels: dispatch control, upper level control and lower level control [31]. This control hierarchy is presented in Figure 23. The dispatch control manages the operating set point for the converter to meet both the ac and dc requirements. These reference points of operation are coordinated by a system operator responsible for the grid.

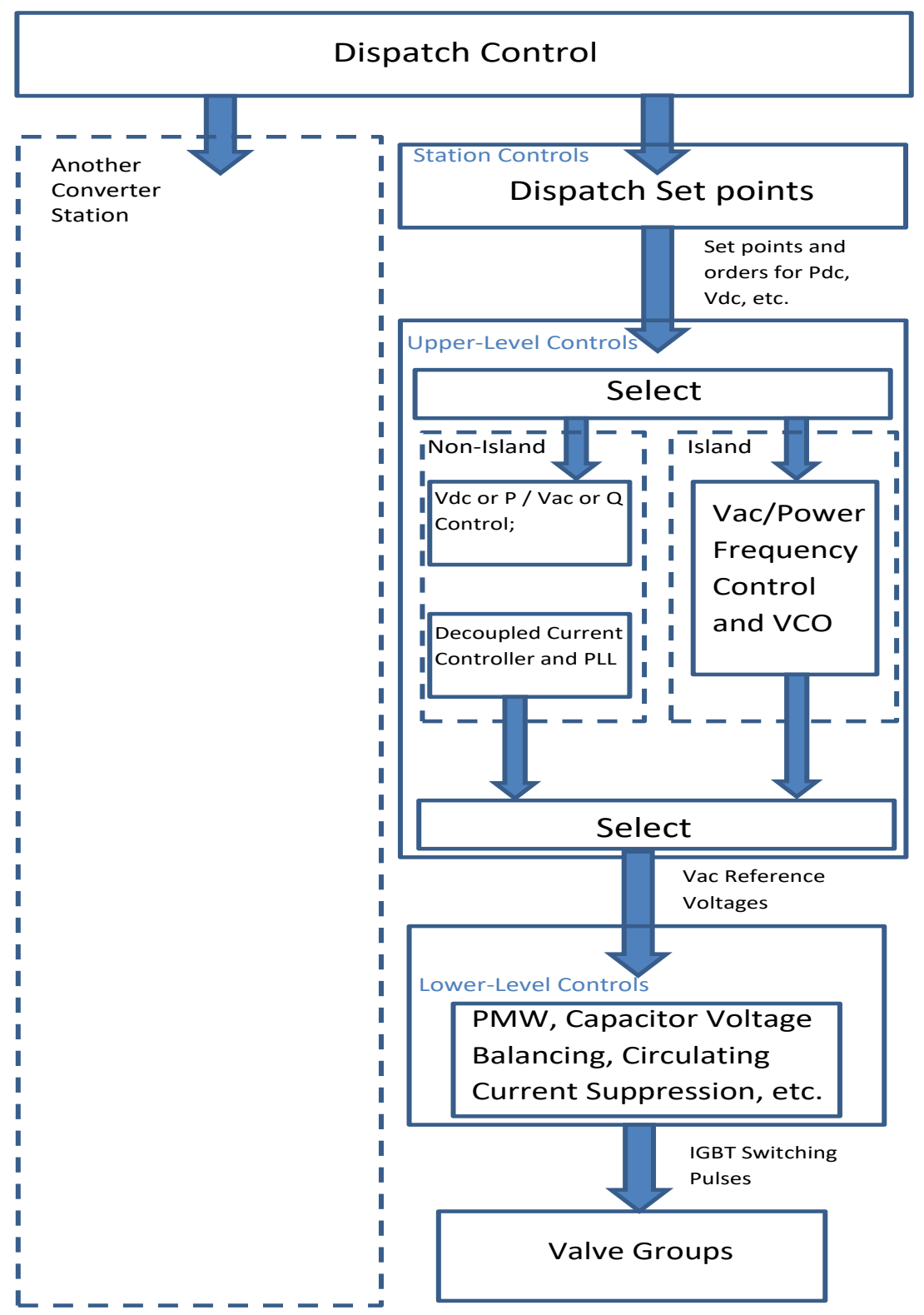

Figure 23. Control hierarchy for an MMC-HVDC multi-terminal converter. Inspired based on original illustration in [31]. 


\subsection{Upper Control (VSC Control)}

\subsubsection{Outer control}

The upper control of the converter consists of two parts, the outer and inner loops. The faster vector controller which is the inner loop $(10 \mathrm{~ms})$ and the outer controllers which supply the references for the vector controller $(100 \mathrm{~ms})$. The outer controllers include the active power controller, dc voltage controller, reactive power controller, ac voltage controller, and frequency controller.

The complete mathematical derivation of all the equations presented in this section is given in [44]. The use of a rotating dq0 frame simplifies the control analysis of three-phase circuits. Initially, the voltages and currents in the abc frame are transformed into the $\alpha \beta$ complex frame by the Clark transformation. Then the $\alpha \beta$-dq transformation is given by the Park transformation.

For the required transformation from the abc frame to the dq reference frame it is considered that the vector of the voltage at the PCC is aligned with the d-axis, and the q component is zero. During balanced steady state operation, the dq voltages are constant at the rated value.

The final equations for the control of the active power in the MMC are:

$$
\begin{gathered}
P_{a c}=v_{P C C_{d}} i_{d} \\
i_{d}^{r e f}=\frac{1}{v_{P C C_{d}}}\left(\frac{k_{i_{P}}}{s}\right)\left(P_{a c}^{r e f}-P_{a c}\right)
\end{gathered}
$$

The control equation for the dc voltage is defines as:

$$
i_{d}^{r e f}=C_{V_{d c}}(s) *\left(V_{d c_{r e f}}-V_{d c}\right)
$$

The reactive power in the dq frame, considering that the vector of the voltage at the PCC is aligned with the d-axis, and the q component is zero, is:

$$
Q_{a c}=-v_{P C C_{d}} i_{q}
$$

And the final control equation is:

$$
i_{q}^{r e f}=-\frac{1}{v_{P C C_{d}}}\left(\frac{k_{i_{Q}}}{s}\right)\left(Q_{a c}^{r e f}-Q_{a c}\right)
$$

The voltage drop on the equivalent interface reactance can be calculated as:

$$
\Delta v_{P C C}=v_{c o n v}-v_{P C C} \approx \frac{\omega\left(L_{t r f}+L_{a r m} / 2\right) Q_{a c}}{v_{P C C}}
$$

Which can be represented in the dq frame as:

$$
\Delta v_{P C C} \approx \omega\left(L_{t r f}+L_{a r m} / 2\right) i_{q}
$$

With final control equation:

$$
i_{q}^{r e f}=\left(\frac{k_{i_{V}}}{s}\right)\left(v_{\text {PCCref }}-v_{P C C}\right)
$$


Simplified structure of the control loops for the outer controllers are shown in Figure 24 [44]:

P-control

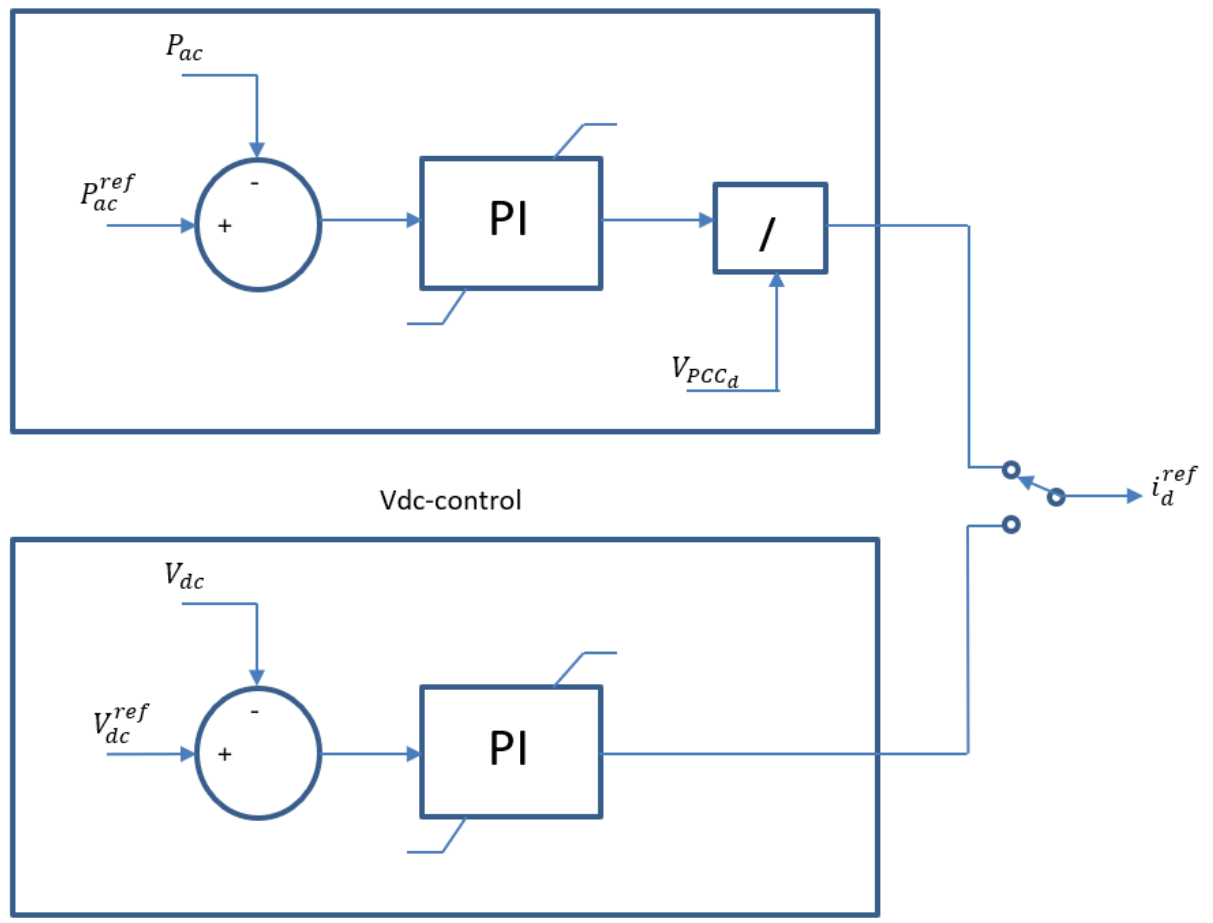

(a)

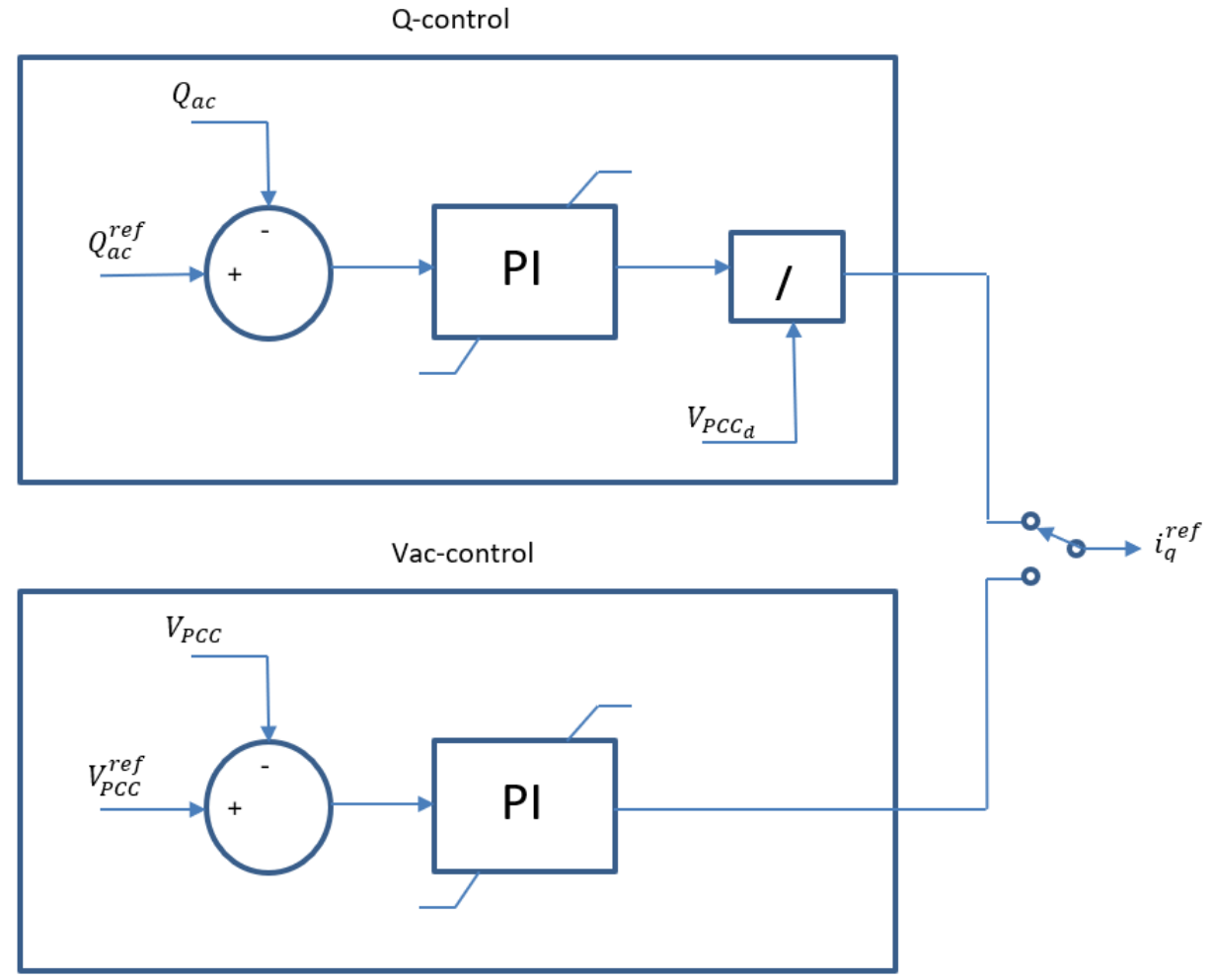

(b)

Figure 24. Outer control block: (a) for $i_{d}^{r e f}$ (b) for $i_{q}^{\text {ref }}$. Inspired based on original illustration in [44]. 
The PSCAD representation of all this control modes for the VSC control can be seen in Figure 25 and Figure 26, where the control loops are also valid for converters in multiterminal dc grids, as indicated in the CIGRÉ DC Grid test network. All the droops controls have been set to zero for the point-to-point HVDC link.

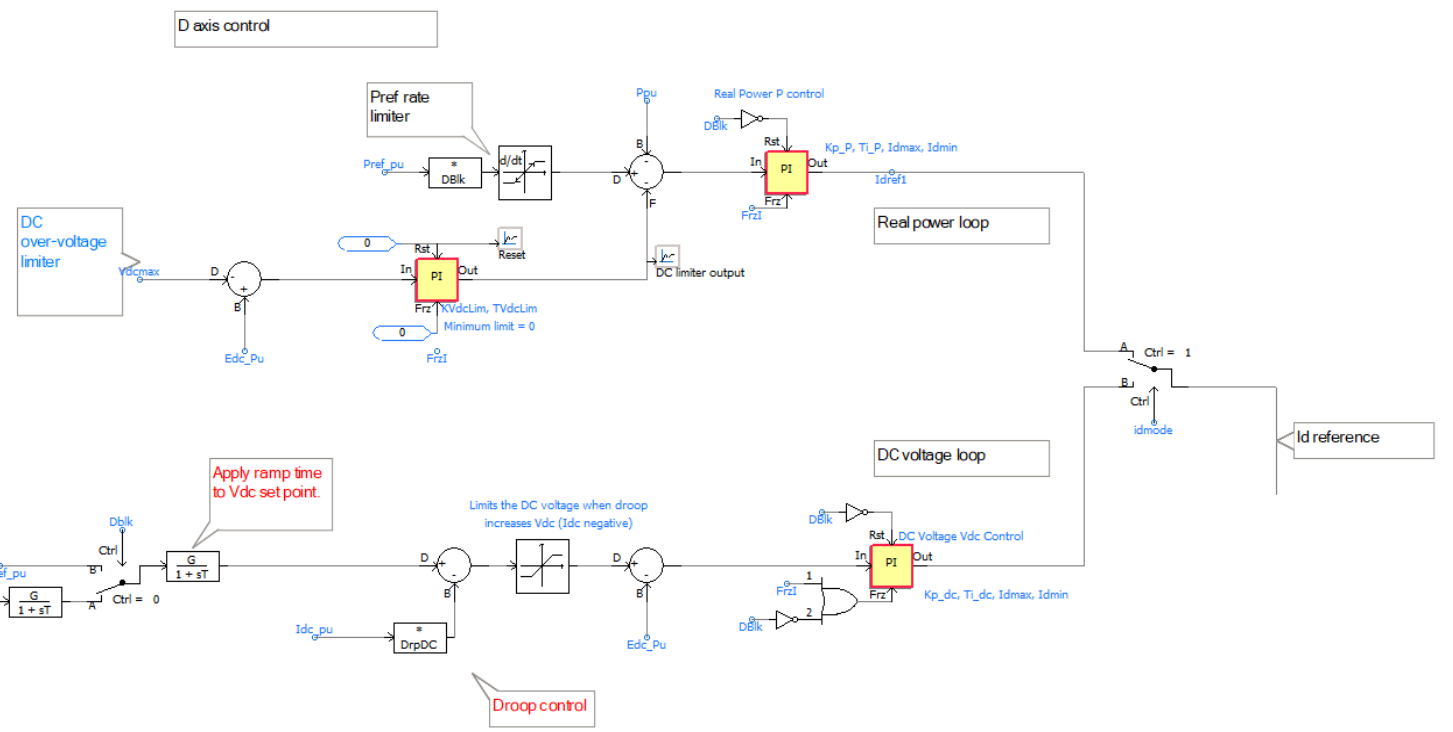

Figure 25. Outer control block for $i_{d}^{\text {ref }}$.

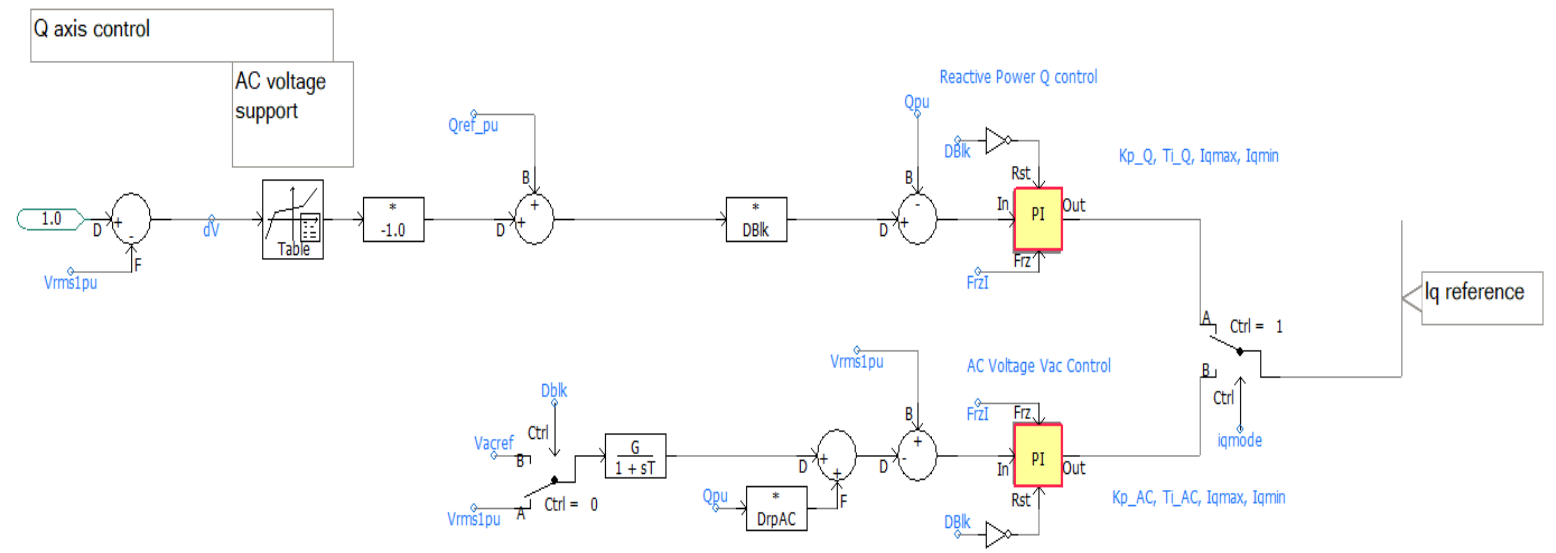

Figure 26. Outer control block for $i_{q}^{\text {ref }}$.

The most appropriate control modes for MMC-HVDC stations at the receiving end of a link connecting OWFs are ac voltage control and dc voltage control [9]. These two control modes are configured in the modules available in the PSCAD representation of the converters for the test network under study in this thesis. The onshore converter has a grid following behavior. The onshore MMC connected to the ac grid detects the frequency and phase from the system at the PCC to synchronize the converter and control accordingly. This action is performed by the PLL system which synchronizes with the ac voltage. With this reference, the PLL will produce the phase angle $\theta$ necessary to transform the voltages and currents from the abc to the dq reference frame. The onshore converter station can also operate in a STATCOM style mode.

For the sending end the converter station works in ac voltage control mode and islanded mode, which means that the offshore MMC controls the frequency of the offshore ac grid by generating the angle reference of the voltage waveform by an independent VCO. No PLL is used because the angle is provided by the frequency regulator. The offshore converter has a grid forming behavior and must be capable of accepting and delivering the power generated 
by the OWFs and transfer it to the onshore station and enforce the power balance and protect integrity of the operation of the WTGs units within the offshore WPP [7]. Since all generating units are type 4 wind turbines, the rotating inertia directly connected to the island grid is zero. The frequency control of the offshore grid is driven by the MMC terminal. The offshore converter operates as a power slack bus. The islanded control loop is depicted in Figure 27 along with its PSCAD implementation in Figure 28 [38].

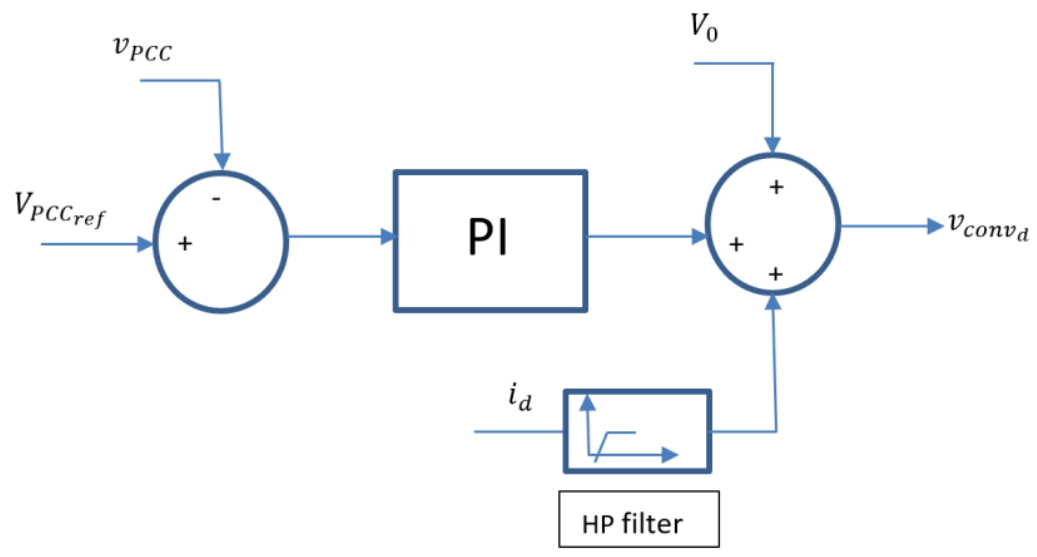

Figure 27. V/F control block diagram. Inspired based on original illustration in [38].

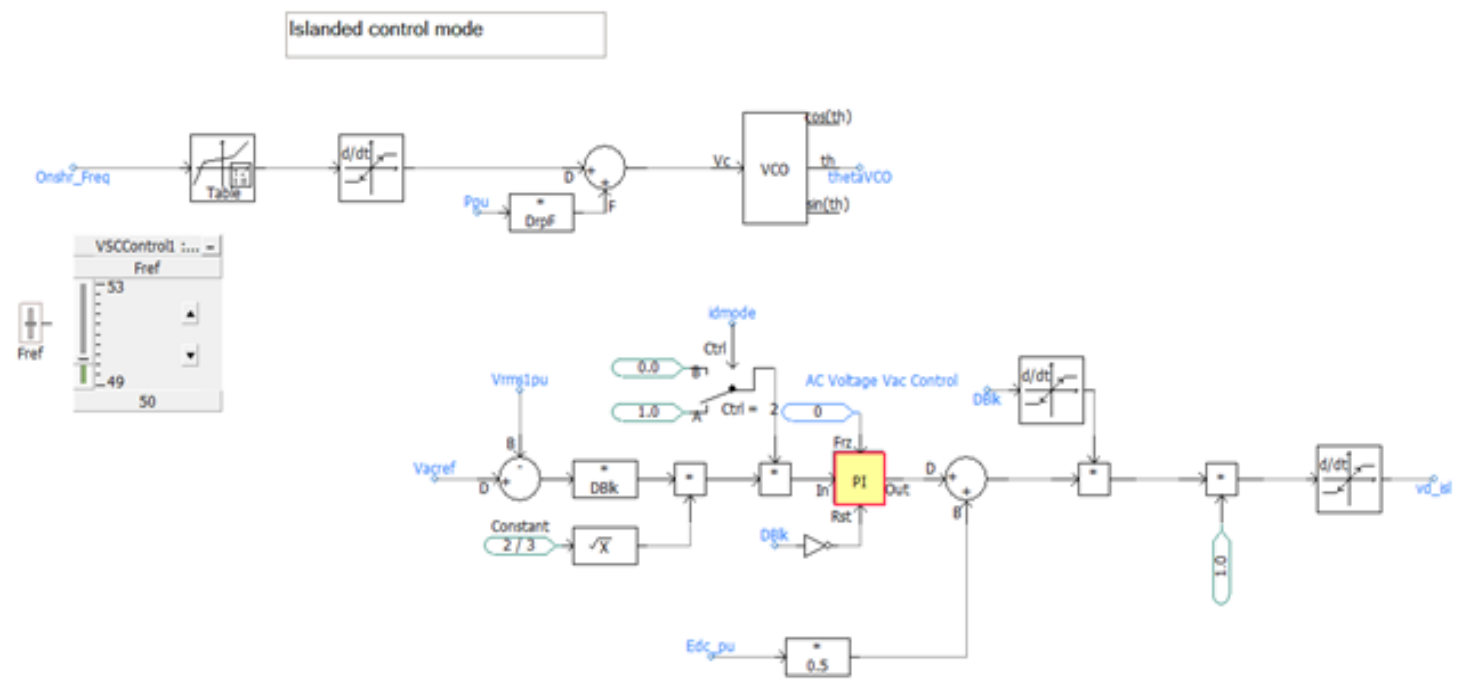

Figure 28. Islanded control mode.

\subsubsection{Inner control}

The objective of the vector-current control strategy is to regulate the instantaneous active and reactive powers independently through a fast inner current control loop. Three-phase currents are transformed into $d$ and $q$ axis quantities based on abc to dq transformation. The references of the inner current control, id and iq, are generated by the two outer controllers which can use the $\mathrm{d}$ component to control the active power or dc voltage or droop control (P/Vdc), and the $q$ component to control reactive power or ac voltage at the PCC. One of the main advantages of this control strategy is that it limits the current flowing into the converter during disturbances (overloading). However, it is done by adding current control loops and therefore may slow down the speed of response compared to a direct control strategy. 
The dq components of the current are signals under balanced sinusoidal conditions and perfect synchronization. The use of PI controllers ensures zero steady state error and increased robustness of the closed loop system.

Following again reference [44] these equations can be derived from Figure 29 and Figure 30 applying Kirchhoff's voltage law considering the current entering the MMC and neglecting the star point reactor:

$$
\begin{aligned}
& \frac{V_{d c}}{2}=v_{u j}+L_{a r m} \frac{d i_{u j}}{d t}+R_{a r m} i_{u j}-L_{t r f} \frac{d i_{j}}{d t}-R_{t r f} i_{j}+v_{P C C_{j}} \\
& \frac{V_{d c}}{2}=v_{l j}+L_{a r m} \frac{d i_{l j}}{d t}+R_{a r m} i_{l j}+L_{t r f} \frac{d i_{j}}{d t}+R_{t r f} i_{j}-v_{P C C}
\end{aligned}
$$

Where $\mathrm{j}$ denotes phases $\mathrm{a}, \mathrm{b}, \mathrm{c}$ and $\mathrm{u}$ and I refer to the upper and lower arm of the MMC topology respectively.

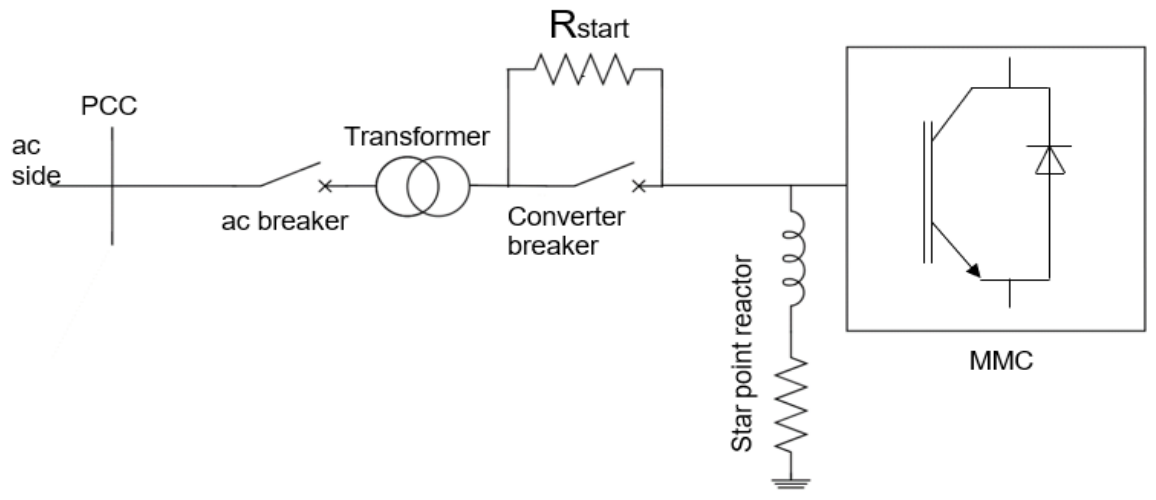

Figure 29. Typical monopole configuration of an MMC station. Inspired based on original illustration in [38].

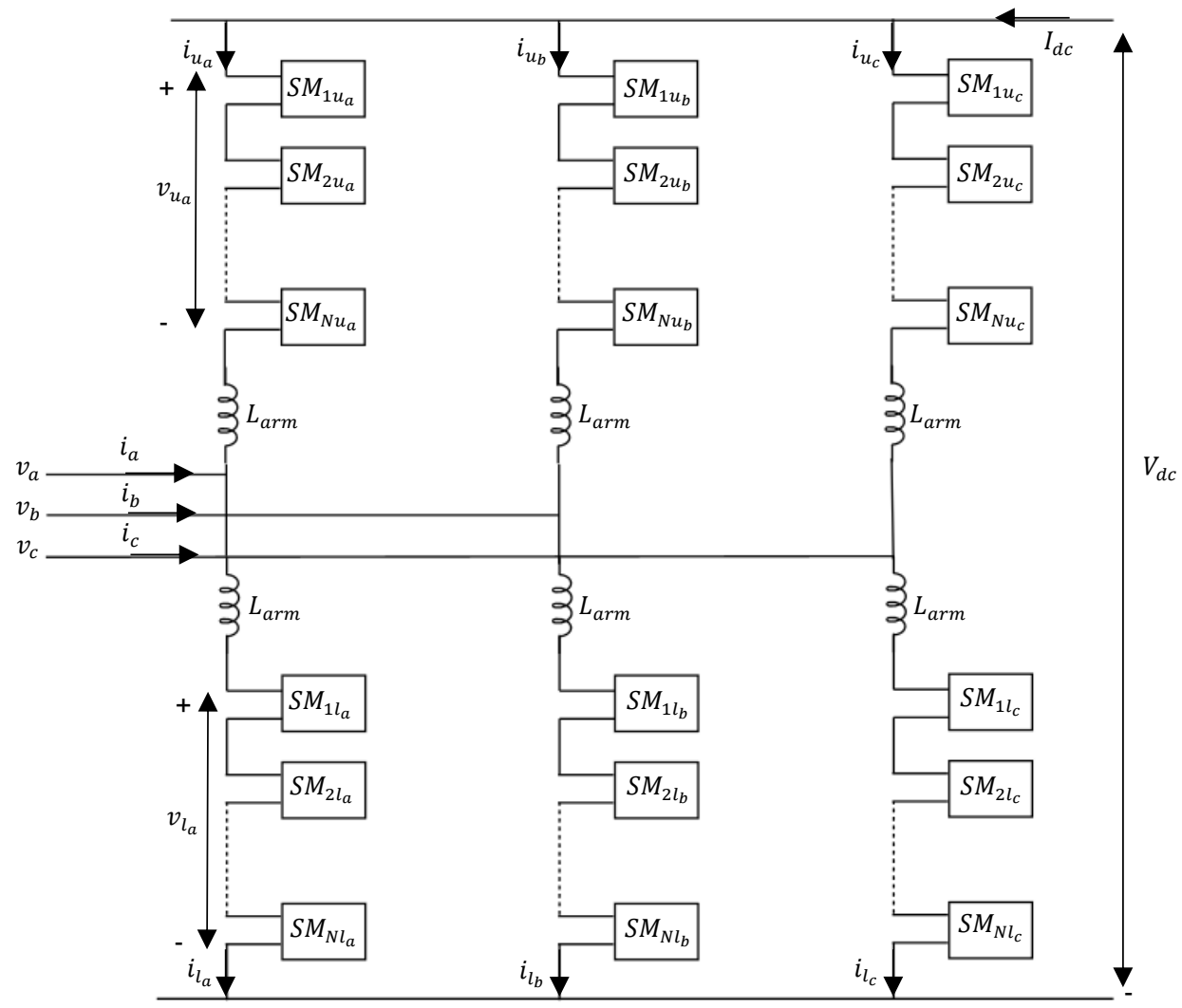

Figure 30. Representation of an MMC unit. Inspired based on original illustration in [38]. 
The corresponding equations in the dq frame can be written as:

$$
\begin{aligned}
& v_{P C C_{d}}-v_{\text {conv }_{a c_{d}}}=\left(\frac{L_{a r m}}{2}+L_{t r f}\right) \frac{d i_{d}}{d t}+\left(\frac{R_{a r m}}{2}+R_{t r f}\right) i_{d}-\omega\left(\frac{L_{a r m}}{2}+L_{t r f}\right) i_{q} \\
& v_{P C C_{q}}-v_{\text {conv }_{a c_{q}}}=\left(\frac{L_{a r m}}{2}+L_{t r f}\right) \frac{d i_{q}}{d t}+\left(\frac{R_{a r m}}{2}+R_{t r f}\right) i_{q}+\omega\left(\frac{L_{a r m}}{2}+L_{t r f}\right) i_{d}
\end{aligned}
$$

And the control loop yields:

$$
\begin{aligned}
& v_{\text {conv }_{a c_{d}}}^{r e f}=-\left(i_{d}^{r e f}-i_{d}\right) C_{i_{a c}}(s)+v_{P C C_{d}}+\left(\frac{L_{a r m}}{2}+L_{t r f}\right) \omega i_{q} \\
& v^{r e f}{ }_{\operatorname{conv}_{a c_{q}}}=-\left(i_{q}^{r e f}-i_{q}\right) C_{i_{a c}}(s)+v_{P C C_{q}}-\left(\frac{L_{a r m}}{2}+L_{t r f}\right) \omega i_{d}
\end{aligned}
$$

Where $C_{i_{a c}}(s)$ is the current control transfer function of the PI controller. The inner controller is shown in Figure 31 and permits the controlling of the reference voltages that will be used for the lower level control. To decouple the $d$ - and q-axes, a feed-forward technique is used to compensate the cross-coupling terms.

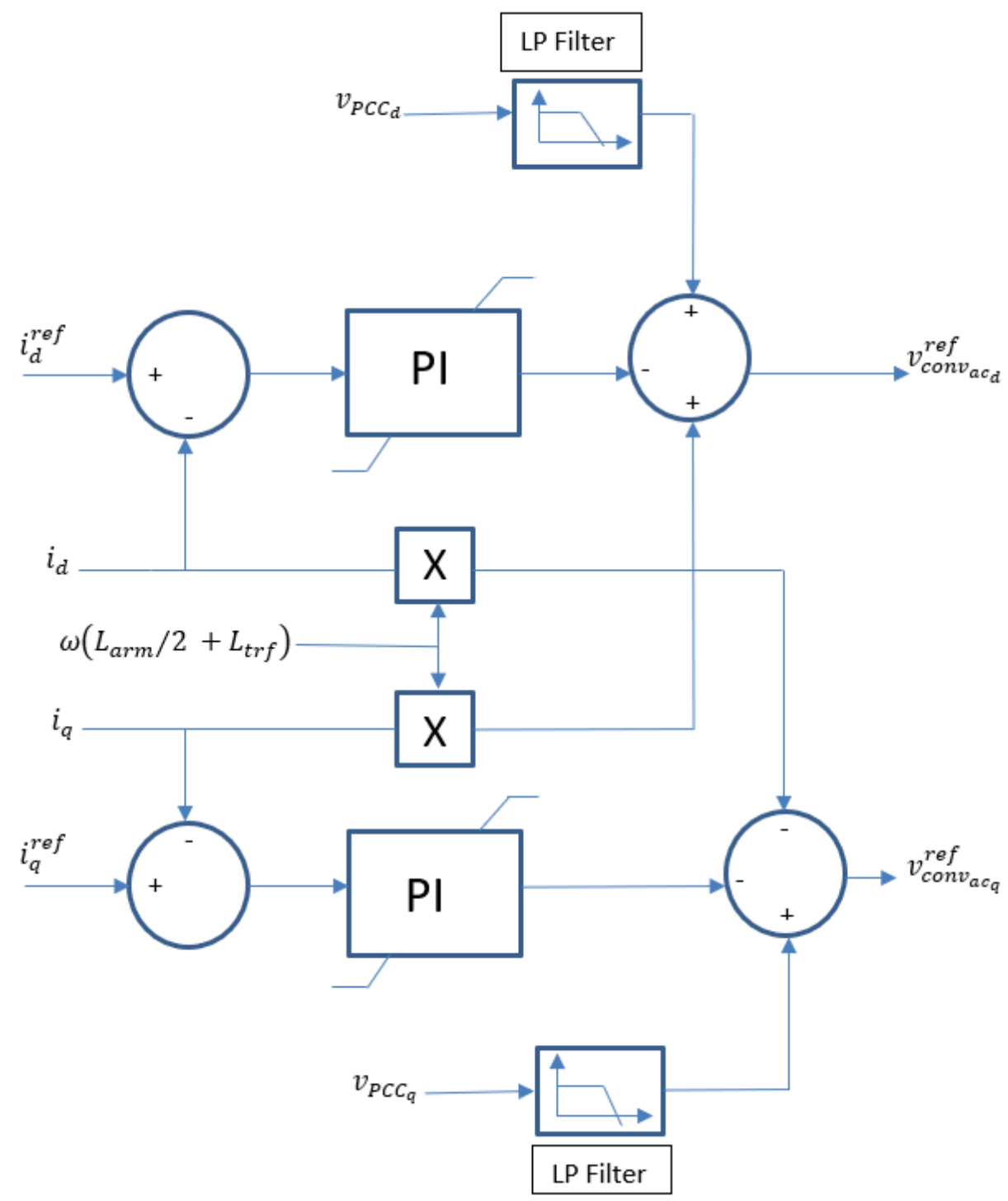

Figure 31. Inner control. Inspired based on original illustration in [44]. 


\subsubsection{Definition of the PCC at the offshore station}

Consistent with the control system proposed by CIGRE, the MMC uses a vector control strategy that calculates a voltage time area across the transformer/converter equivalent reactor which is required to change the current from present value to the reference value. The phase reactance is a combination of the transformer reactance and the arm reactance of the MMC [15]:

$$
L_{P}=L_{T}+\frac{1}{2} L_{V}
$$

Where $L_{P}$ is the total phase reactance, $L_{T}$ is the transformer reactance, and $L_{V}$ is the valve (arm) reactance. The implementation in the control scheme in PSCAD is as illustrated in Figure 32 for a conventional MMC topology:

MMC total inductance in pu

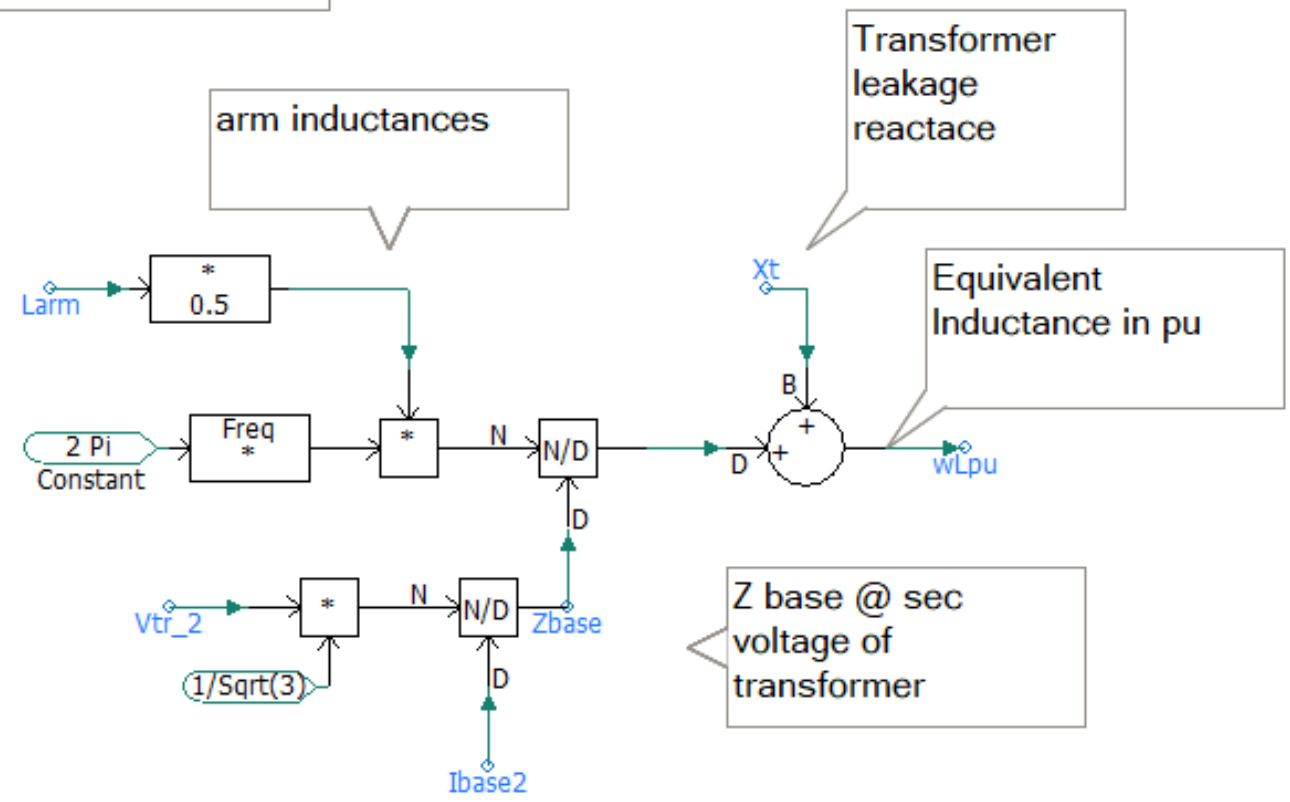

Figure 32. Equivalent phase inductance for a typical MMC unit.

Yet, for the topology considered under study in this thesis the total phase inductance cannot be considered in the same way because the three transformers connected to the offshore MMC station are not in parallel at the low voltage side, i.e. $66 \mathrm{kV}$. Initially, one possible option could be to try to estimate the value of the total phase inductance as one third of the leakage inductance as there might not be huge voltage deviations at the three different $66 \mathrm{kV}$ busbars. Therefore, the final computation of the equivalent total inductance is: 


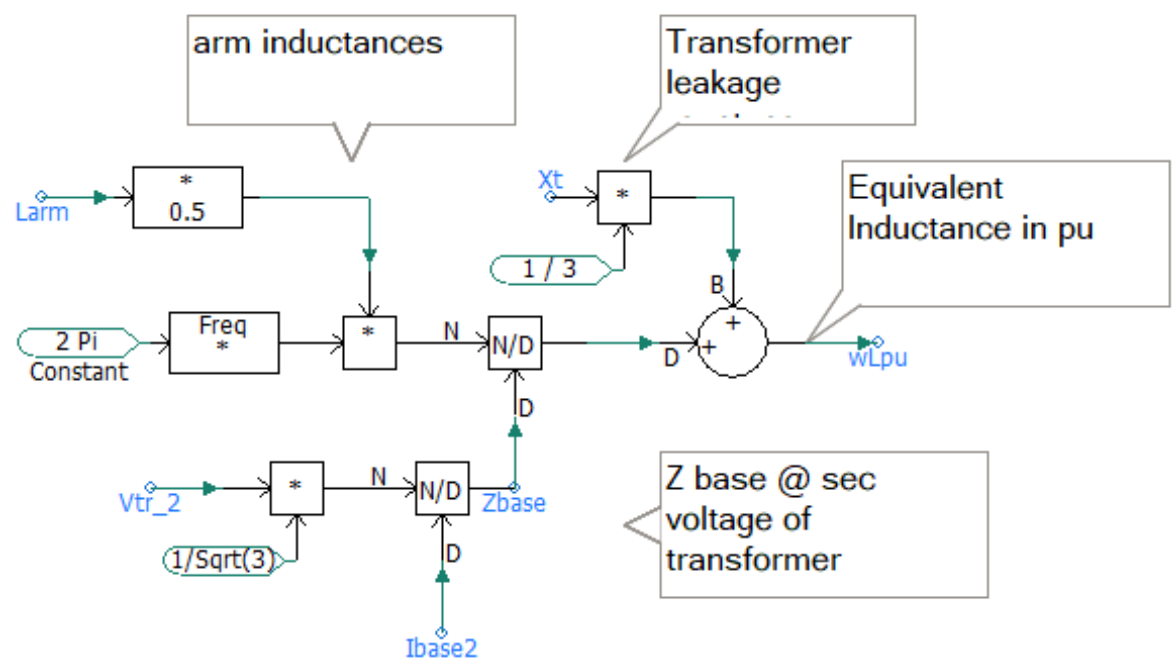

Figure 33. Equivalent phase inductance considering a virtual PCC.

This assumption is not completely valid as the PCC for the offshore wind farms is not unique anymore in the scenario of the topology under study. The PCC is considered the 66-kV busbar on the offshore platform/island, i.e. the connection point of the OWFs to TenneT's offshore grid. The control function of the MMC cannot control the three voltages at the independent nodes at $66 \mathrm{kV}$, which is the voltage after the transformers. Using a virtual PCC that could be defined as the average of the three values of the busbar voltages will not provide a robust control of the voltage due to the variations that can arise product of several operating conditions.

Two possible solutions are proposed in this thesis to define a new unique node for the control of the MMC: defining a new electrical point whose voltage is unique independent of the fact that the converter transformers are not in parallel. The new PCC can be selected to be in the ac side of the MMC. Alternatively, the PCC can be chosen as one the 66-kV busbar of the converter transformers, which will be the leader and the other two transformers will adjust the values accordingly based on a leader-follower scheme possibly including tap changers.

For the first proposed solution, this means relocating the PCC to the converter side of the transformer at the high voltage level of $333 \mathrm{kV}$, so the voltage to be controlled is the one at the ac side of the ac/dc converter, as in Figure 34. Neglecting the leakage reactance of the converter transformers requires the insertion of a new reactance in series with the arm inductors of the MMC to still have a series inductive interface separating the MMC from the ac system required by the operating principle of the converter and to limit the fault current as both the converter phase reactors and the converter transformer reactance limit the amplitude and the rate of rise the dc fault current fed from the ac side [10]. It is therefore necessary to add an additional impedance to the overall circuit when changing the PCC. In this way, the equivalent phase reactance is a combination of the new series reactance and half of the arm reactance. Thus, the equivalent circuit for the converter operation will remain the same as seen in Figure 37 [15]. This will also have an impact on the operation of the converter as the availability of the converter transformers is not a critical aspect for the design of the reactances.

The sizing and selection of reactors impact the overall design of the MMC. There are two possible options for the new impedance in the topology under study, namely to design a bigger 
arm inductance, Figure 35, or add and interface reactance, as in the two-level VSC topology, prior to the converter transformers as seen in Figure 36. The former alternative might be easier to implement and also more economically viable. Theoretically, at control system level increasing the arm inductance value or adding a new interference inductance is identical. In any case, the dimensioning of the additional inductance could be in the order of 0.05 p.u.

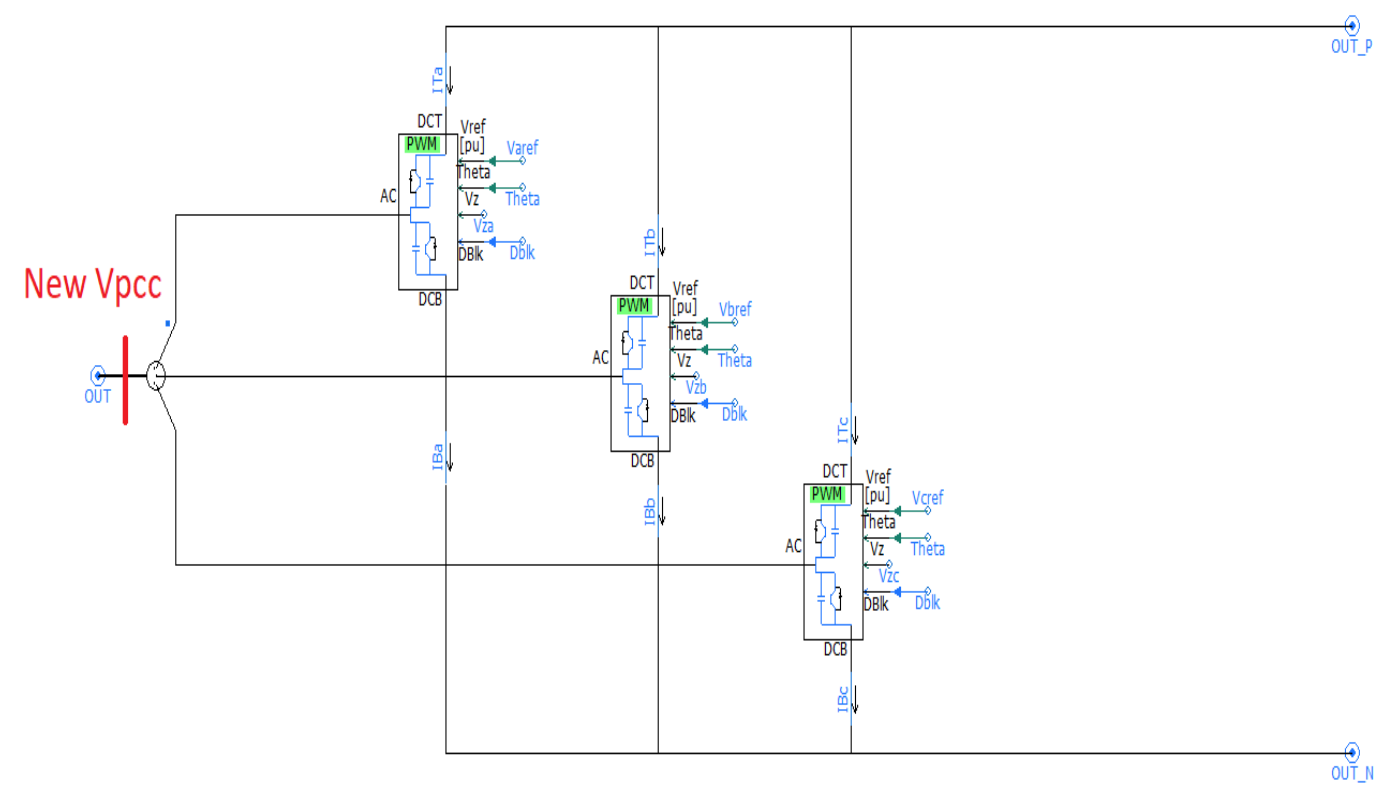

Figure 34. New PCC at the ac side of the MMC unit.

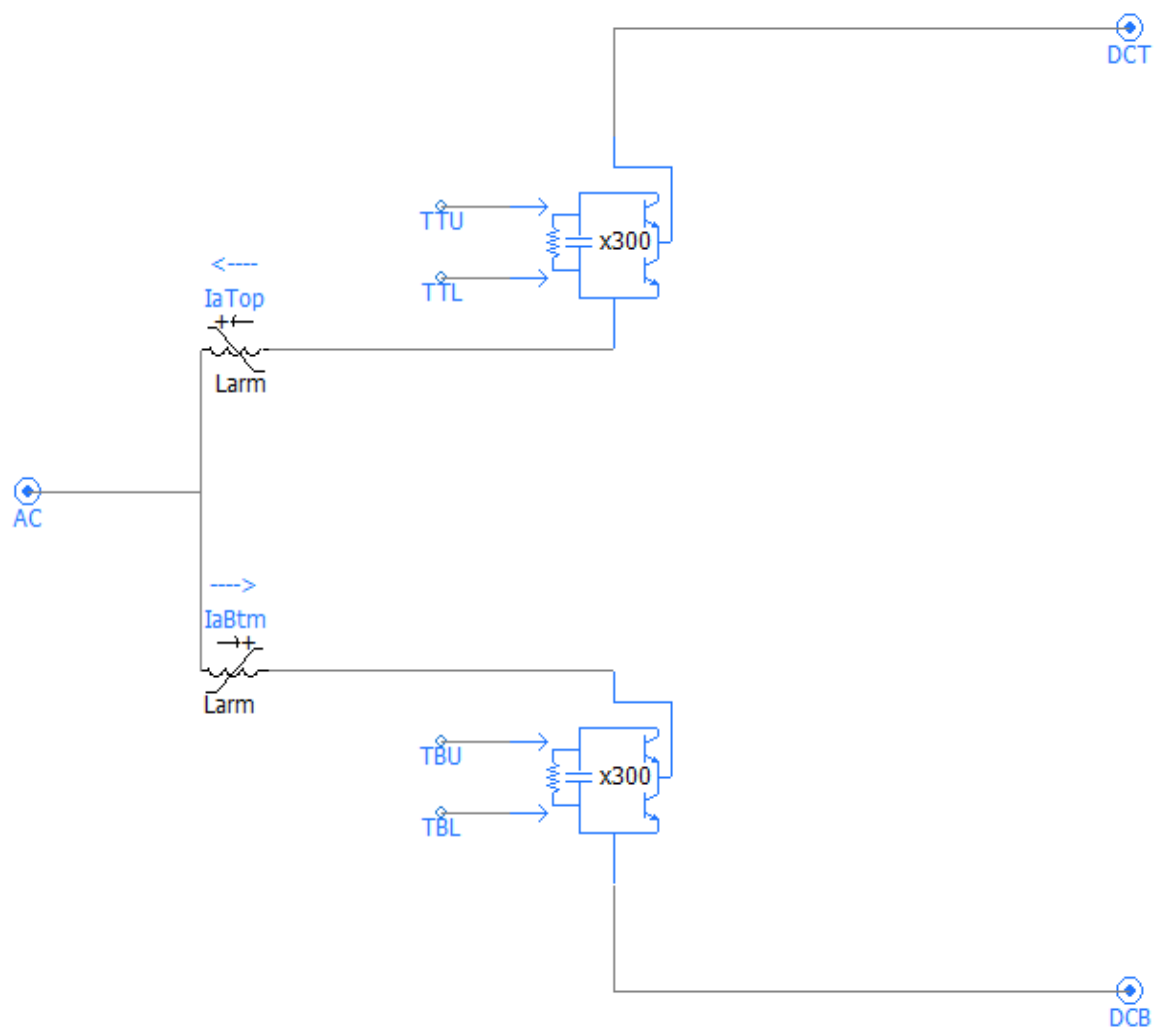

Figure 35. Arm inductances for one phase in the MMC topology. 


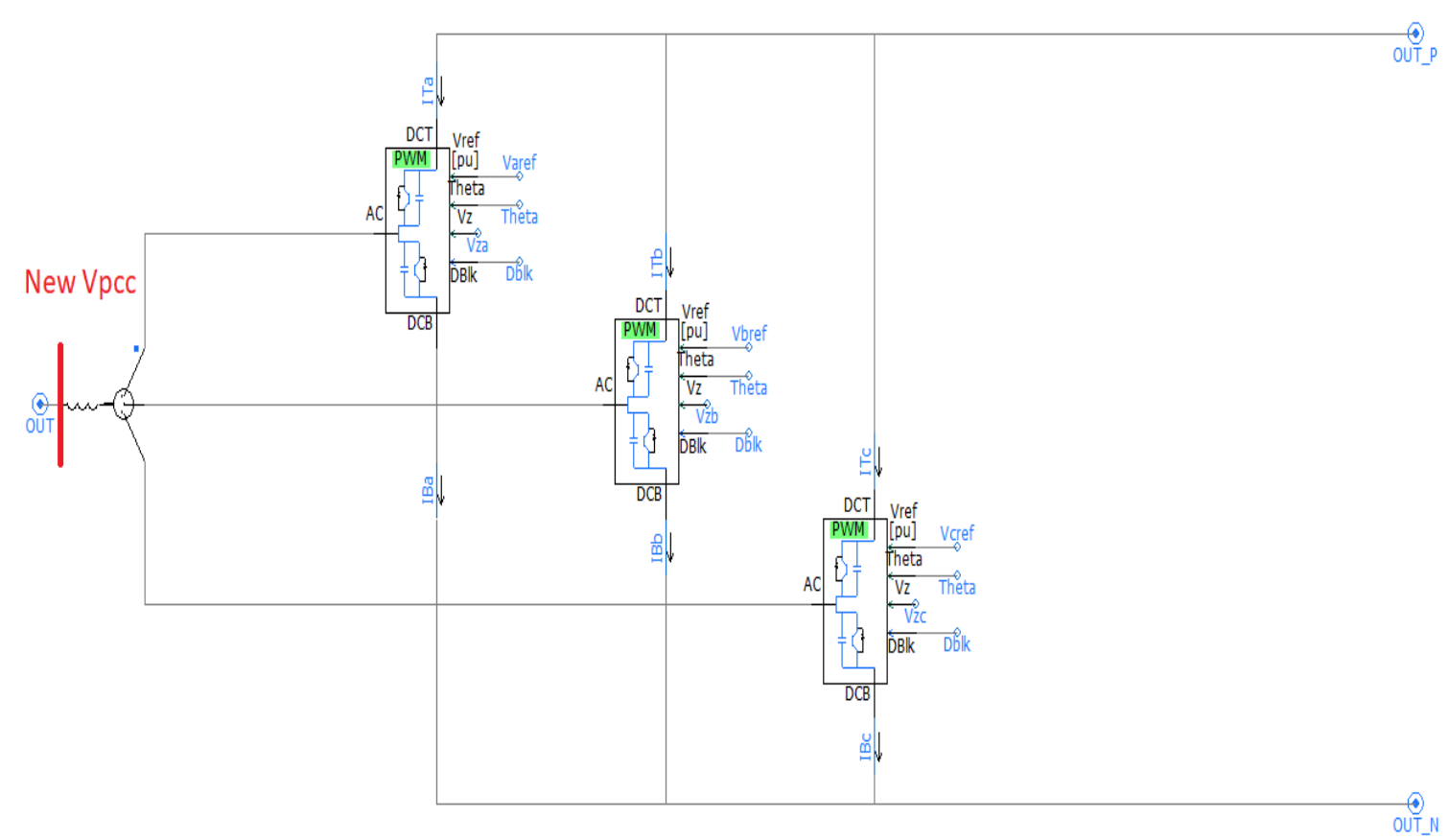

Figure 36. New interface inductance.

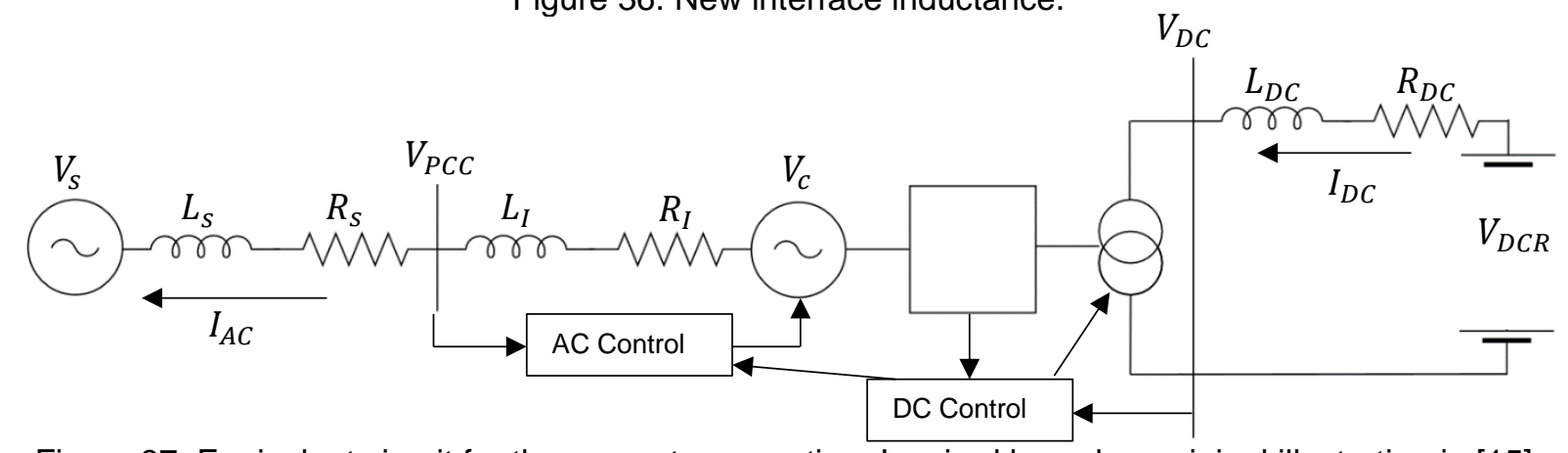

Figure 37. Equivalent circuit for the converter operation. Inspired based on original illustration in [15].

The second solution is simpler and implements a leader-follower scheme possibly including tap changers to the configuration of the three converter transformers at the offshore side. It does not require modifications to the control scheme of the standard MMC topology as the PCC is a node at $66 \mathrm{kV}$ and all the changes are external to the converter. No additional inductance will be needed since the equivalent phase inductance remains the same as in the currently used control structures of MMC-HVDC links.

\subsection{Lower Level Control (MMC Control)}

The lower level control structure comprises basically the circulating current suppression control, modulation, and capacitor voltage balancing control as indicated in Figure 23. The submodule circuit configuration for the MCC stations under study in this thesis are half-bridge as mentioned previously in chapter 2 .

The circulating current is defined as the current which circulates through both upper and lower arms. This current consists of three main components with different frequencies [28]: zero frequency current that is its dc offset, $50 \mathrm{~Hz}$ current that is transferring power to the load, and $100 \mathrm{~Hz}$ circulating current flowing through phases. The undesired negative sequence secondharmonic component is produced by the voltage unbalances between the phase units of the MMC as these voltages are not exactly the same. The effect of this current is a distortion of the arm currents and an increase in the converter power losses and the ripple on the 
submodule capacitor voltages. There are two methods to suppress this second-harmonic circulating current: adding a parallel capacitor between the midpoints of the upper and lower arm inductances on each phase or using an active control over the ac voltage reference. Adding a new element to the MMC topology as another capacitor creates is a more complex solution than just implementing a control strategy, which is why the latter is the preferred option to eliminate the $100 \mathrm{~Hz}$ circulating current.

The associated equations in the dq frame to create the circulating current control structure are derived in [28] and are presented here along with the control block diagram [45]:

$$
\begin{aligned}
& v_{d i f f_{d}}=L_{a r m} \frac{d i_{2 f_{d}}}{d t}-2 \omega L_{a r m} i_{2 f_{q}}+R_{a r m} i_{2 f_{d}} \\
& v_{d i f f_{q}}=L_{a r m} \frac{d i_{2 f_{q}}}{d t}+2 \omega L_{a r m} i_{2 f_{d}}+R_{a r m} i_{2 f_{q}}
\end{aligned}
$$

Two PI controllers are applied to the dq differential currents:

$$
\begin{aligned}
& v_{d i f f_{d}}=\left(0-i_{2 f_{d}}\right)\left(k_{p}+\frac{k_{i}}{s}\right)-2 \omega L_{a r m} i_{2 f_{q}} \\
& v_{\text {diff } f_{q}}=\left(0-i_{2 f_{q}}\right)\left(k_{p}+\frac{k_{i}}{s}\right)-2 \omega L_{a r m} i_{2 f_{d}}
\end{aligned}
$$

The MMC module in the PSCAD model has a circulating current suppression control (CCSC) as the one depicted below:

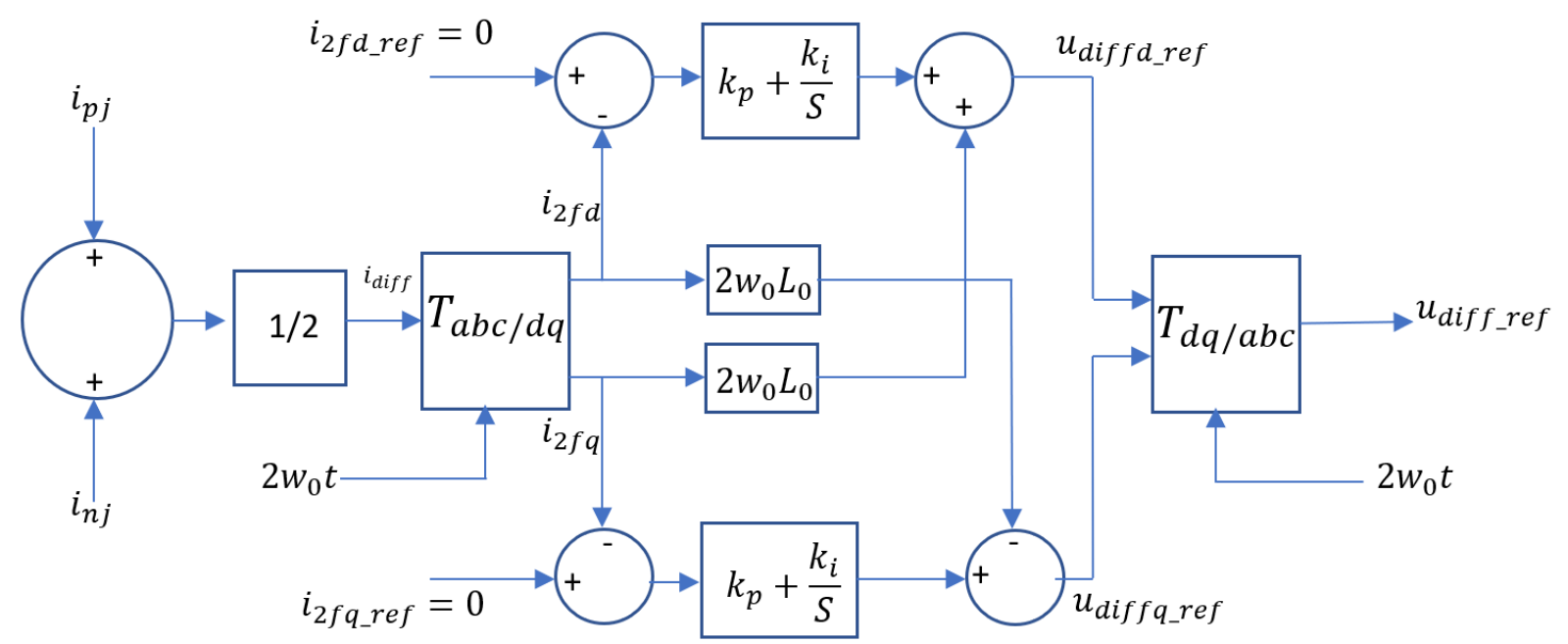

Figure 38. Circulating current control (where $\mathrm{j}=\mathrm{a}, \mathrm{b}, \mathrm{c} ; \mathrm{p}$ : positive, $\mathrm{n}$ : negative). Inspired based on original illustration in [45].

There are several modulation techniques for the MMC such as modulation at high switching frequencies modulations based on triangular-wave carrier signals with phase shifting and level shifting, space vector modulation, low-frequency modulation, selective harmonic elimination (SHE), and nearest level modulation [46]. The MMC stations for the HVDC transmission scheme under analysis in this thesis uses SPWM with a phase shifted technique [39] and a carrier frequency of three times the fundamental frequency of the system.

Capacitor balancing control is another very important component of the whole control structure of the MMC because the capacitor voltage at all submodules must be balanced and kept within a tolerance band during normal operation. There are different techniques for submodule 
capacitor voltage balancing as explained in detail in [39]. For a large number of submodules (n), normally an algorithm is implemented to control the voltage of all capacitors of each arm at $V_{d c} / n$. The balancing control algorithm (BCA) measures the capacitor voltages at each submodule at any instant and sorts them before selecting the upper and lower submodule to switch on. The number of submodules to be inserted is determined by $n_{u, l_{j}}$. To improve the efficiency of the algorithm, the model includes a trigger control that activates the BCA only when an on/off state in the $n_{u, l_{j}}$ functions is reached. This will avoid switching the submodules at each time-point [38]. The mentioned algorithm is represented in Figure 39 [38]. The submodule capacitor voltages of each arm are measured and sorted. If the upper (lower) arm current is positive the submodules with the lowest voltages are identified and inserted. Therefore, the inserted capacitors are charged, and their voltages increase. In the case the upper (lower) current is negative, the submodules with the highest voltages are identified and inserted. Therefore, the inserted capacitors are discharged, and their voltages decrease. When a submodule in the arm is bypassed, regardless of the direction of the upper (lower) arm current, the corresponding capacitor voltage remains unchanged. The BCA implemented in the PSCAD model is very generic and uses capacitor voltage sorting. It either inserts or bypasses the capacitor based on the number of levels that are required.

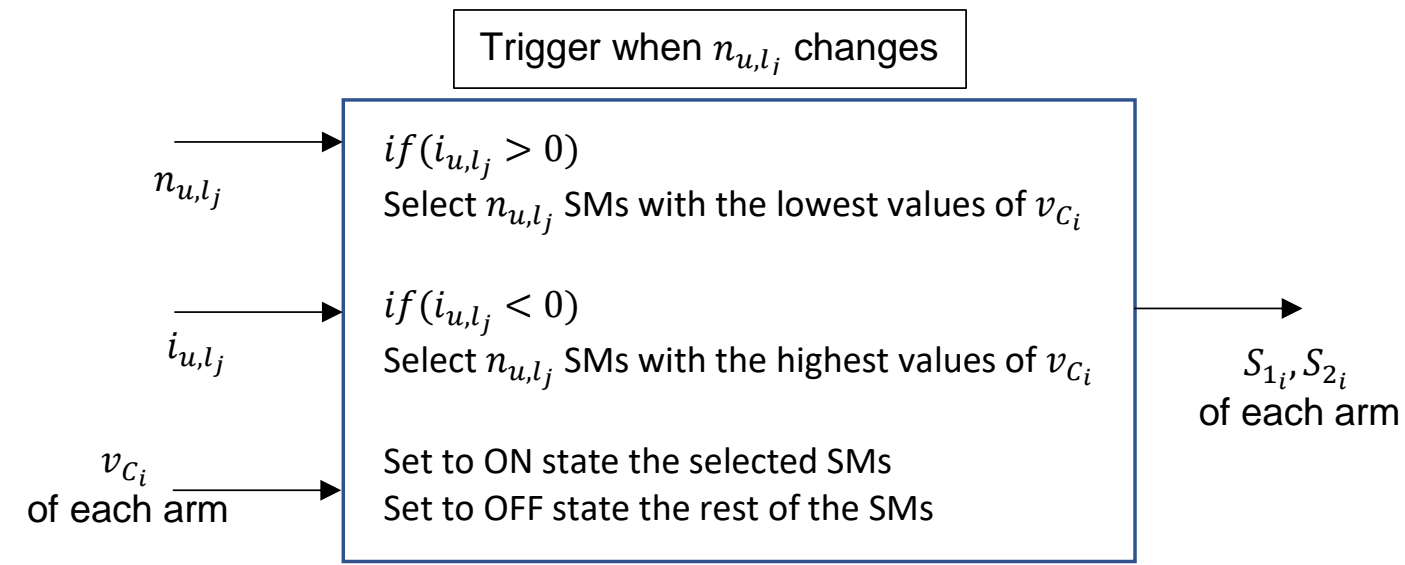

Figure 39. Capacitor Balancing Algorithm (CBA). Inspired based on original illustration in [38].

\subsection{Additional Control Structures}

The third harmonic injection method to distort the converter voltage is used as one of the additional control structures previously mentioned. The objective of this practice is to improve the operating efficiency by reducing the magnitude of the ac current that contributes to the converter losses. The fundamental component of the ac generated waveform rises above the dc voltage of the link while the peak converter voltage remains below this limit [15]. This is done by adding a zero-sequence component to the phase voltage references to extend the modulation index to $2 / \sqrt{3} \approx 1.15$. The third harmonic component coefficient that has been selected is 0.15 p.u. The PSCAD implementation is as shown in Figure 40. 


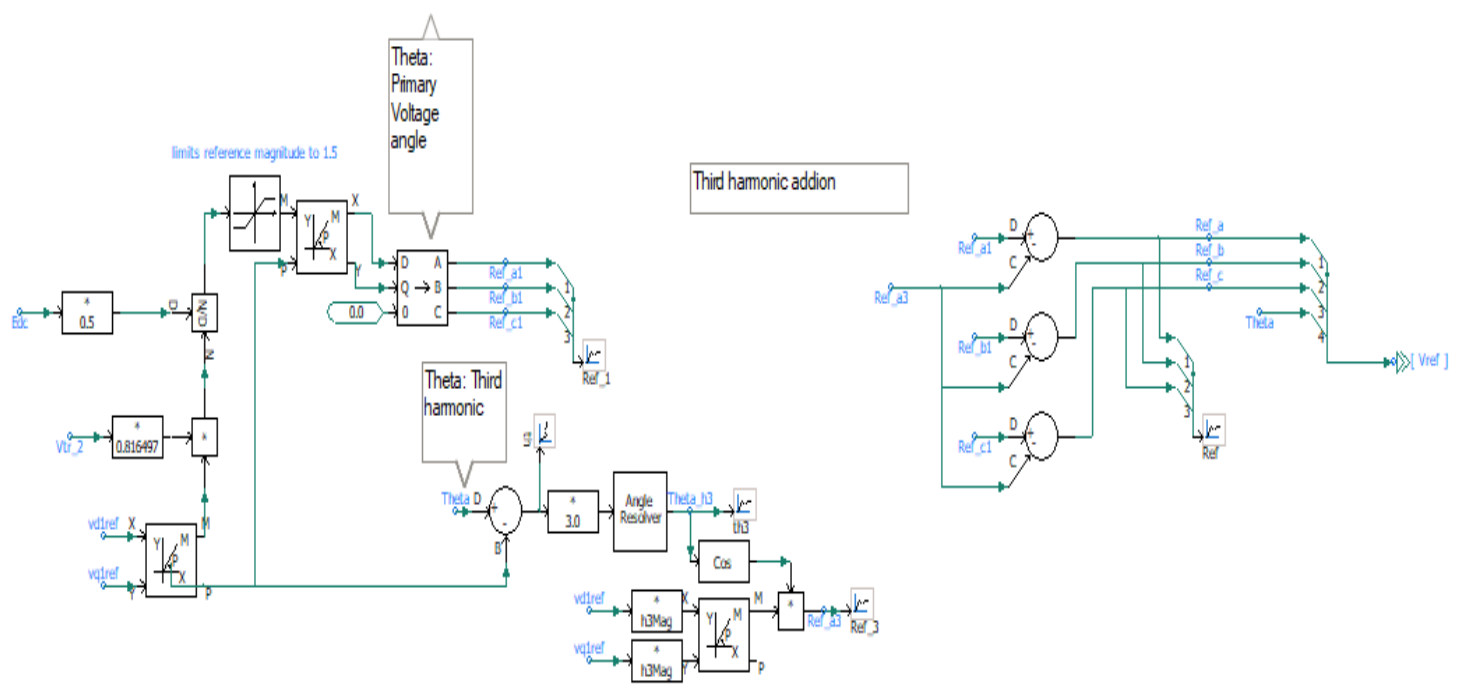

Figure 40. Third Harmonic Injection.

Another important control function is the current reference limiter, which is designed to avoid damage of the semiconductors due to large transient currents considering the MMC has no overload capability. The current limit $i_{\text {lim }}$ is compared to the current magnitudes calculated from $i_{d_{r e f}}$ and $i_{q_{r e f}}$. Whenever the limit is surpassed the components $i_{d_{r e f}}$ and $i_{q_{r e f}}$ have to be restricted. It is possible to set a priority based on the application, i.e. P-priority and Q-priority to produce more active or reactive power. The following equations define these relationships [38]:

$$
\begin{aligned}
& \text { For } P-\text { priority } \quad i_{\text {lim }} \geq \sqrt{i_{d_{\text {ref } f_{l i m}}^{2}+i_{q_{\text {ref }}}^{2}}} \\
& \text { For } Q-\text { priority } \quad i_{\text {lim }} \geq \sqrt{i_{d_{\text {ref }}^{2}}^{2}+i_{q_{\text {ref }}{ }_{\text {lim }}}^{2}}
\end{aligned}
$$

The control block diagram and its implementation in PSCAD are presented in the Figure 41 [38] and Figure 42:

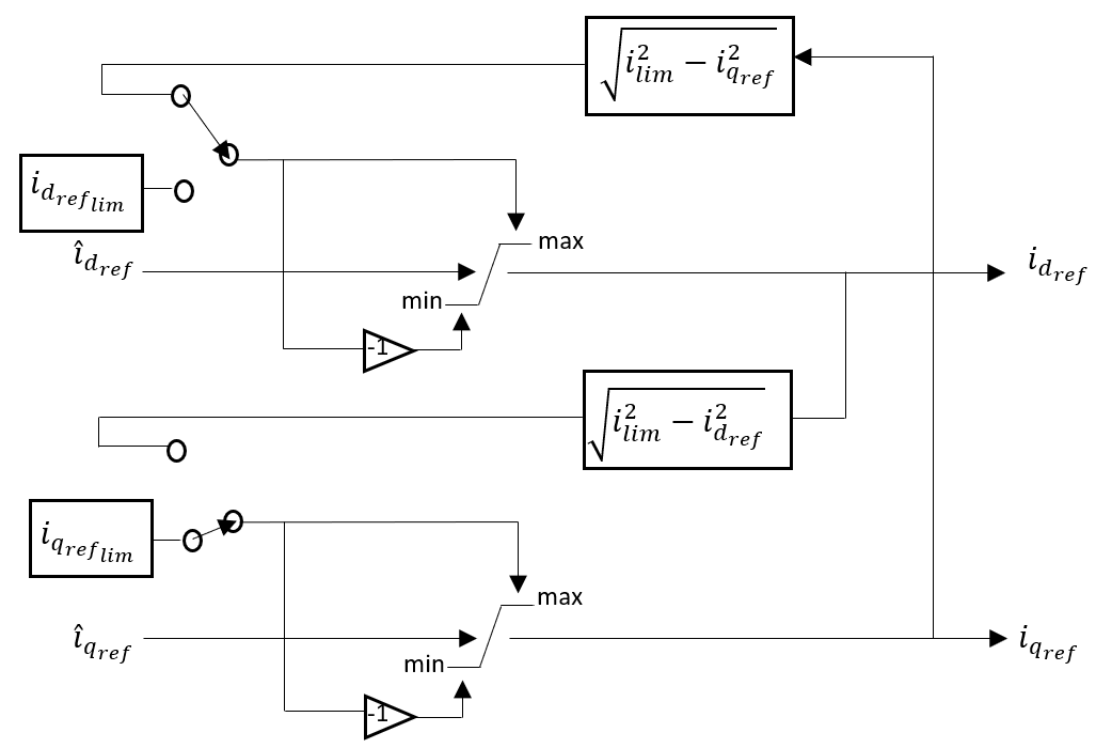

Figure 41. Current reference limiter. Inspired based on original illustration in [38]. 


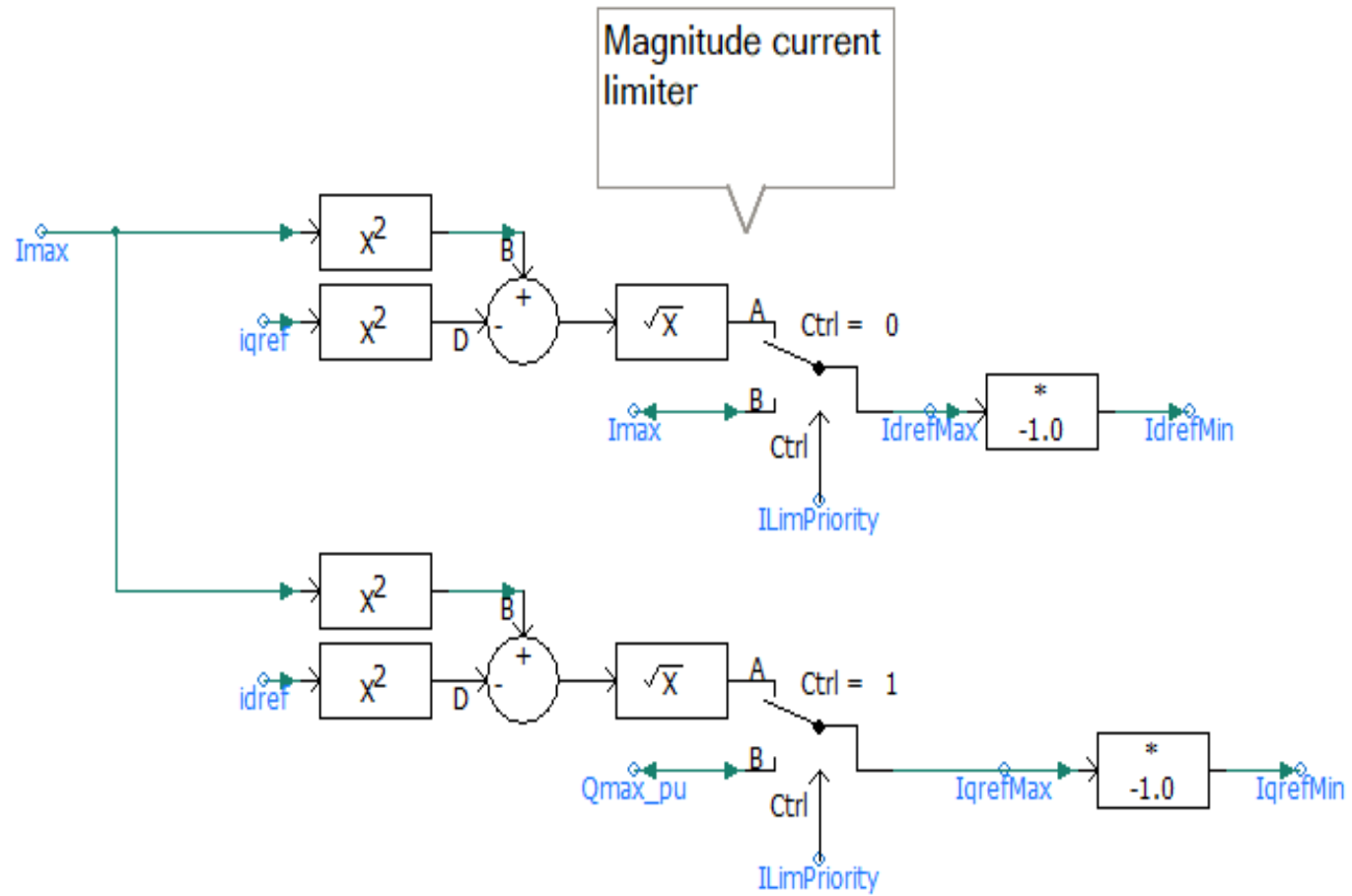

Figure 42. Control block for the current reference limiter.

49 


\section{Operation of the MMC-HVDC Transmission Scheme}

The main goal in this master's thesis is to assess the performance of the offshore $66-\mathrm{kV}$ ac grid using the control schemes of MMC converters as in a typical grid connection topology for OWFs. Dynamic system performance can only be studied properly using simulation tools. A PSCAD model was developed to enable the analysis of the proposed connection topology for offshore wind farms connected to an MMC-HVDC transmission scheme. Evaluating the response of the system to fault disturbances with precision is only possible using an EMT model. The disturbances considered were designed partially following the cases given in [47] for HVDC-based networks.

\subsection{General Assumptions and Simplifications}

To accomplish the objectives presented in the introduction, many assumptions are needed when using a simulation tool as PSCAD/EMTDC. Some of the main assumptions and simplifications made are explained below so that the results presented in the next subchapters can be understood correctly.

Wind Power production is a very unpredictable power source. For the following test cases the wind power variations were simplified using a speed wind generation function. This simple approach is enough as the goal is to analyse the offshore grid and the HVDC link and at the same time allows for easy interpretations of the results.

Each of the three offshore wind farms is a cluster of 70 turbines for which only one turbine is modelled, identical component for the three wind parks, and then scaled up to obtain a production of $350 \mathrm{MW}$. Depending on the simulation being performed the total production of $1050 \mathrm{MW}$ is increased by steps of $350 \mathrm{MW}$ in different time points. Therefore, the ramp up of the power produced by the wind turbines is not done one by one but the 70 units at the same time using an aggregated model. The average model used in the following simulations has negligible differences with the detailed model of a type 4 wind turbine as has been verified in [48].

Control structures implemented in the MMC units are based on generic schemes found in literature [31]. Actual MMC controls consist of two decoupling loops, one for the positive sequence and other for the negative sequence. The model built in this thesis only includes the positive sequence loop. These standard controls offer enough detail and all the main functionalities of real MMC-HVDC transmission schemes to be represented in an EMT simulation.

The representation of each MMC station is done using a detailed equivalent model to be able to capture de dynamics of the systems. This simplification is very important to reduce the computational burden produced by the large amount of nonlinear switching devices in the MMC.

The representation of the ac network is limited to an equivalent voltage source determining the short-circuit power of the ac system.

The simulation time step for all simulations was set to $50 \mu \mathrm{s}$. The plot time step was $250 \mu \mathrm{s}$.

A special library in PSCAD, namely VSC_MMC_Lib, is required to model the MMC stations. The half-bridge submodules and the control structures of the lower level control are elements 
found in this library. These components are very specific for HVDC projects and are not included in the master library which is the default library in PSCAD.

Frequency variations are normally analysed for very long periods of time, at least $60 \mathrm{~s}$, which are beyond the scope of this thesis.

Internal faults in the HVDC transmission system are not considered as the symmetrical monopole configuration of the HVDC link used here has no new additional features, i.e. is a standard configuration. The results for faults in the dc system have already been studied before in literature.

All the graphs presented in this chapter have been made using MATLAB with the data imported form the results in PSCAD.

\subsection{Topology with a Leader-Follower Configuration for the Offshore Transformers}

This section presents the expected operational modes of the MMC-HVDC transmission scheme under analysis: energization of the HVDC link, ramping up of the power, steady state, and fault state. Different scenarios were simulated to demonstrate the normal operation of the three OWFs with the MMC-HVDC connection to the onshore grid. The wind parks and the HVDC link are started from completely de-energized state. The energization protocol here will follow the standard procedure established in Germany, within the limitations of the model, i.e. first the HVDC converters and cables are energized and then the wind farms cable by cable. After that, the wind farm operator switches on turbine by turbine and ramps up the power generation to the rated values.

\subsubsection{Operational Modes and Dynamic System Performance}

The assessment of the dynamic behaviour of the test network is necessary to demonstrate that the basic control parameters proposed will provide stable operation and good dynamic performance of the system. To this end, the control modes and set points of the MMC units are:

- Onshore converter:

- DC voltage control, Vdc ref $= \pm 320 \mathrm{kV}$

- $\quad$ C voltage control, Vac ref $=1 \mathrm{p} . \mathrm{u}$

- Offshore converter:

- Islanded mode

- $\quad$ AC voltage control, Vac ref $=1$ p.u

\subsubsection{Charging of the MMC units and energizing the offshore grid}

The start-up procedure of the MMC station is a two-stage process [10]. Initially, the ac-side circuit breaker is closed in order to charge the dc side of the converter through the diodes of the submodules of the MMC, the onshore terminal is connected to the transmission grid through the converter transformer. During the energization process the MMC becomes a diode bridge as it is required that all capacitor voltages are initially set to zero and all submodules 
are in blocked state. However, in series with the ac-side circuit breaker there is the preinsertion resistor. After some time, the voltage on the dc side is approximately equal to the peak value of the line-to-line voltage times the turns ratio of the transformer. It has been set in the simulations that the value of the secondary ac voltage at which the insertion resistor is bypassed is 0.95 p.u. At this point, when the dc side is charged, the submodule capacitors in all arms are charged to approximately half of their rated values. Simultaneously, the preinsertion resistor can be short-circuited by a bypass circuit breaker. Here both stations of the MMC-HVDC link are partially charged.

In the second stage of the process, the number of inserted submodules is gradually reduced in each phase-leg from $2 \mathrm{n}$ to $\mathrm{n}$ to let the capacitors charge from $V_{d c} / 2 n$ to $V_{d c} / n$. The cable capacitance is also charged to the peak line to ground voltage level, i.e. $\pm 320 \mathrm{kV}$ or $640 \mathrm{kV}$ pole-to-pole voltage. The offshore transformers are energized as well. The energization of the HVDC link is shown in Figure 43 (a), (b), (c), and (d). The deblocking times for the onshore and onshore converters are 0.2 and 0.6 seconds, respectively. The connection of the transmission system is in no load operation.

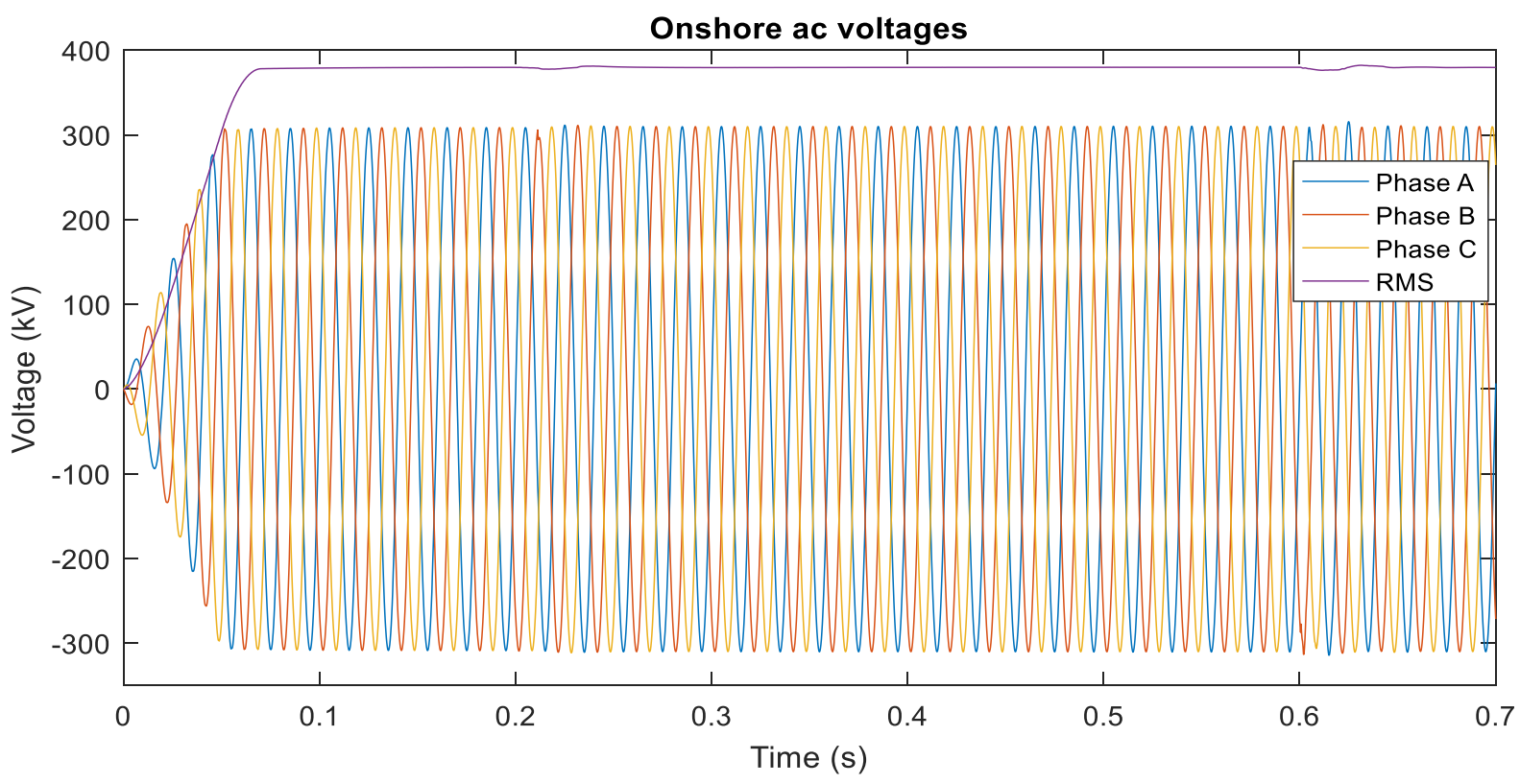

(a) Onshore ac voltage, instantaneous phase-to-ground values and rms value.

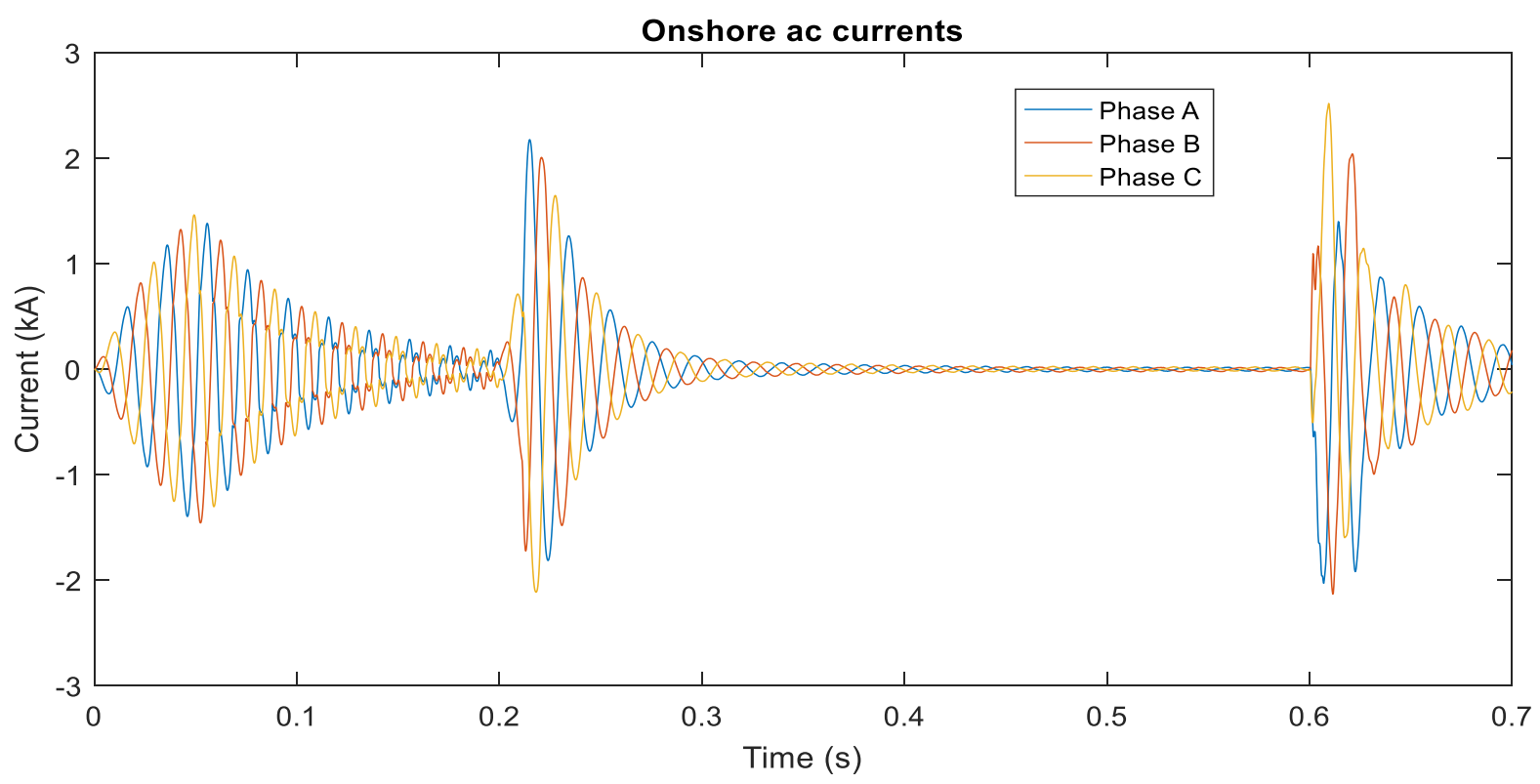

(b) Onshore ac currents. 


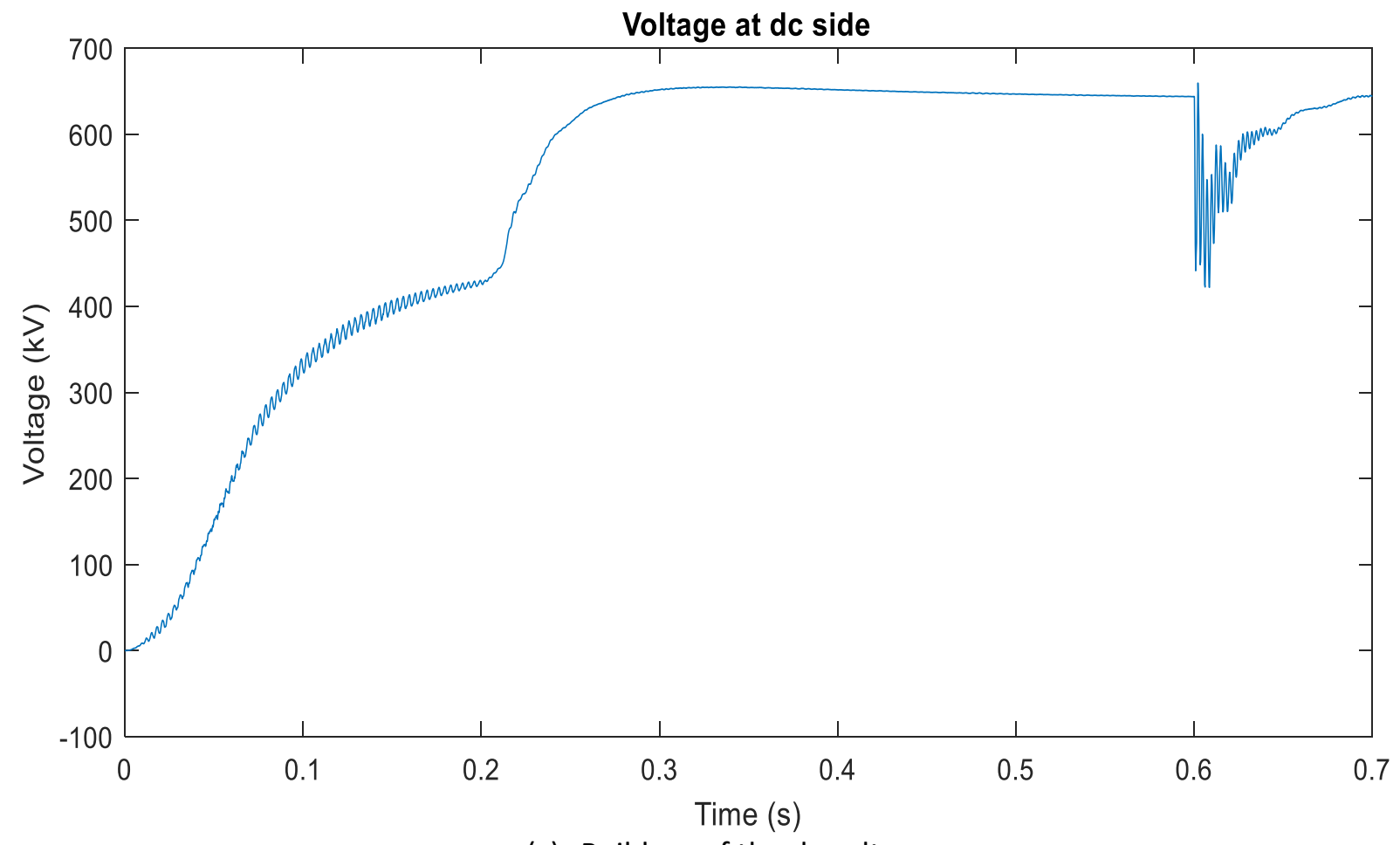

(c) Build-up of the dc voltage.

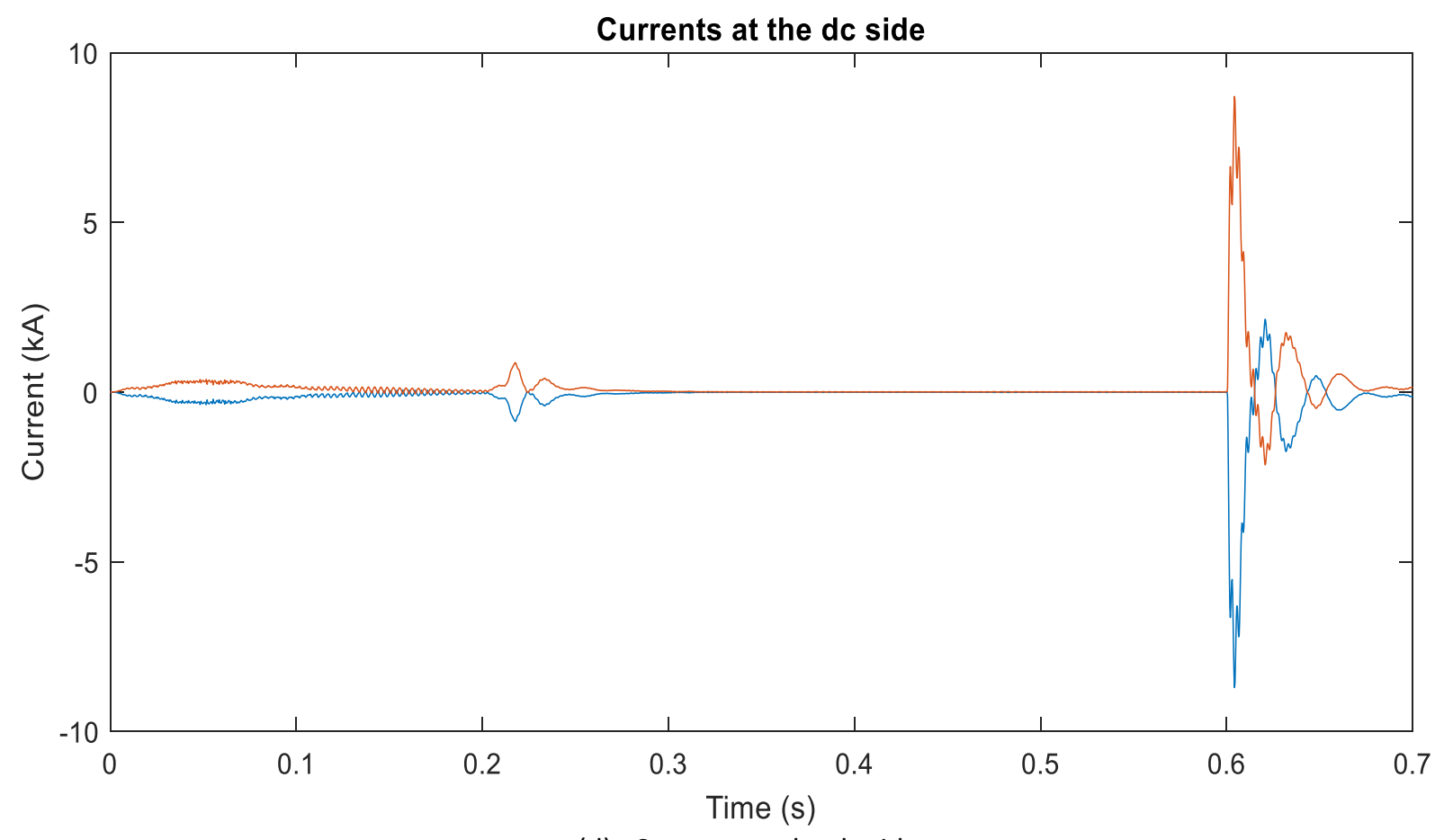

(d) Currents at the dc side.

Figure 43. Energization of the MMC-HVDC system.

In Figure 44 it is shown the frequency of the offshore ac grid, set by the offshore MMC unit. 


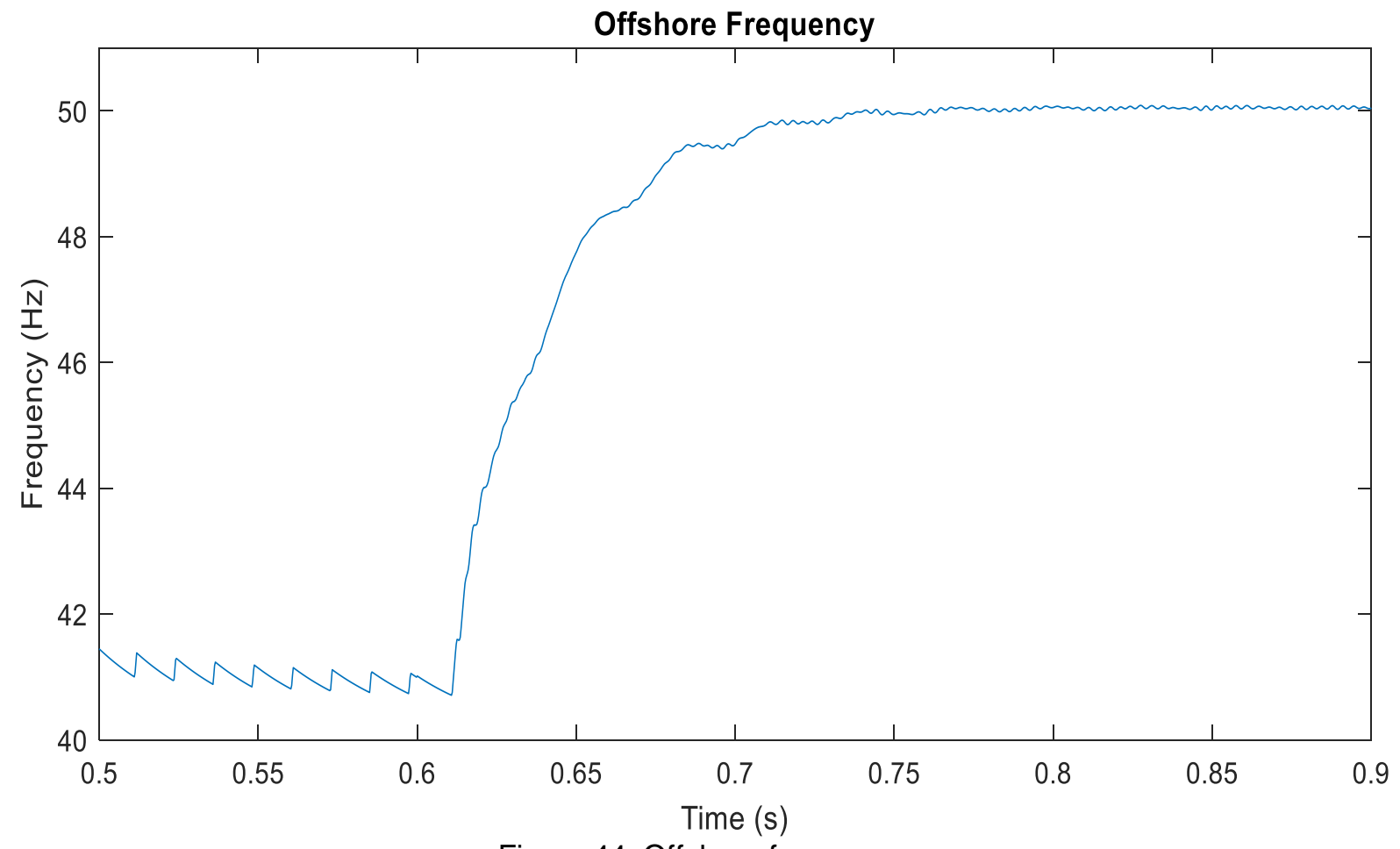

Figure 44. Offshore frequency.

The voltages waveforms, both instantaneous phase-to-ground and rms, at $66 \mathrm{kV}$ at the terminals of the three offshore transformers are illustrated in the following figure.

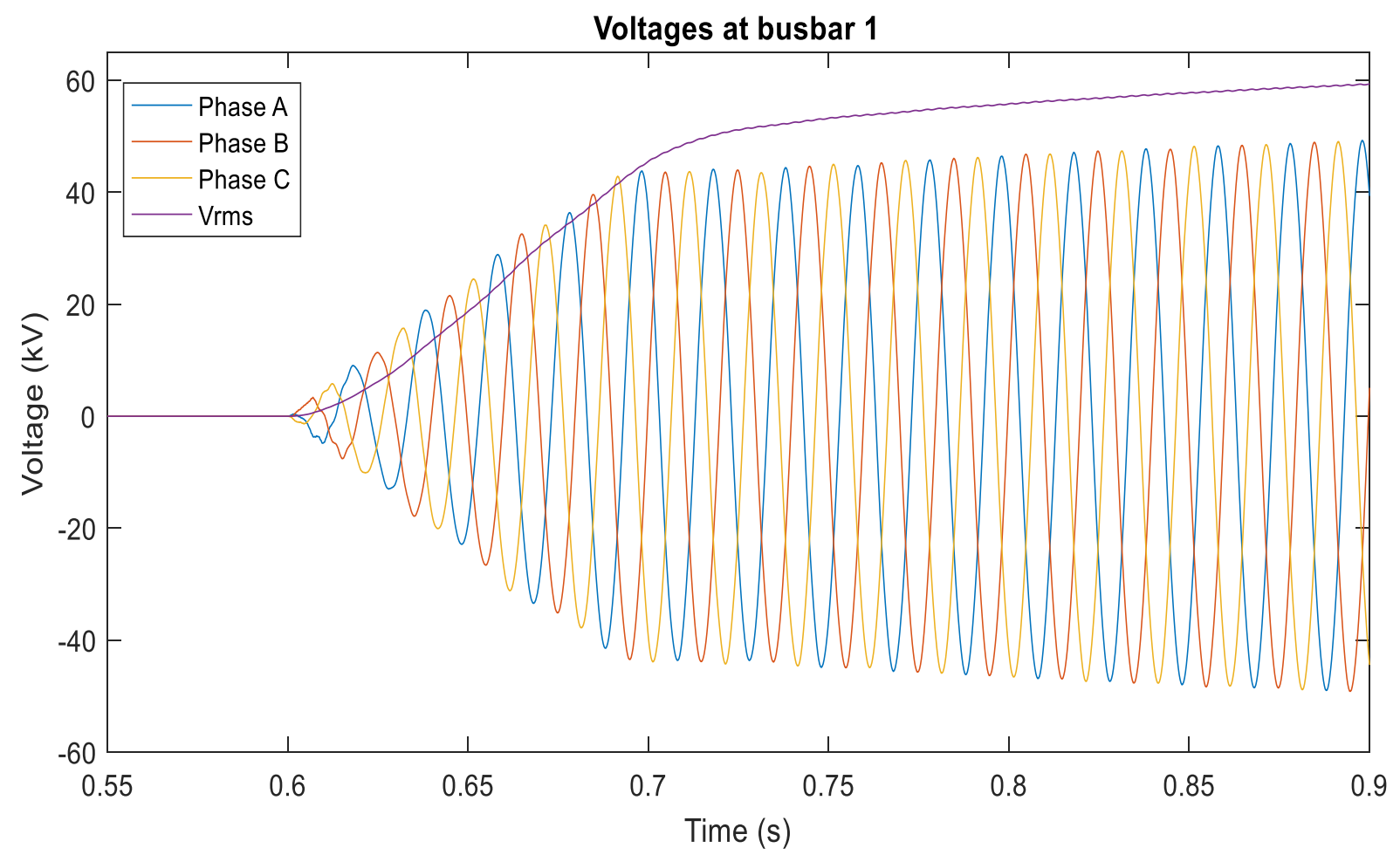

(a) Voltages at busbar 1. 


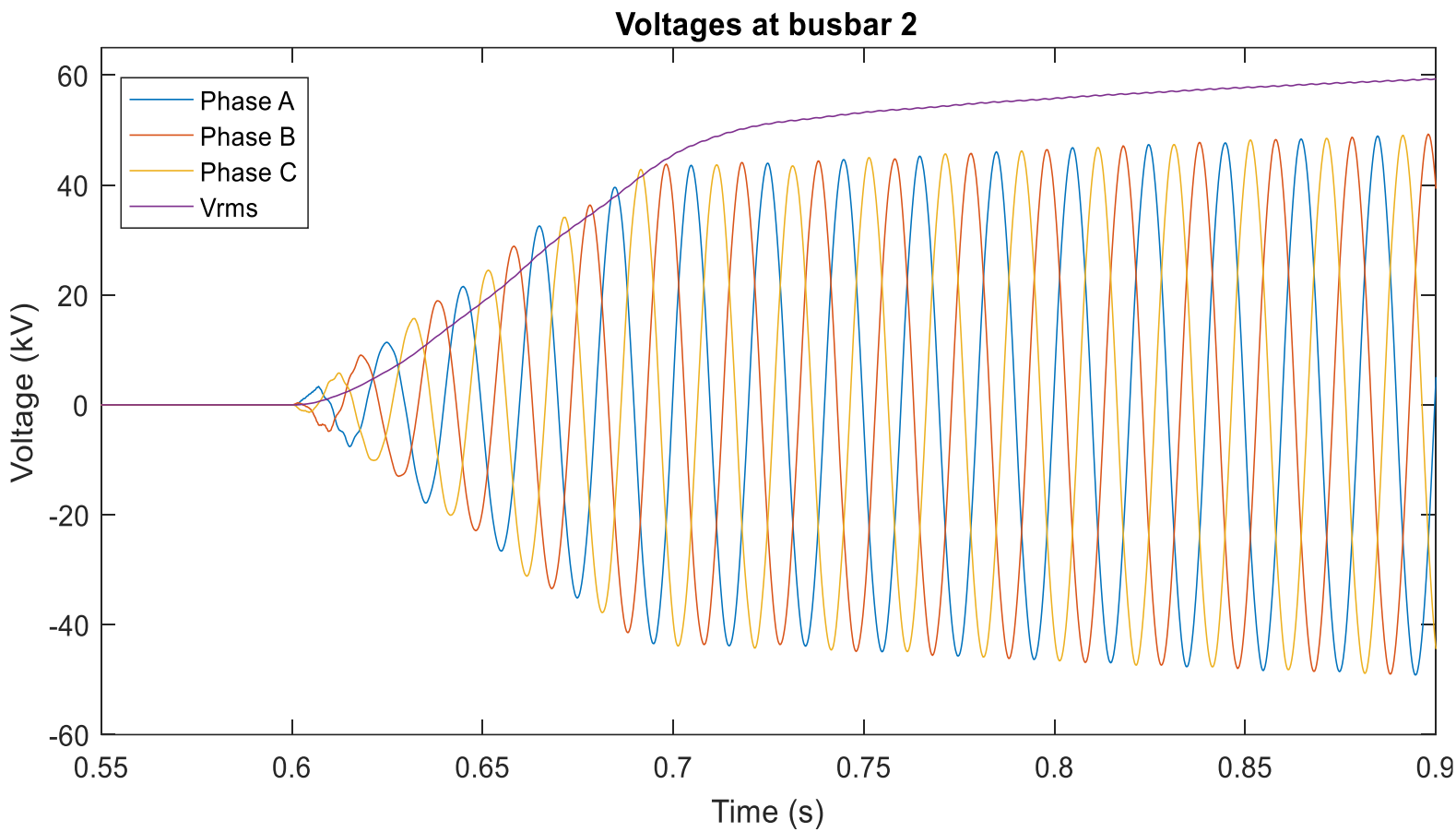

(b) Voltages at busbar 2.

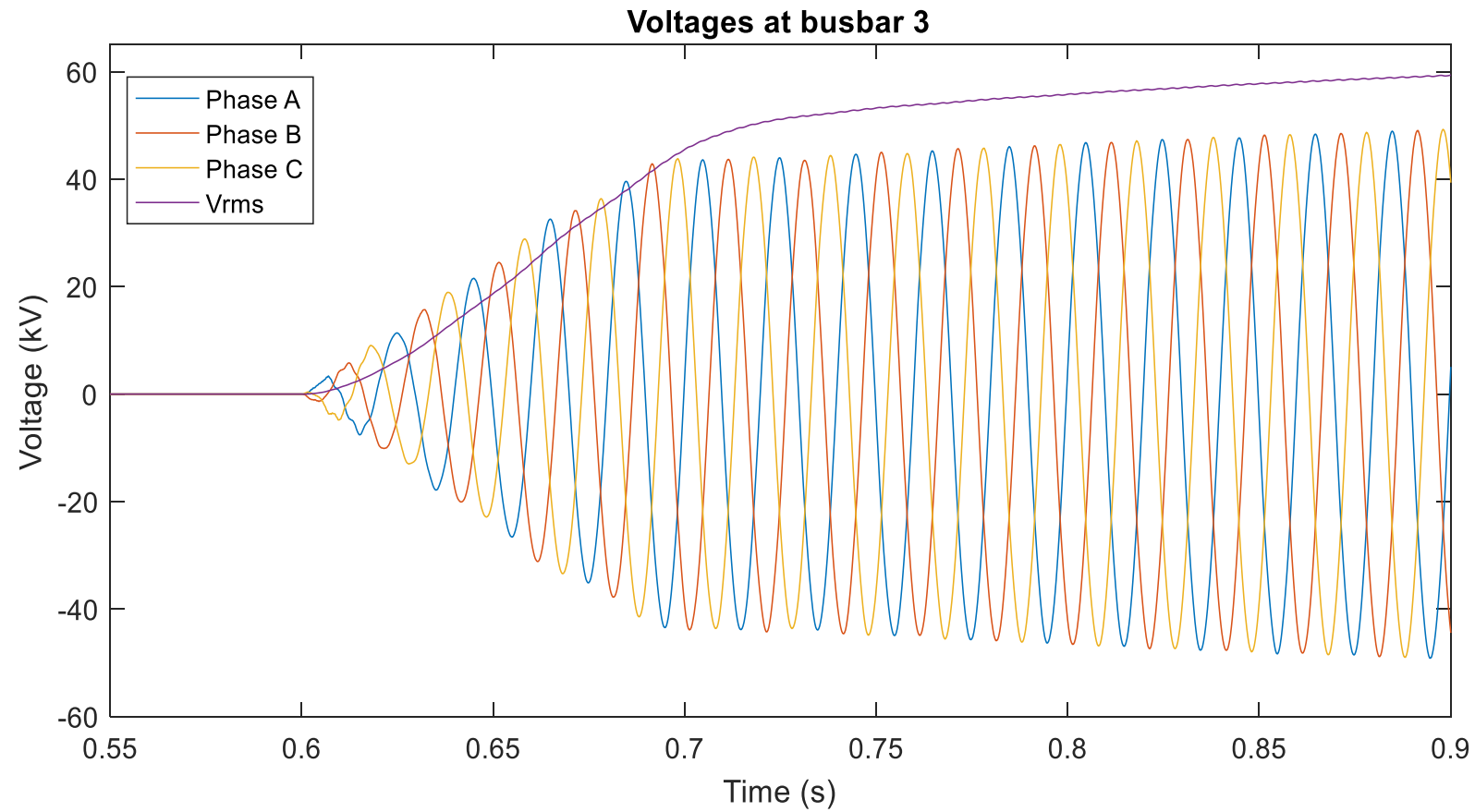

(c) Voltages at busbar 3.

Figure 45 . Voltages at the $66-\mathrm{kV}$ busbars.

After the MMC-HVDC voltage was stabilized, the offshore MMC unit was deblocked. Its controller ramped up the ac reference voltage and the offshore voltage gradually built up. The voltages at the $66 \mathrm{kV}$ terminals of the offshore transformers are reached. To avoid oscillations the connection of the OWFs was sequentially done. Here the model for the OWFs is an aggregated model where one individual wind turbine is modelled and then its output current is multiplied by the number of units, i.e. 70, and injected to the power system through current sources. In this simulation each OWF is connected one after the other with a time span of 2 seconds, starting at 1.5 seconds. Figure 46 (a), (b), and (c) present the power generated per reference wind turbine at each OWF, and the total scaled production that flows through the HVDC link (d). 


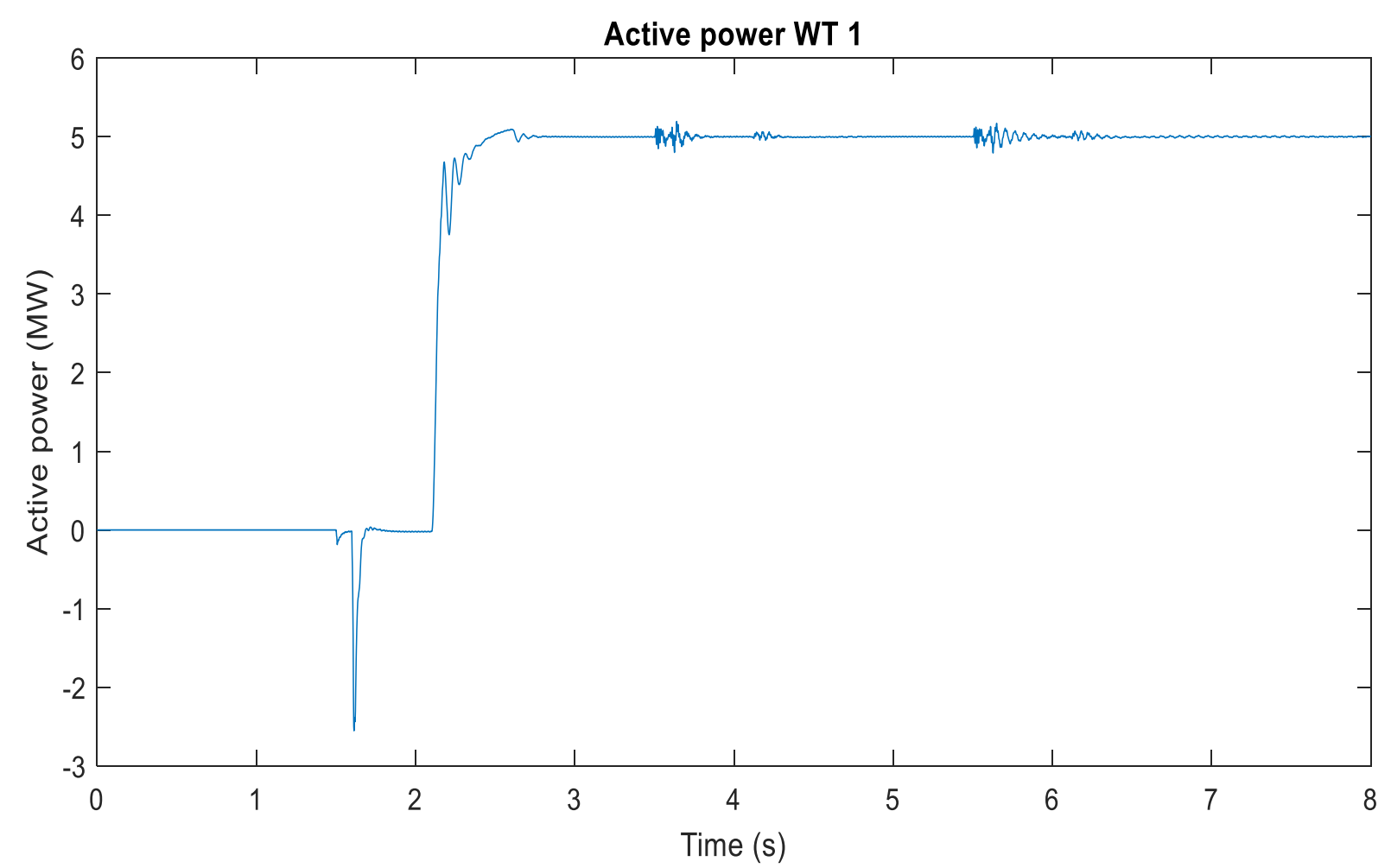

(a) Reference unit for OWF 1.

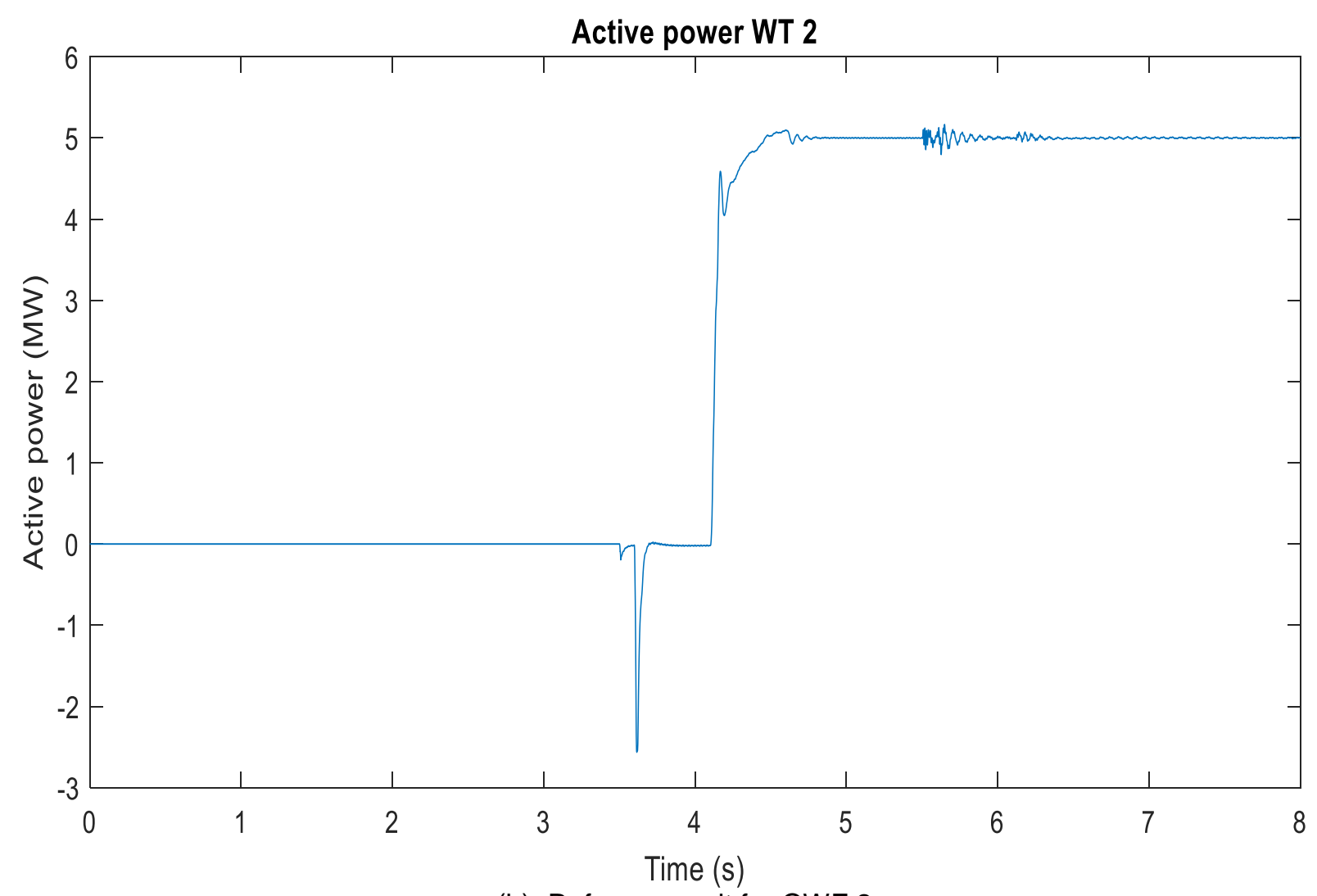

(b) Reference unit for OWF 2. 


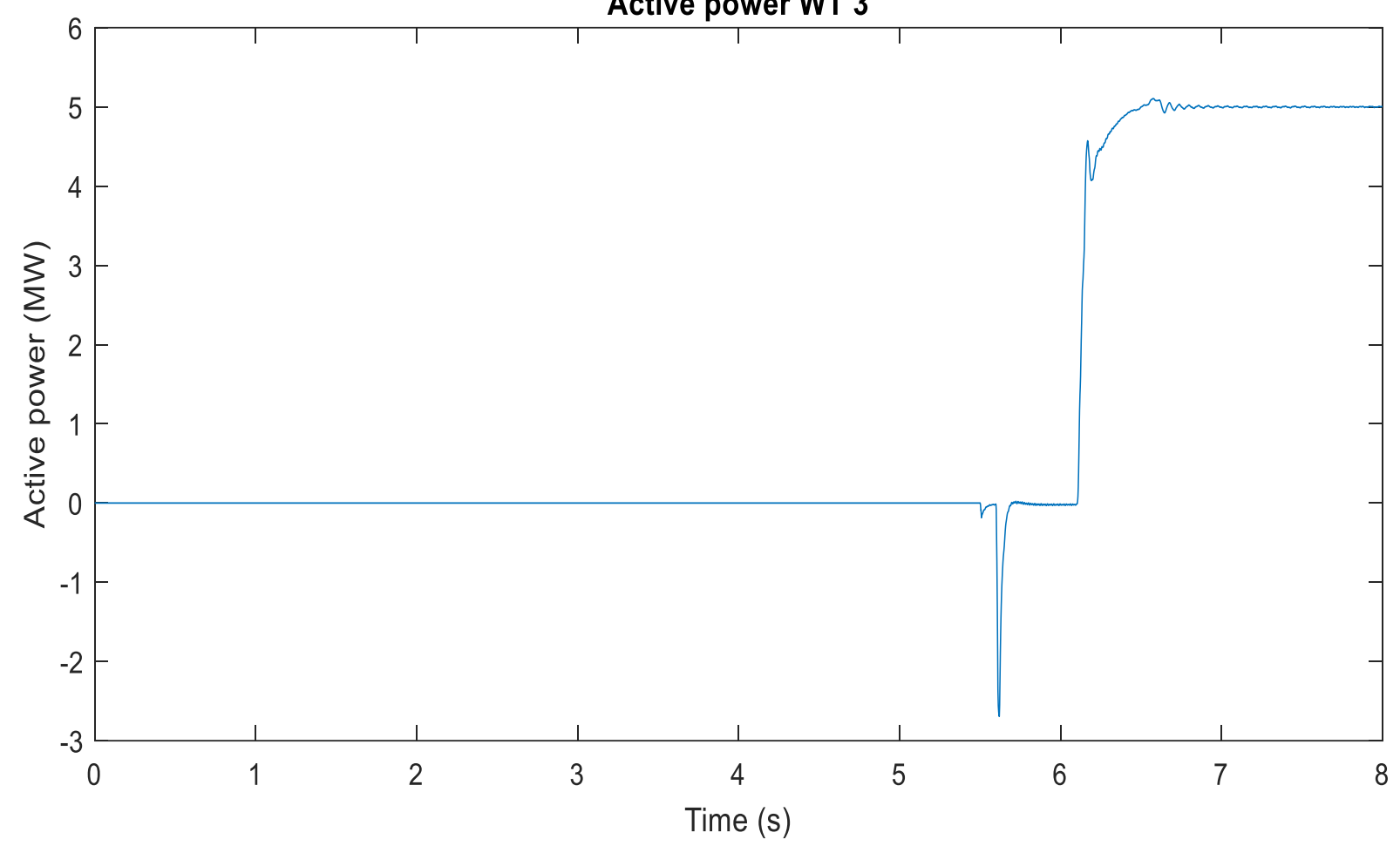

(c) Reference unit for OWF 3.

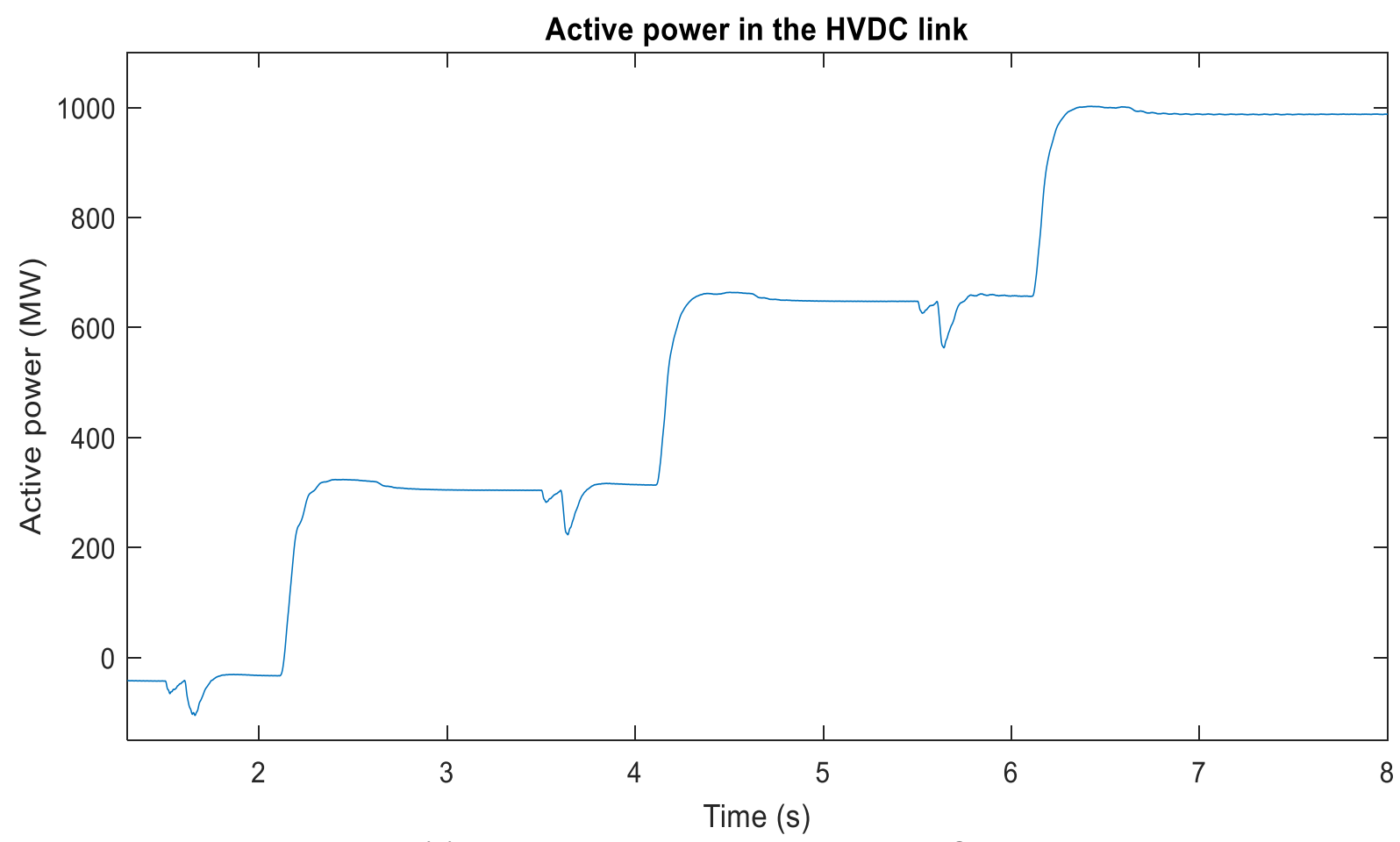

(d) Total power produced by the three OWFs.

Figure 46. Active power production by the OWFs and total power flowing through the HVDC link.

The wind speed profiles considered are shown in Figure 47. For the OWFs 1 and 3 the wind speeds were within the range of 4 and $25 \mathrm{~m} / \mathrm{s}$, at nominal speed of $11.9 \mathrm{~m} / \mathrm{s}$. In the case of the second cluster the wind speed was ramped up to $26.9 \mathrm{~m} / \mathrm{s}$ to demonstrate the correct operation of the controls implemented in the type 4 wind turbine model to produce the nominal power of $350 \mathrm{MW}$ with wind speeds above the cut-out speed. 


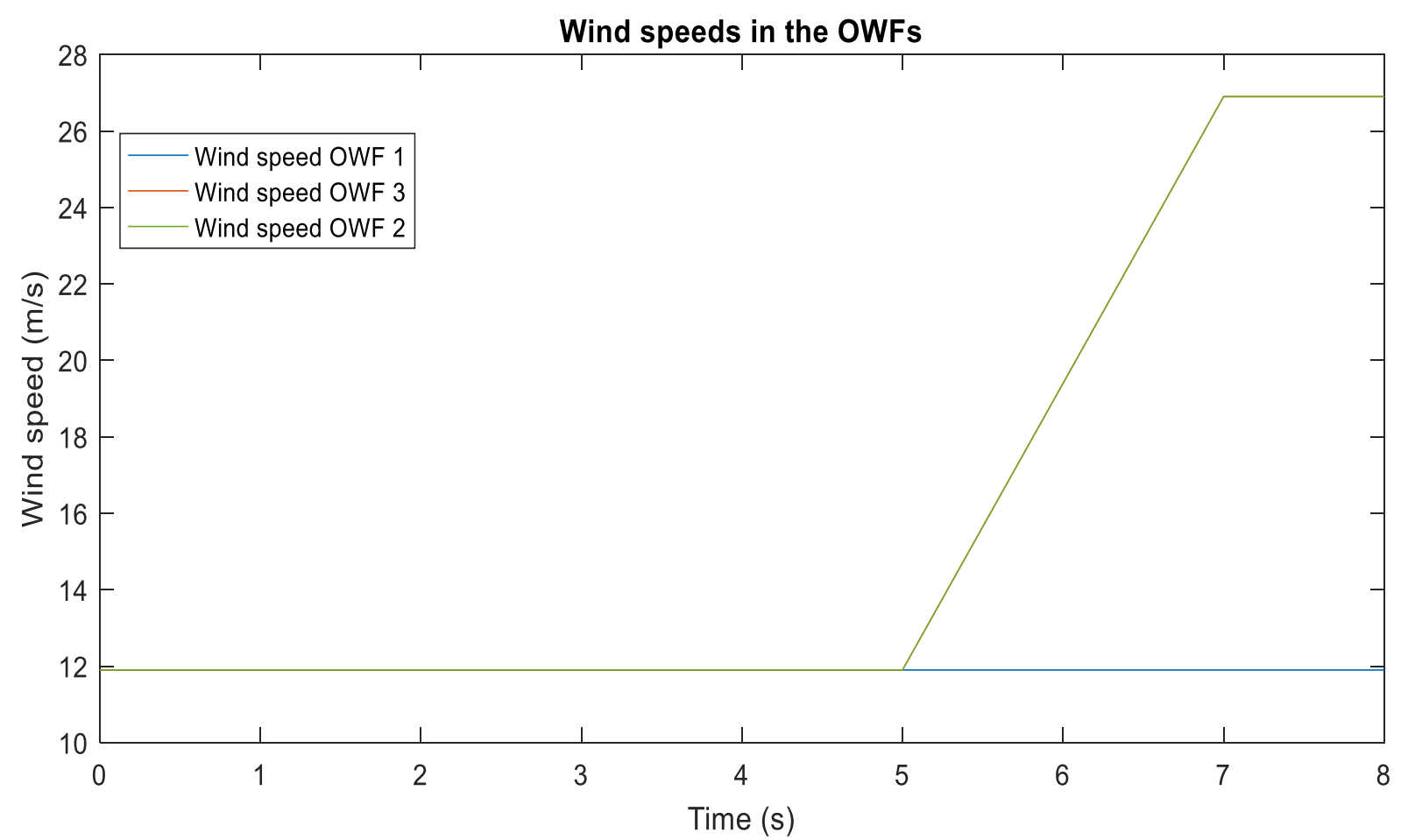

Figure 47. Wind speed profiles during energization state.

The dc voltage and currents during the initialization of the wind parks are presented next in Figure 48.

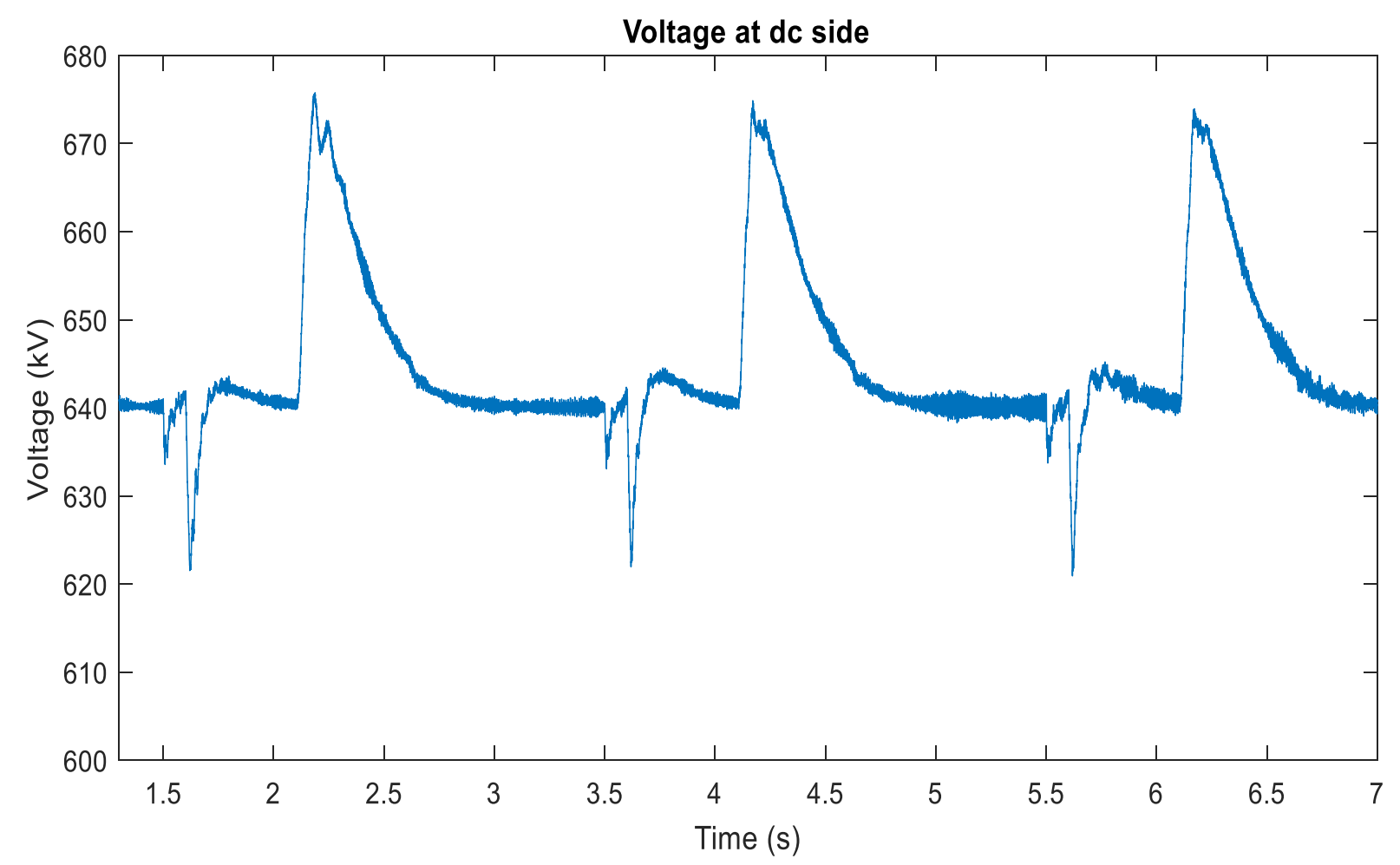

(a) Voltage at the dc side. 


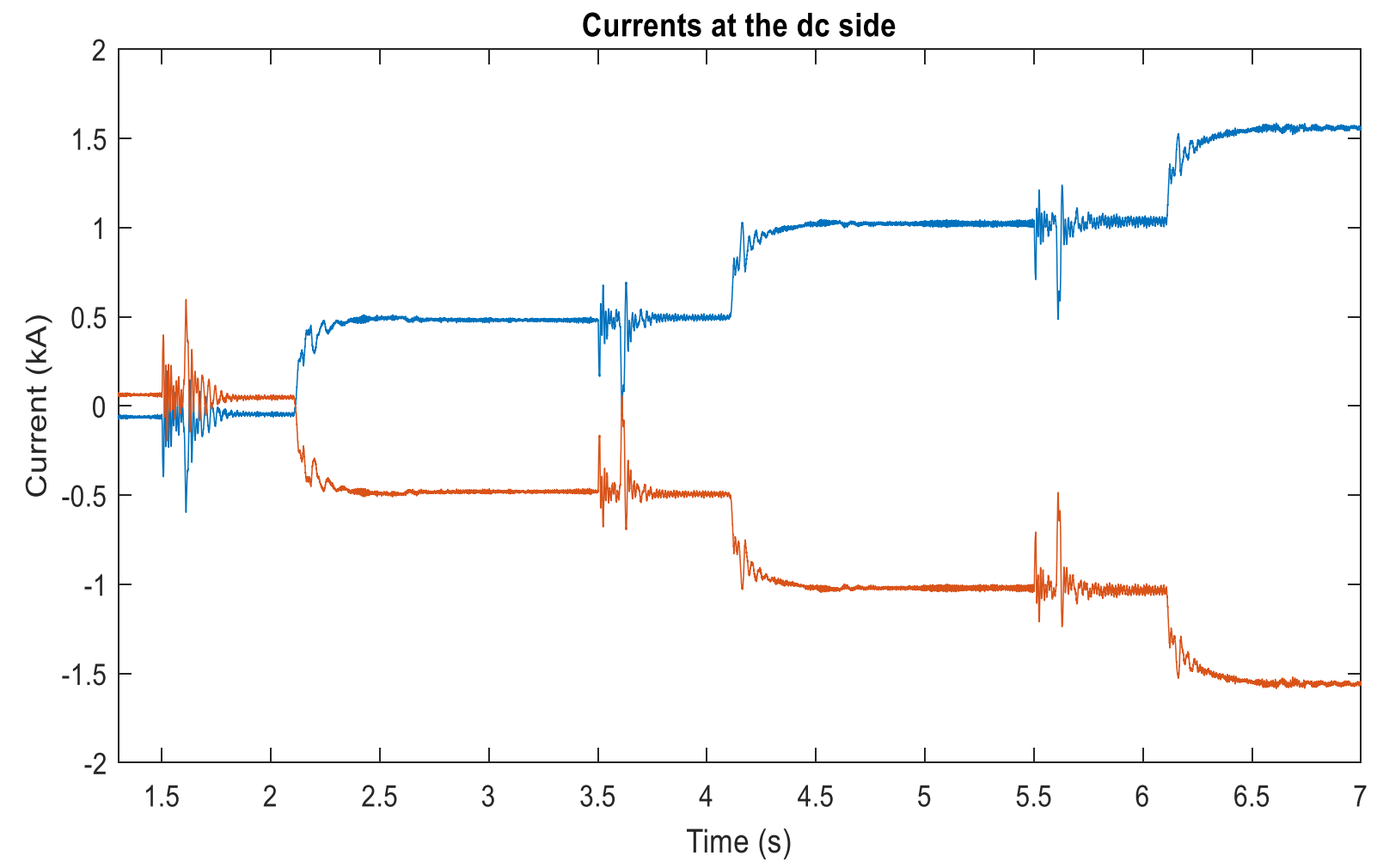

(b) Currents at the dc side.

Figure 48. The dc voltage and currents during the initialization of the OWFs.

The waveforms of the onshore ac voltage and currents are captured in the subsequent figures.

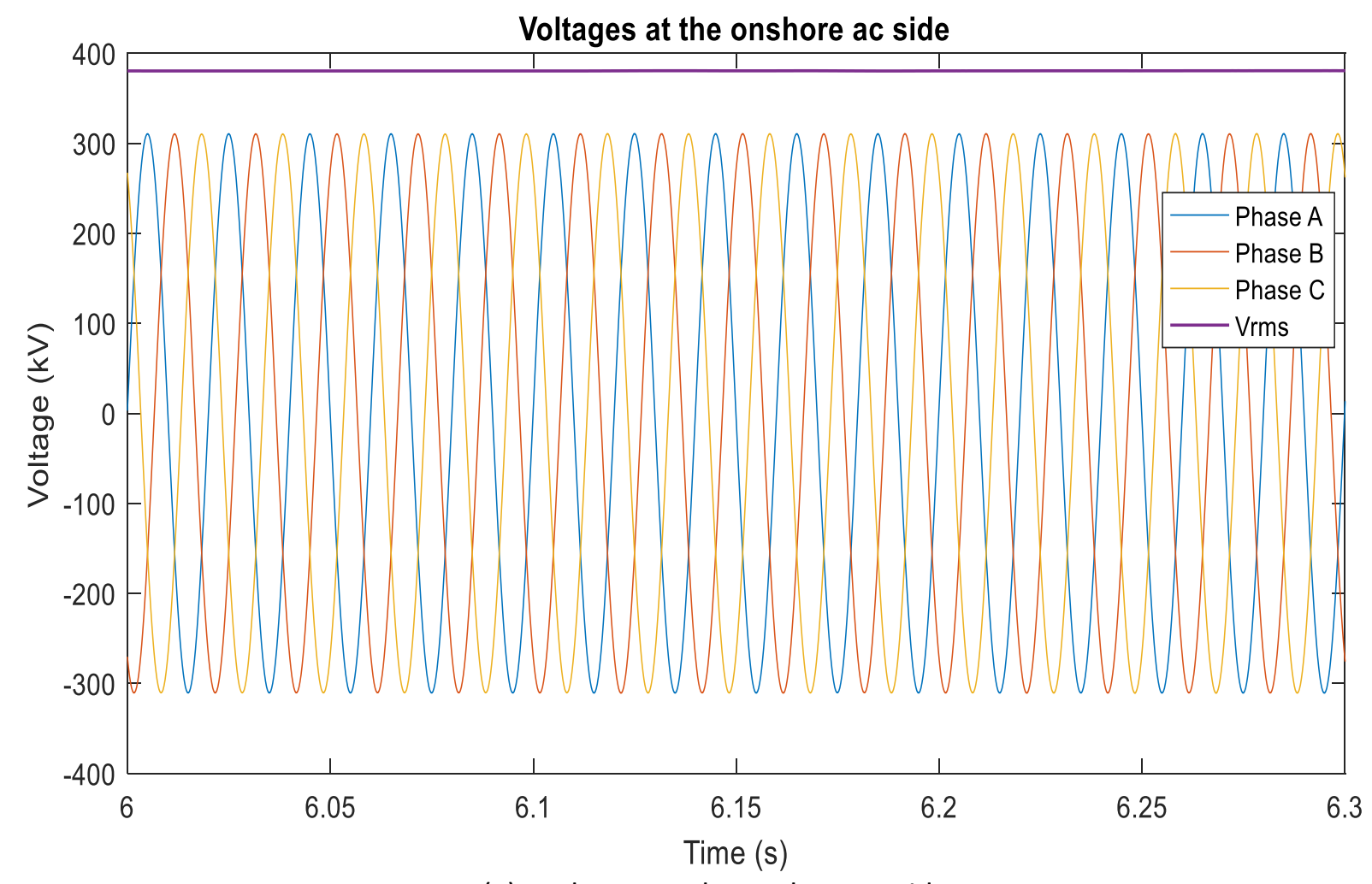

(a) Voltages at the onshore ac side. 


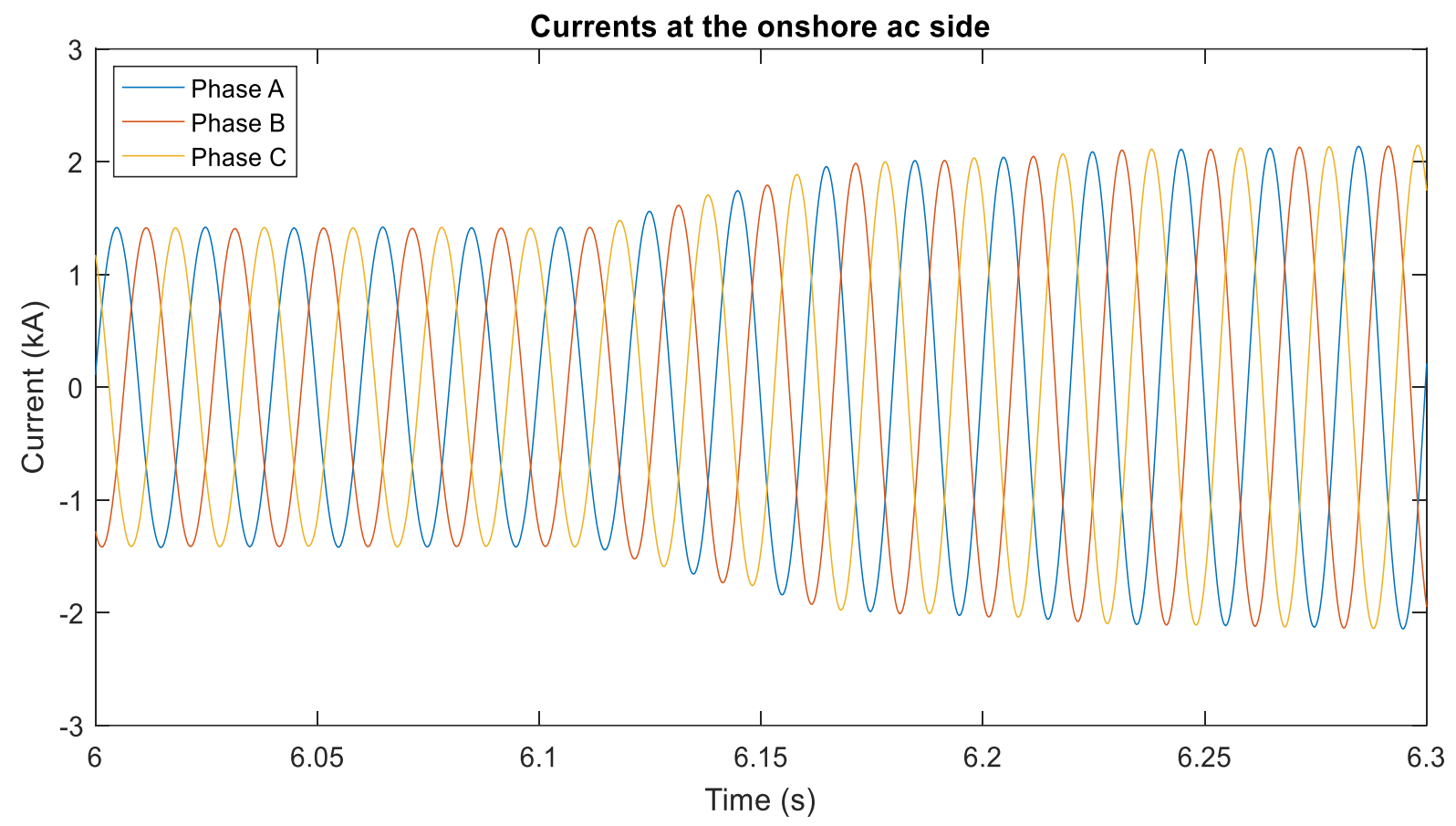

(b) Currents at the onshre ac side

Figure 49. Voltages and currents at the onshore ac side.

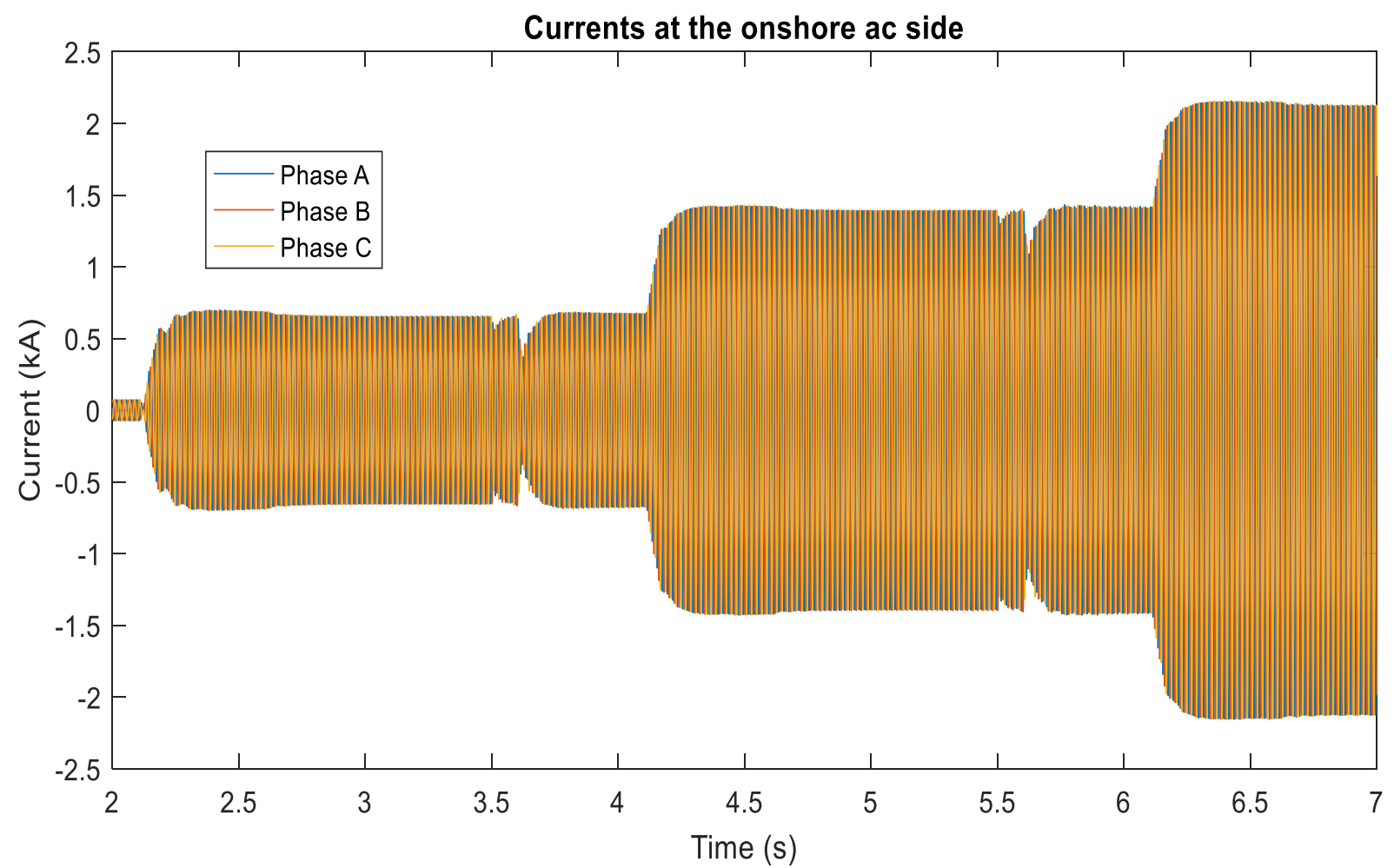

Figure 50. Currents at the onshore ac side for the complete sequence.

The frequency of the offshore ac grid during the energization of all three wind parks is shown in the next figure. The wind turbines are not connected to the system individually, but in groups of 70 at the same time. The frequency variations for a real start-up sequence will not be as pronounced as here because the insertion of each generation unit is sequentially. 


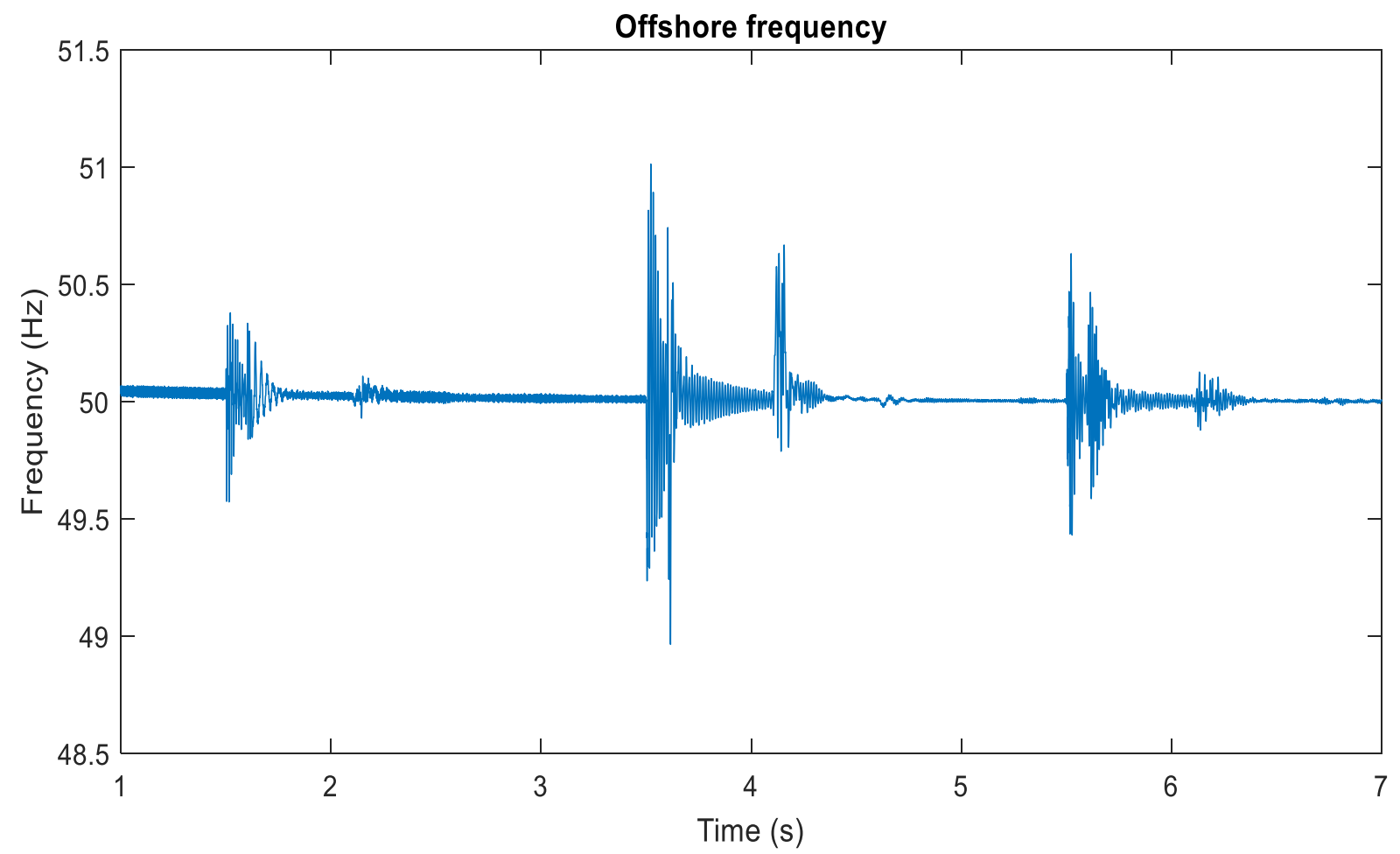

Figure 51. Offshore frequency.

The start-up sequence of the MMV-HVDC transmission link and the energization of the offshore ac grid was successfully done, and the value of the different parameters were within the expected limits of normal operation. The voltages at the offshore converters reached 66 $\mathrm{kV}$, the dc voltage was set at $\pm 320 \mathrm{kV}$ and the active power production was nominal at 1050 MW.

The model correctly represents the energization of the HVDC link and the offshore ac grid. The frequency was stablished at $50 \mathrm{~Hz}$. The system was stable during this first state of operation. The controls operated as expected deblocking the MMC terminals, starting up the wind turbines and capturing all the wind power generation to transport it to shore.

\subsubsection{Steady state operation}

For the steady state scenario when the three OWFs are generating nominal power, i.e. 1050 $\mathrm{MW}$, the ac and dc voltage and current waveforms are presented in Figure 52 and Figure 53. The same wind speed profiles used in the previous case are assumed here. Nominal values are obtained for all the measured quantities in the test network. All the measurements captured were after 10 seconds of simulation, i.e. 4.5 seconds after all the wind parks had already been connected. 


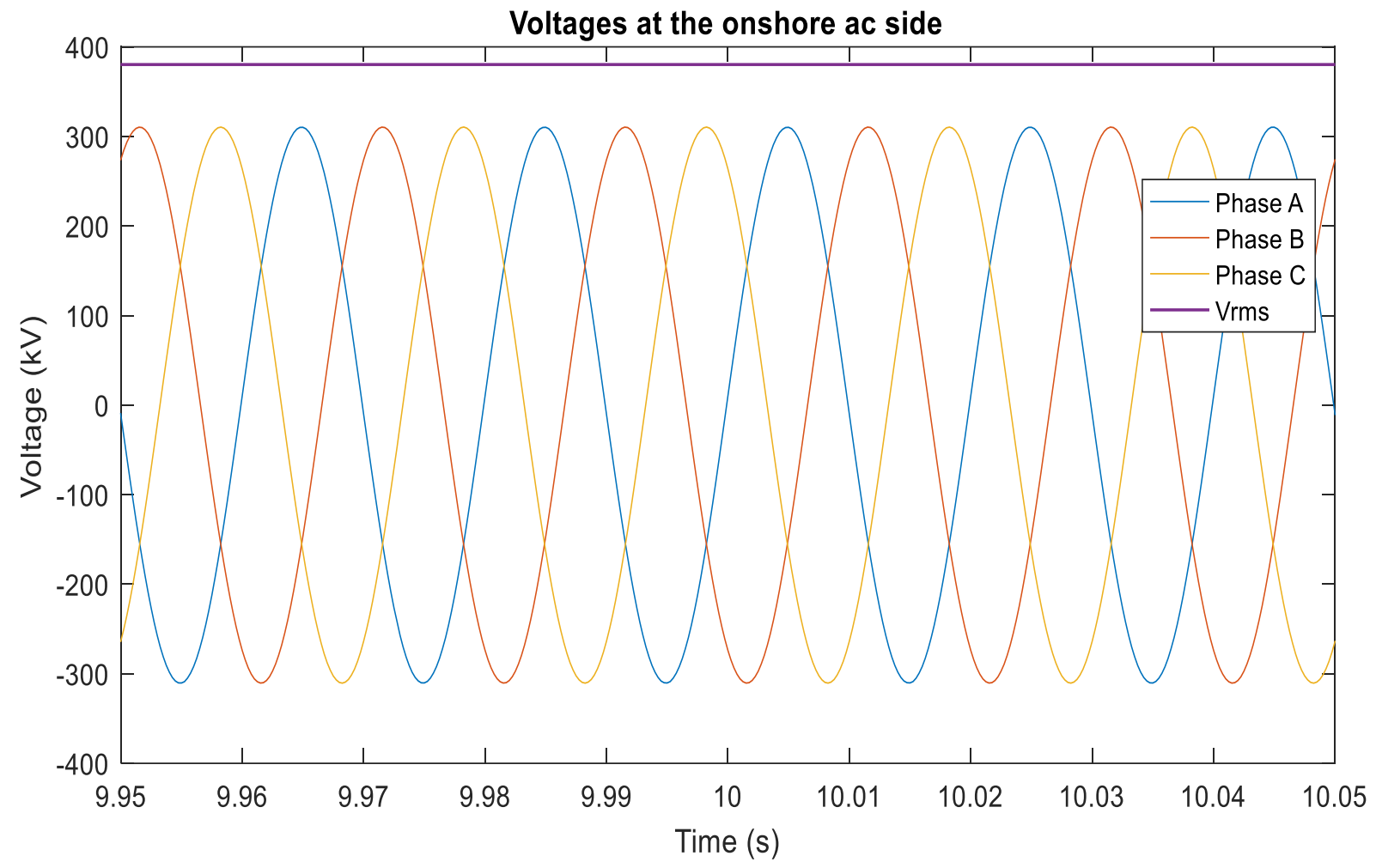

(a) Voltages at the onshore ac side.

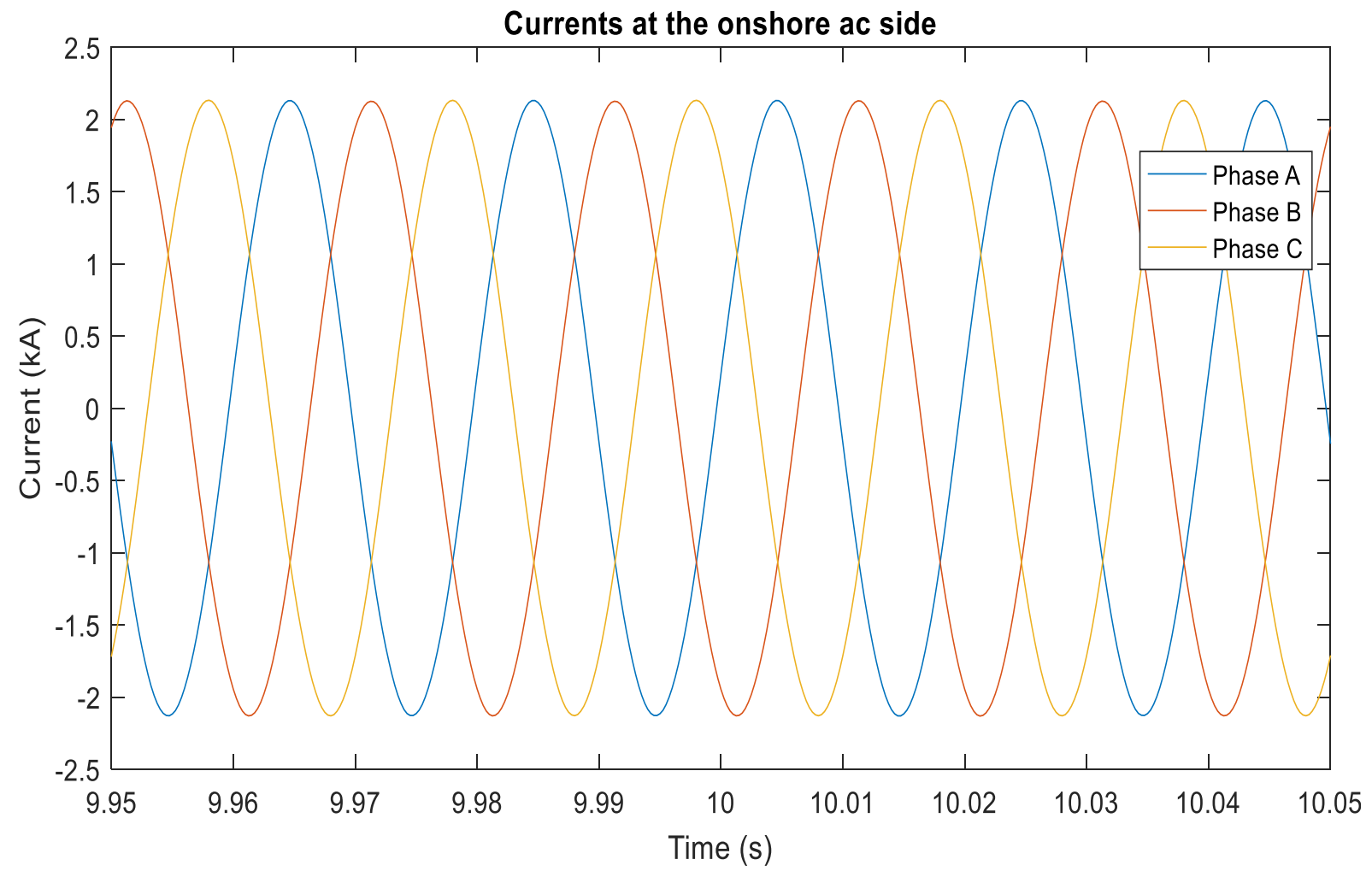

(b) Currents at the onshore ac side.

Figure 52. Voltages and currents at the onshore ac side. 


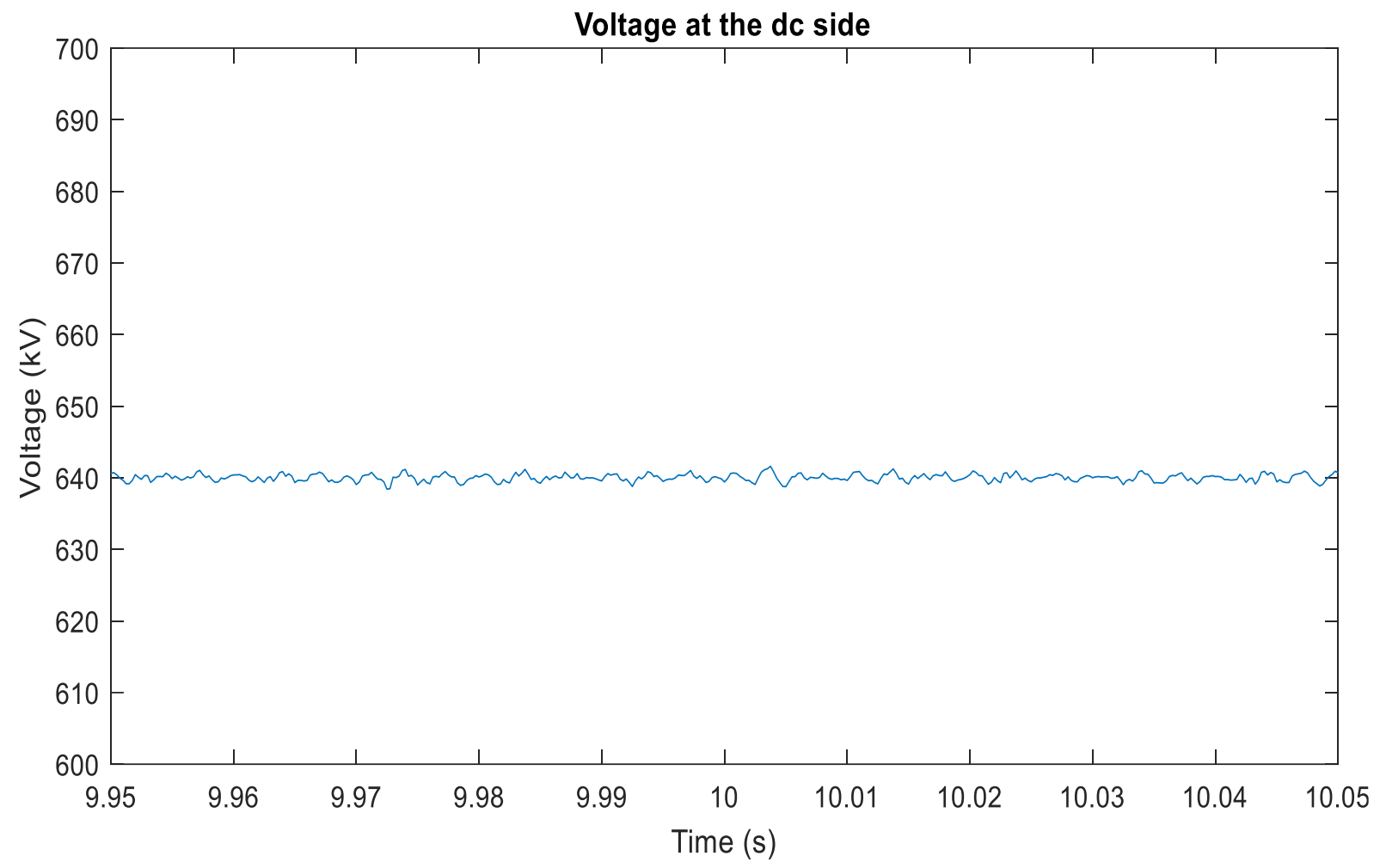

(a) Voltage at the dc side.

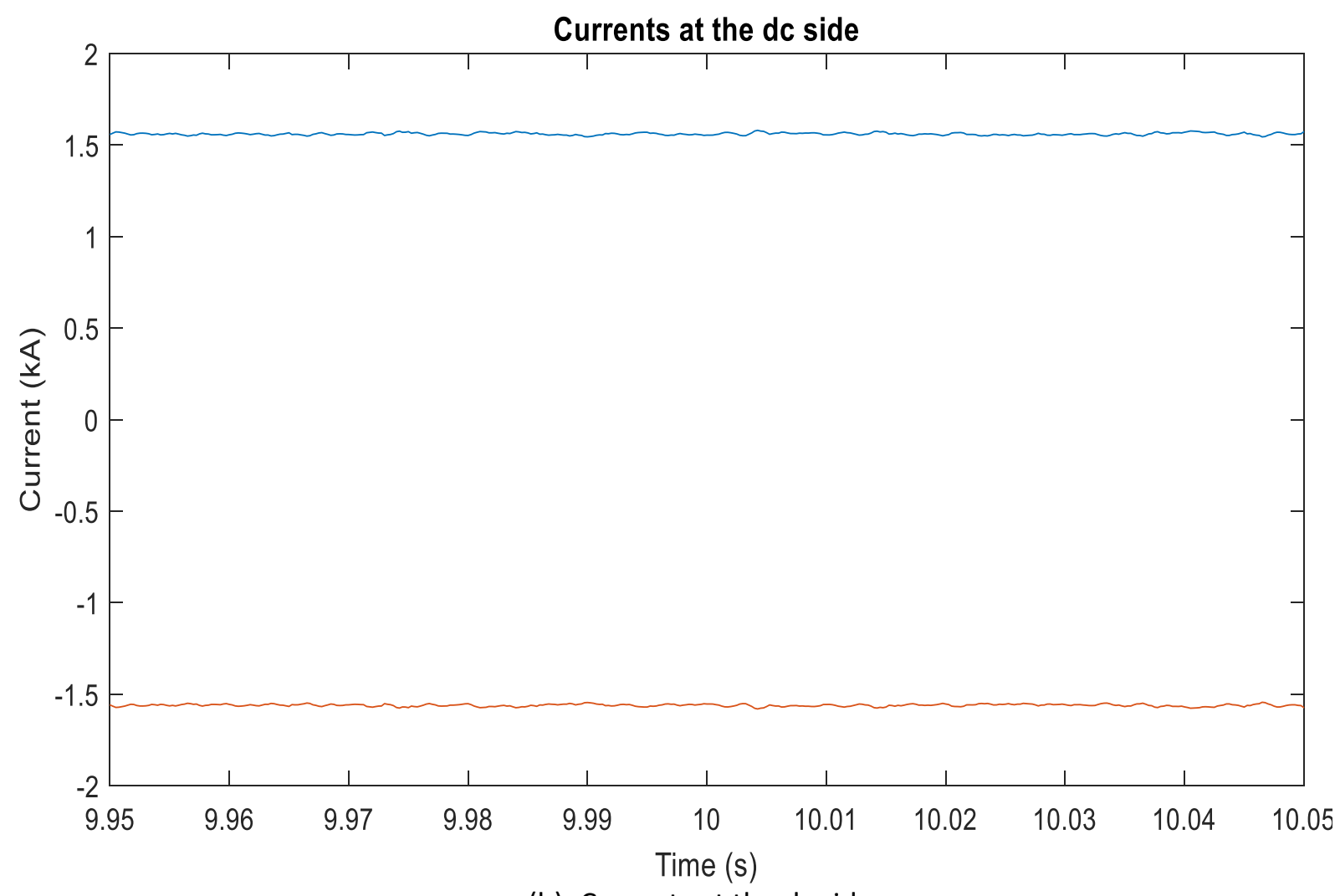

(b) Currents at the dc side

Figure 53. Voltage and currents at the dc side. 
The total power production is at nominal value.

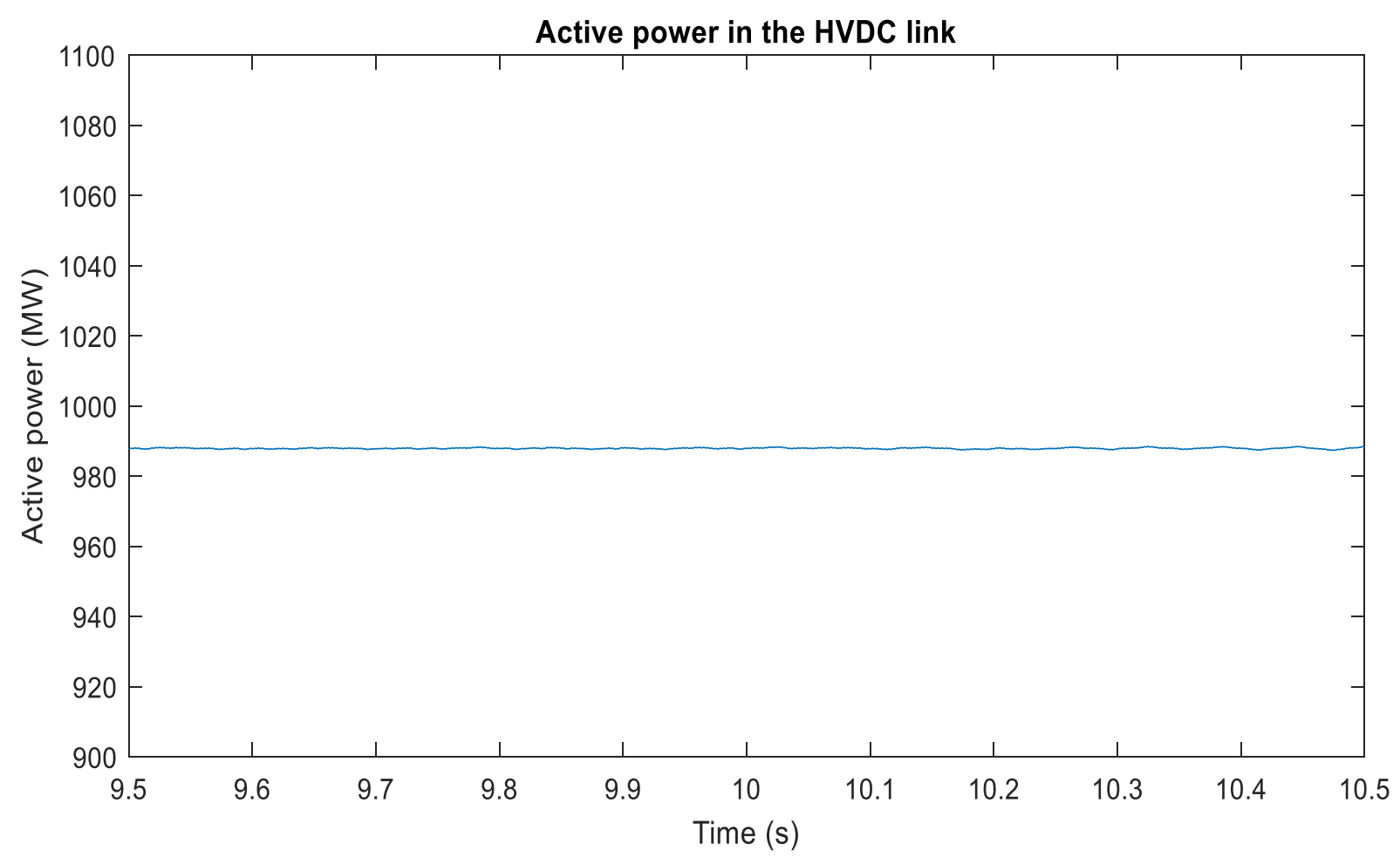

Figure 54. Total power through the HVDC link.

The offshore frequency is at $50 \mathrm{~Hz}$.

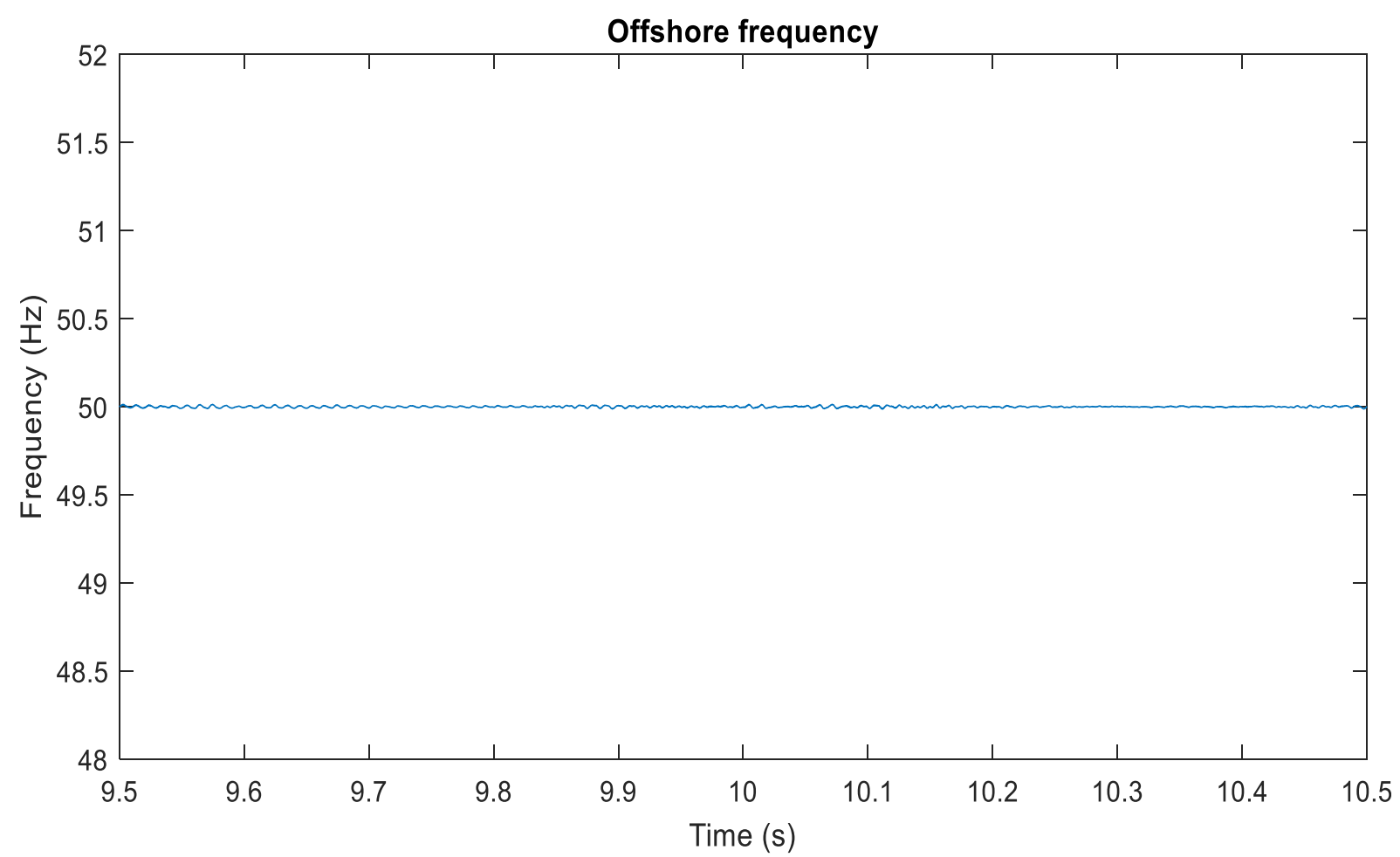

Figure 55. Offshore frequency. 
The voltage waveforms of the instantaneous and $\mathrm{rms}$ values at the three $66-\mathrm{kV}$ busbars are depicted in Voltages at busbar 3.

Figure 56.

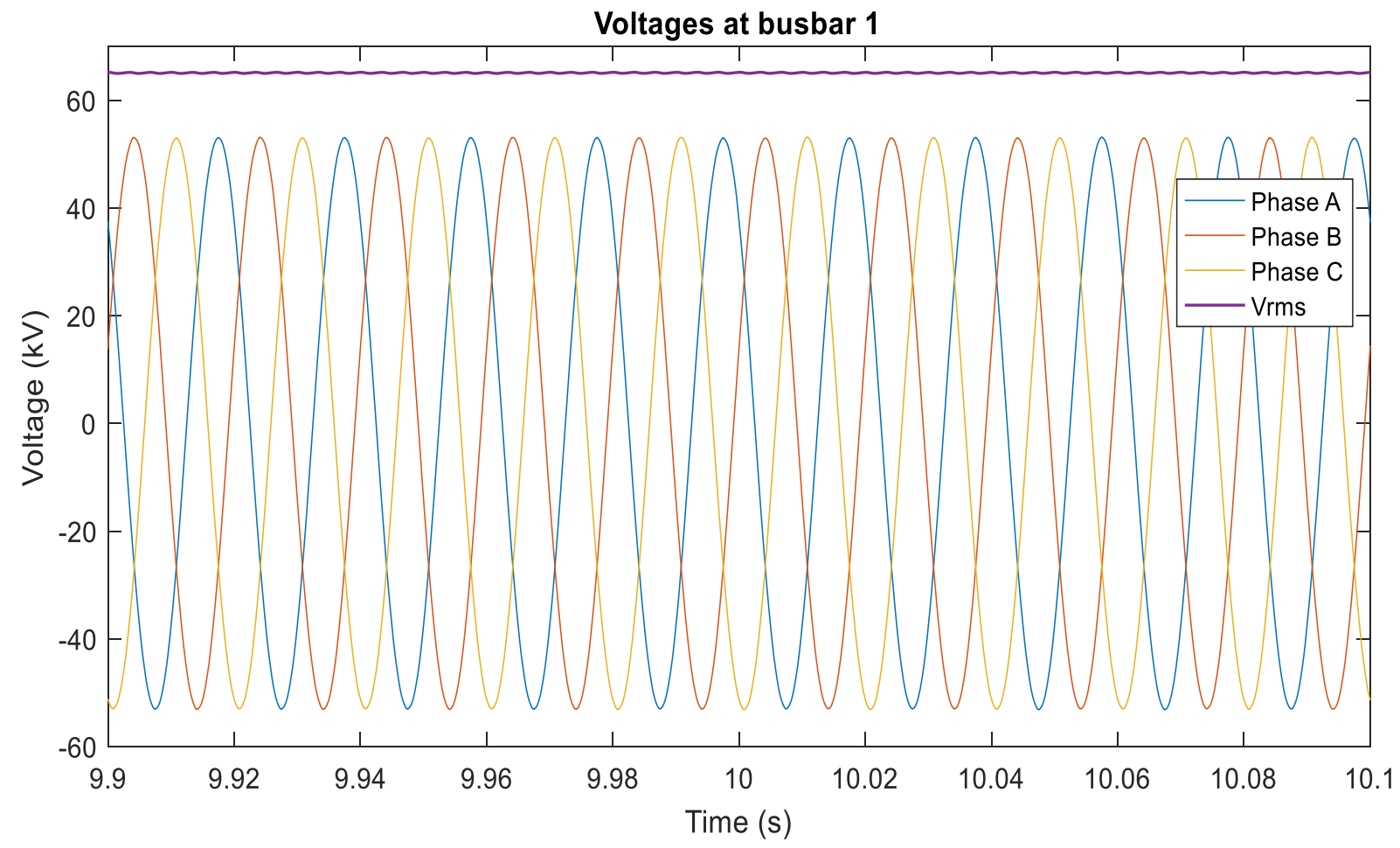

(a) Voltages at busbar 1.

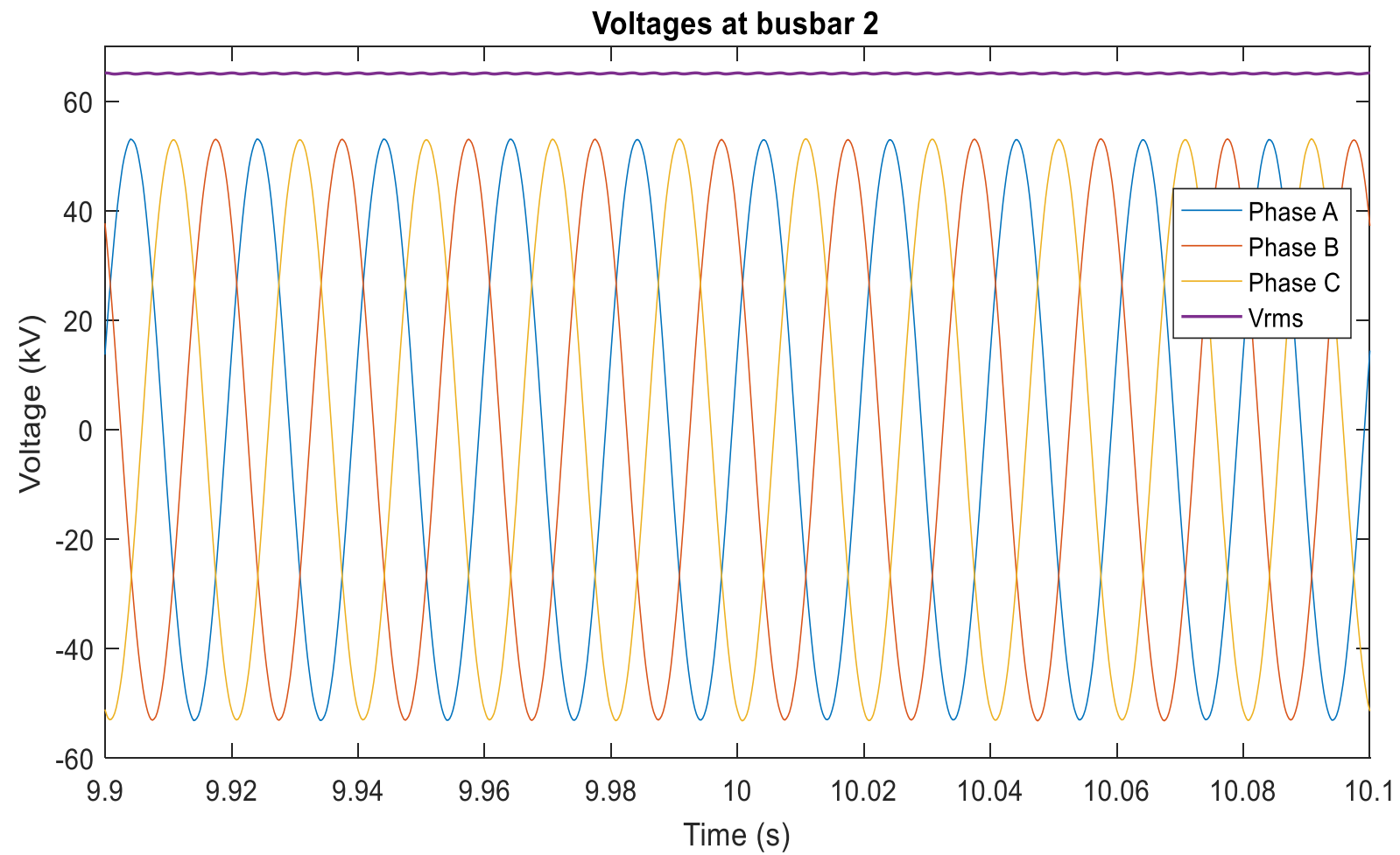

(b) Voltages at busbar 2. 


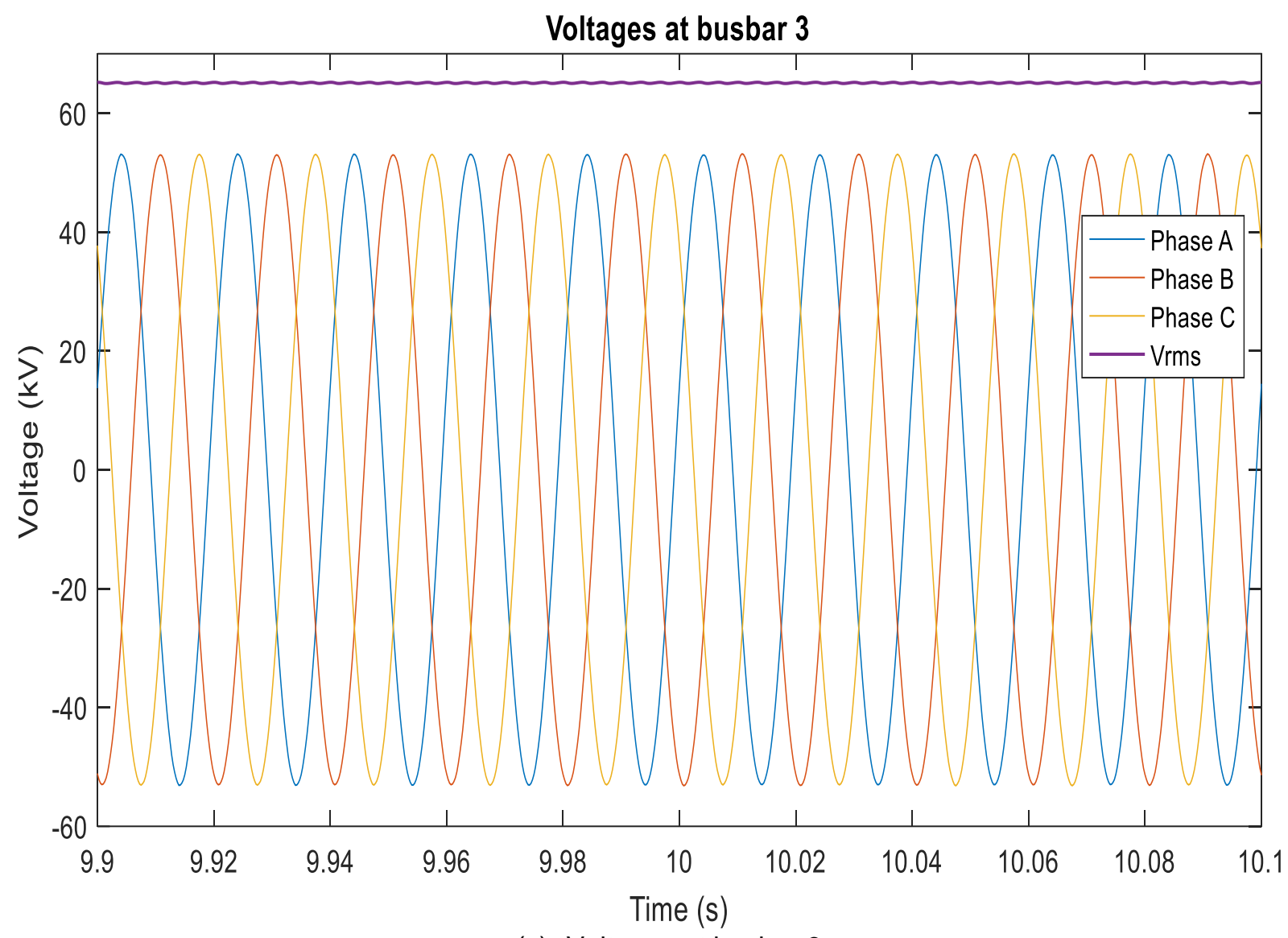

(c) Voltages at busbar 3.

Figure 56. Voltages at the $66-\mathrm{kV}$ busbars.

\subsubsection{Perturbations in the grid}

Events and disturbances are expected during the operation of power systems and equipment for energy transmission is designed to withstand transient overvoltages and fault currents for short periods of time [49]. The test network was subjected to various cases where different perturbations were simulated.

The first event simulated is the shutdown of the OWF 1 due to the reduction of the wind speed below the cut-in speed of $4 \mathrm{~m} / \mathrm{s}$. The wind speed of this wind park was ramped down from the nominal speed of 11.9 to $3.9 \mathrm{~m} / \mathrm{s}$ in two seconds, between 5 and 7 seconds. The behaviour of the system was captured in the following figures. The total time simulated was 13 seconds when the production of active power was stabilized again to the rated value produced by only two clusters of wind turbines. The OWFs were connected at 1.2, 2.2, and 3.2 seconds, respectively. 


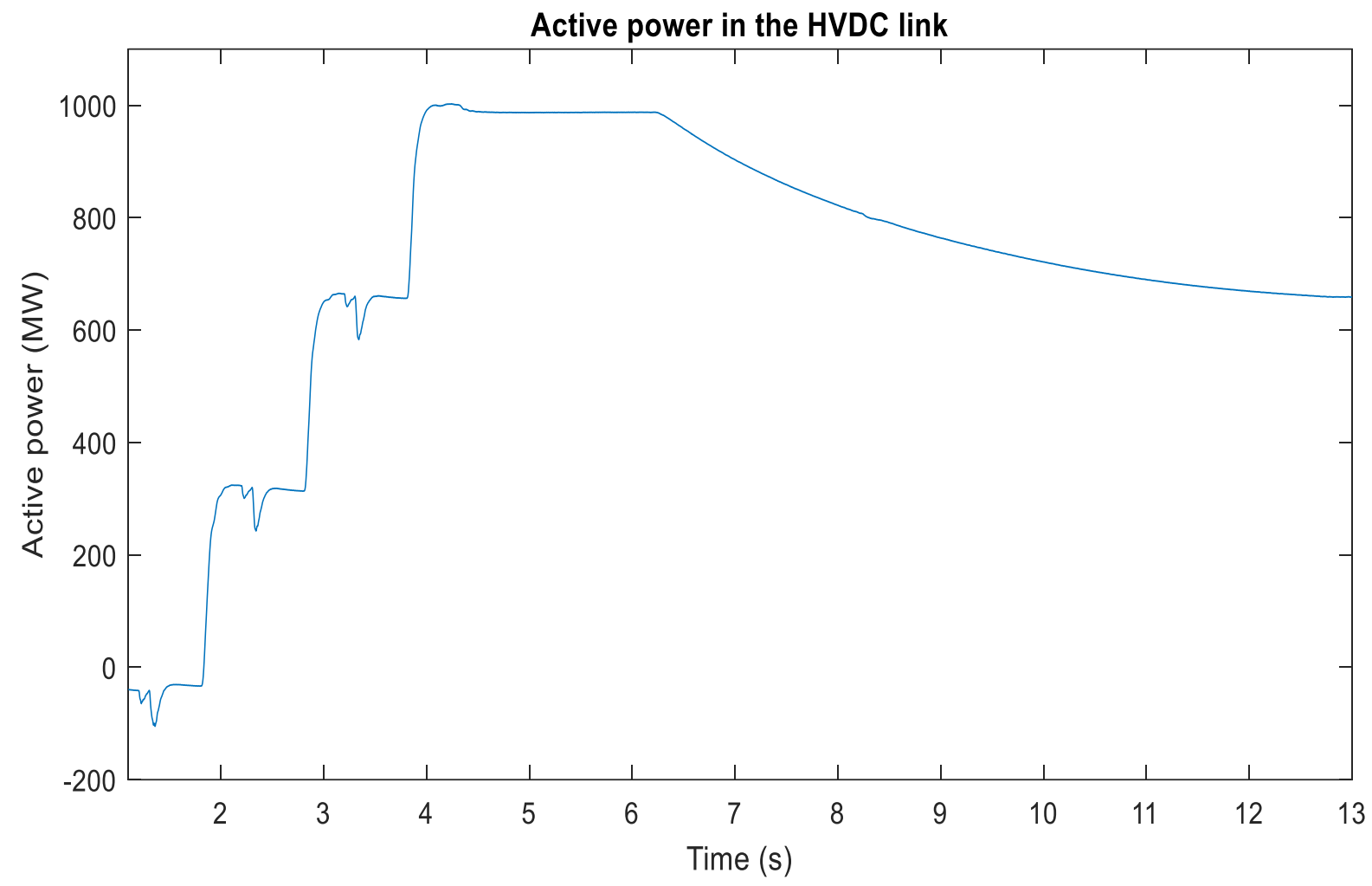

Figure 57. Changes in the power generation after the shutdown of OWF 1.

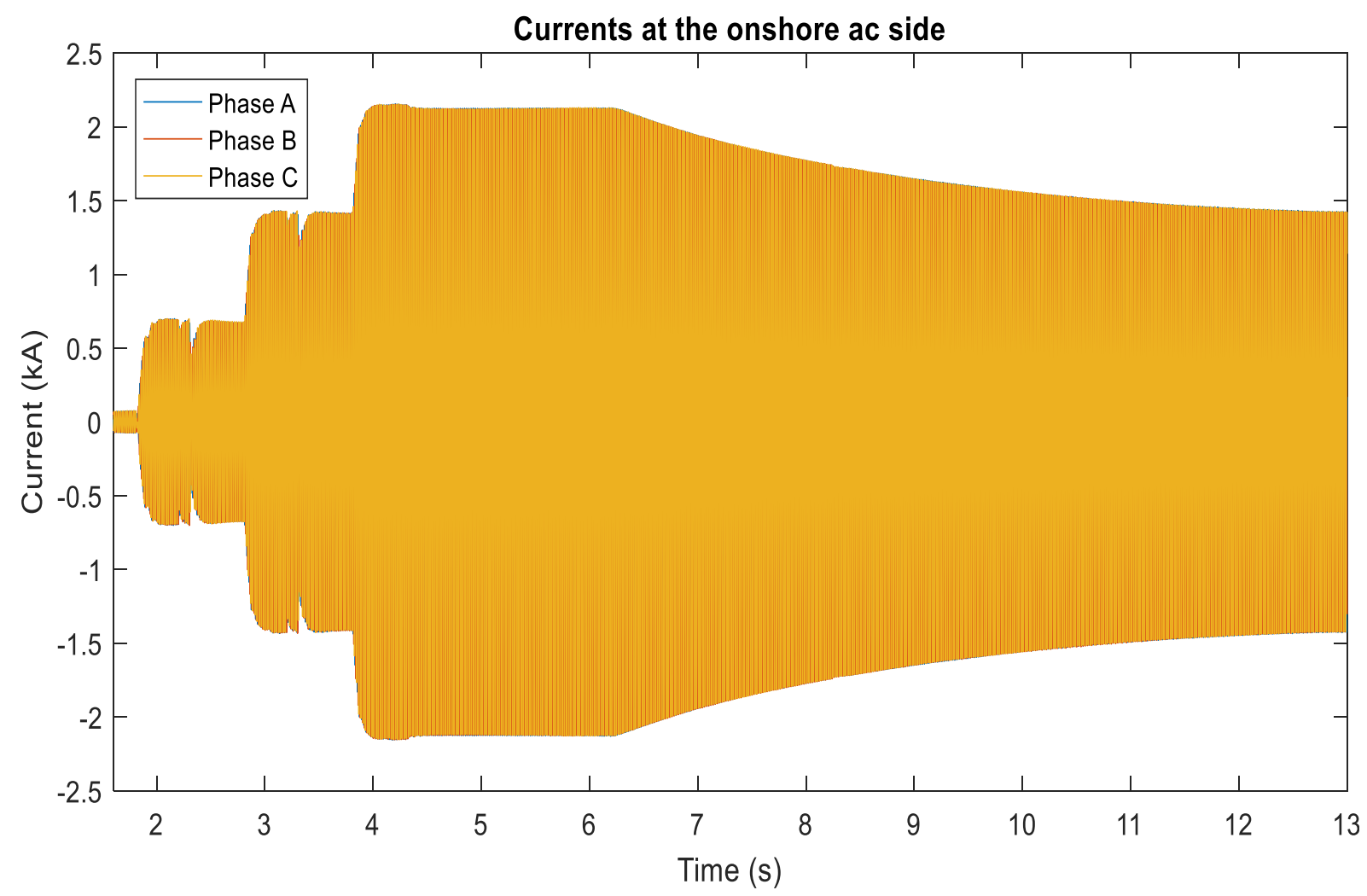

Figure 58. Onshore ac currents - complete time span. 


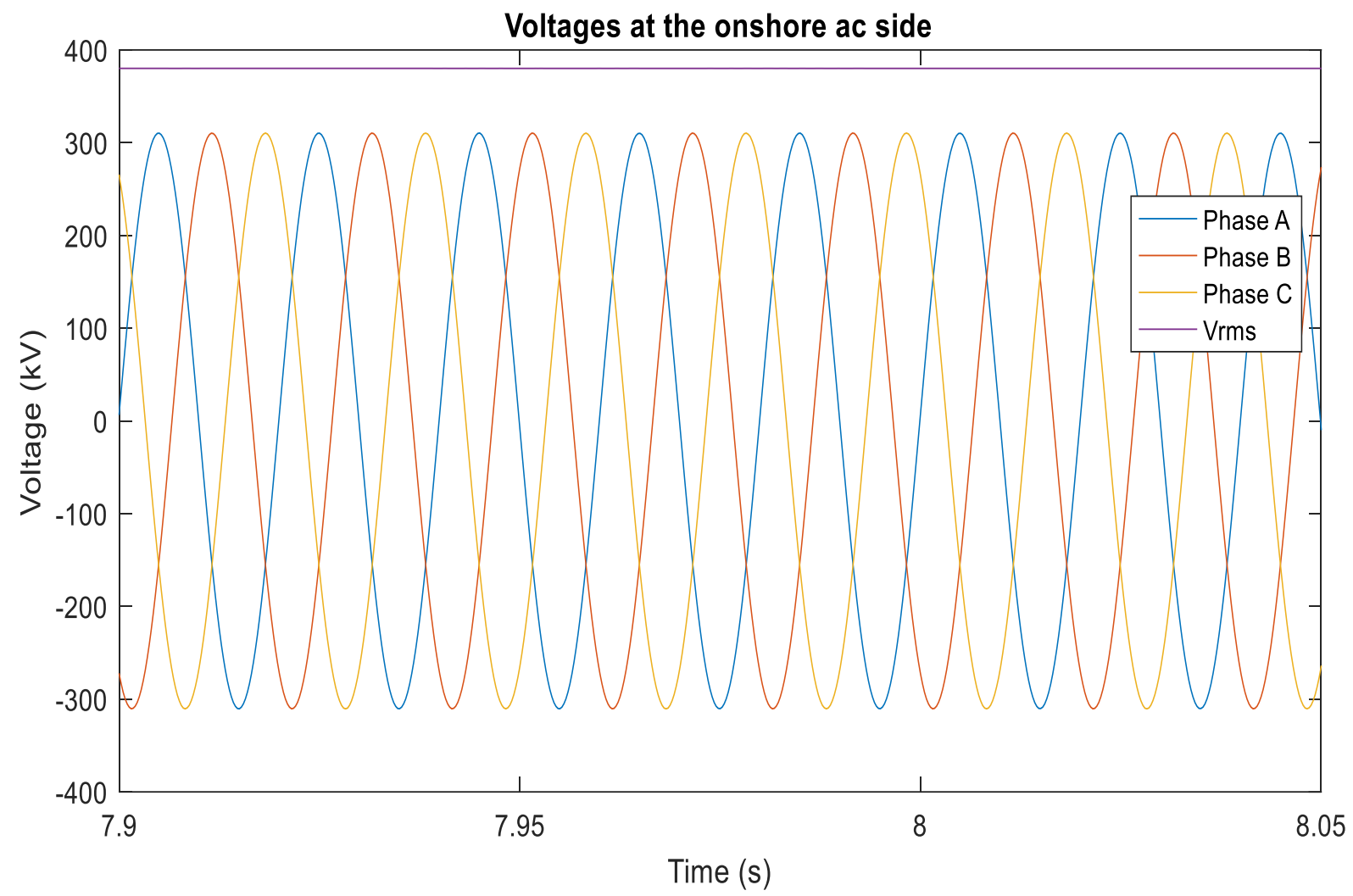

(a) Voltages at the onshore ac side.

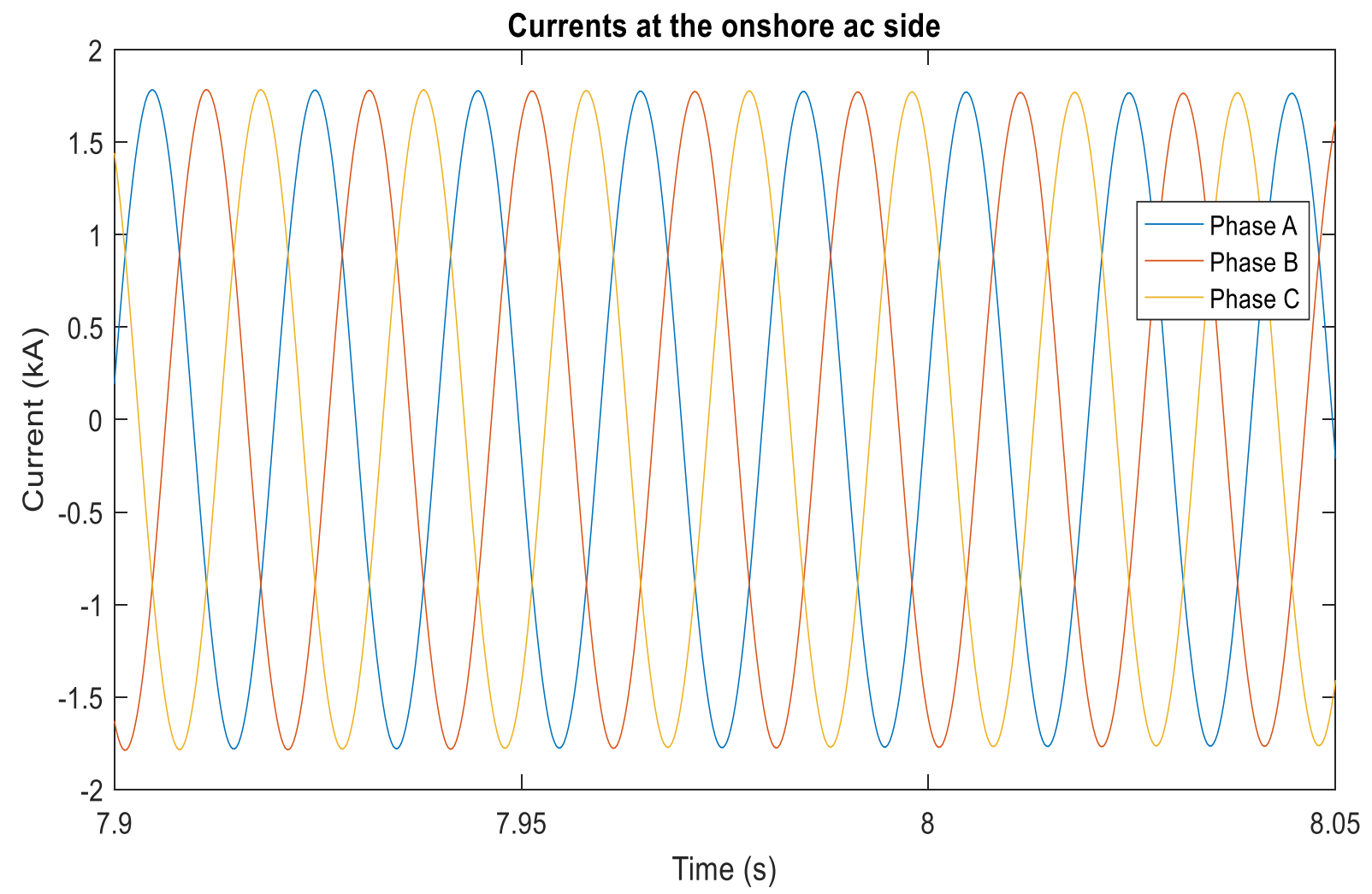

(b) Currents at the onshore ac side.

Figure 59. Voltages and currents at the onshore ac side. 


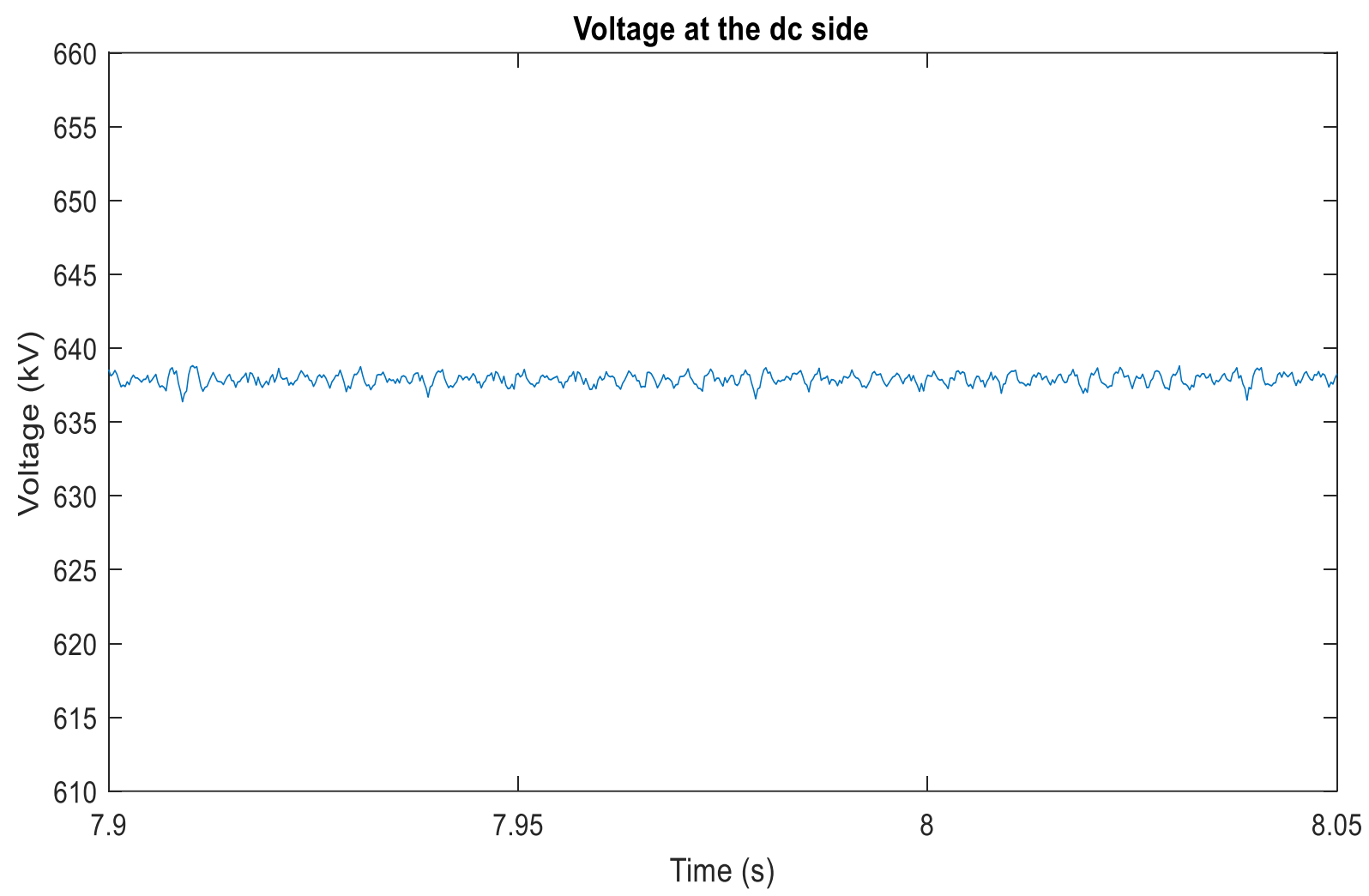

(a) Voltage at the dc side.

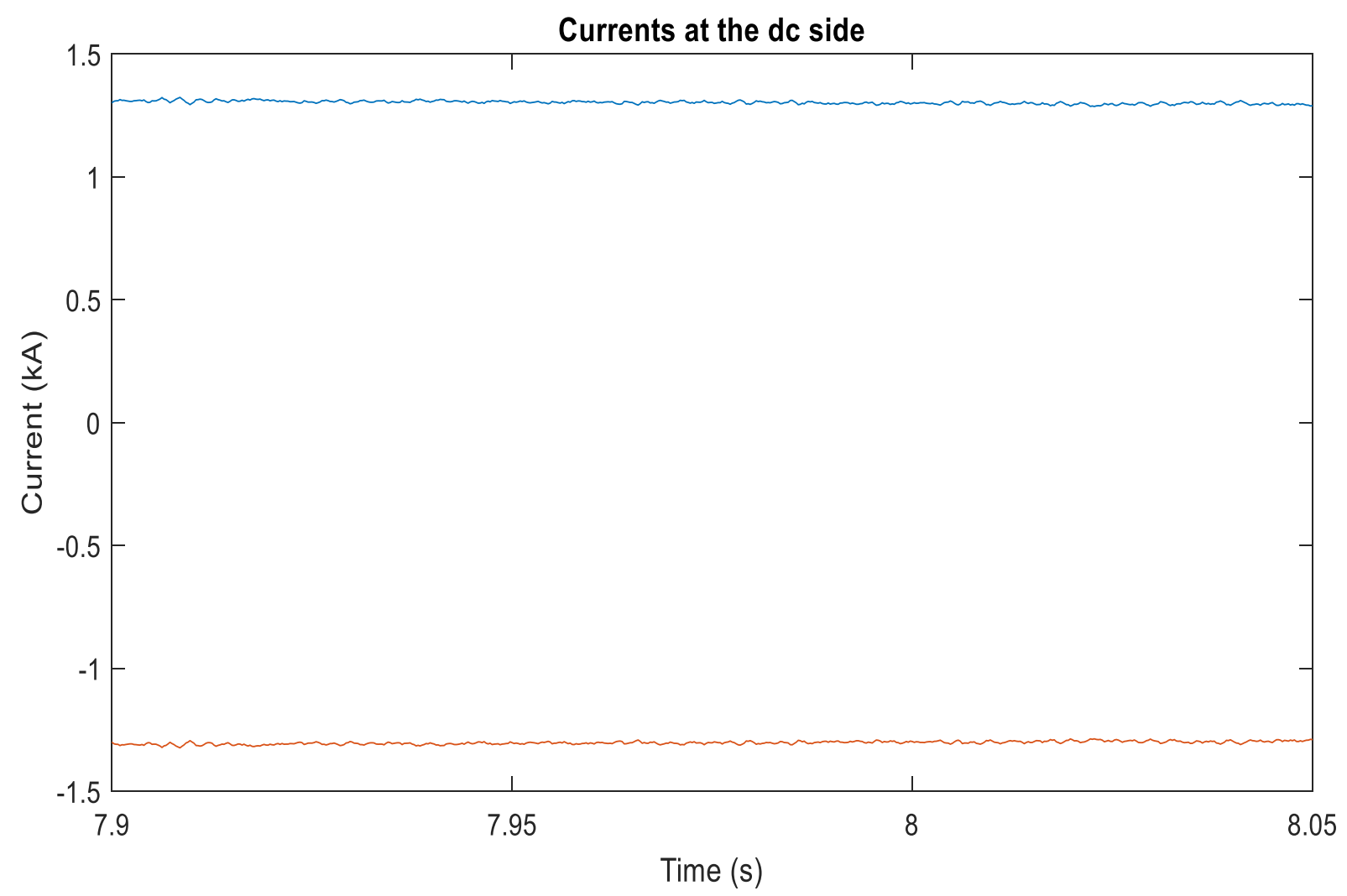

(b) Currents at the dc side.

Figure 60. Voltage and currents at the dc side. 
Voltages at the $66-\mathrm{kV}$ busbars are presented next.

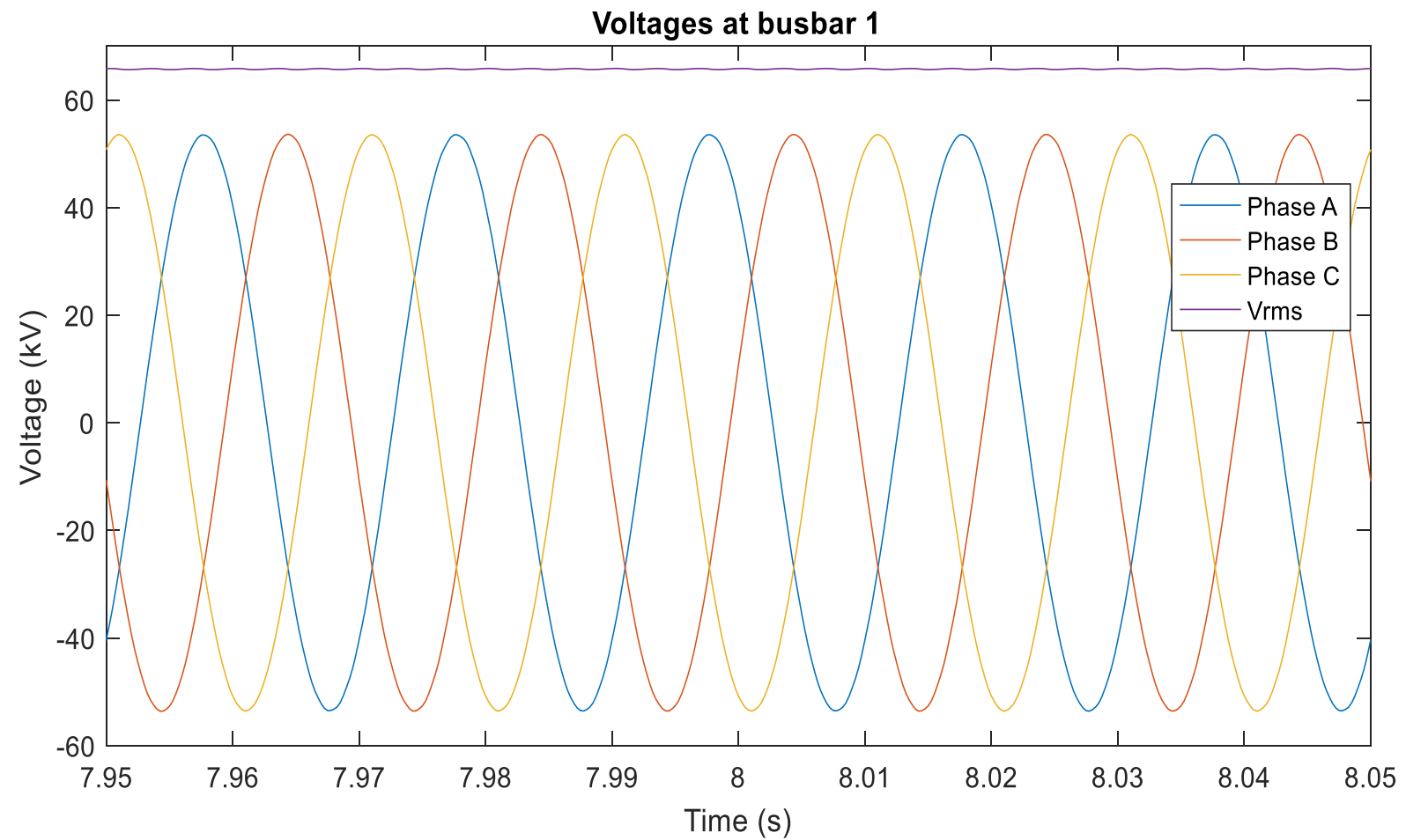

(a) Voltages at busbar 1.

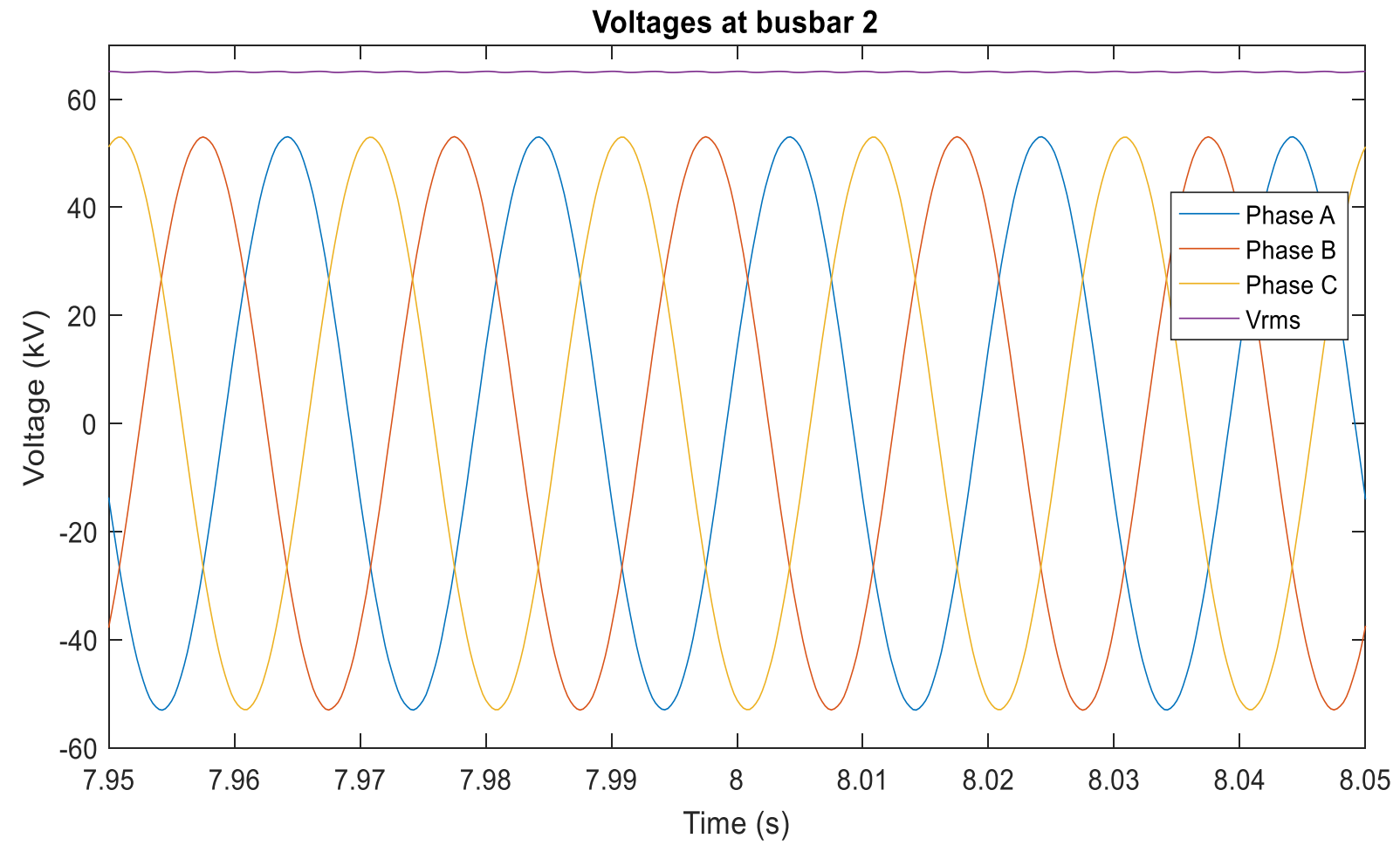

(b) Voltages at busbar 2. 


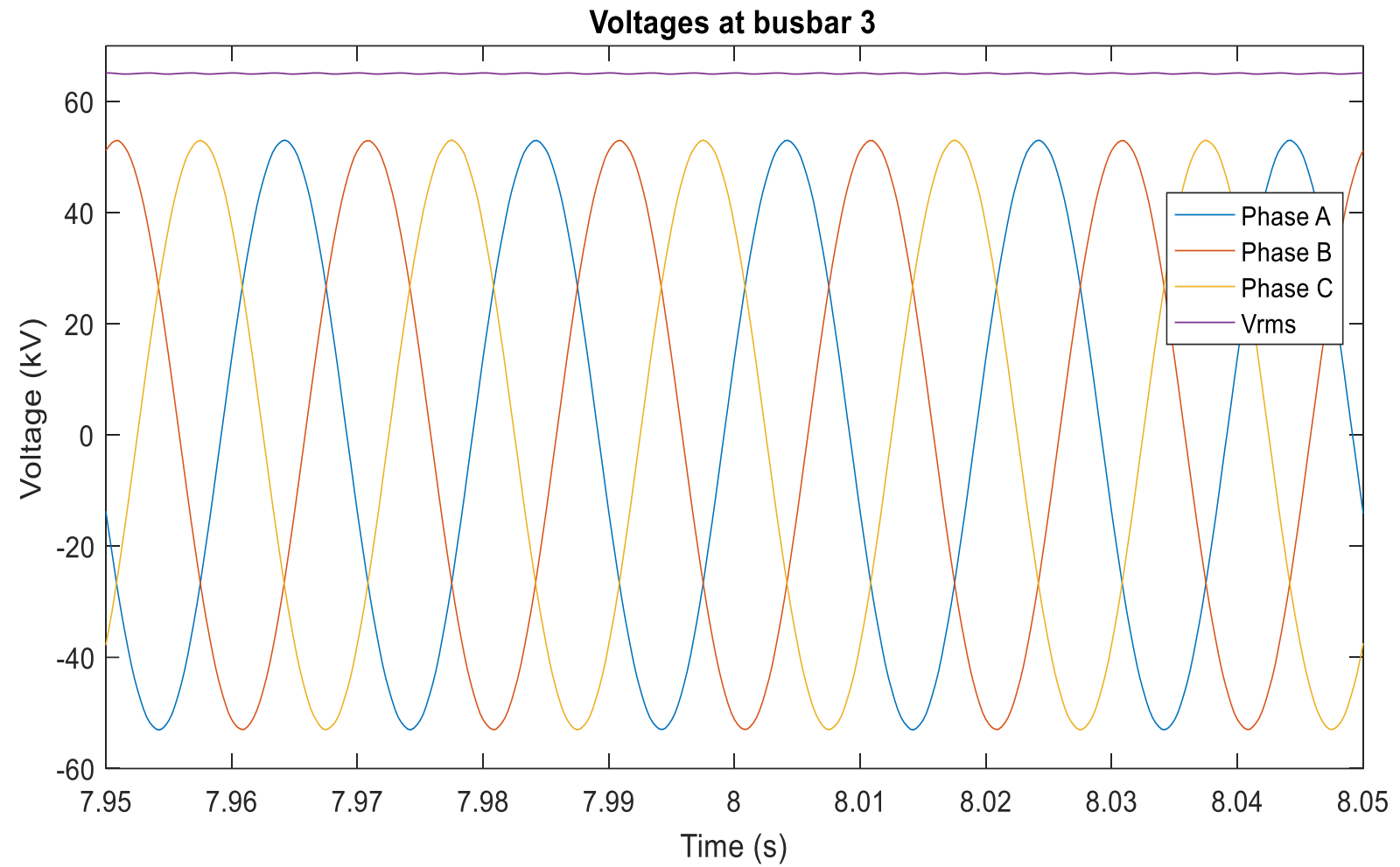

(c) Voltages at busbar 3

Figure 61. Voltages at the $66-\mathrm{kV}$ busbars.

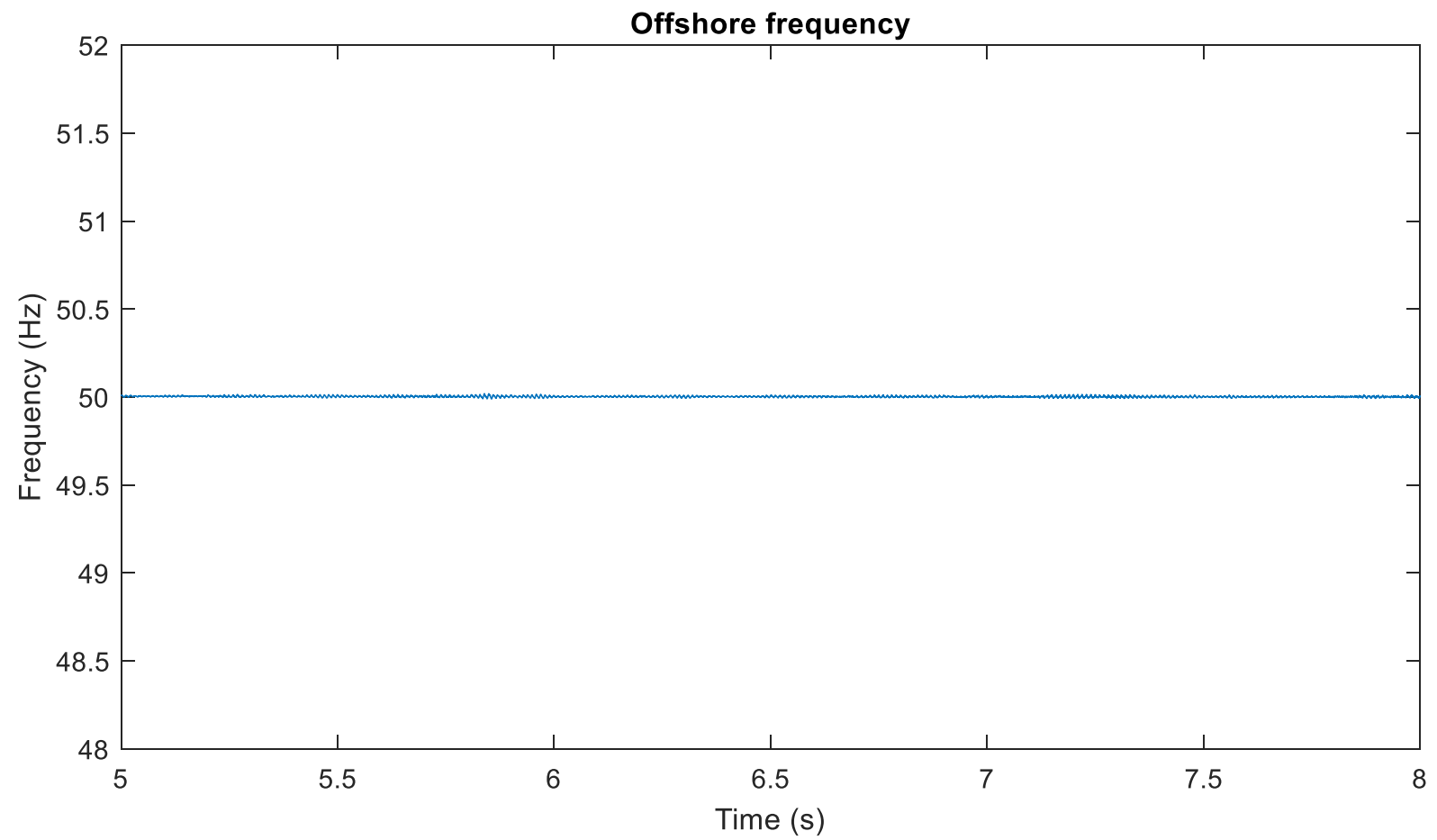

Figure 62. Offshore frequency.

After the shutdown of the OWF 1, the system is stable. All the power production from the OWFs 2 and 3 is being captured by the HVDC link and the voltages at the busbars at $66 \mathrm{kV}$ are within the accepted values. No abnormal conditions were detected at the ac or dc sides. Controls in the HVDC link could keep the dc voltage at its nominal value after the reduction of the supply of the active power. The offshore MMC terminal could also keep the voltage at $66 \mathrm{kV}$ for the busbar of the leader transformer associated to the OWF 1 after the perturbation. 
The second perturbation in the grid is a sudden large disconnection, in this case the circuit breaker of OWF 2 trips and the dynamic performance of the grid is obtained. The three wind parks are operating at nominal wind speeds. All other conditions are the same as in the previous case. After six seconds the event is applied to the network. The following figures present the behaviour of the system.

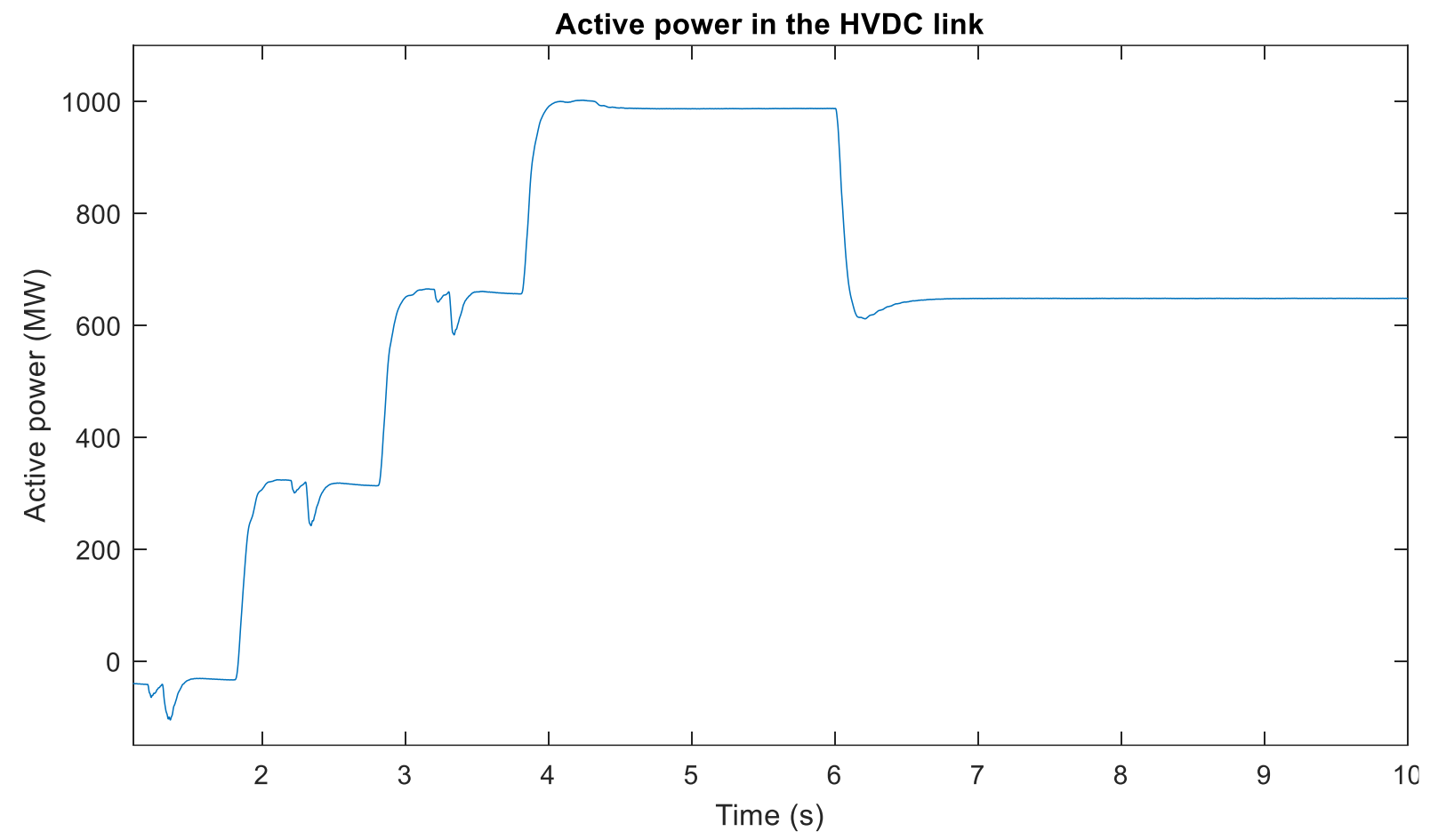

Figure 63. Active power through the HVDC link - disconnection of OWF 2.

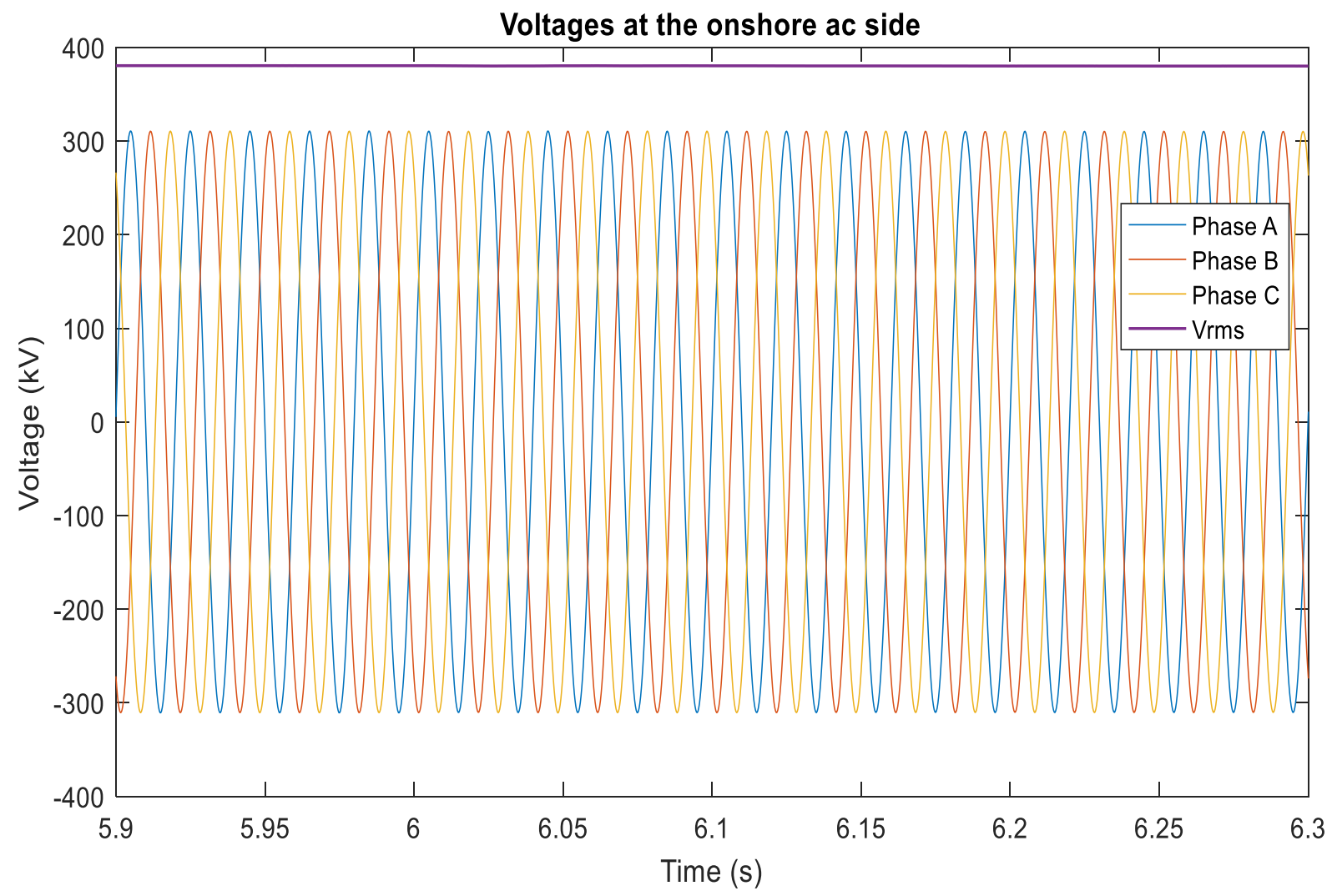

(a) Voltages at the onshore ac side. 


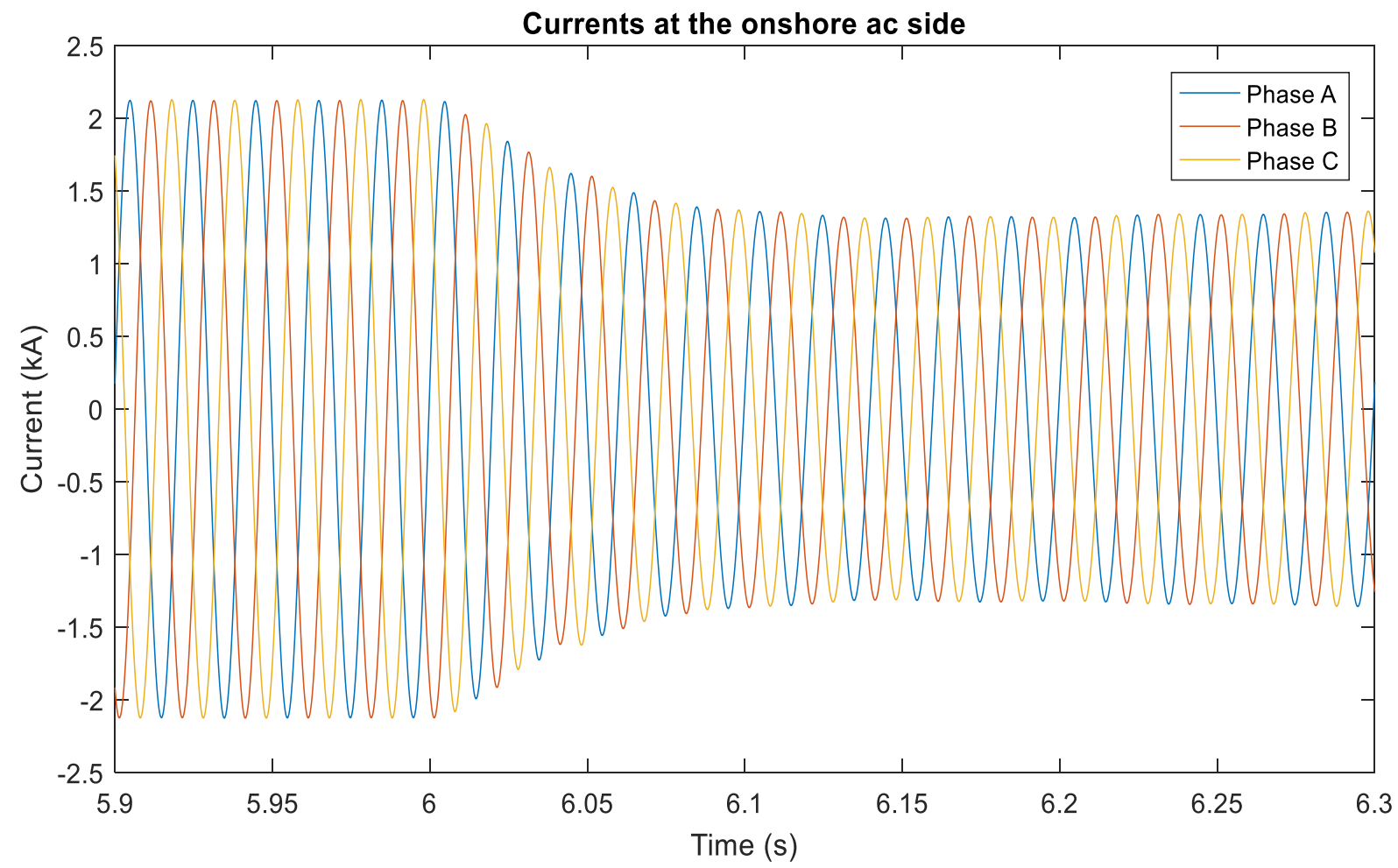

(b) Currents at the onshore ac side.

Figure 64. Voltages and currents at the onshore ac side.

The ac voltage at the 380-kV side is not affected, see Figure 64 (a). The Vdc is affected with a dip because there is a sudden trip and the power flowing into the HVDC link is reduced abruptly. The frequency of the offshore ac grid is perturbated by the disturbance, generation is lost. The dc voltage and currents at the dc side decreased, temporarily and permanently respectively as it is illustrated in Figure 65.

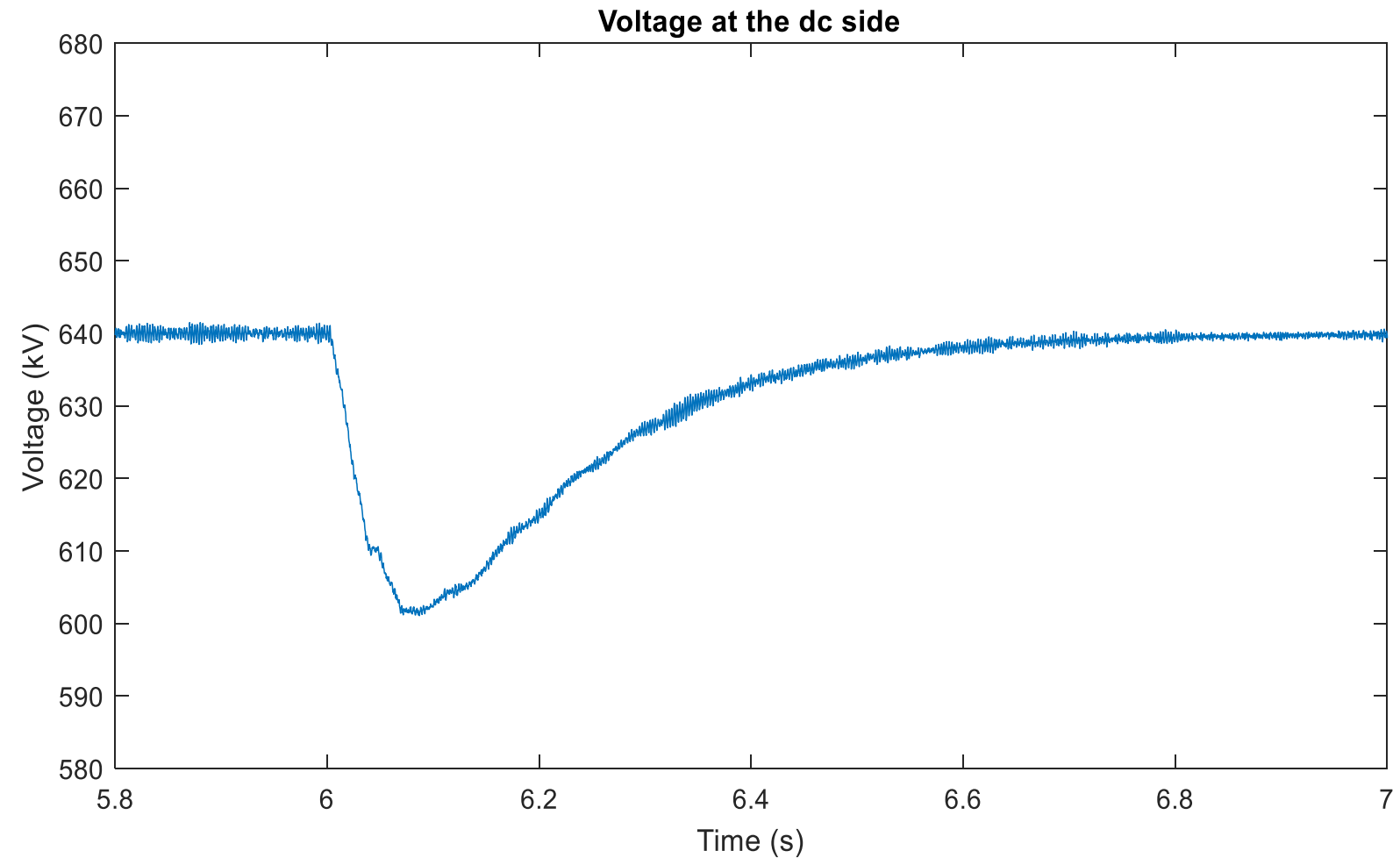

(a) Voltage at the dc side. 


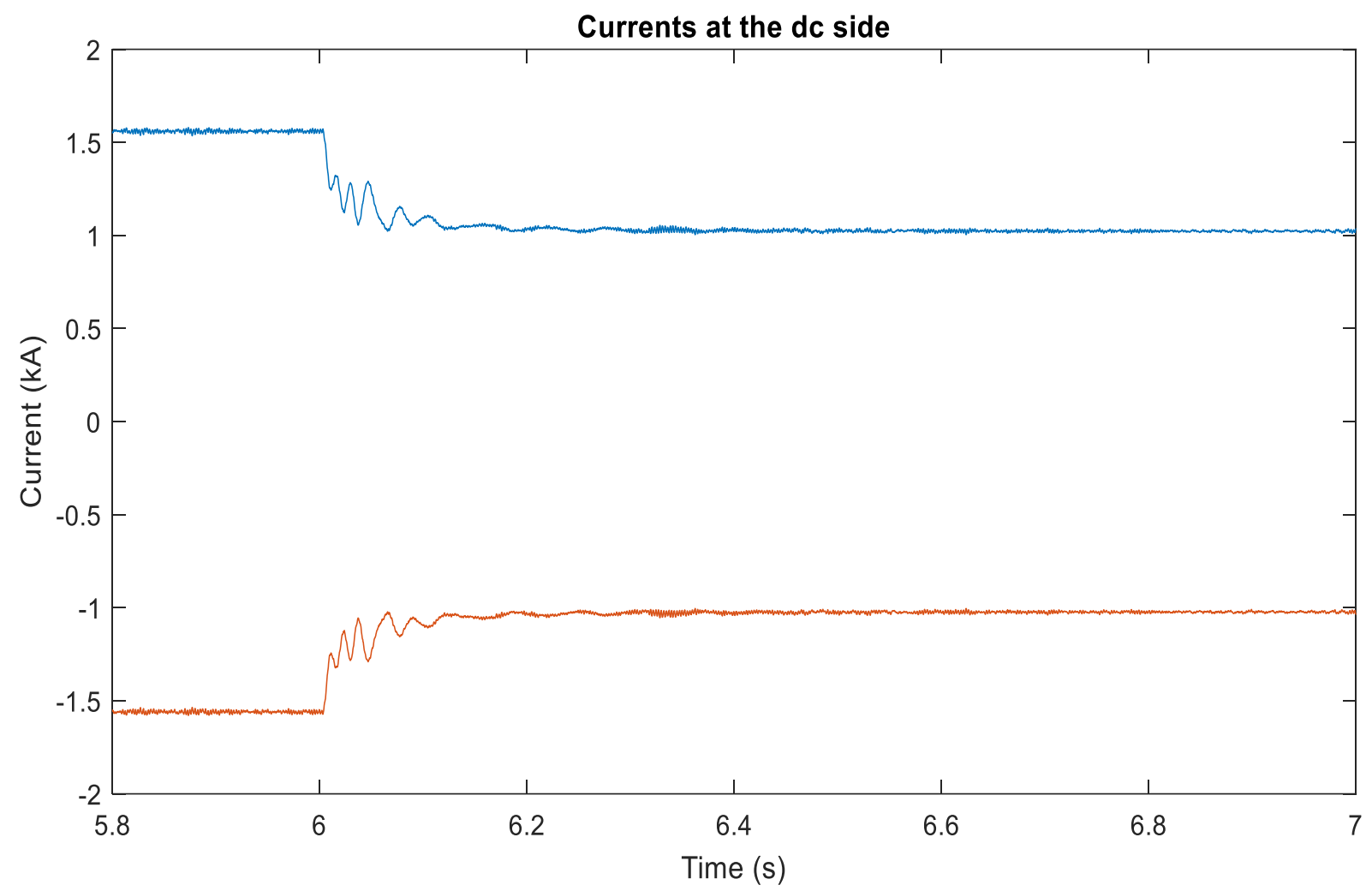

(b) Currents at the dc side.

Figure 65. Voltage and currents at the dc side.

The voltages at the 66-kV busbars are shown in Figure 66. The circuit radially connected to the busbar 2 associated to the OWF 2 is in no load condition after the trip of the circuit breaker. Minimum disturbances occur for busbars 1 and 3.

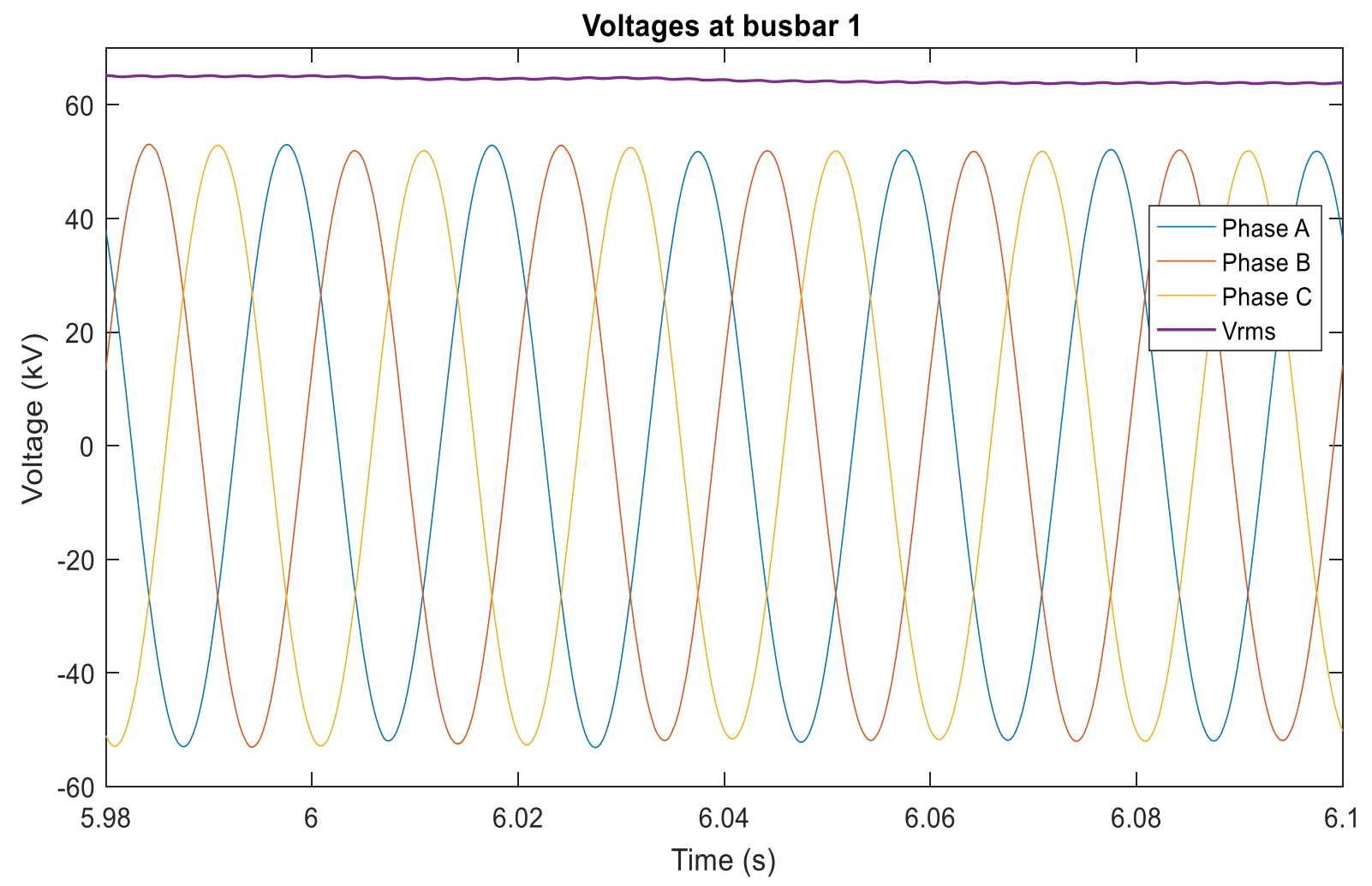

(a) Voltages at busbar 1. 


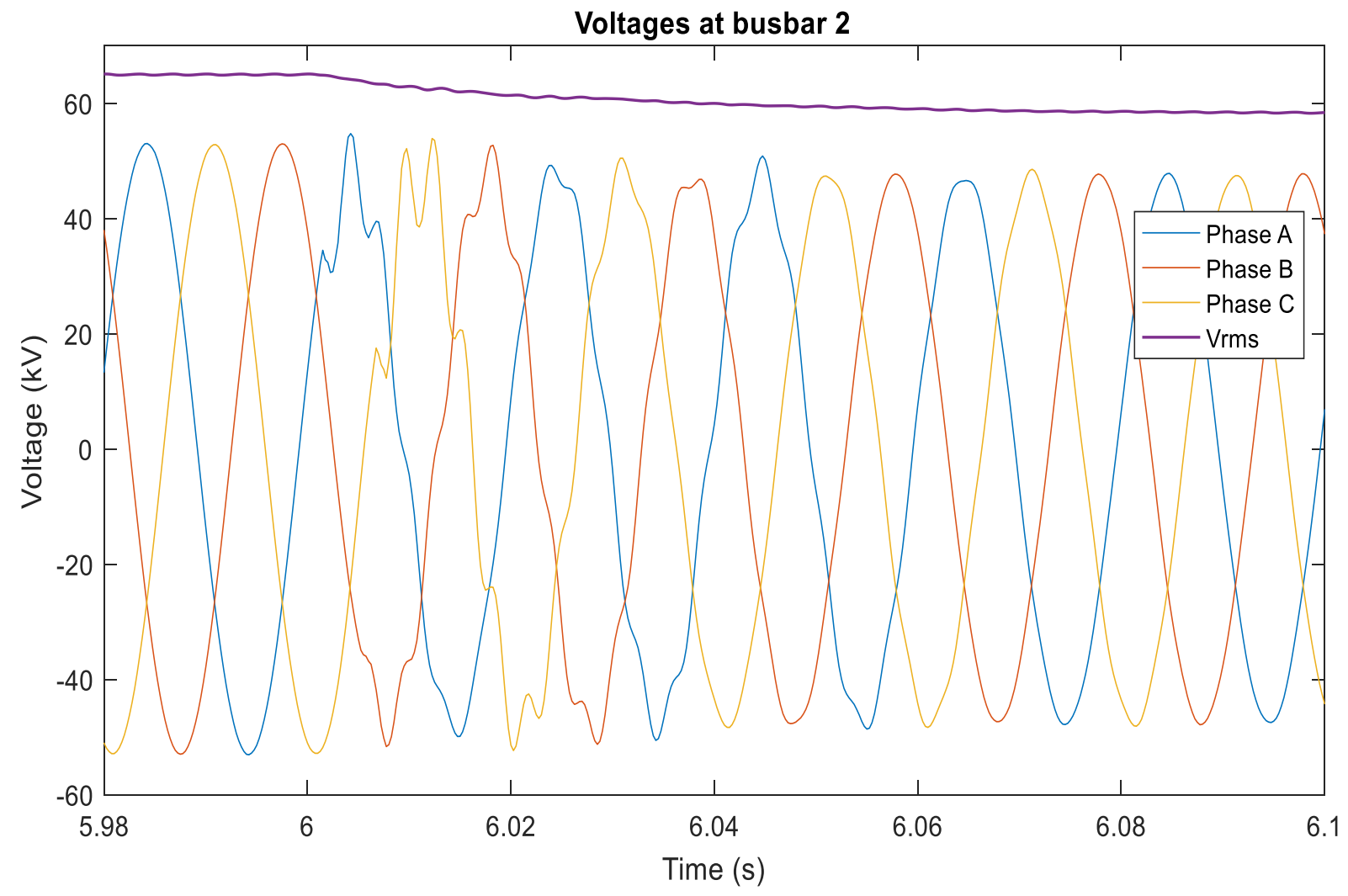

(b) Voltages at busbar 2 .

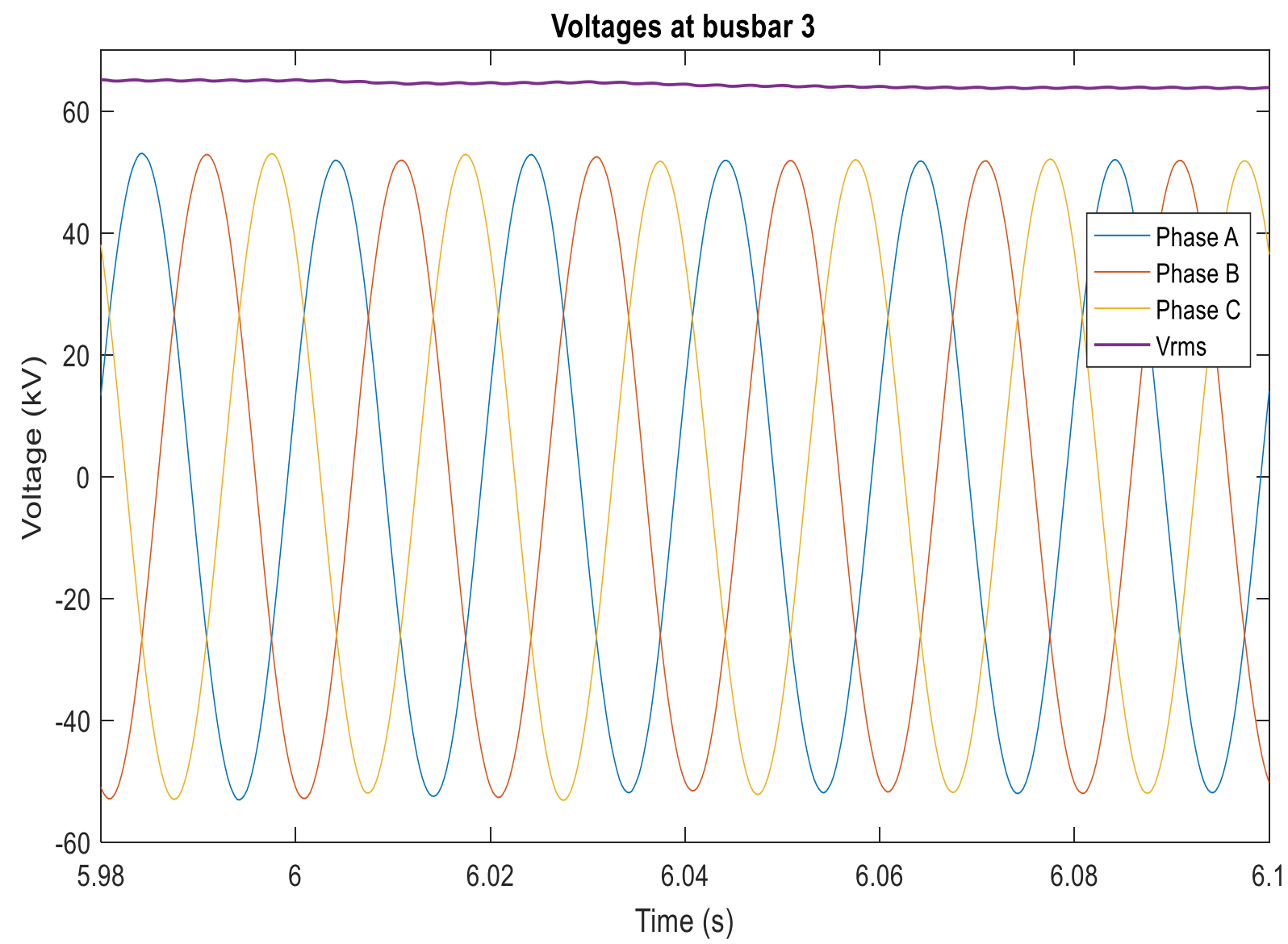

(c) Voltages at busbar 3.

Figure 66. Voltages at the 66-kV busbars. 


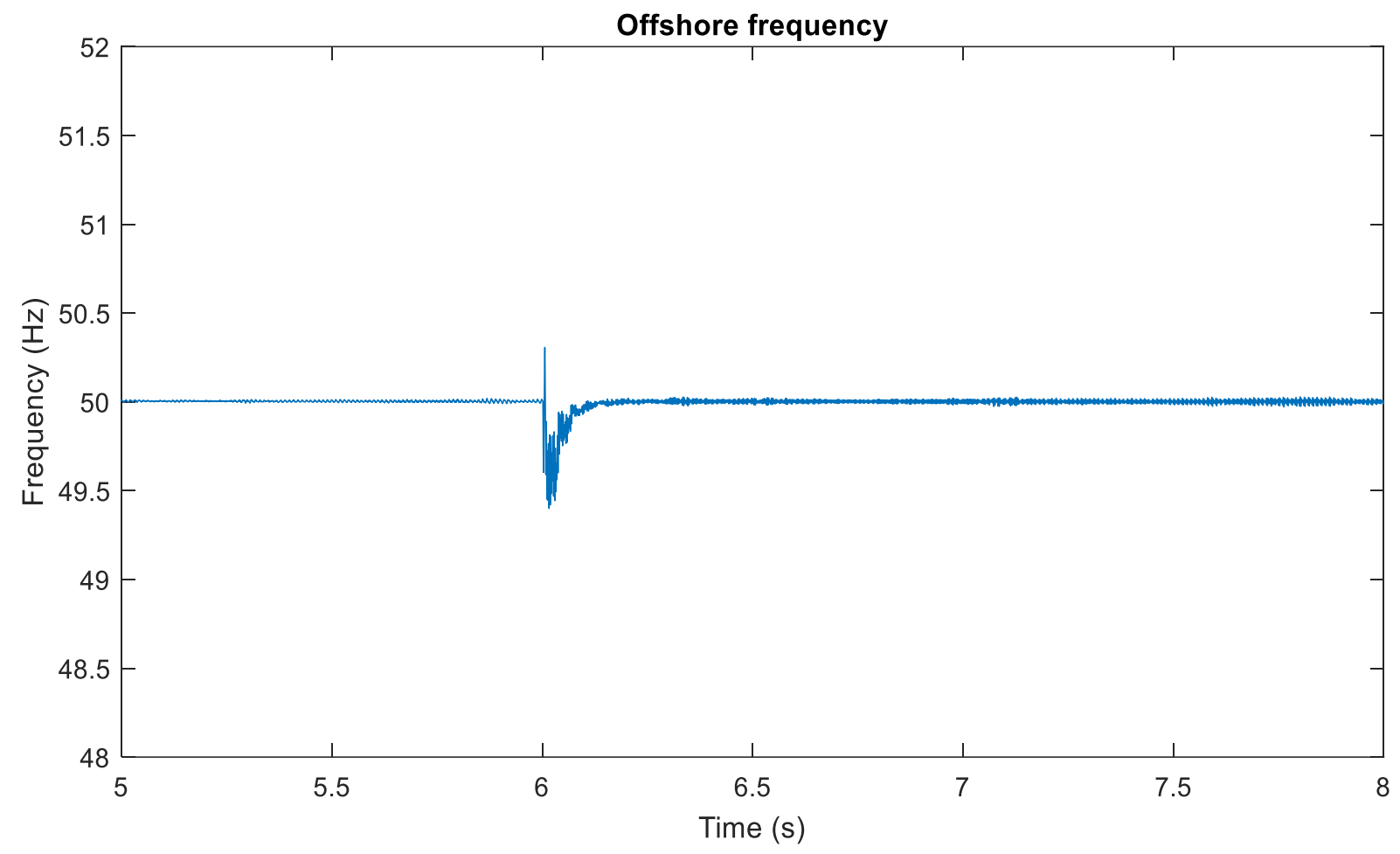

Figure 67. Offshore frequency.

These first two cases where the disturbances are not product of a fault in the power system can represent several other cases where disconnections planned or unplanned happen in the grid. For the second scenario, the unplanned trip of the circuit breaker of OWF 2 could be associated to problems with the secondary circuits of protection devices and control schemes, malfunction of some equipment or even a human error.

After this event, the system reached a new equilibrium point and values of all the variables monitored were normal. The controls operated correctly. The voltages of the busbars at $66 \mathrm{kV}$ remained within the expected range.

Using a fault logic in PSCAD, the third disturbance to be analysed is a single phase-to-ground fault applied on phase A of the submarine cable of the OWF 3 at the end of the cable near to the cluster of turbines at $66 \mathrm{kV}$, as indicated in Figure 68. The fault is present in the system for $150 \mathrm{~ms}$ and occurs after five seconds. The other conditions are kept as in the second event.

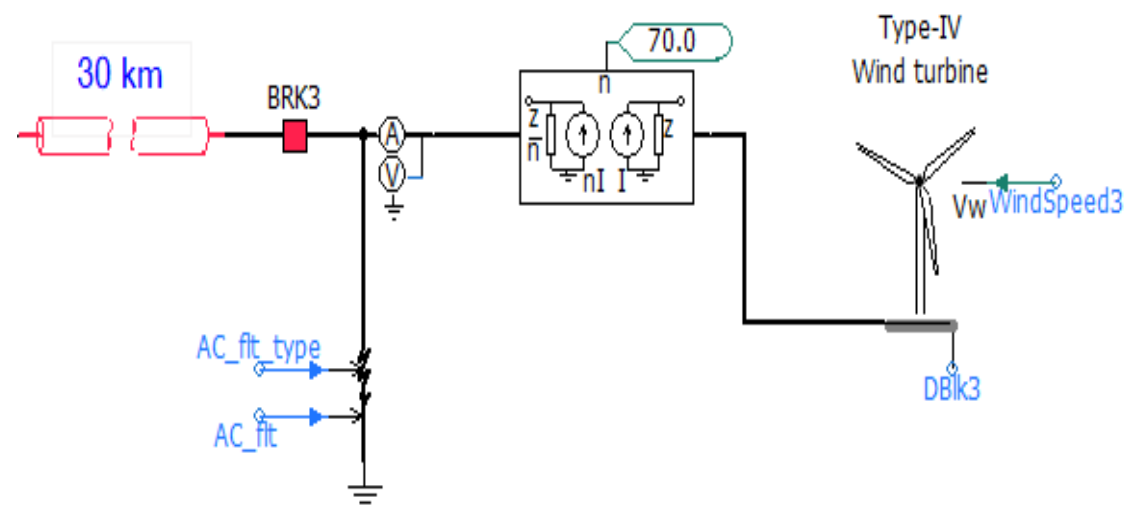

Figure 68. Phase-to-ground fault at the offshore ac grid. 
The system performance is shown in the next figures.

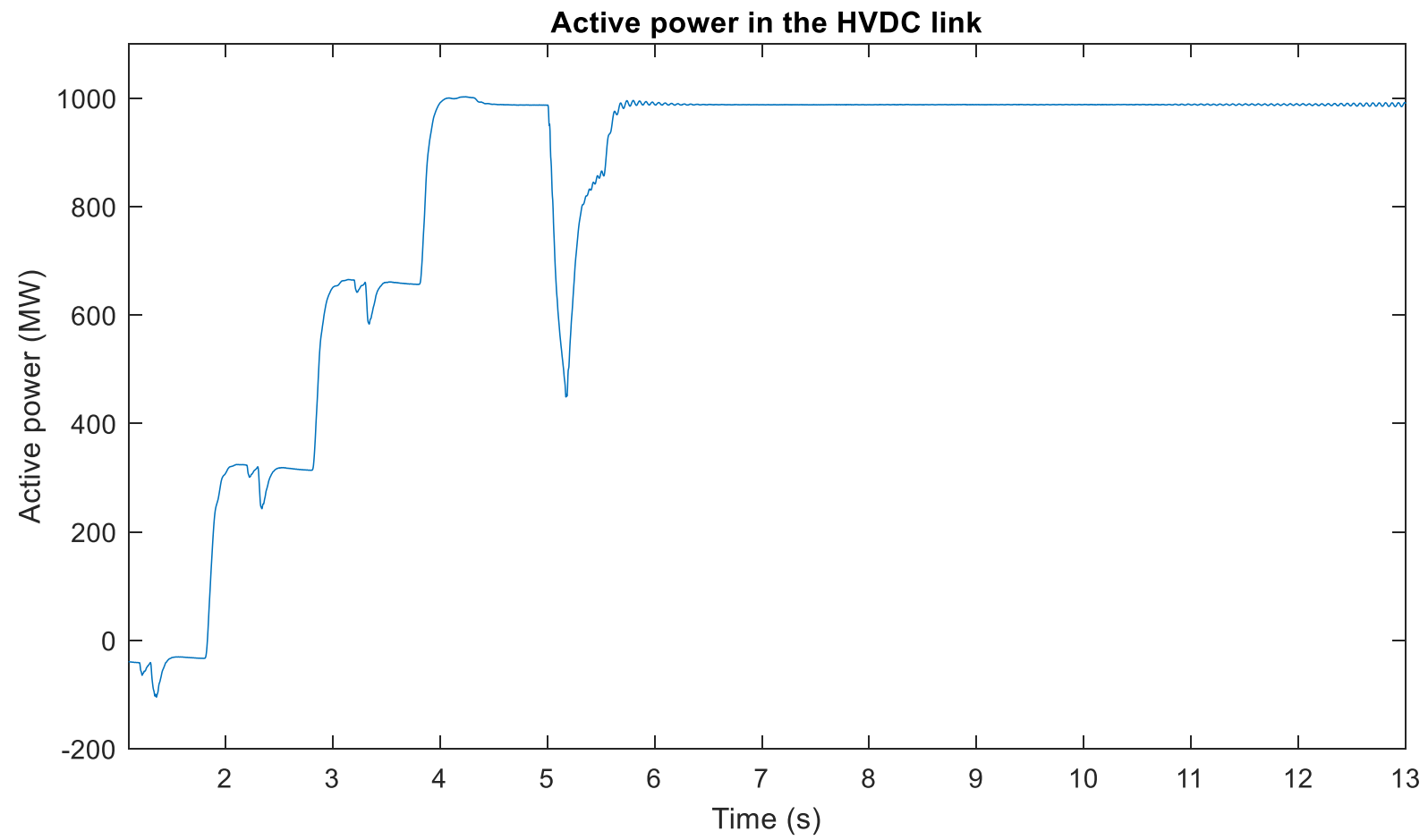

Figure 69. Power generation reduction due to the fault.

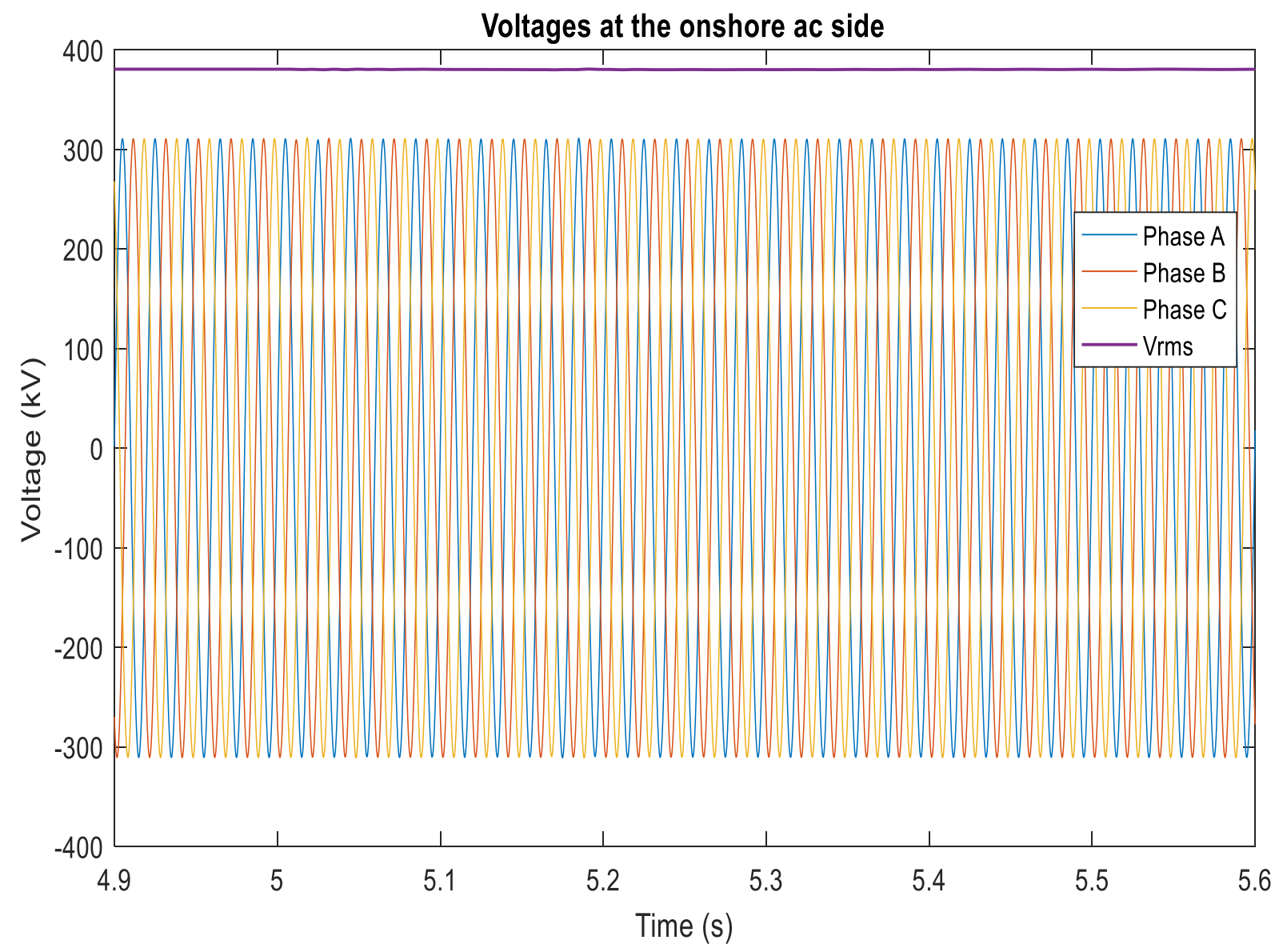

(a) Voltages at the onshore ac side. 


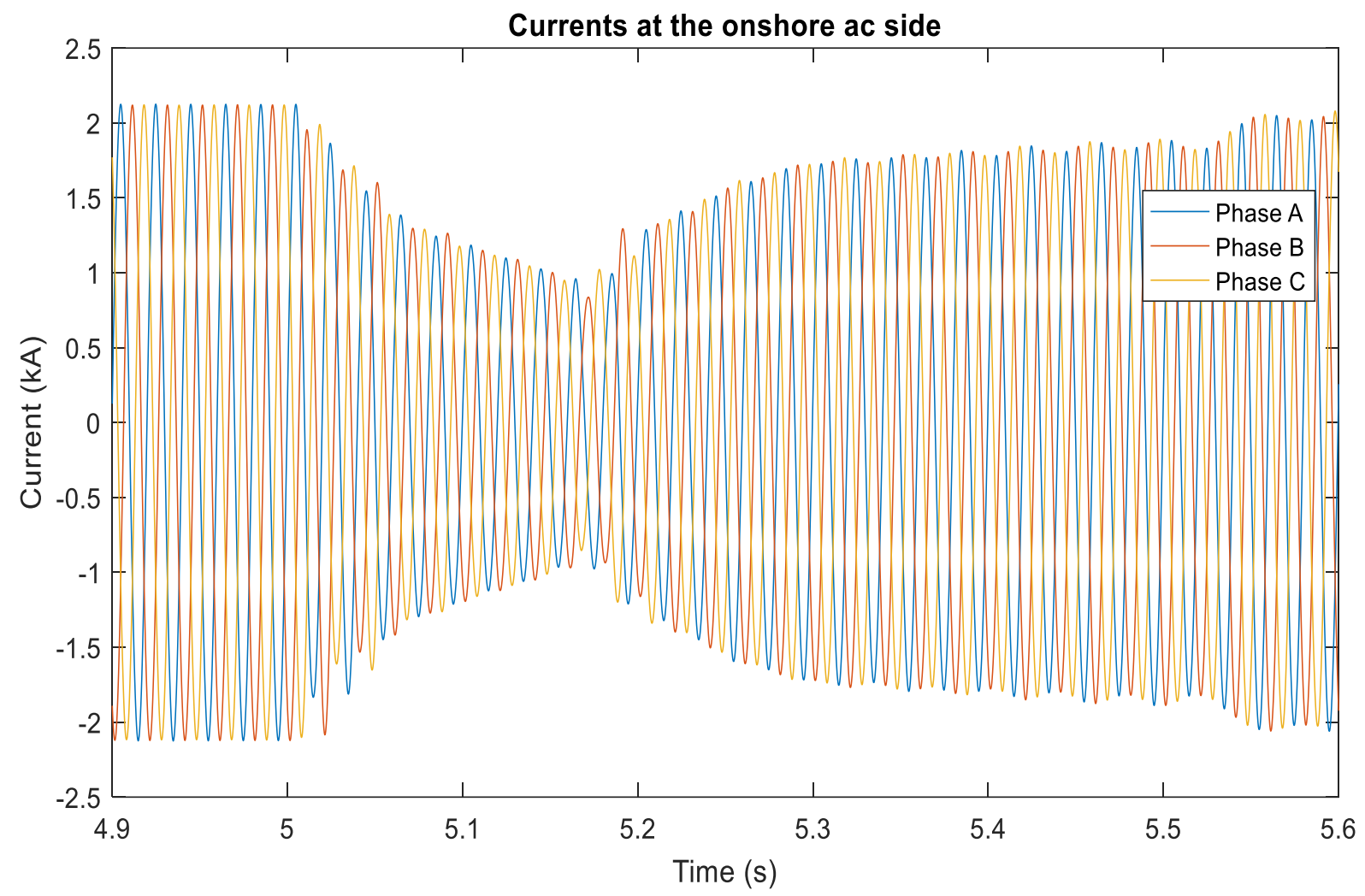

(b) Currents at the onshore ac side.

Figure 70 . Onshore ac voltages and currents.

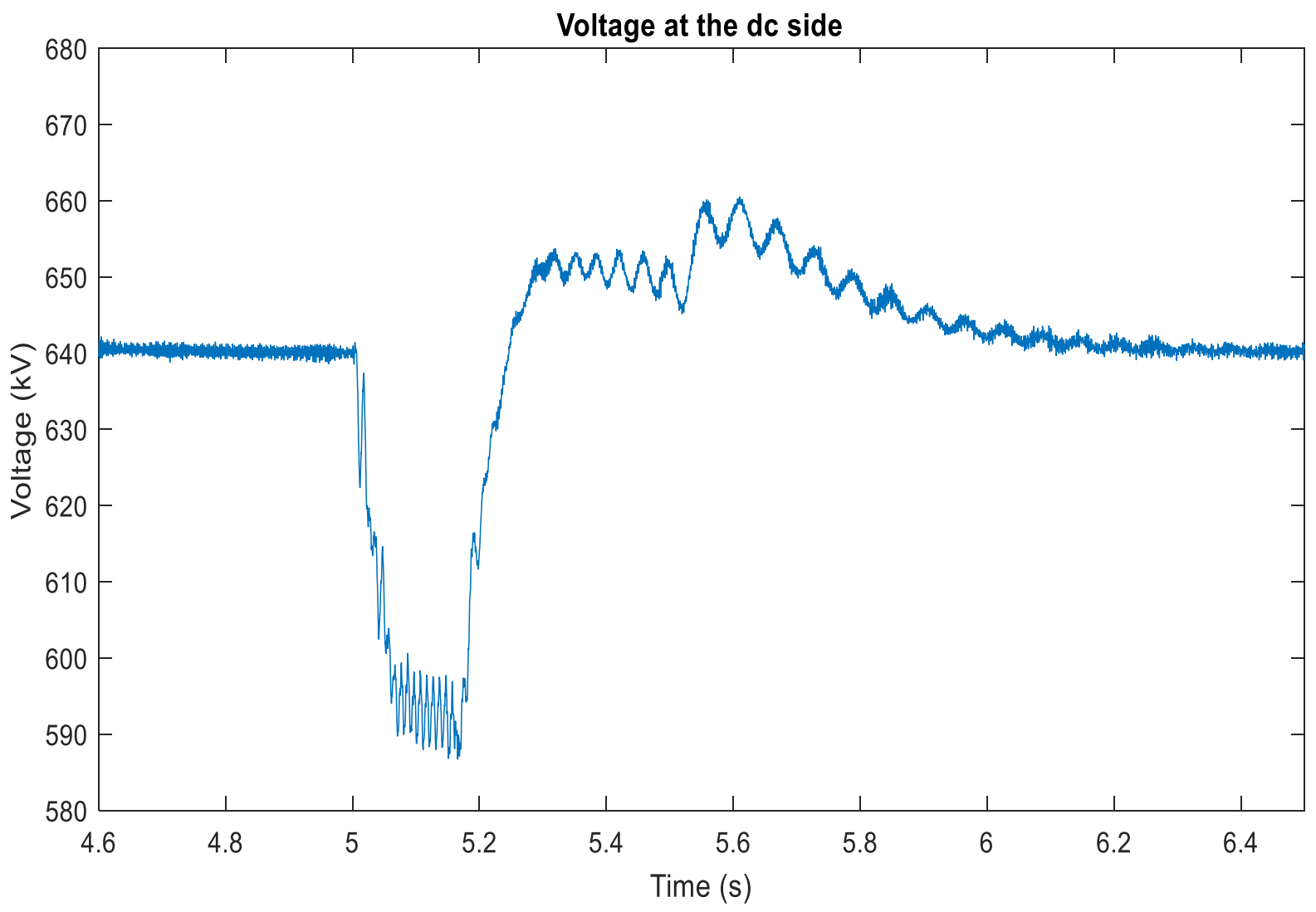

(a) Voltage at the dc side. 


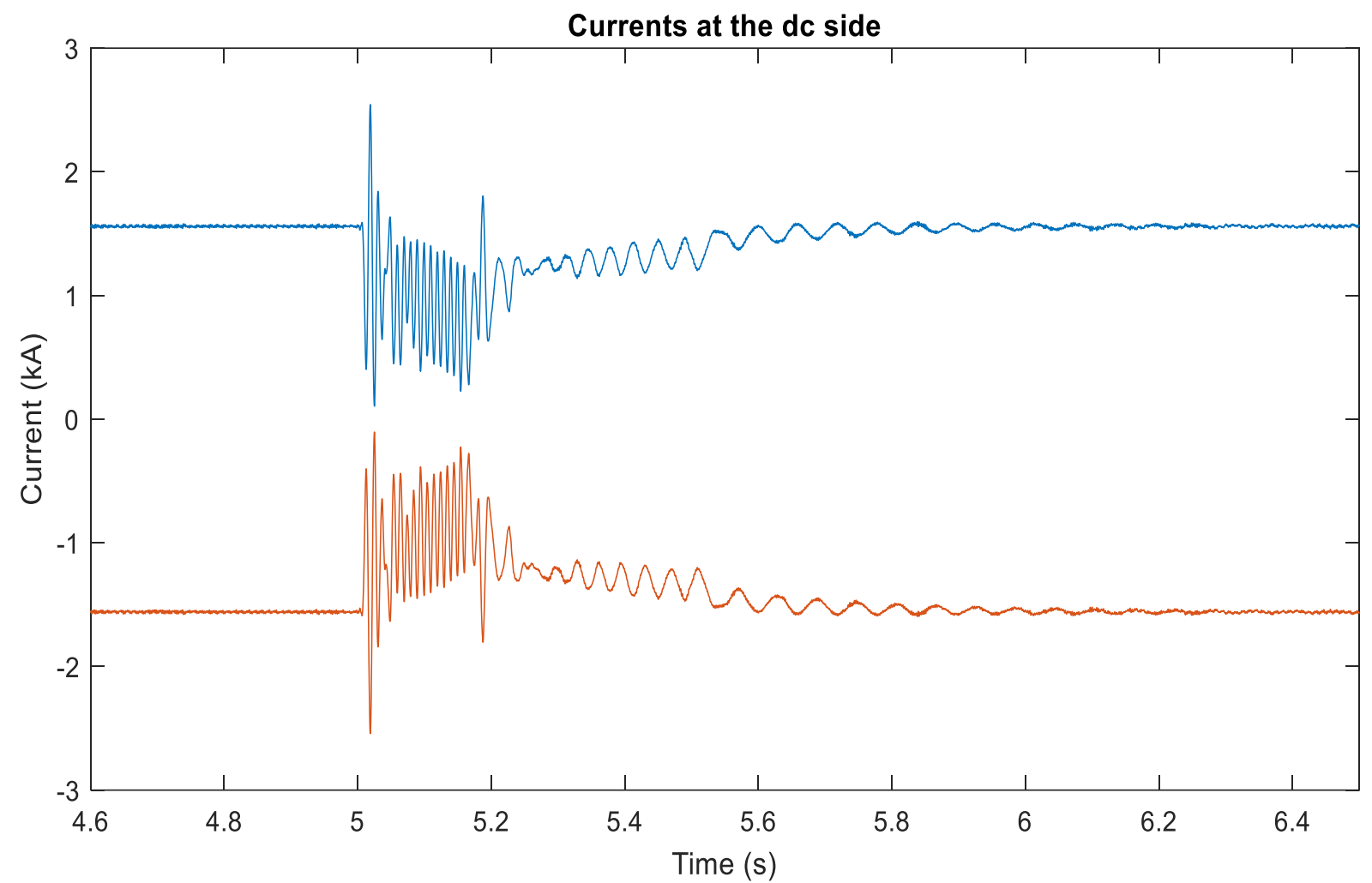

(b) Currents at the dc side.

Figure 71 . Voltage and currents at the dc side.

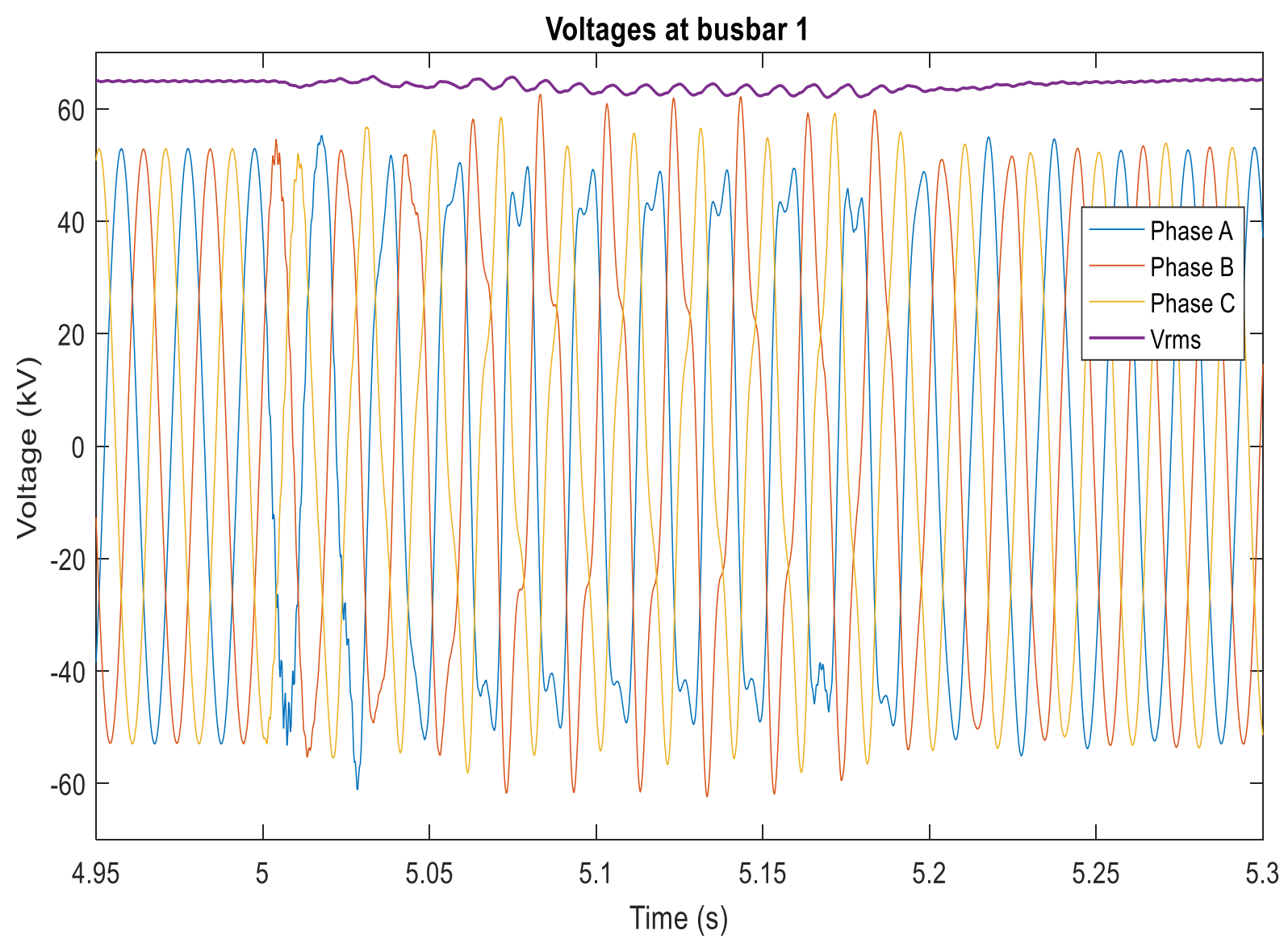

(a) Voltages at busbar 1. 


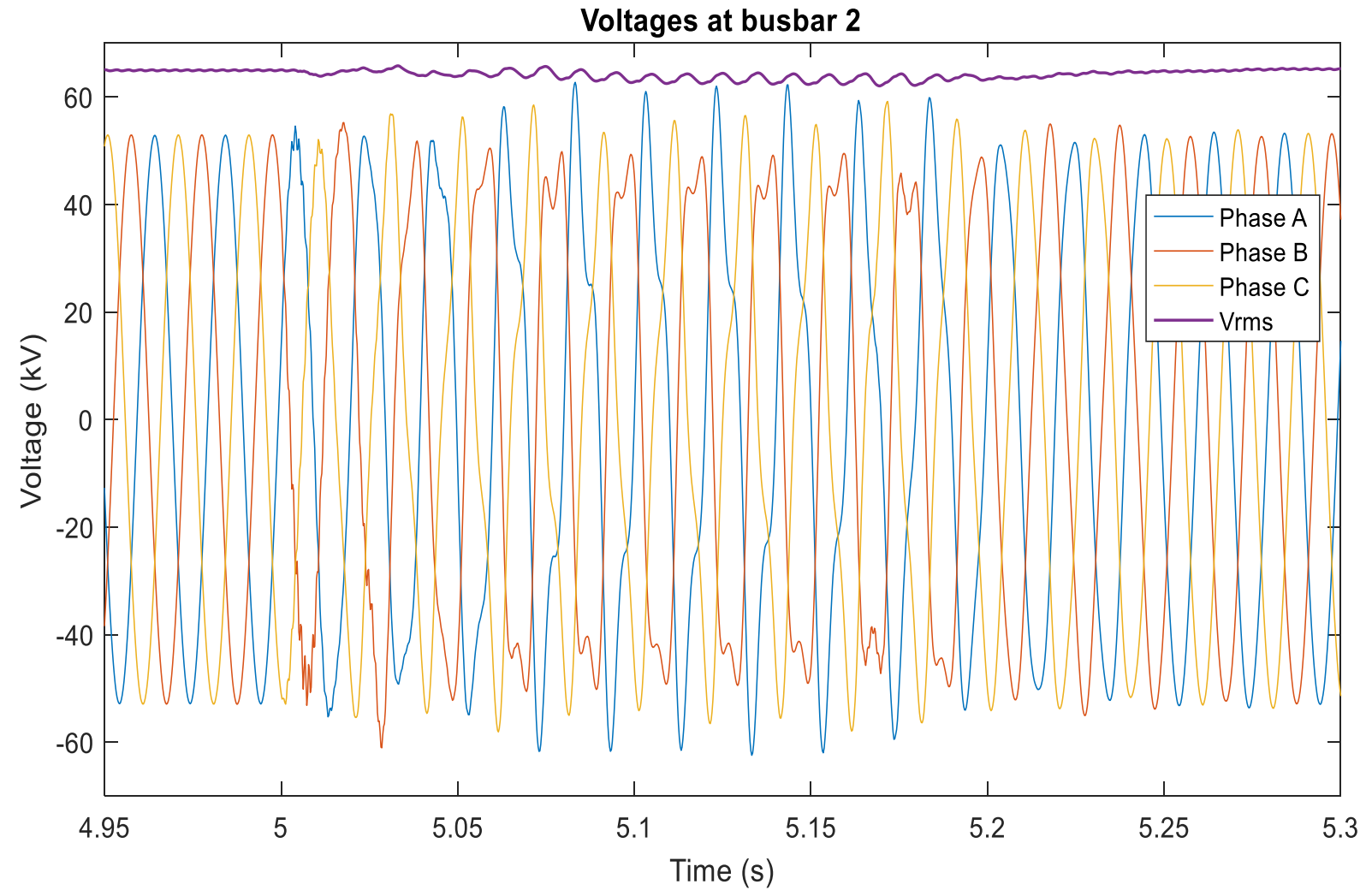

(b) Voltages at busbar 2.

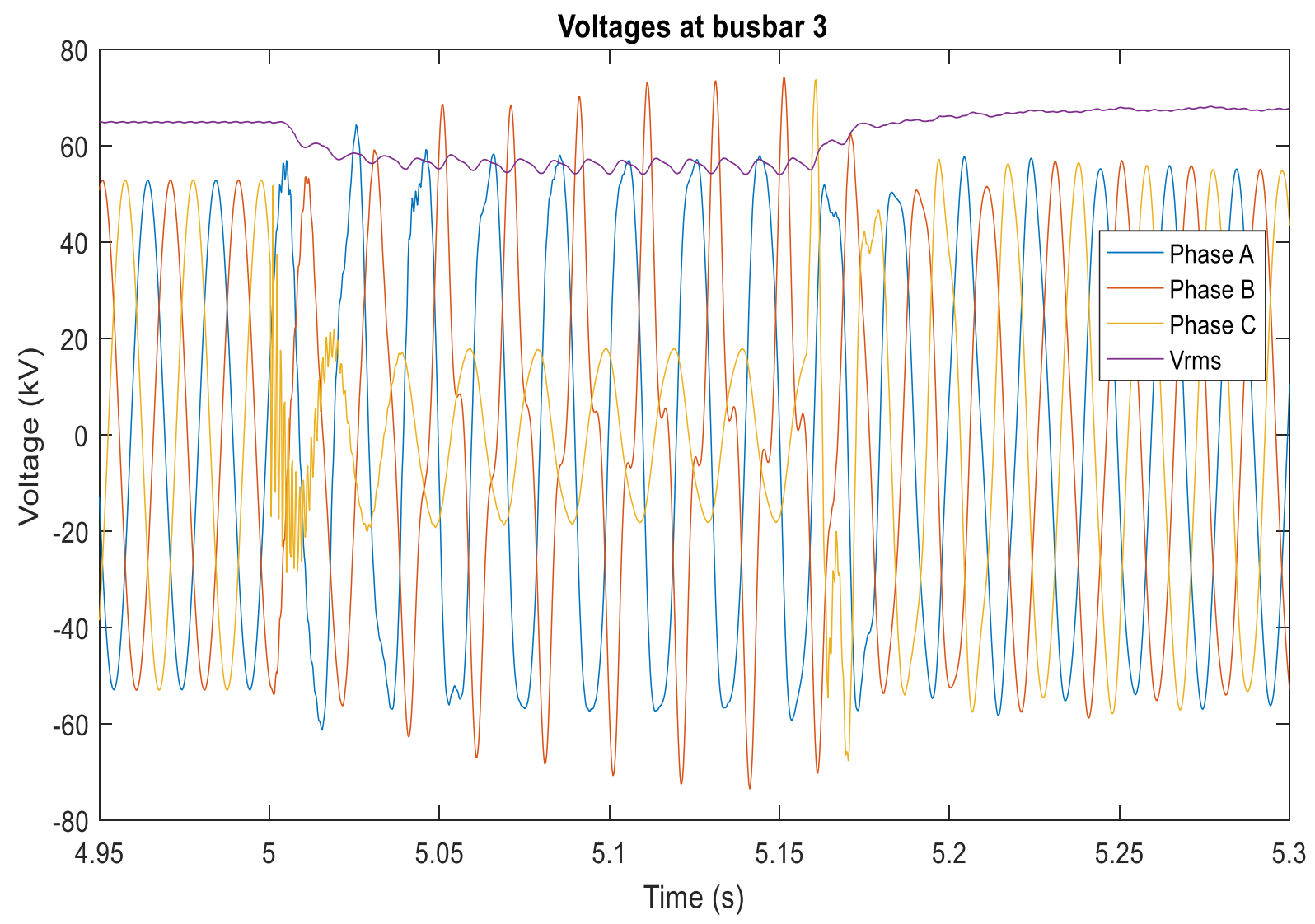

(c) Voltages at busbar 3 .

Figure 72. Voltages at the $66-k V$ busbars. 


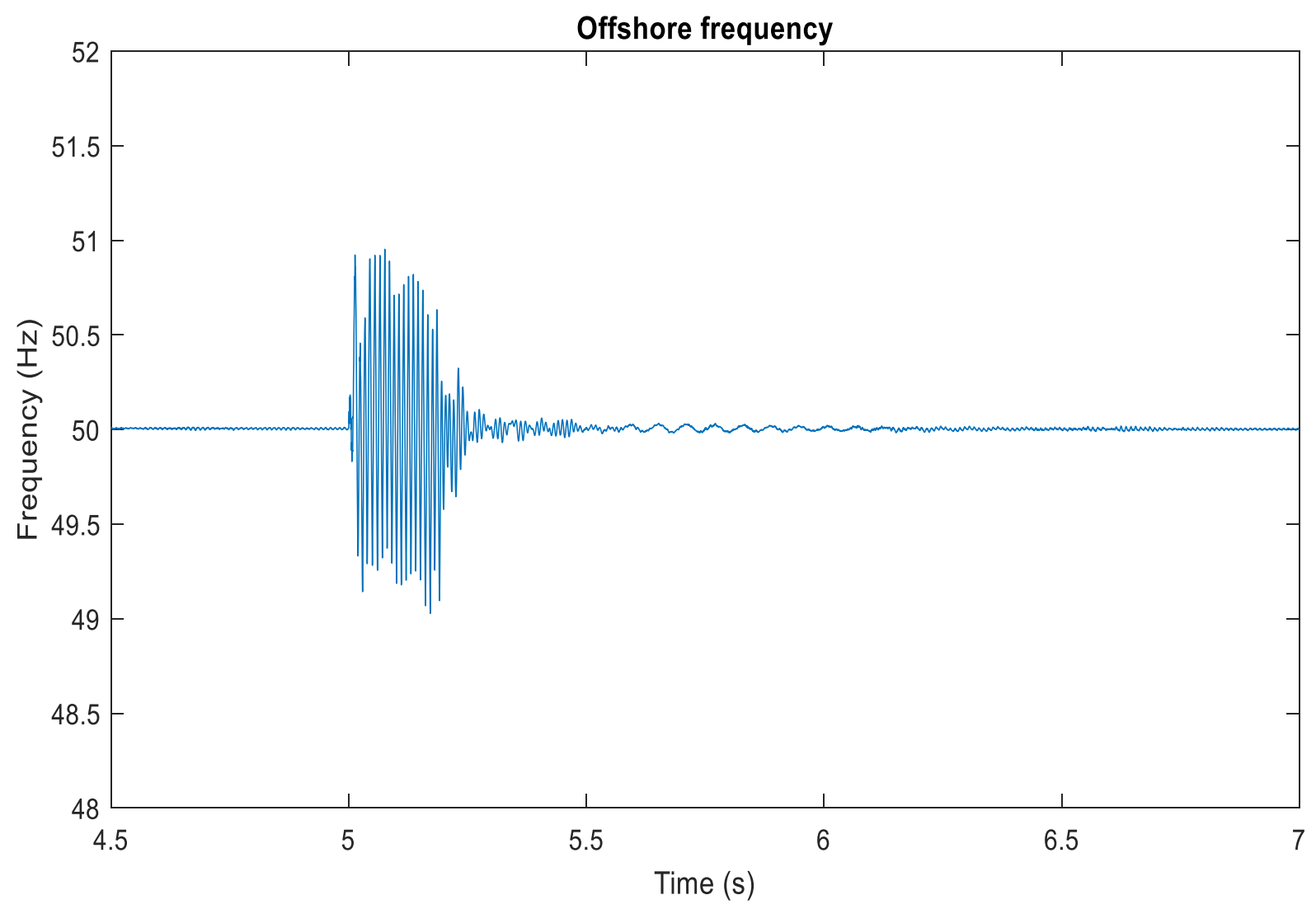

Figure 73. Offshore frequency.

It can be seen from the figures above that the dc system returns to the stable condition once the single phase-to-ground fault is removed. It is the same result for the offshore ac grid. No protection devices are modelled in the test network in PSCAD, so the fault is just automatically cleared after $150 \mathrm{~ms}$ as it were a self-extinguishing fault. The system could withstand the fault.

Transient overvoltages are noticeable in the sound phases at the busbar 3 rated at $66 \mathrm{kV}$. The behaviour of the voltages at the busbars 1 and 2 is very similar. These values of the overvoltages are to be considered for the insulation coordination study, the specification of the equipment and further studies of the grid.

Now a three-phase-to-ground fault is applied to the 66-kV side of the converter transformer associated to the OWF 2, see Figure 74, after eight seconds. Again, the fault has a duration of $150 \mathrm{~ms}$ and all other conditions are kept the same as in the previous fault simulations.

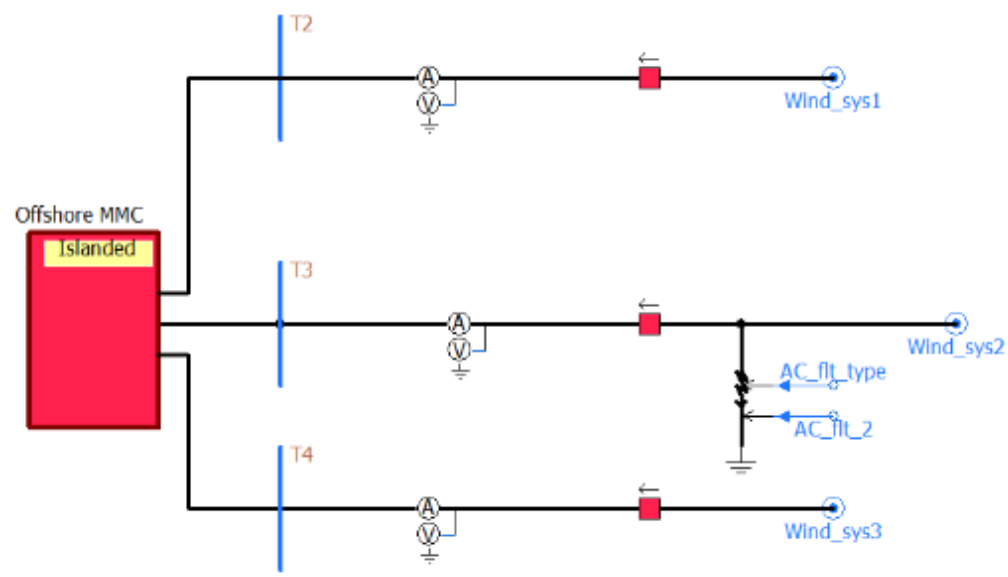

Figure 74. Three-phase-to-ground fault at the offshore ac grid. 
The results of the simulations are given in the following graphs.

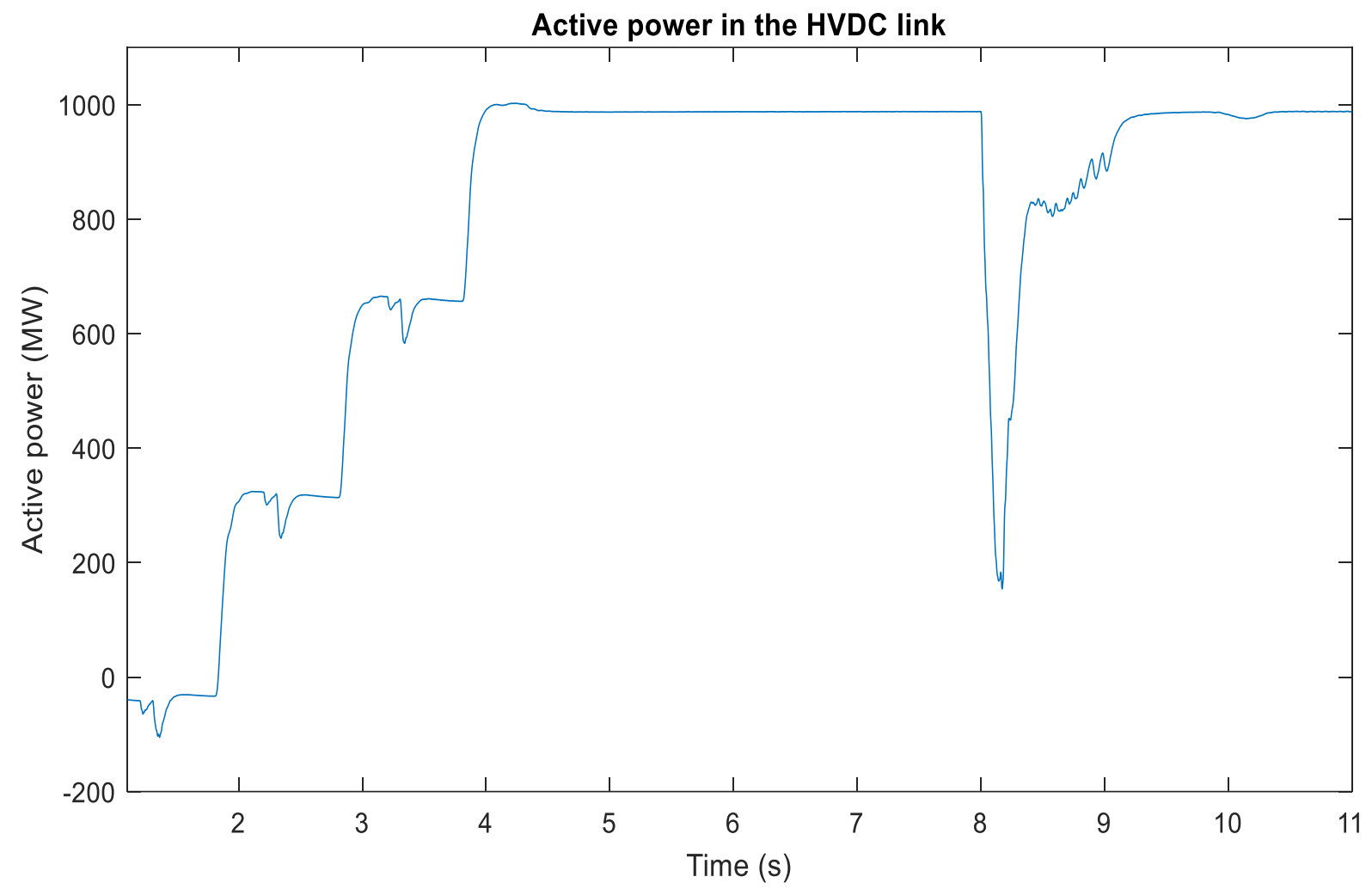

Figure 75. Reduction in the power generation due to the fault.

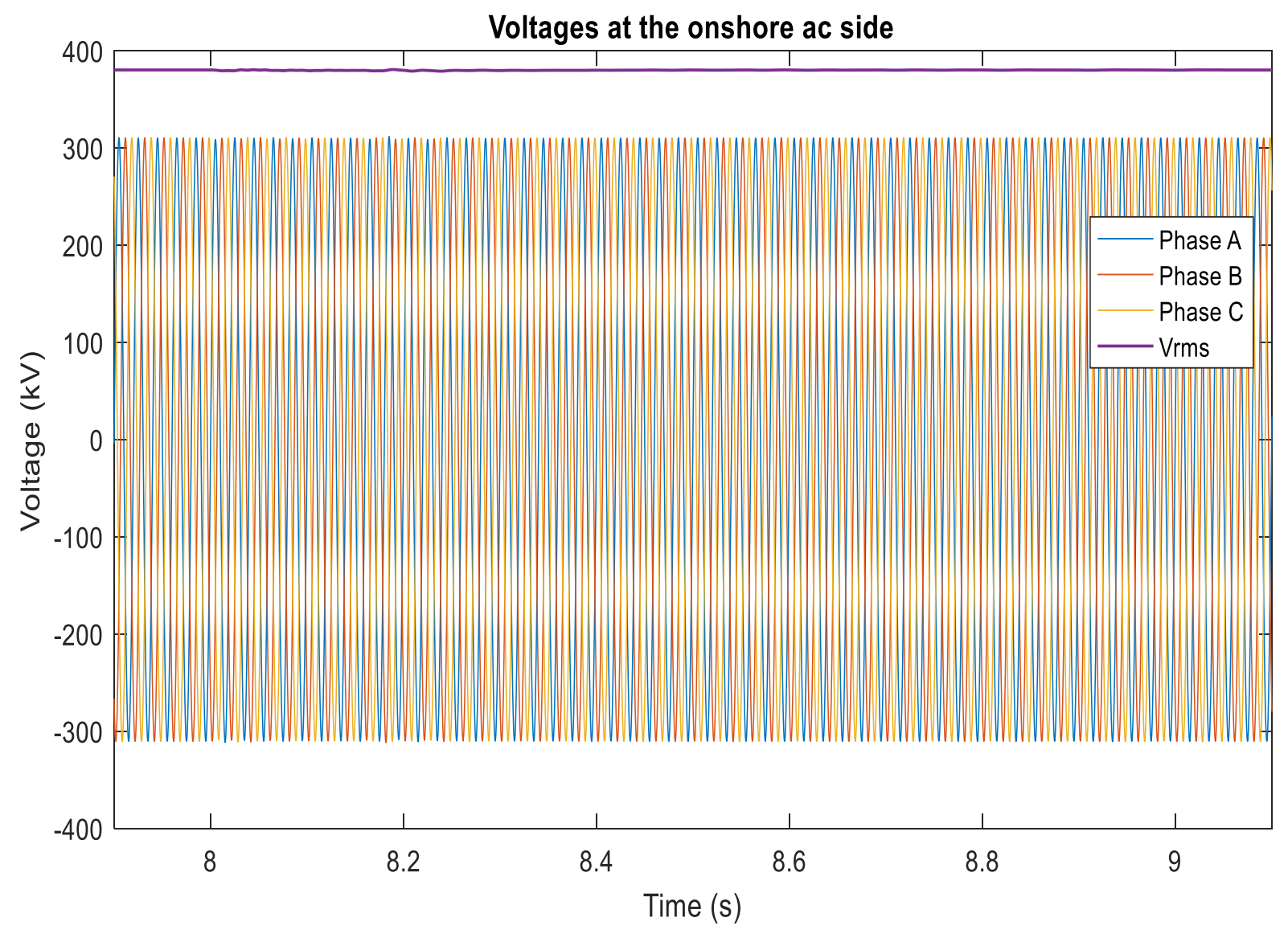

(a) Voltages at the onshore ac side. 


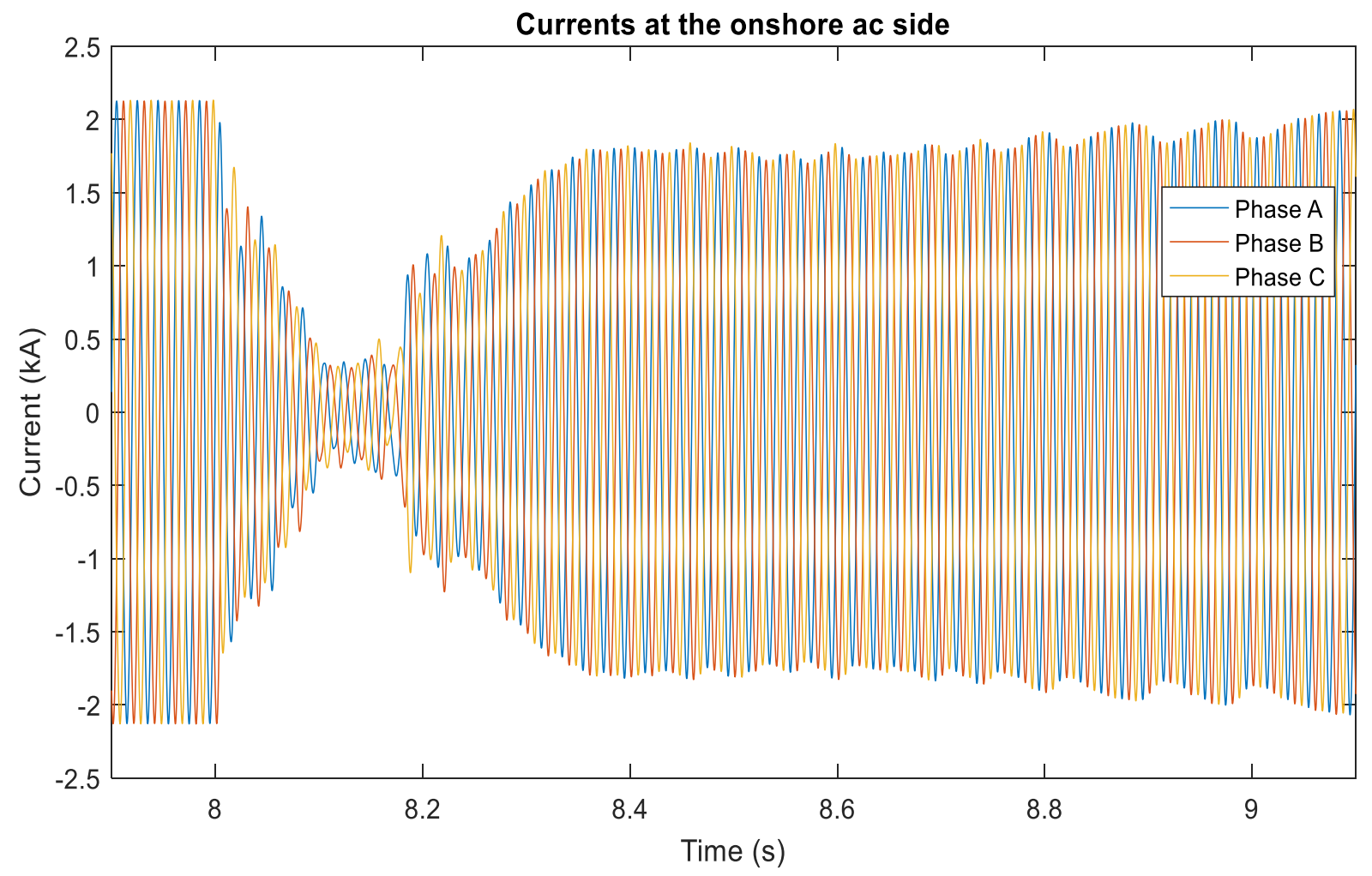

(b) Currents at the onshore ac side.

Figure 76. Voltages and currents at the onshore ac side.

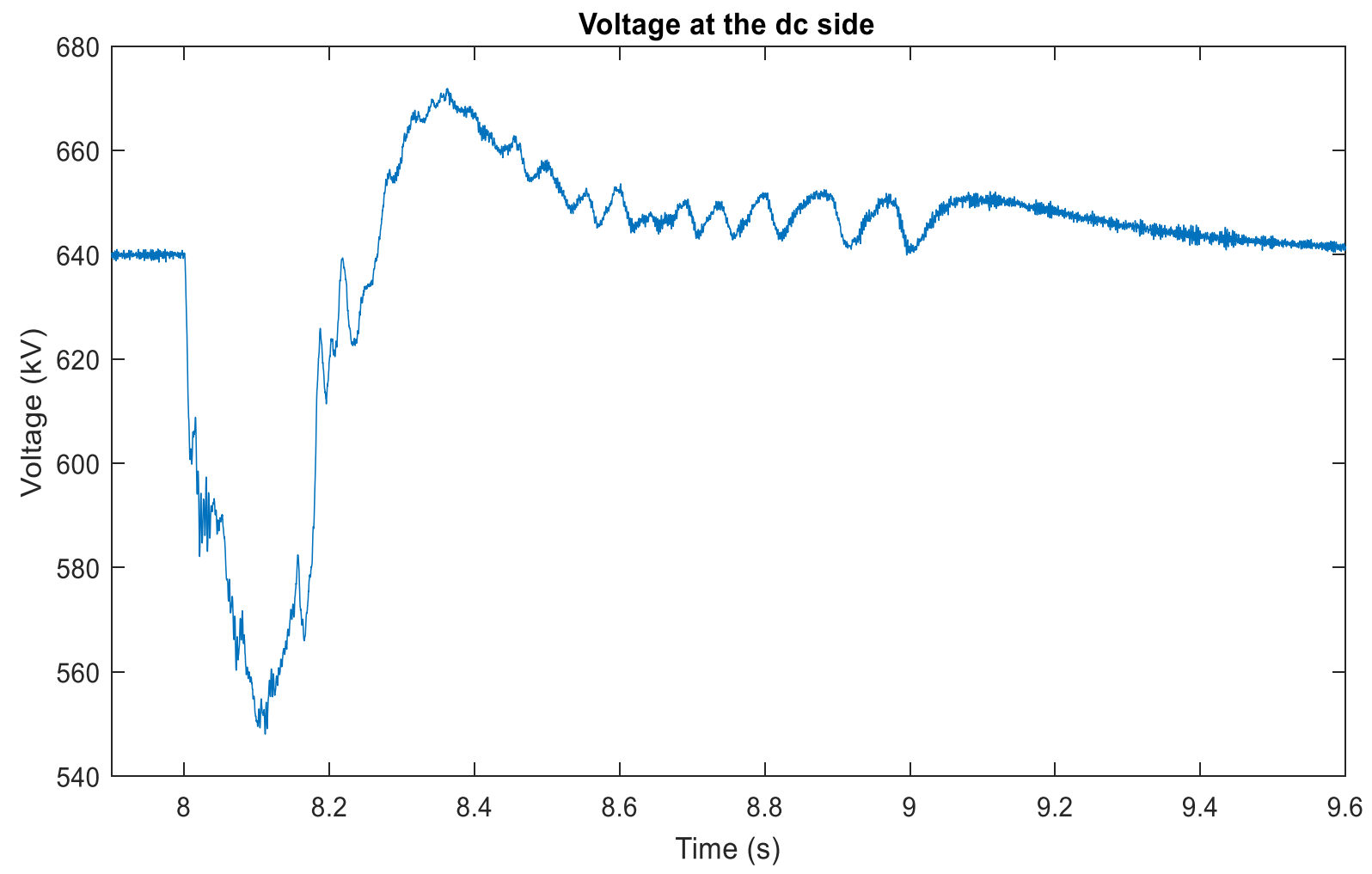

(a) Voltage at the dc side. 


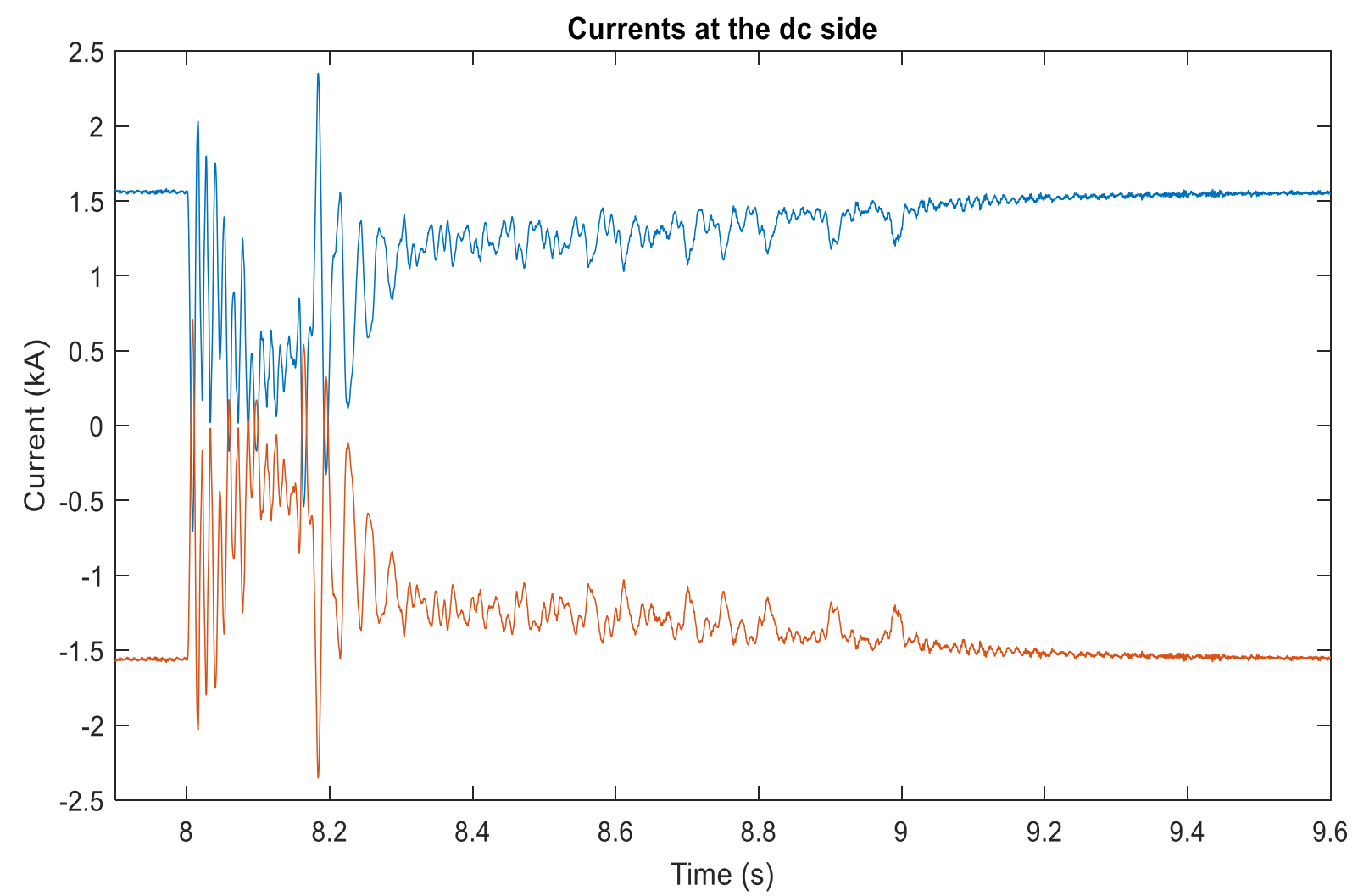

(b) Currents at the dc side.

Figure 77 . Voltage and currents at the dc side.

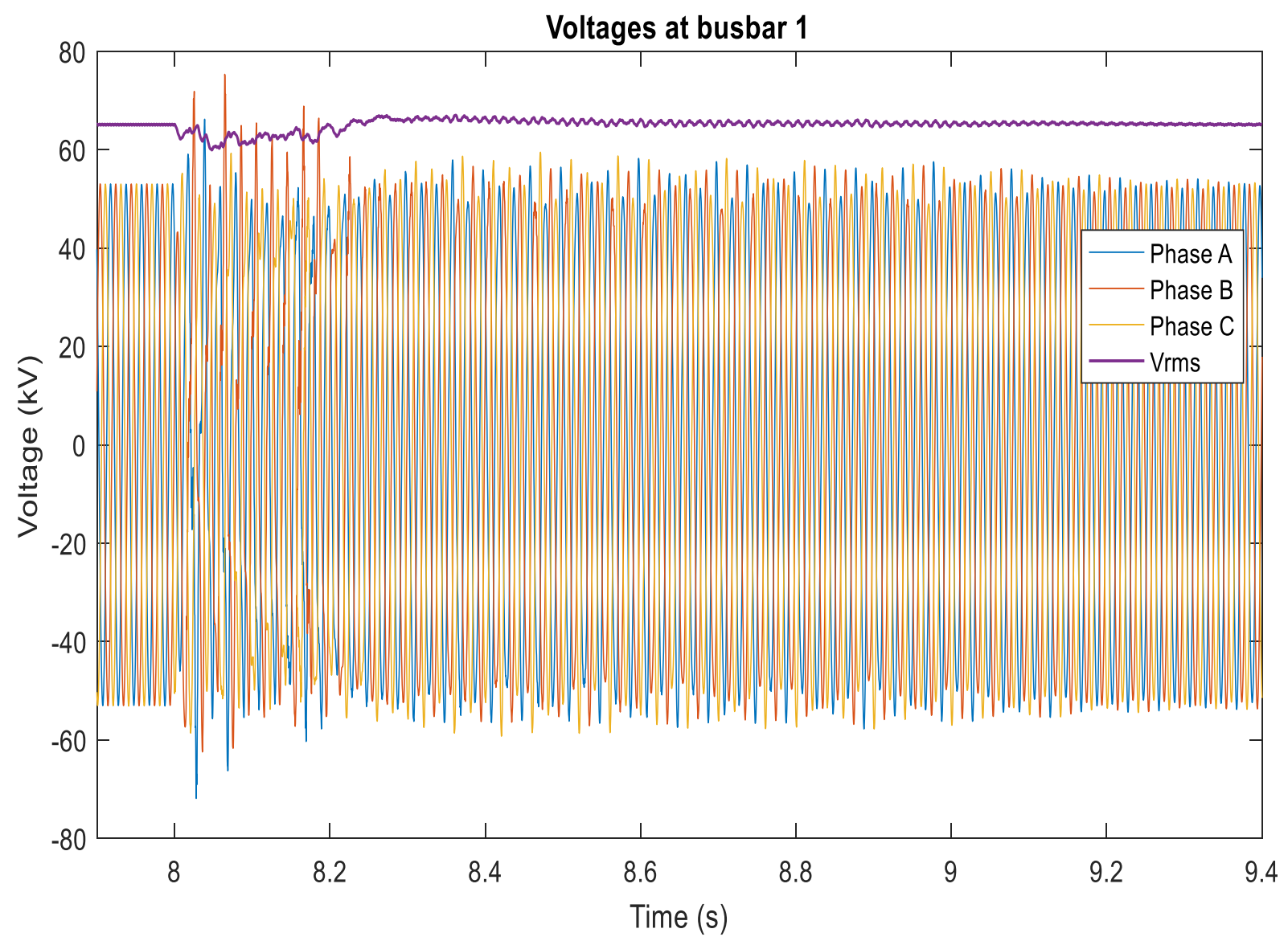

(a) Voltages at busbar 1. 


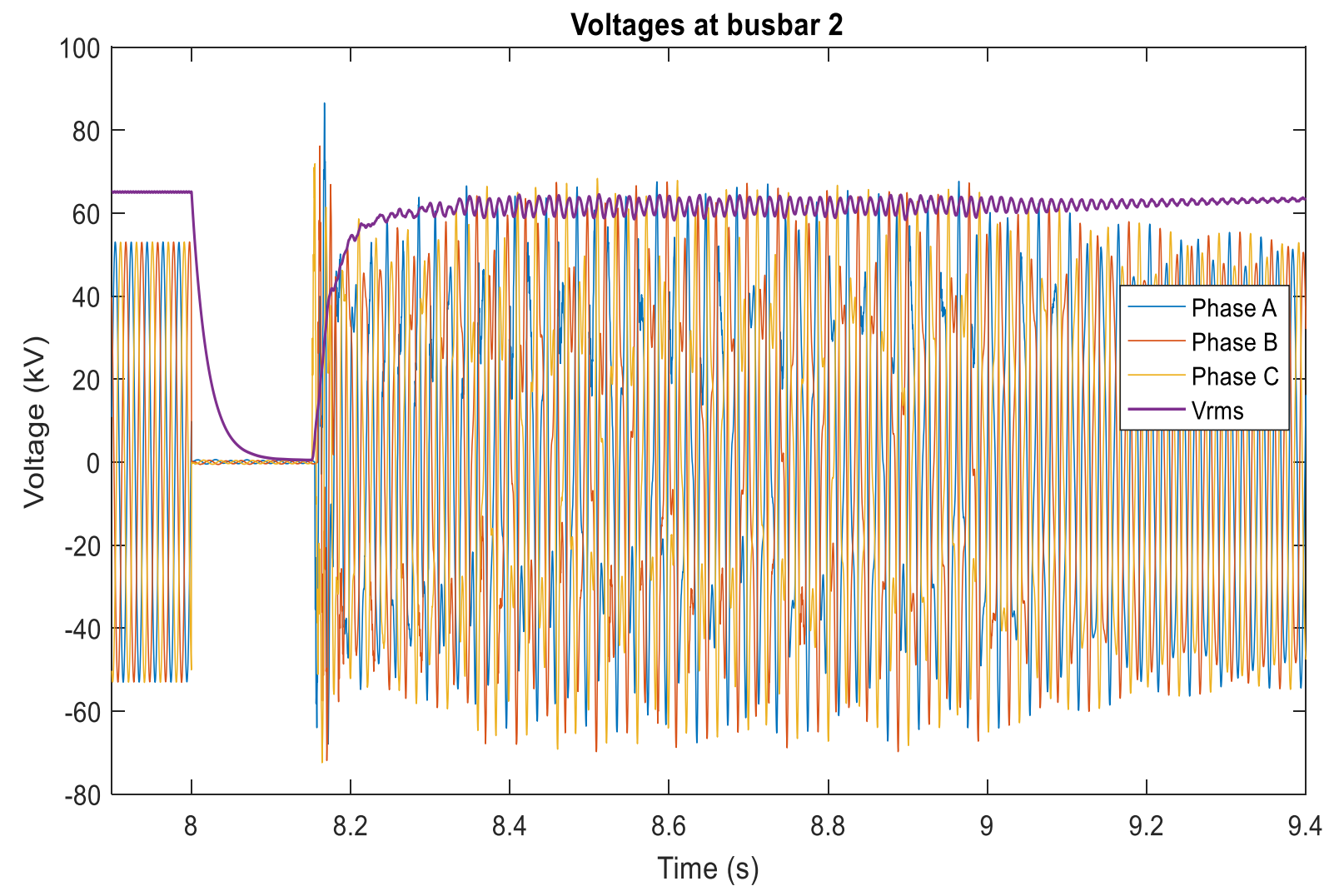

(b) Voltages at busbar 2.

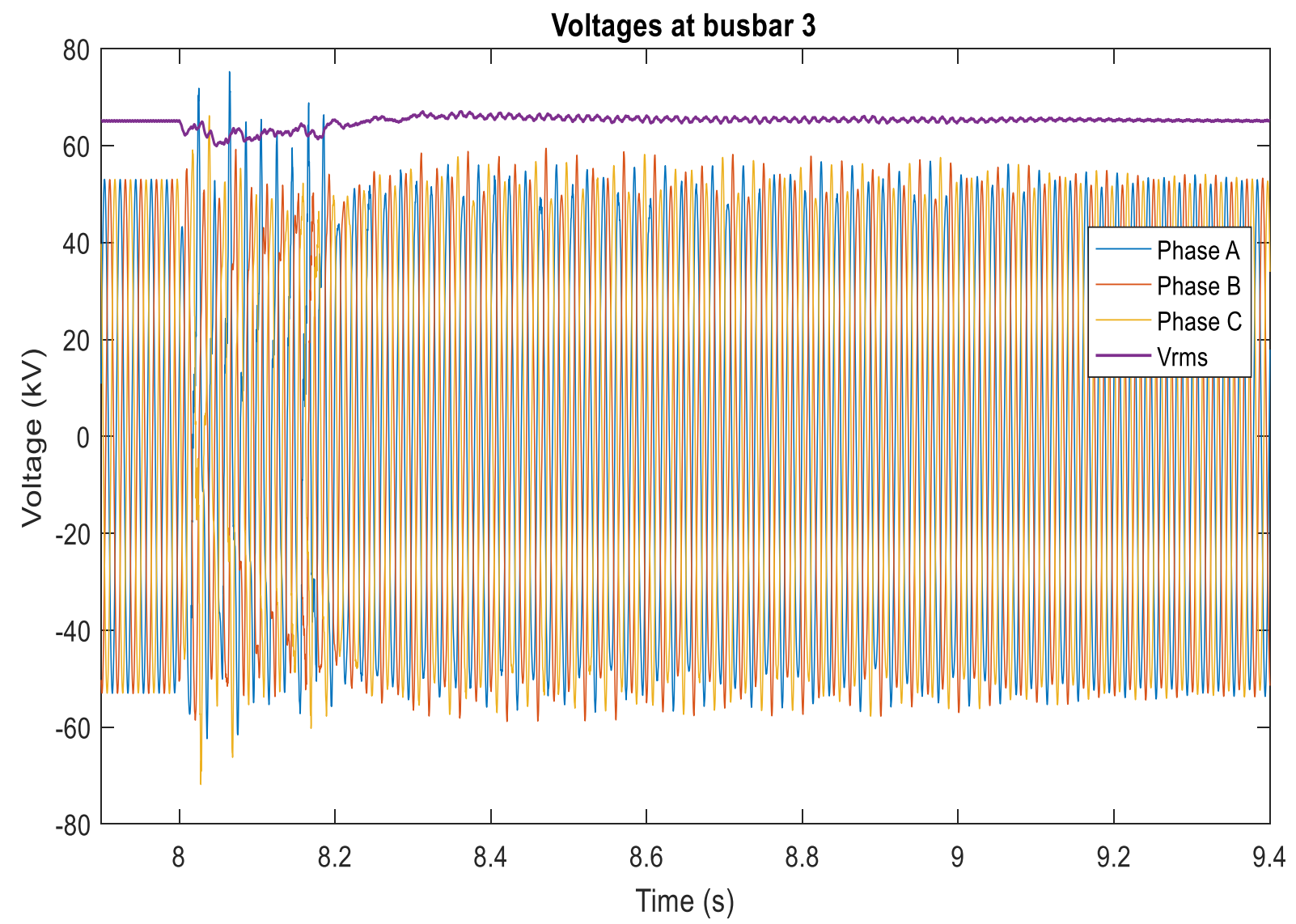

(c) Voltages at busbar 3.

Figure 78. Voltages at the 66-kV busbars. 


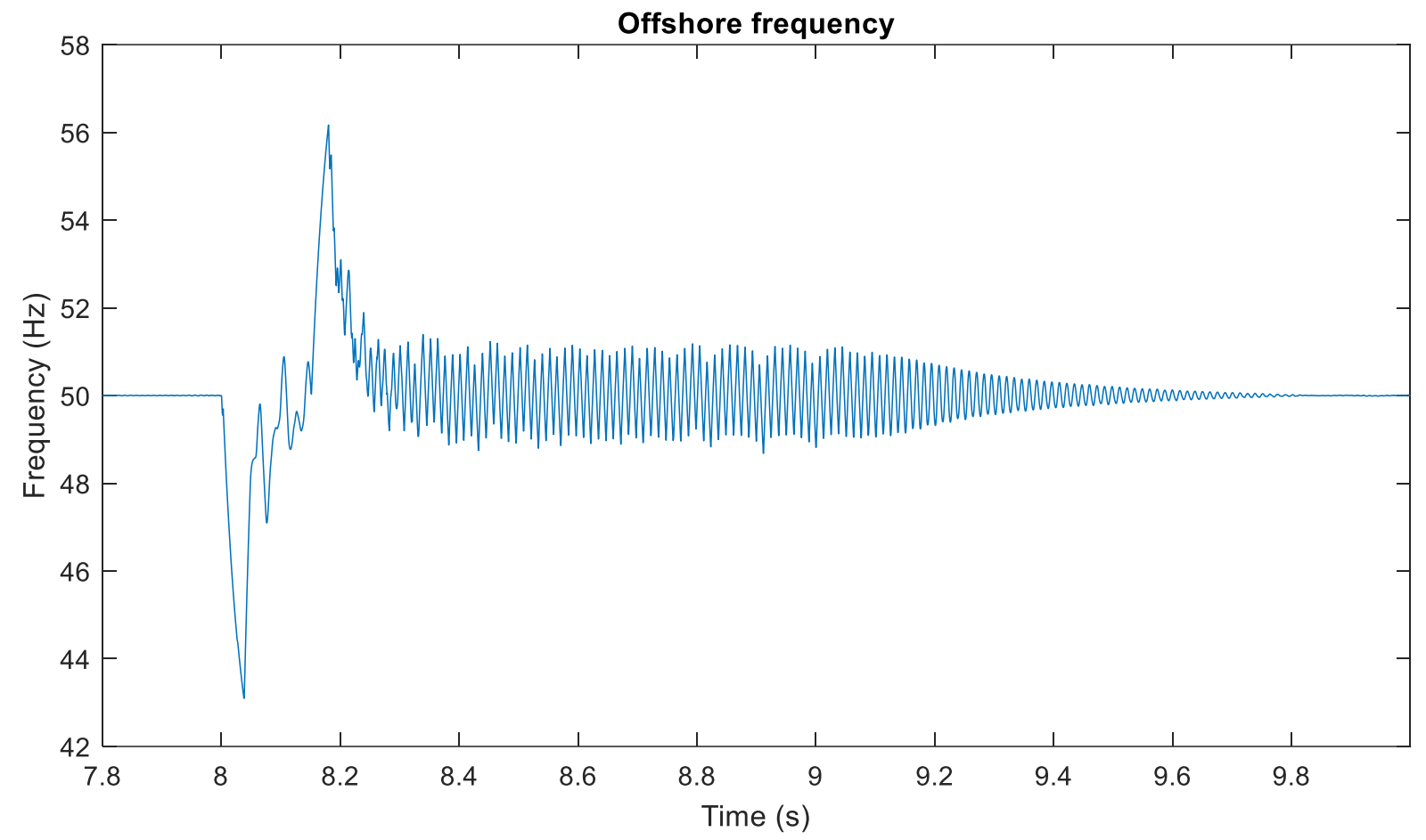

Figure 79. Offshore frequency.

This fault is more severe than the single phase-to-ground fault. For a bolted fault, the voltages at the busbar associated to the OWF 2 go to zero. Transient overvoltages for the busbars with the sound circuits are detected. Mitigation actions are required as the transient overvoltages are high. Moreover, transient overvoltages are found in the busbars of the OWFs 1 and 3 . The controls operate correctly, the network survives the fault until it is removed from the system and is stable again.

Additionally, a single phase-to-ground fault is applied to onshore grid, i.e. the high voltage transmission grid at $380 \mathrm{kV}$. The phase affected is phase A for $150 \mathrm{~ms}$ after six seconds of the simulation. All other parameters are kept as aforementioned cases.

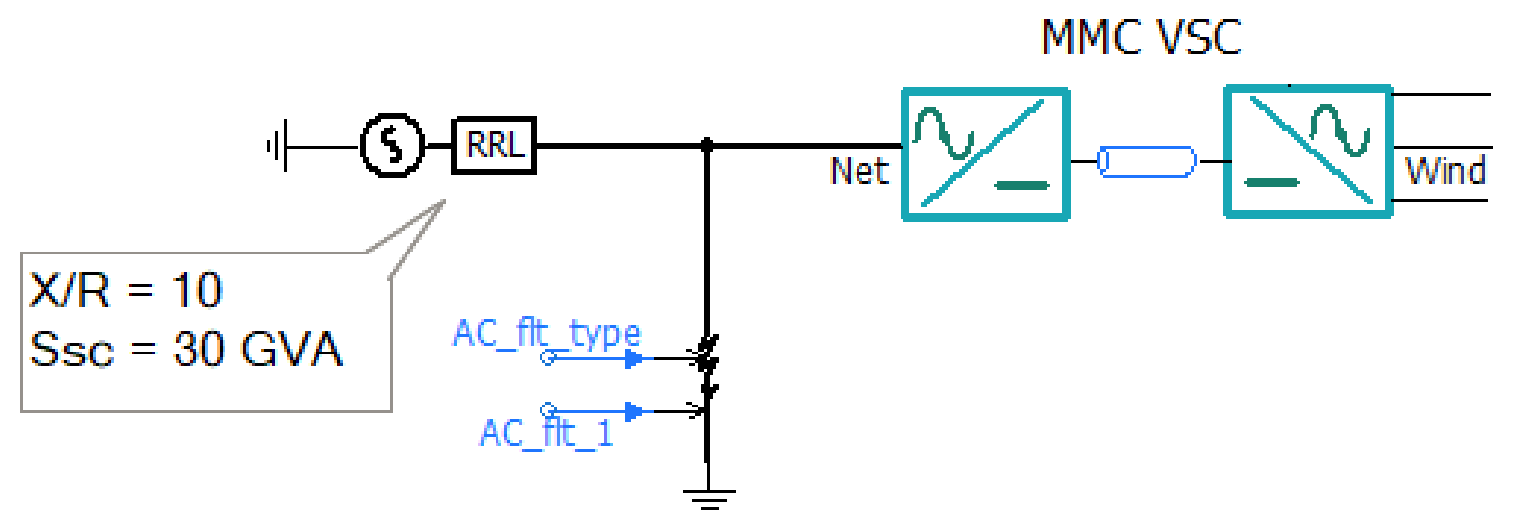

Figure 80 . Single phase-to-ground fault at the $380-\mathrm{kV}$ grid.

For this event in the high-voltage transmission grid, the following figures present the dynamic behaviour of the test system. 


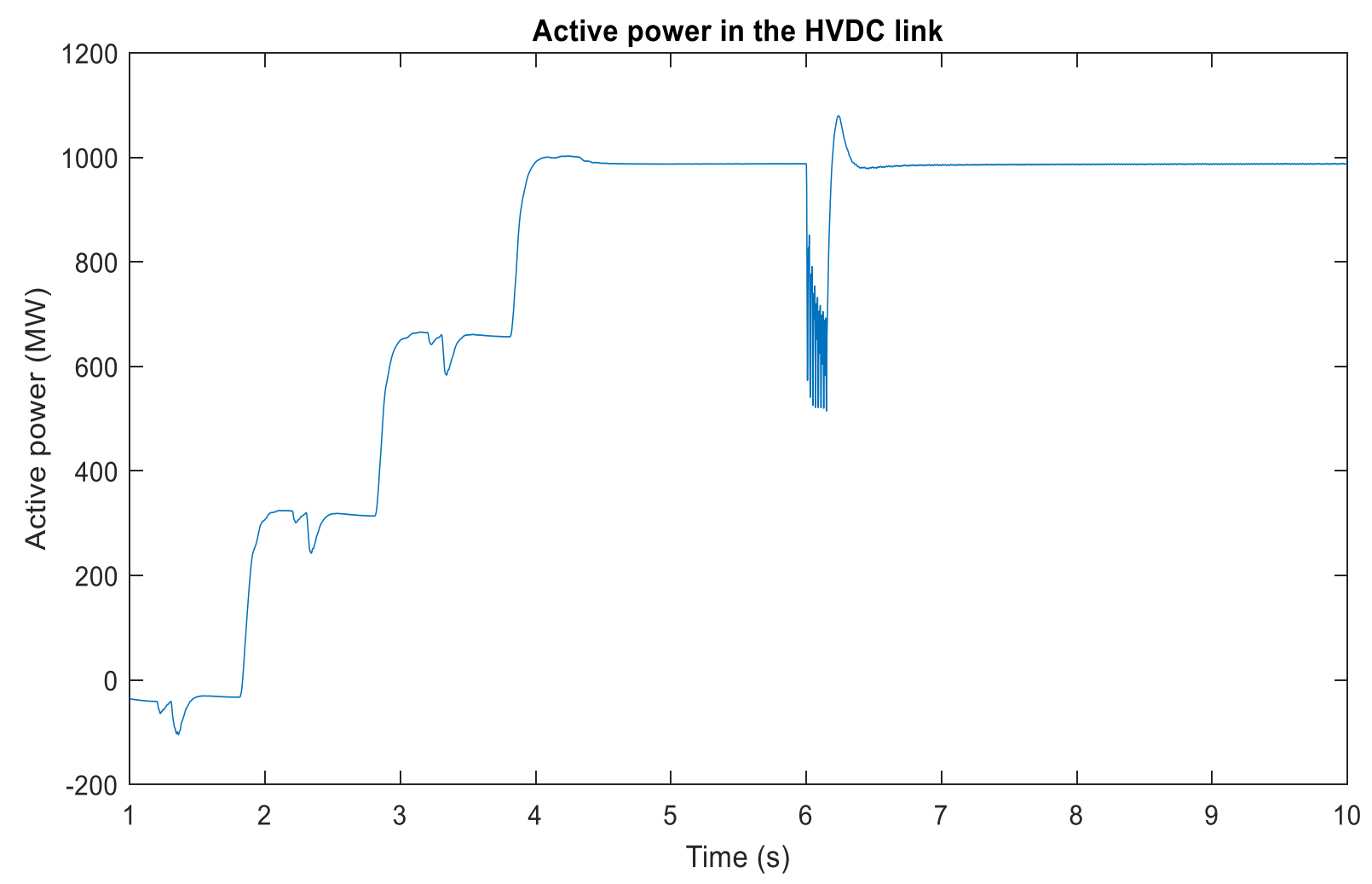

Figure 81. Power reduction due to the fault at the onshore side.

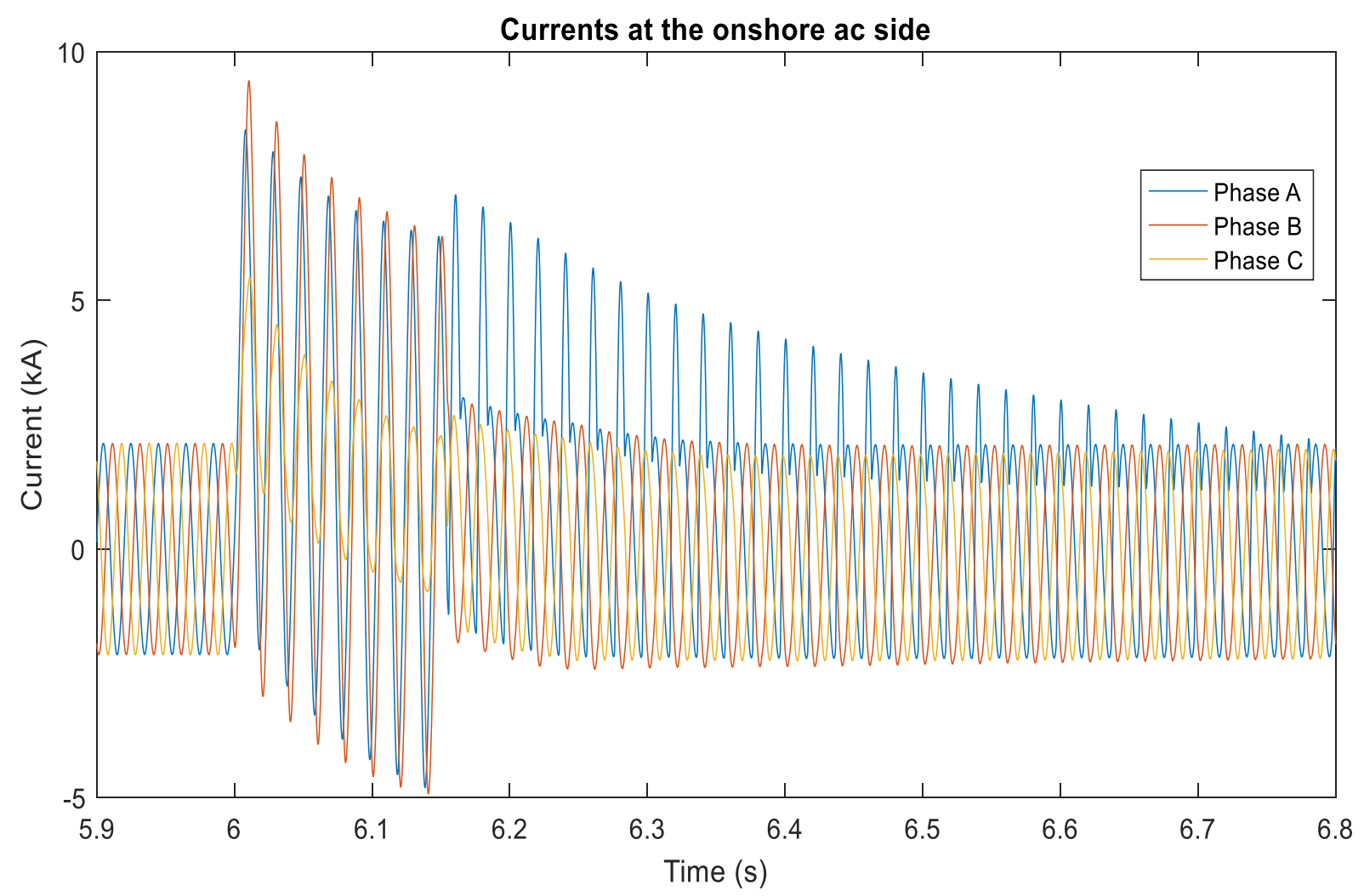

Figure 82. Currents at the onshore ac side. 
The fault currents obtained are considerably high, but it is because there is no fault ridethrough capability in the model. The effect of the saturation of the transformers is also evident after the bolted fault is cleared. Standard parameters were used in the model based on literature and these results are considered very conservative. Optimization of the specification for the equipment to be used will be possible in later stages when real data from manufactures becomes available.

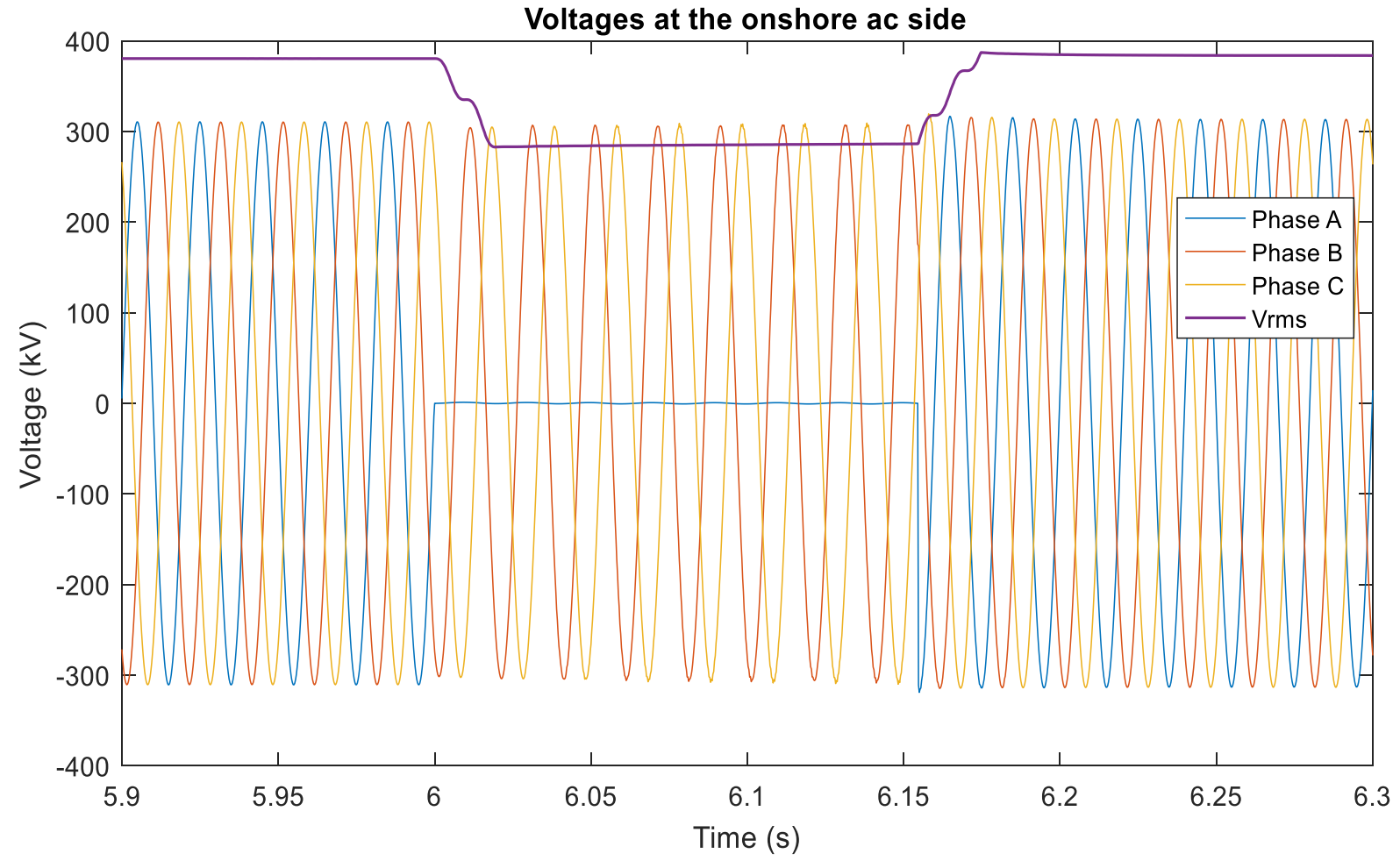

(a) Voltages at the onshore ac side.

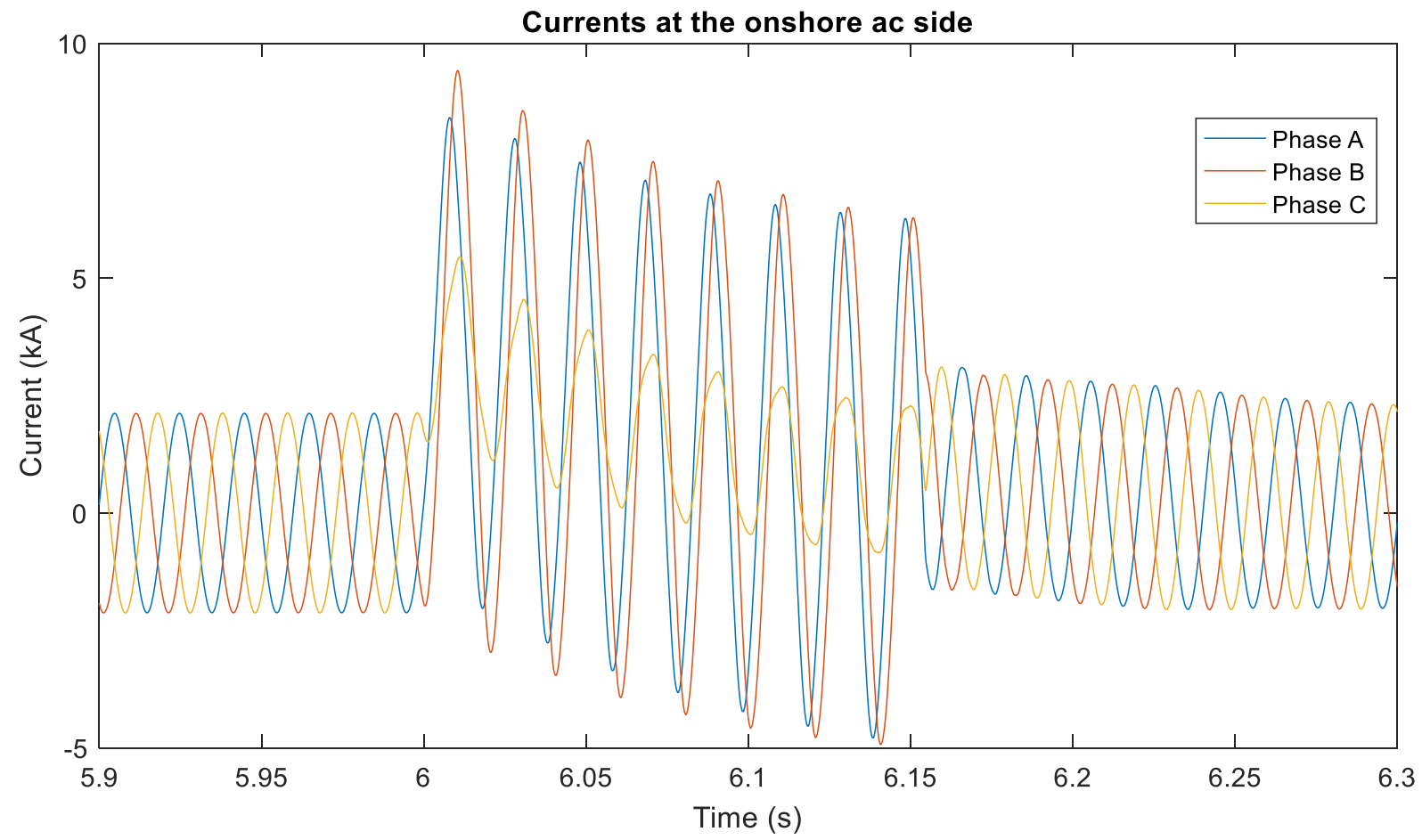

(b) Currents at the onshore ac side - no saturation effect considered for the onshore transformer.

Figure 83. Voltages and currents at the onshore ac side. 


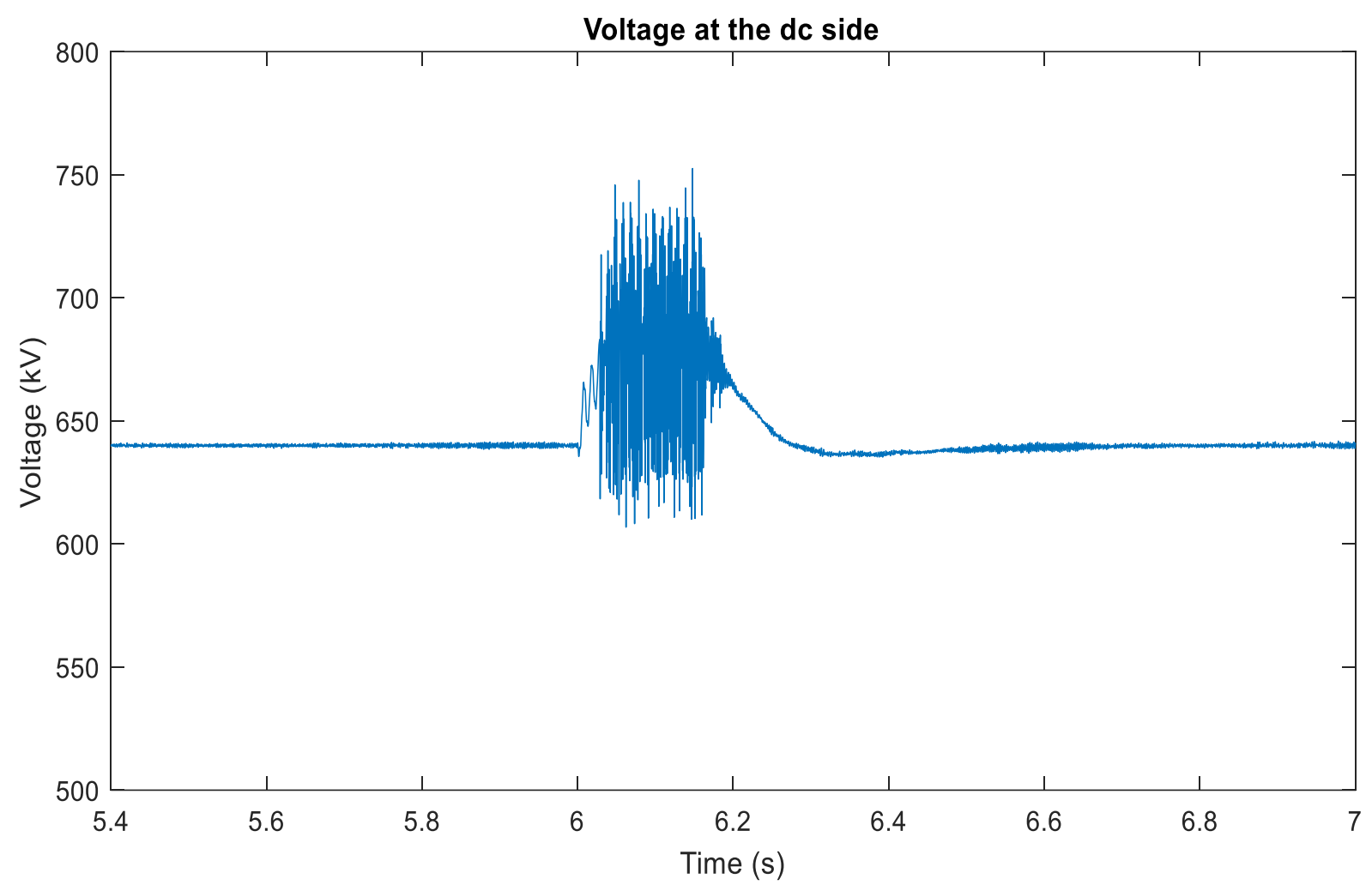

(a) Voltage at the dc side.

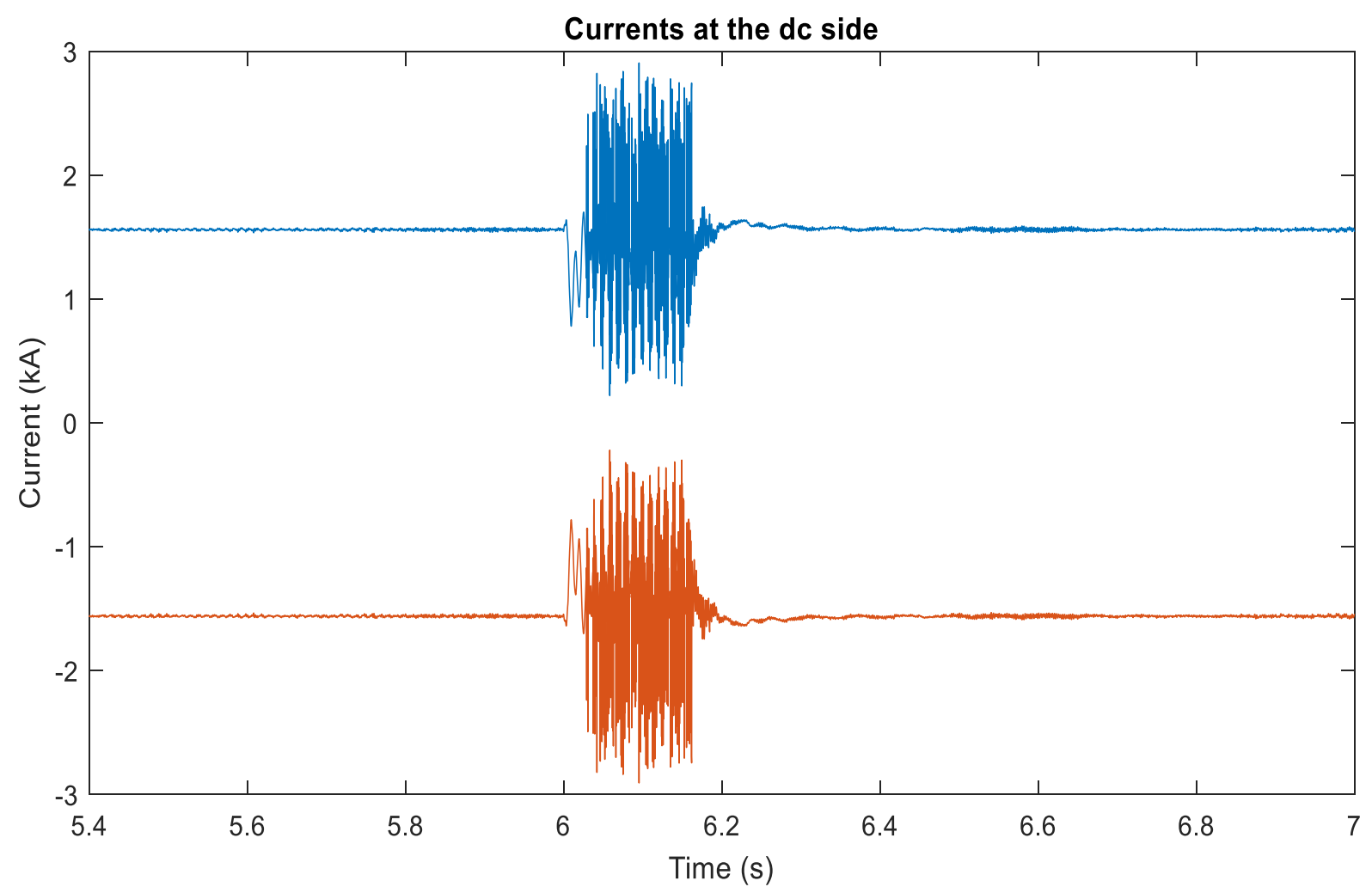

(b) Currents at the dc side.

Figure 84. Voltage and currents at the dc side.

Due to the HVDC link, the onshore and offshore systems are not going to be affected by the faults at the other side. The offshore voltages at the $66-\mathrm{kV}$ busbars are slightly disturbed for a single phase-to-ground fault at the onshore grid. The power generation from the wind parks 
has to be dissipated by the dc chopper while the transmission system is not able to absorb it. Once again, the controls demonstrated correct operation.

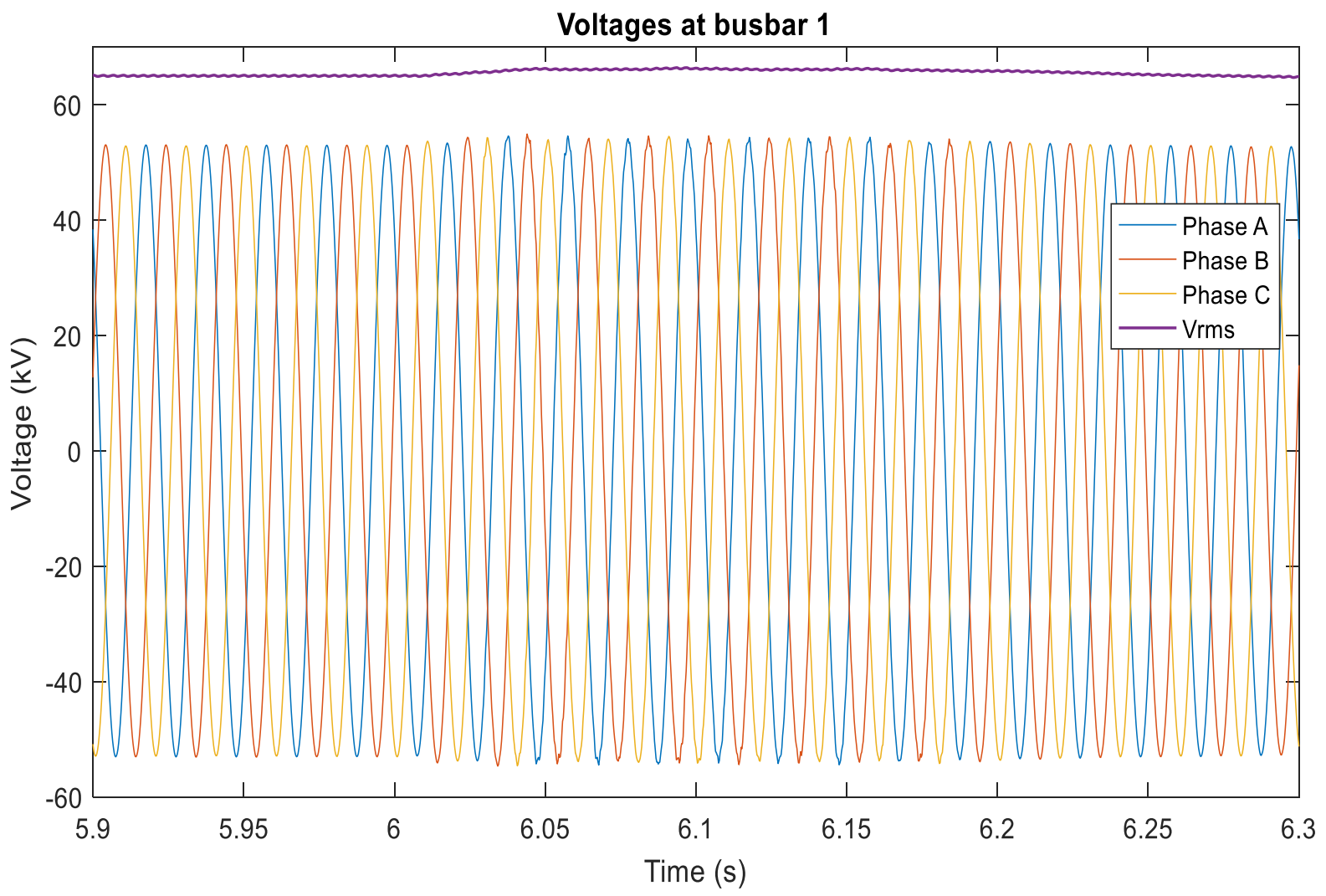

(a) Voltages at busbar 1.

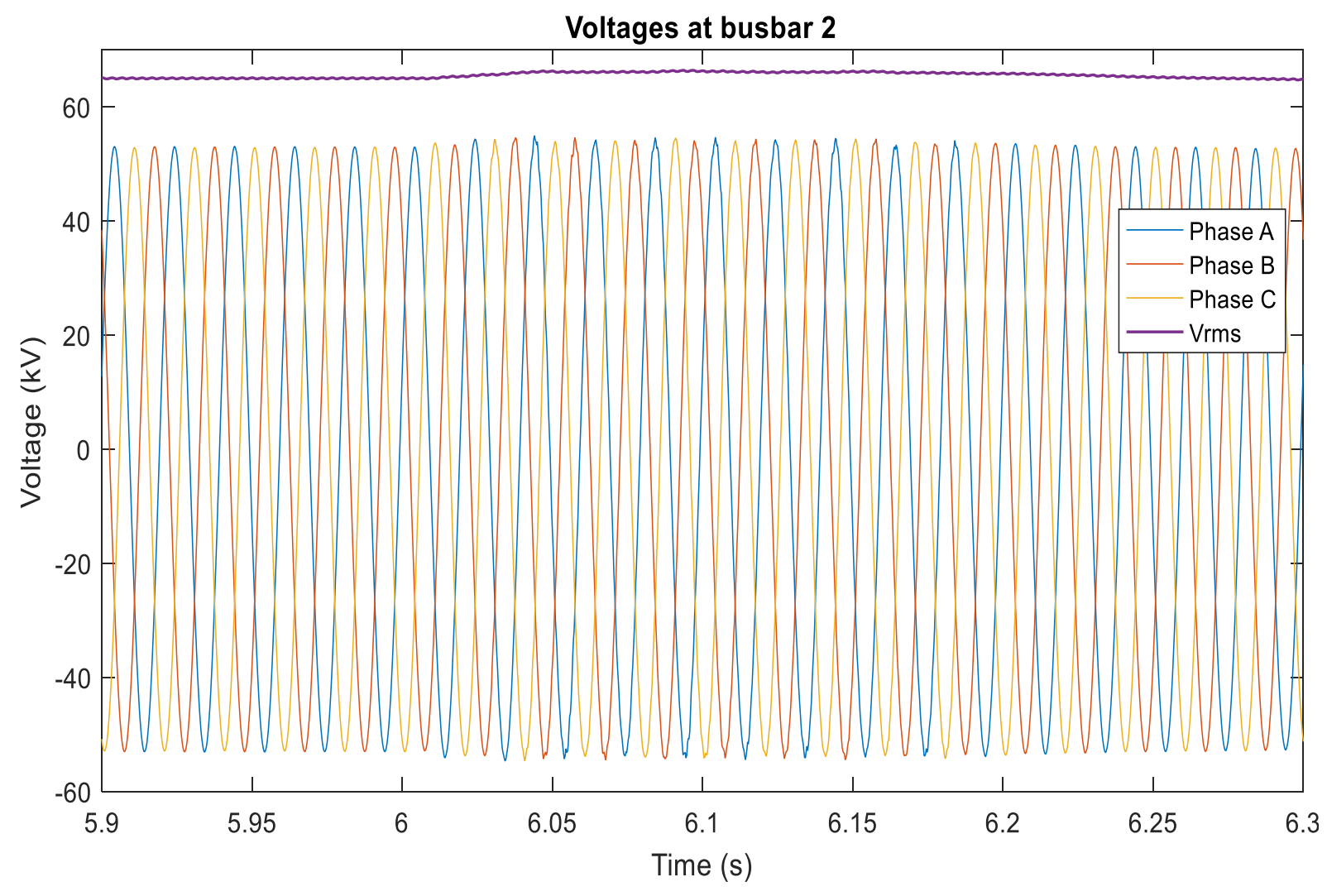

(b) Voltages at busbar 2 . 
Voltages at busbar 3

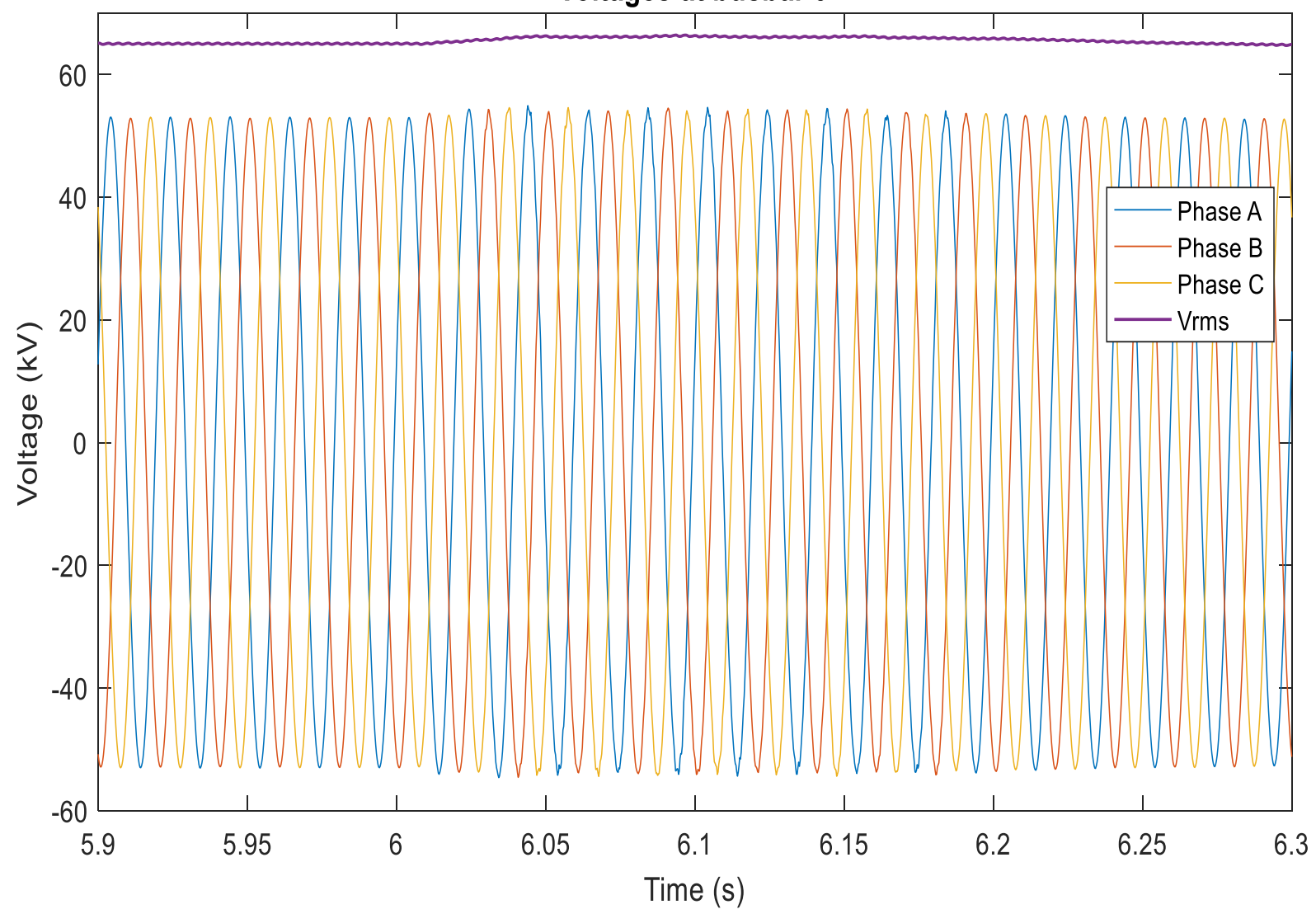

(c) Voltages at busbar 3.

Figure 85 . Voltages at the $66-\mathrm{kV}$ busbars.

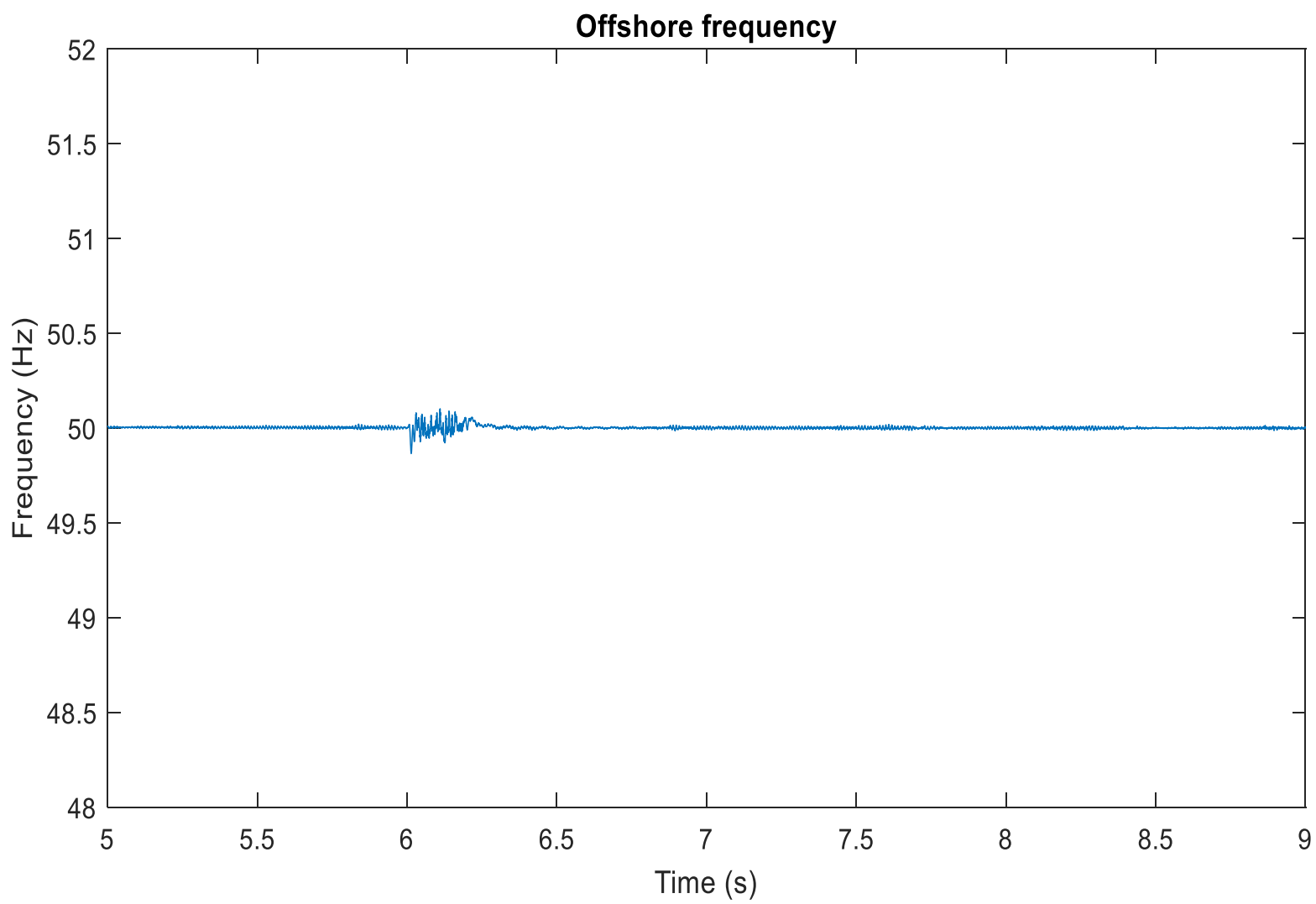

Figure 86. Offshore frequency. 
Finally, a three-phase-to-ground fault in the onshore grid at $380 \mathrm{kV}$ is applied after nine seconds. The location of the fault is the same as in shown in Figure 80. All the other parameters were kept as in the previous cases. The results of the simulations are shown in the next figures.

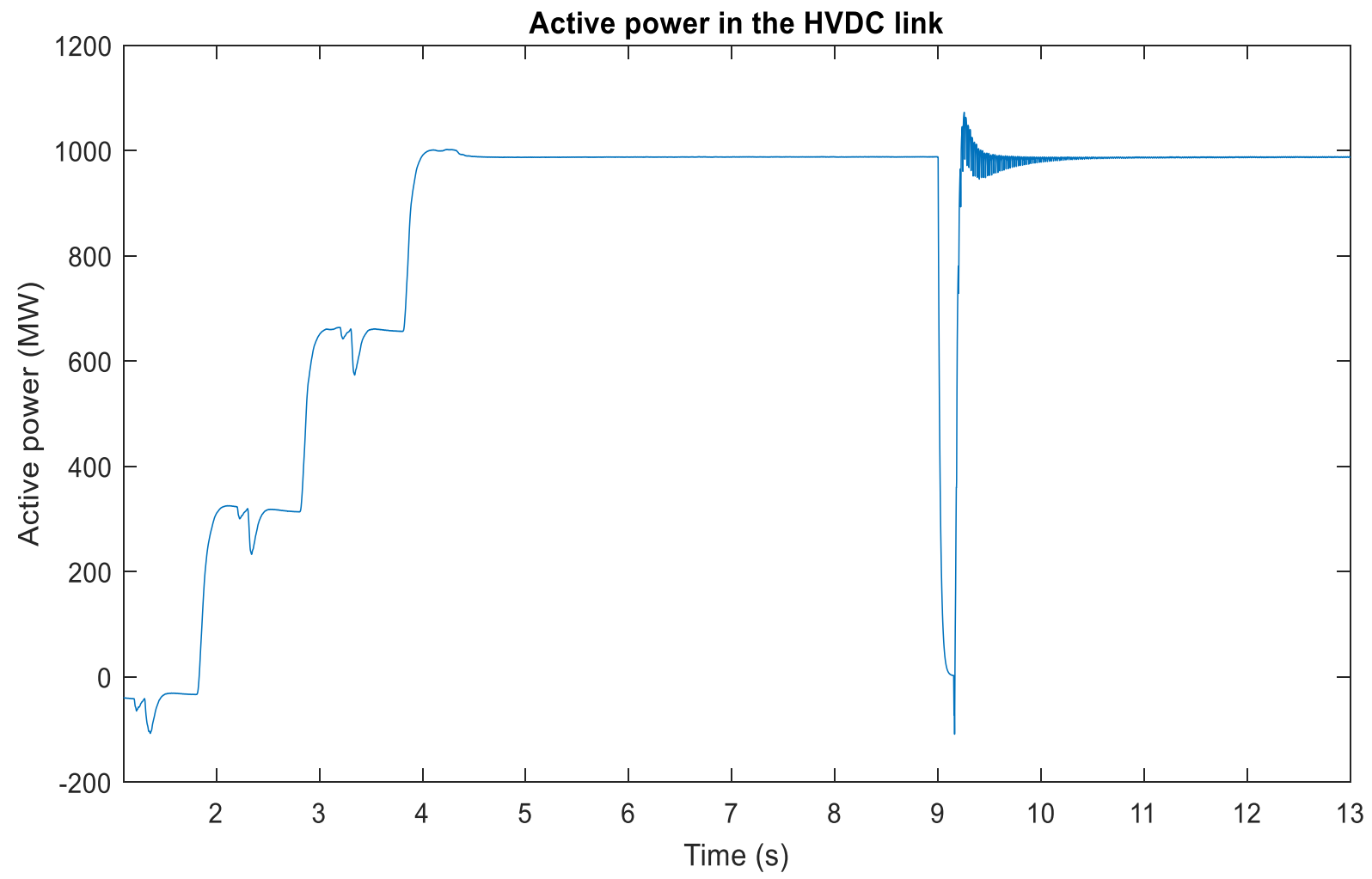

Figure 87. Power reduction due to the onshore fault.

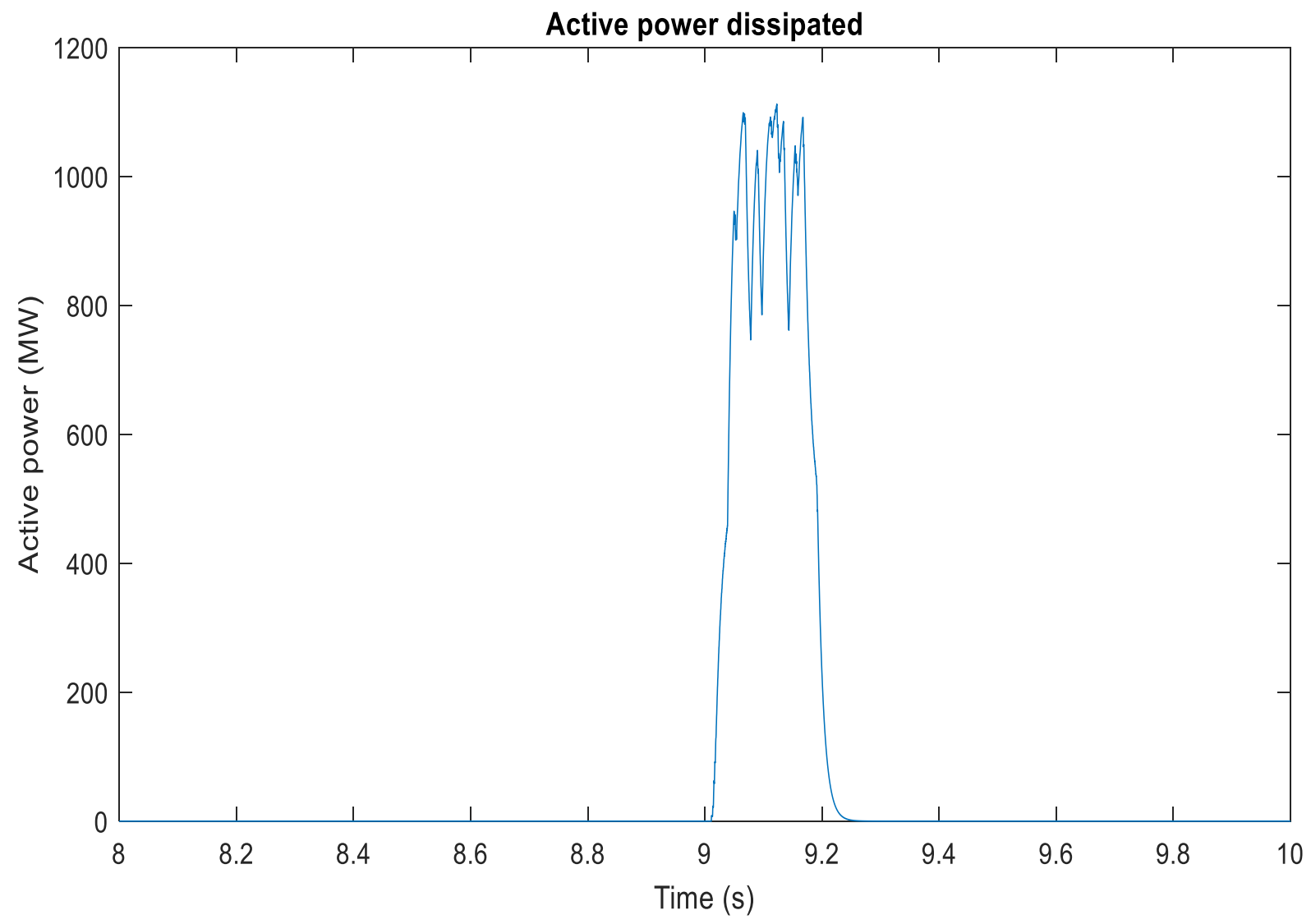

Figure 88. Operation of the dc chopper. 


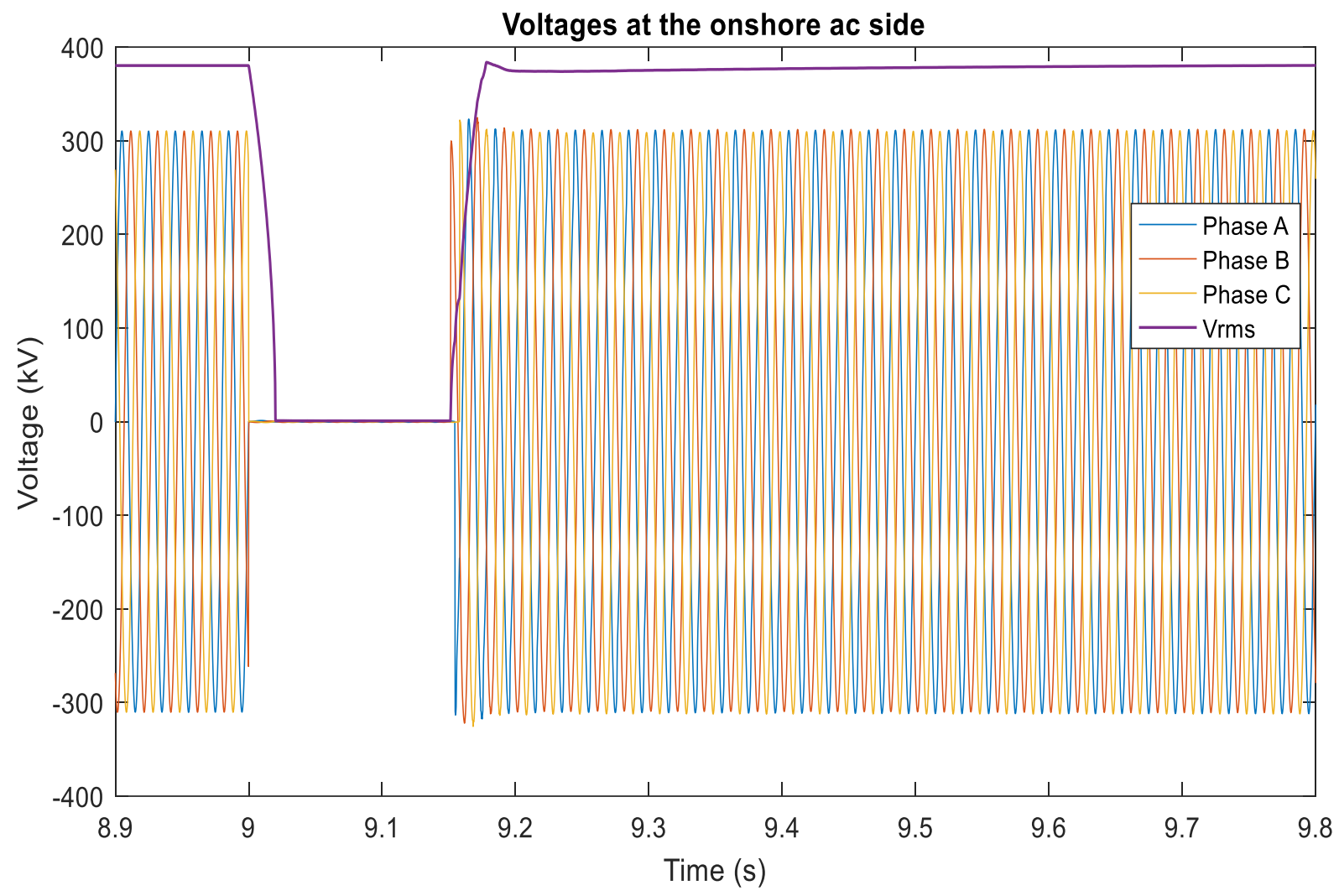

(a) Voltages at the onshore ac side.

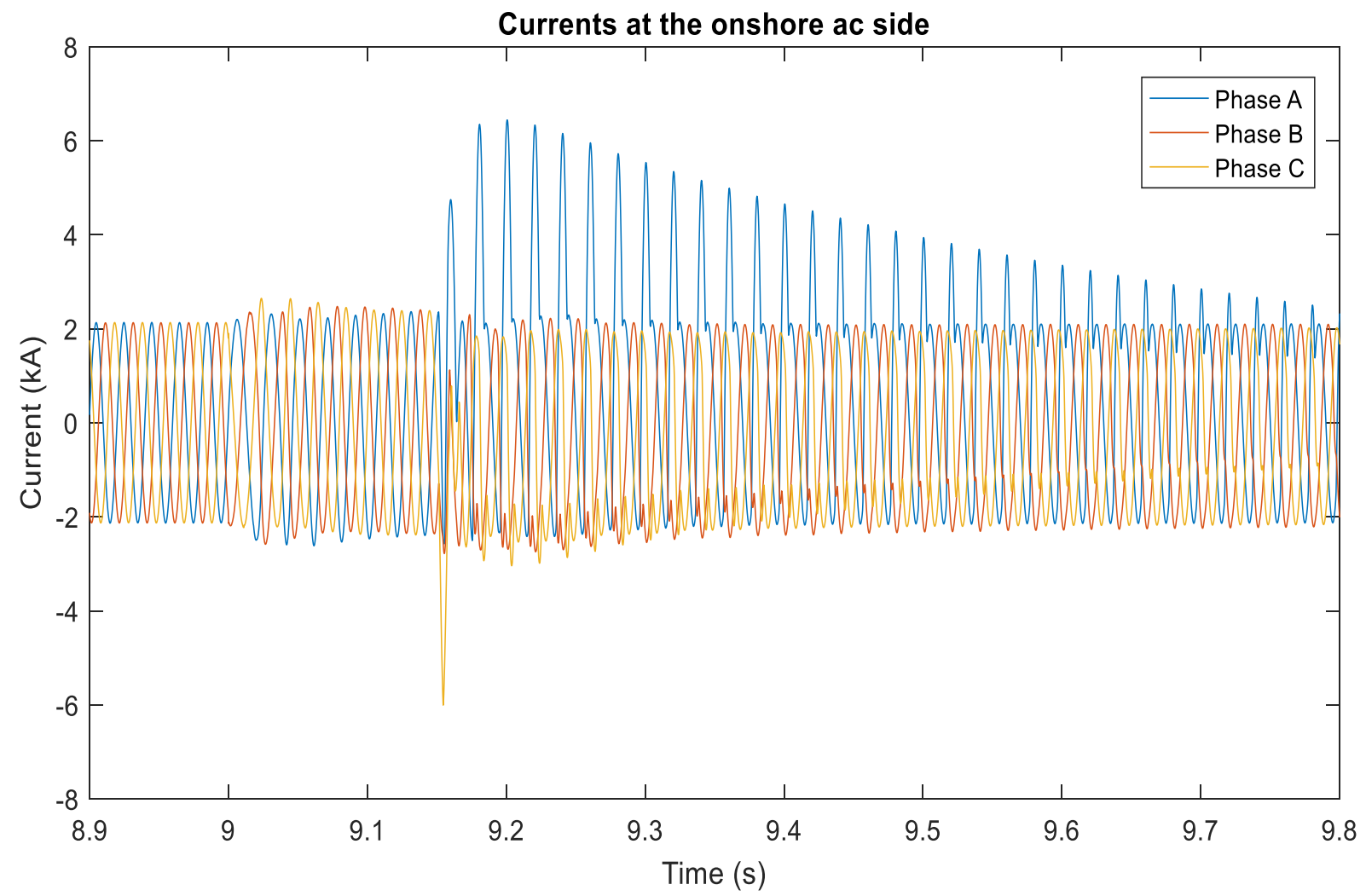

(b) Currents at the onshore ac side.

Figure 89. Voltages and currents at the onshore ac side. 
Because of the bolted fault the ac voltages at the onshore side go to zero for the duration of the disturbance, as seen in Figure 89. The saturation effect of the transformer model is appreciated after the fault has been removed from the system.

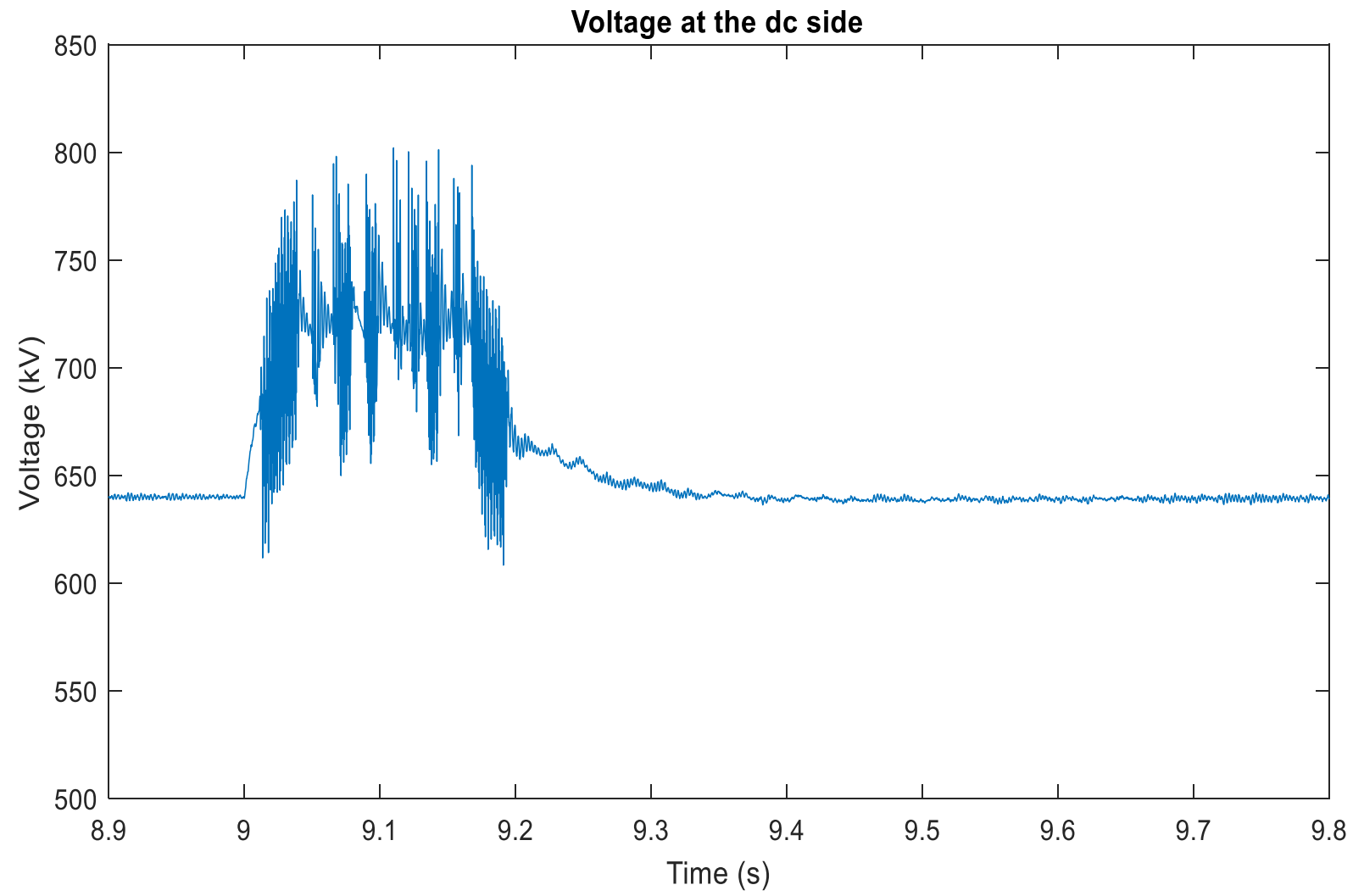

(a) Voltage at the dc side.

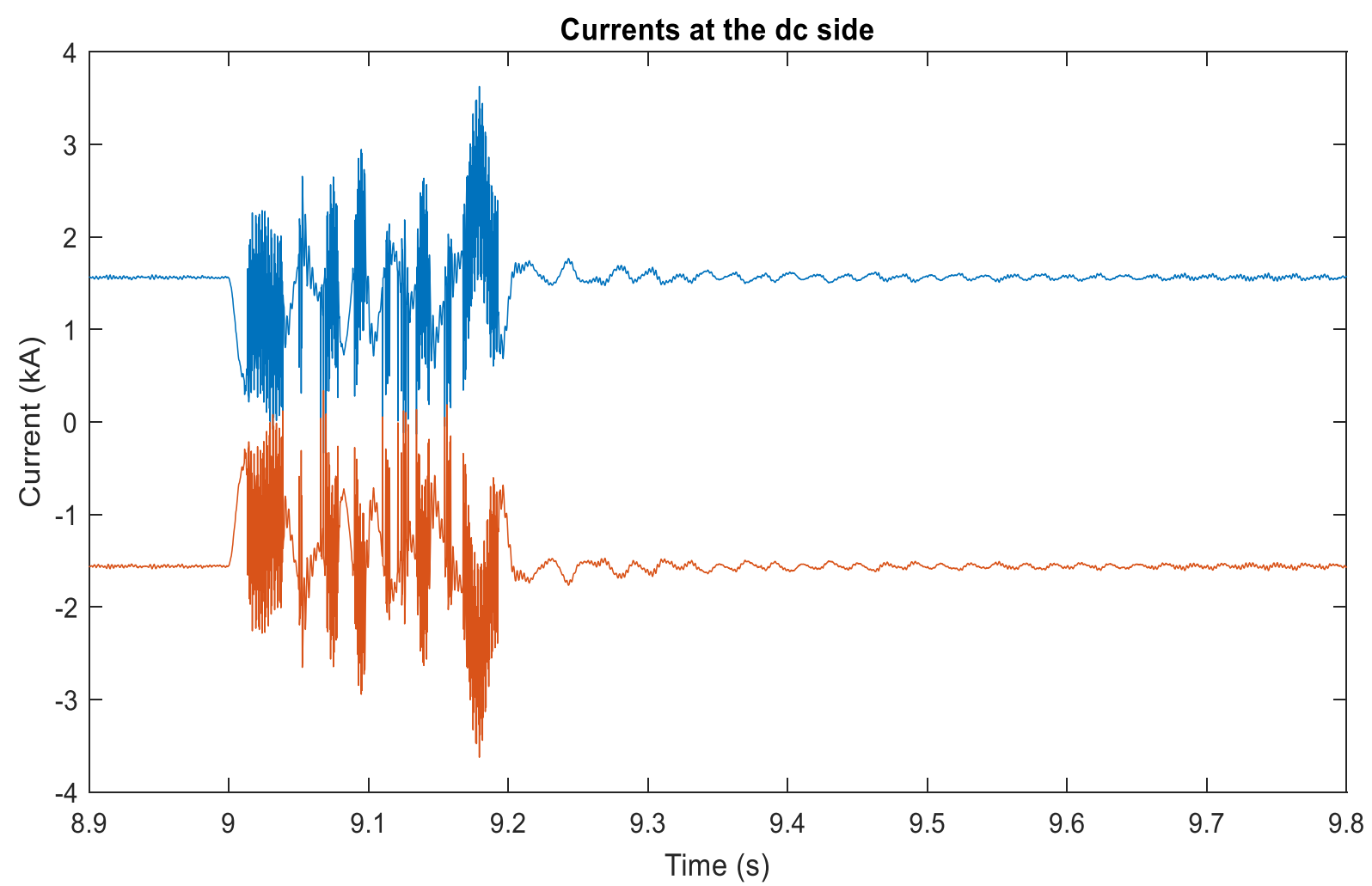

(b) Currents at the dc side.

Figure 90. Voltage and currents at the dc side. 


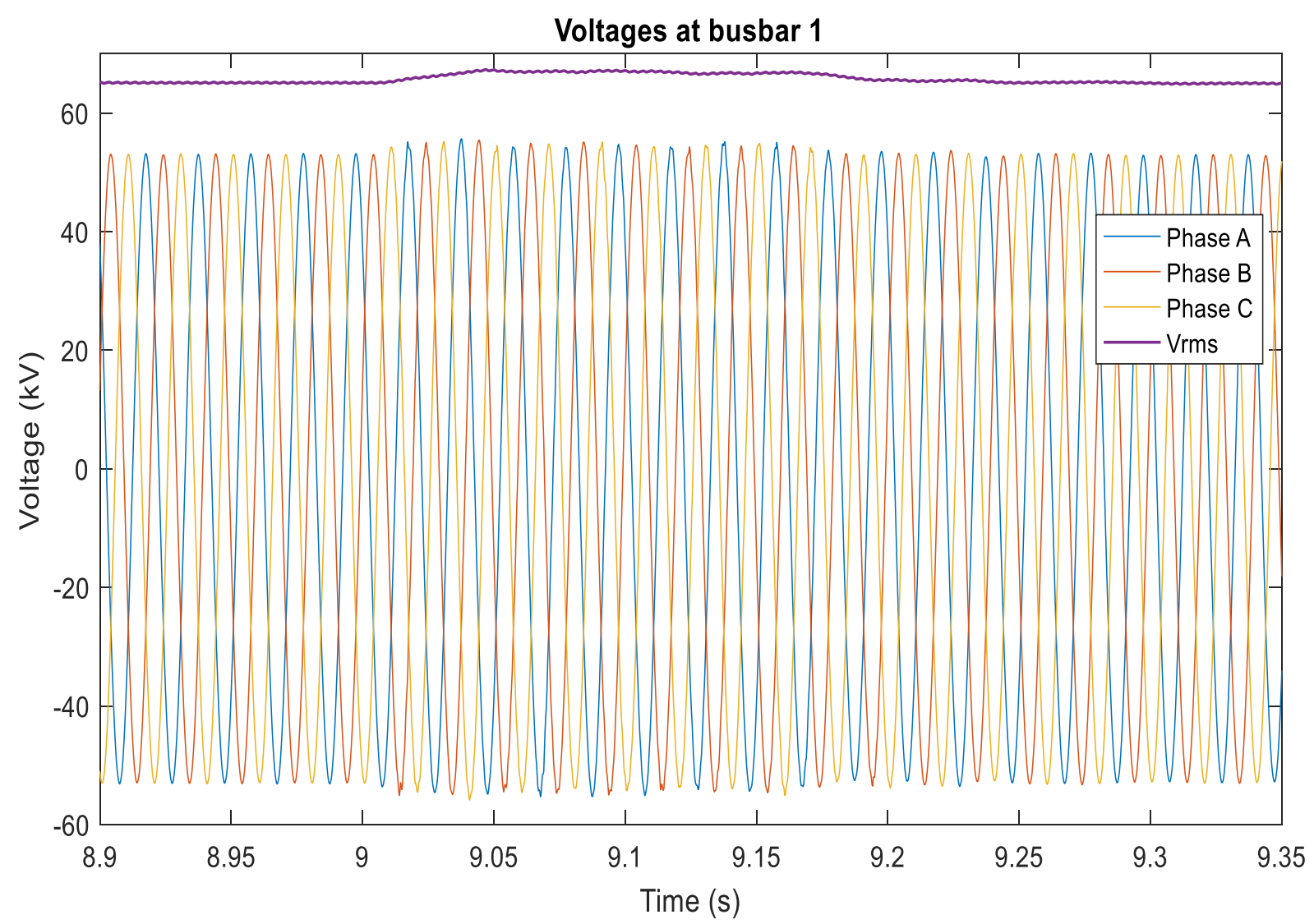

(a) Voltages at busbar 1.

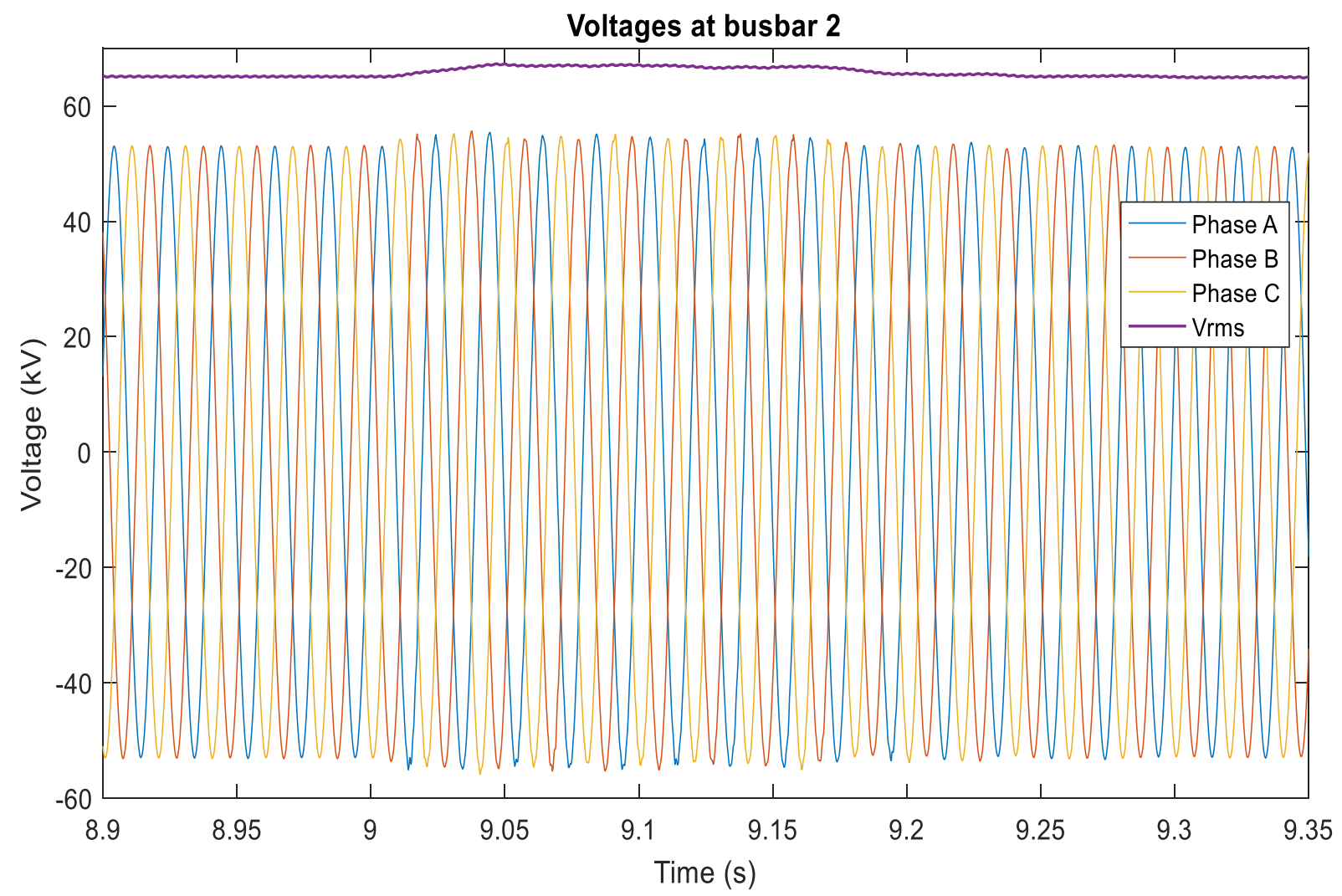

(b) Voltages at busbar 2. 


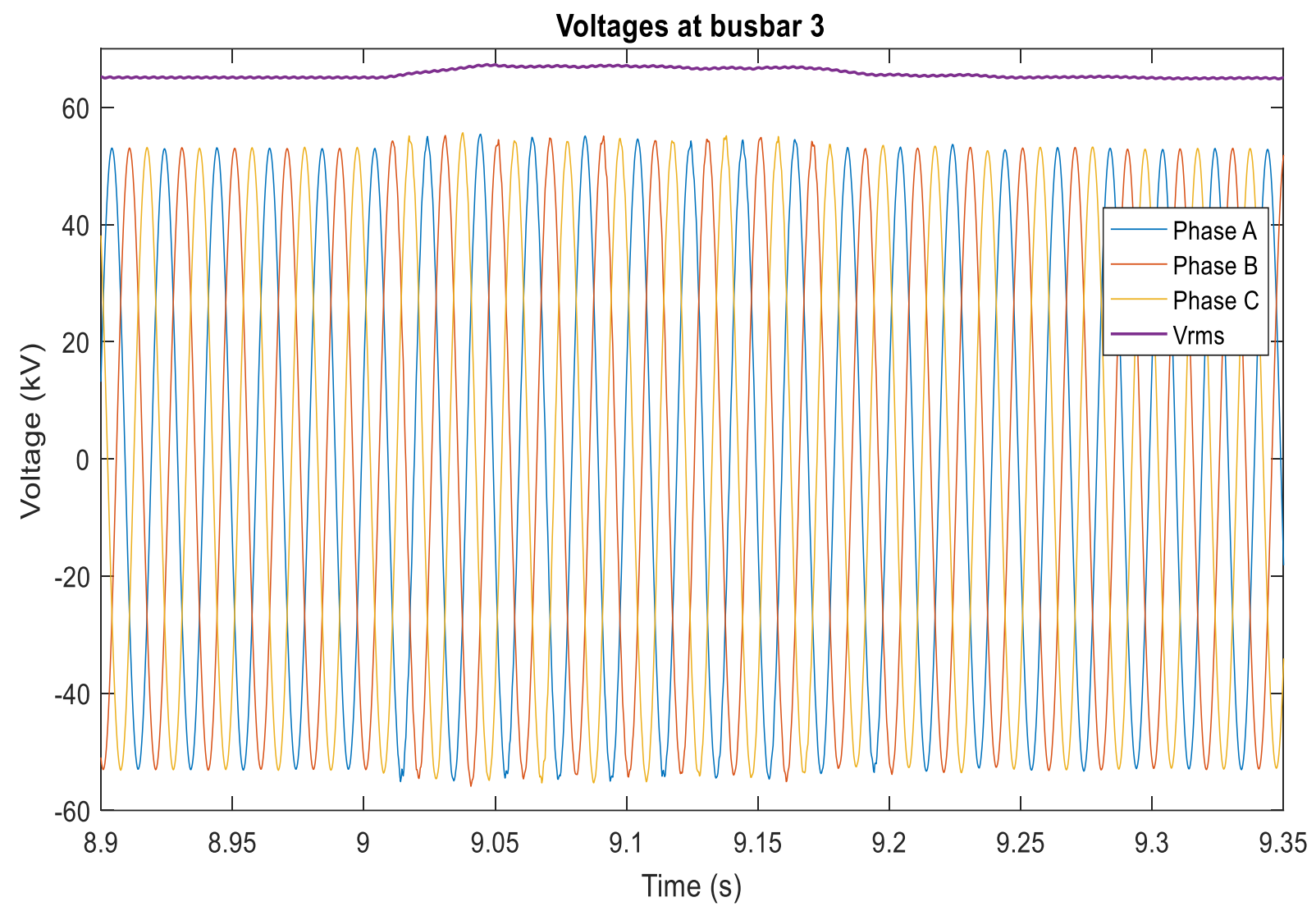

(c) Voltages at busbar 3.

Figure 91 . Voltages at the $66-\mathrm{kV}$ busbars.

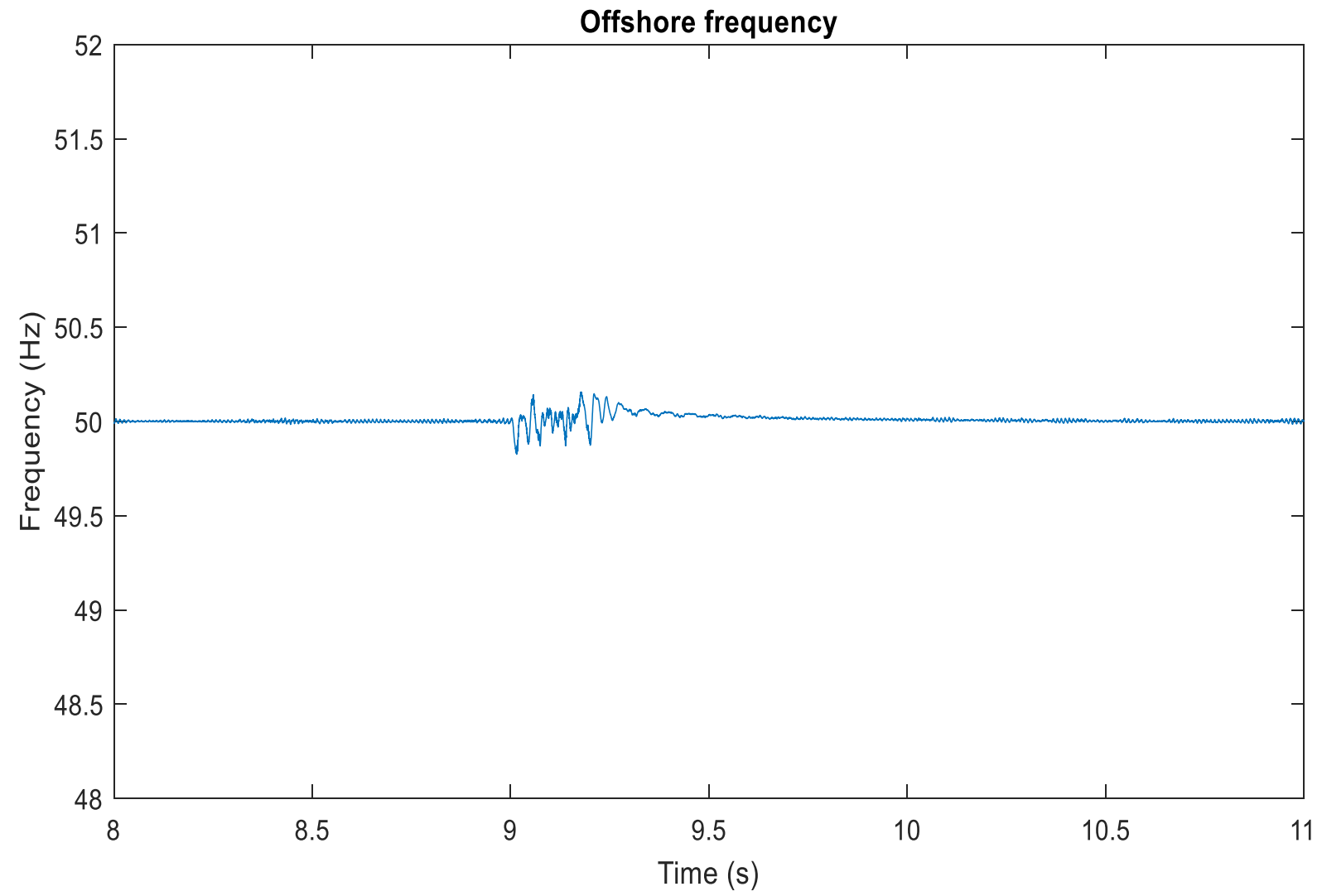

Figure 92. Offshore frequency. 
When faults are applied at the terminals of the onshore MMC-HVDC station, as in the events simulated in this case and the one before, the active power of the onshore station goes to zero. However, the power in-feed to the HVDC link from the offshore wind farms is not changed. This results in a power imbalance between the onshore and the offshore stations which creates direct overvoltages in the HVDC link as the energy is stored in the dc capacitors. In Figure 88 it is seen the operation of the dc chopper as a measure to prevent this phenomenon as it was explained in section 3.7.

\subsection{Discussion}

All the different operation scenarios presented in the eight cases above for the test network demonstrate that the designed test network for the dynamic performance study of the novel grid connection topology proposed in this thesis is stable during steady state and contingencies. These results provide an overview of parameter variations during different operation stages and scenarios of the system.

The control structures currently applied to MMC-HVDC transmission schemes for the connection of offshore wind parks to high-voltage grid at the onshore side, such as outer controls for the active power, the dc voltage, the reactive power, and the ac voltage can be used with no problems in the new connection topology. The lower level controls associated to the MMC VSC were not modified.

The typical control modes of the MMC terminals are also valid. The islanded configuration for the active power mode ( $\mathrm{d}$ mode) and the ac voltage control with $\mathrm{Vac}$ ref $=1 \mathrm{p}$.u for the reactive power mode (q mode) were used in the offshore station. Active power mode ( $d$ mode) in Vdc configuration and the ac voltage control with $\mathrm{Vac}$ ref $=1 \mathrm{p} . \mathrm{u}$ for the reactive power mode ( $\mathrm{q}$ mode) were used in the onshore station.

The offshore MMC terminal operates as the slack bus that absorbs all the generated offshore wind power. Regardless of the conditions considered, the offshore MMC station has captured the active power generated by the OWFs within the rated power transmission capability of the HVDC link.

The grid code for HVDC connections defines the frequency ranges between $49.0-51 \mathrm{~Hz}$ for normal variations in the island ac offshore grid connected to the HVDC station, which are the values obtained for the simulated scenarios.

With MMC-HVDC connection the offshore electrical grid becomes completely decoupled from the onshore power system. The faults evaluated at each side did not have impact on the network at the other end of the HVDC link. The dc chopper operated correctly to dissipate the power from the wind parks when there was a fault in the onshore ac grid.

Transient overvoltages were obtained at the 66-kV busbars which can be critical for the operation of the offshore ac grid. Fault currents were also considerably high in some of the test cases. Mitigation actions have to be considered in later stages of the project as in this moment the results are very conservative. The EMT model developed in this thesis does not have all the capabilities of a control scheme of real network. Manufactures always add extra control functionalities to improve the controllability of the system. The results of the simulations allow for an understanding of the behaviour of the system and indicate the order of magnitude of the real values for the monitored variables. 


\section{Conclusion}

The energy transition is one of the greatest societal challenges of the century. Research and innovation are of utmost importance to achieve the objectives declared by many countries in Europe and the rest of the world. As part of the efforts made by the Dutch government, it is foreseen that new large offshore wind sites will be located at distances close to $100 \mathrm{~km}$. These wind parks must be connected to the onshore power system in a standardized, modular, and cost-efficient manner.

TenneT TSO is one of the key players in the energy transition in the Netherlands. In this thesis a solution to integrate large-scale wind power generation is presented using a new connection topology able to integrate transmission capacities above $1 \mathrm{GW}$ applying HVDC technology based on VSC conversion techniques and MMC topology. The offshore wind farms are connected with $66-\mathrm{kV}$ cables to a centralised platform. The 66-kV cables will not be connected to a single busbar through paralleled converter transformers. There will be at least three converter transformers connected to each other on the valve side but not connected on the 66-kV side.

With the new topology it is possible to avoid the so-called collector platform that uses a transformer to step up the voltage as the cables are rated at $66 \mathrm{kV}$ and are then connected to the converter station (rectifier). This represents saves on CAPEX and OPEX. The tender model of offshore wind sites with different parties involved creates a scenario in which different grid connection points must be available to connect the wind turbine clusters.

Power system studies with appropriate dynamic models are needed to verify the interconnection requirements of new offshore wind farms. An EMT model was built in PSCAD to study a test network with a new connection topology and evaluate its dynamic performance. Detailed response from the system was obtained with the time-domain simulations. Several assumptions and simplifications were made to the model in order to reduce the computational burden of the simulations. However, the results are valid as the models used correctly represent the behaviour of each element of the grid for the different cases and scenarios evaluated.

The solution presented in this thesis is only one of different possible solutions being considered for future projects integrating offshore wind energy. However, the model built in PSCAD is flexible and will also allow to study other topologies and add extra control functionalities. Another important benefit of this model is that all control structures are modifiable. All components are available from libraries in PSCAD with no restrictions. No blackboxed modules are used.

Offshore ac grids at $66 \mathrm{kV}$ will become the new standard voltage for wind parks in the coming years in Europe as it offers several advantages compared to the 33-kV grids and collector platforms design as mentioned in section 3.2. Converter stations based on MMC topology are also the state-of-the-art VSC for HVDC transmission. The network under study in this thesis includes both considerations and adds the new topology of the offshore converter transformers. With the EMT model, it is possible to identify problems or abnormal situations for the operation of this grid as it emulates the electrical response very accurately.

Insights on the effects of the proposed connection topology are given through the assessment of the results of the simulations of different operational scenarios in steady state and with disturbances. Test cases included the start-up sequence, the shutdown of a complete offshore wind farm, a large rejection of one of the wind turbine clusters, faults in the offshore ac grid and faults in the onshore network. 
The control modes and selected parameters for the designed test network operated correctly for the selected leader-follower configuration of the offshore converter transformers. This was the easiet solution to implement based on the options considered. No extra modifications are required for the converter units, no new elements are needed, and the control structures of currently implemented in MMC-HVDC transmission links were not fundamentally changed.

The controllers had a stable and fast response for the offshore disturbances and the behaviour in the case of the onshore faults was expected as they remained unchanged compared to typical configurations being used nowadays extensively studied in literature.

Based on the results obtained it was demostrated that the test network has stable operation and good dynamic performance during different operational conditions including post fault recovery. The main parameter variations were found for each of the scenarios of the system.

This study and other studies such as harmonic studies will provide very valuable information for the justification, confirmation and design that are required in HVDC projects as the one defined in this thesis.

\subsection{Answer to Research Questions}

\section{What are the necessary assumptions and simplifications to perform simulations in the software tool PSCAD/EMTDC for the desired point-to-point MMC-HVDC link and the rest of the test network?}

Several assumptions and simplifications were made to the model in order to reduce the computational burden of the simulations. However, the results are valid as the models used correctly represent the behaviour of each element of the grid for the different cases and scenarios evaluated.

An aggregated model for the wind farms was implemented. Each of the three offshore wind farms is a cluster of 70 turbines for which only one turbine was modelled and then scaled up to obtain a production of $350 \mathrm{MW}$. Depending on the simulation being performed the total production of $1050 \mathrm{MW}$ was increased by steps of $350 \mathrm{MW}$ in different time points. The average model used has negligible differences with the detailed model of a type 4 wind turbine and allows for faster simulations. Wind speeds were modelled with controlled ramp functions.

Control structures implemented in the MMC units were based on generic schemes found in literature [31]. The upper and lower level controls follow the design of the controllers presented in the CIGRE DC Grid Test System. Actual MMC controls consist of two decoupling loops, one for the positive sequence and other for the negative sequence. The model built in this thesis only includes the positive sequence loop. These standard controls offer enough detail and all the main functionalities of real MMC-HVDC transmission schemes to be represented in an EMT simulation.

The representation of each MMC station was done using a detailed equivalent model. This simplification is very important to reduce the computational burden produced by the large amount of nonlinear switching devices in the MMC. It is assumed that IGBTs and diodes can be treated as two-state resistive devices. With this approach, each arm of the MMC is replaced by a Norton equivalent circuit. The number of electrical nodes is reduced while maintaining the simulation accuracy.

The representation of the ac network in this model was limited to an equivalent voltage source determining the short-circuit power of the ac system. 
A special library in PSCAD, namely VSC_MMC_Lib, is required to model the MMC stations. The half-bridge submodules and the control structures of the lower level control are elements found in this library. These components are very specific for HVDC projects and are not included in the master library which is the default library in PSCAD. The library VSC_MMC_Lib can be downloaded from the Knowledge Library on the PSCAD website.

\section{What are the associated limitations of control structures currently implemented in MMC- HVDC transmission links if multiple transformers are connected as intended in the new topology?}

The control modes currently implemented in MMC-HVDC transmission links worked well for the connection topology with three converter tranformers not in parallel at the offshore side. The offshore MMC station was modelled using the islanded configuration for the active power mode ( $\mathrm{d}$ mode) and the ac voltage control with Vac ref $=1 \mathrm{p}$.u for the reactive power mode ( $\mathrm{q}$ mode). These modes are normally implemented in the offshore terminals connecting wind energy to shore. The control modes have no limitations when applied to the new topology. The definition of the PCC is what required a throrough analysis.

The typical connection of converter transformers in parallel was modified and the definition of a new PCC became a very important question to solve. For the topology considered under study in this thesis the total phase inductance could not be considered as in the case for paralleled transformers because the three transformers connected to the offshore MMC station are not in parallel at the low voltage side, i.e. $66 \mathrm{kV}$. Options such as moving the PCC to the high voltage side of the converter transformer, possibly adding an interface reactance, and using a leader-follower scheme for the three transformers were considered.

The PCC would normally be considered the $66-k V$ busbar on the offshore platform/island, i.e. the connection point of the OWFs to TenneT's offshore grid. The control function of the MMC cannot control the three voltages at the independent nodes at $66 \mathrm{kV}$, which is the voltage after the transformers. Relocating the PCC to the converter side of the transformer at the high voltage level of $333 \mathrm{kV}$ means that the voltage to be controlled is the one at the ac side of the ac/dc converter.

A simpler approach was to implement a leader-follower scheme possibly including tap changers to the configuration of the three converter transformers at the offshore side. It does not require modifications to the control scheme or modes of the standard MMC topology as the PCC is a node at $66 \mathrm{kV}$ and all the changes are external to the converter. No additional inductance will be needed since the equivalent phase inductance remains the same as in the currently used control structures of MMC-HVDC links.

\section{What are the necessary modifications of control structures currently implemented in MMC-HVDC transmission links considering the new topology of big-transmission- capacity and long-transmission-distance OWFs proposed in this research?}

The solution presented in this thesis is a leader-follower scheme for the configuration of the three converter transformers at the offshore side. In practice, the leader transformer will provide the PCC at its 66-kV busbar for the control of the MMC terminal. The other two 66-kV busbars will have nominal value during steady state and transients will be present during disturbances. Even when the disturbance was not at the busbar of the PCC the system survived the perturbation. When the selected transformer as leader is not available, one of the other two transformers will take this role based on a control logic.

The control modes and structures that are normally implemented in MMC-HVDC transmission are suitable for the new connection topology using the leader-follower scheme. For the option controlling the voltage at the 333-kV side, some changes are necessary. Theoretically, controlling the voltage at either side of the converter transformer is possible for the MMC. The total phase inductance has to be modified, which can be done in different ways. 


\section{Future Work}

In this thesis an EMT model was developed to study the dynamic performance of a test network with a novel connection topology for the integration of OWFs to the high-voltage power grid using MMC-HVDC. For future work there are several areas in which further developments will contribute to getting a comprehensive understanding of the grid under study.

The PSCAD model can be enhanced by implementing additional control schemes which enable fault ride-through capability of the MMC-HVDC station connected to the offshore ac grid at $66 \mathrm{kV}$. One important aspect here is that a method to limit the current through the valves should be added. This will ensure optimal grid code compliance in the light of future requirements by the TSOs. Moreover, fault studies to test protection schemes and harmonics studies to test power quality are also feasible using the EMT model developed in this thesis.

Generic or average models for most of the elements in the EMT model has been used. Detailed models of some equipment represented in the test network can eliminate part of the assumptions made to obtain even more accurate results. However, the simulation time will increase. The average model of the type 4 wind turbine could be improved. Data from manufactures of different components could be used apart from the input parameters based on the CIGRE DC grid test system.

The control structures implemented are based on standard schemes used for MMC stations. However, new trends have recently been introduced for the grid forming control of renewable generation units. If those controls become the new standard for the next generation of MMC technology in the near future, then they must be adapted to the test network and extra simulations will be needed.

Other studies are essential to guarantee the stable operation of the offshore network. Particularly, harmonic stability is a critical aspect that has to be carefully investigated. The high frequency interactions between the power converters and the offshore ac cables must always be damped. 


\section{Bibliography}

[1] European Commission, "Climate Action," [Online]. Available: https://ec.europa.eu/clima/policies/strategies/2020_en. [Accessed 21 June 2018].

[2] Ecofys, "Translate COP21 2045 outlook and implications for offshore wind in the North Sea," Utrecht, 2017.

[3] Global Wind Energy Council, "Global Wind Report - Annual Market Update 2017," Brussels, 2018.

[4] Wind Europe, "Offshore Wind in Europe - Key trends and statistics 2017," Brussels, 2018.

[5] Tweede Kamer der Staten-Generaal, "Routekaart windenergie op zee 2030," [Online]. Available: https://www.tweedekamer.nl/kamerstukken/brieven_regering/detail?id=2018Z05409\&did=2018D21716. [Accessed 21 June 2018].

[6] G. Chen, M. Hao, Z. Xu, A. Vaughan, J. Cao and H. Wang, "Review of High Voltage Direct Current Cables," CSEE Journal of Power and Energy Systems, vol. 1, no. 2, pp. 9-21, 2015.

[7] CIGRÉ Working Group B4.55, "HVDC Connection of Offshore Wind Power Plants, Technical Brochure 619," CIGRÉ, 2015.

[8] TenneT TSO, "Offshore Projects Germany," [Online]. Available: https://www.tennet.eu/our-grid/offshoreprojects-germany-2/?tx_kesearch_pi1\%5Bview\%5D=grid\&tx_kesearch_pi1\%5Bfilter\%5D\%5B-

2\%5D\%5B0\%5D=syscat72\&tx_kesearch_pi $1 \% 5 \mathrm{Bfilter} \% 5 \mathrm{D} \% 5 \mathrm{~B}-1 \% 5 \mathrm{D} \% 5 \mathrm{~B}-4 \% 5 \mathrm{D}=-$

4\&tx_kesearch_pi1\%5Bpage\%5D=2\&tx_kesearch_pi1\%5Bsword\%5D=\&cHash=a2b. [Accessed 14 June 2018].

[9] CIGRE Working Group B4.37, "VSC Transmission, Technical Brochure 269," 2005.

[10] K. Sharifabadi, L. Harnefors, H.-P. Nee, S. Norrga and R. Teodorescu, Design, Control, and Application of Modular Multilevel Converters for HVDC Transmission Systems, John Wiley \& Sons, Ltd., 2016.

[11] S. Allebrod, R. Hamerski and M. R., "New transformerless, scalable Modular Multilevel Converters for HVDC-transmission," in 2008 IEEE Power Electronics Specialists Conference, Rhodes, 2008.

[12] J. Dorn, H. Huang and D. Retzmann, "A new Multilevel Voltage-Sourced Converter Topology for HVDC Applications," in CIGRE Session 2008, Paris, 2008.

[13] T. Westerweller, K. Friedrich and U. Armonies, "Trans Bay Cable - World's First HVDC System using Multilevel Voltage-Sourced Converter," in CIGRÉ Session 2010, Paris, 2010.

[14] J. Dorn, H. Huang and D. Retzmann, "Novel Voltage-Sourced Converters for HVDC and FACTS Applications," in CIGRÉ Symposium, Osaka, 2007.

[15] C. Oates, "Modular Multilevel Converter Design for VSC HVDC Applications," IEEE Journal of Emerging and Selected Topics in Power Electronics, vol. 3, no. 2, pp. 505 - 515, 2015.

[16] Siemens, "HVDC PLUS (VSC Technology)," [Online]. Available: https://www.energy.siemens.com/hq/en/power-transmission/hvdc/hvdc-plus.htm. [Accessed 14 June 2018].

[17] GE, "HVDC Systems," [Online]. Available: https://www.gegridsolutions.com/PowerD/catalog/hvdc.htm. [Accessed 14 June 2018].

[18] CIGRÉ Working Group B4.52, "HVDC Grid Feasibility Study, Technical Brochure 533," CIGRÉ, 2013.

[19] J. Liang, O. Gomis-Bellmunt and D. Van Hertem, "Chapter 8: HVDC Grid Layouts," in HVDC Grids: For Offshore and Supergrid of the Future, John Wiley \& Sons, Inc., 2016, pp. 171 - 191.

[20] Friends of the Supergrid, "Roadmap to the Supergrid Technologies," Brussels, 2016.

[21] N. e. a. Ahmed, "HVDC SuperGrids with modular multilevel converters - The power transmission backbone of the future," in International Multi-Conference on Systems, Sygnals \& Devices, Chemnitz, 2012.

[22] R. Wiser, K. Jenni, J. Seel, E. Baker, M. Hand, E. Lantz and A. Smith, "Forecasting Wind Energy Costs and Cost Drivers: The Views of the World's Leading Experts (IEA Wind Task 26)," Lawrence Berkeley National Laboratory, 2016. 
[23] B. Bulder, E. Bot and G. Bedon, "Optimal wind farm power density analysis for future offshore wind farms," ECN Wind Energy, Petten, 2018.

[24] V. Yaramasu, B. Wu, P. C. Sen, S. Kouro and M. Narimani, "High-Power Wind Energy Conversion Systems: State-of-the-Art and Emerging Technologies," Proceedings of the IEEE, vol. 102, no. 5, pp. 740-788, 2015.

[25] DNV GL , "66 kV Systems for Offshore Wind Farms," TenneT, Arnhem, 2015.

[26] Manitoba HVDC Research Centre, "User's guide on the use of PSCAD V4.6.0," Winnipeg, 2016.

[27] S. R. Deore, P. B. Darji and A. M. Kulkarni, "Switching function analysis of half- and full-bridge modular multi-level converters for HVDC applications," IET Generation, Transmission \& Distribution, vol. 7, no. 11, pp. 1344 - 1356, 2013.

[28] A. Nami and H. Nademi, "Chapter 17: Modular Multilevel Converter (MMC) and Its Control," in Control of Power Electronic Converters and Systems, Elsevier Inc., 2018, pp. 141 - 166.

[29] A. Abdalrahman and E. Isabegovic, "DolWin1 - Challenges of connecting offshore wind farms," 2016 IEEE International Energy Conference (ENERGYCON), Leuven, 2016.

[30] J. Peralta, H. Saad, S. Dennetiere, J. Mahseredjian and S. Nguefeu, "Detailed and Averaged Models for a 401-Level MMC-HVDC System," IEEE Transactions on Power Delivery, vol. 27, no. 3, pp. 1501-1508, 2012.

[31] CIGRE Working Group B4.57, "Guide for the Development of Models for HVDC Converters in a HVDC Grid, Technical Brochure 604," 2014.

[32] U. N. Gnanarathna, "Efficient Modeling of Modular Multilevel HVDC Converters (MMC) on Electromagnetic Transient Simulation Programs.," University of Manitoba, Winnipeg , 2014.

[33] V. Hussennether, J. Rittiger, A. Barth, D. Worthington, G. Dell'anna, M. Rapetti, B. Huhnerbein and M. Siebert, "Projects BorWin2 and HelWin1 - Large Scale Multilevel Voltage-Sourced Converter Technology for Bundling of Offshore Windpower," in CIGRÉ Session 2012, Paris, 2012.

[34] H. e. a. Saad, "Dynamic Averaged and Simplified Models for MMC-Based HVDC Transmission Systems," IEEE Transactions on Power Delivery, vol. 28, no. 3, pp. 1723 - 1730, 2013.

[35] G. Migliavacca, Advanced Technologies for Future Transmission Grids, London: Springer Science \& Business Media, 2012.

[36] S. Dennetière, S. Nguefeu, H. Saad and J. Mahseredjian, "Modeling of Modular Multilevel Converters for the France-Spain link," in International Conference on Power Systems Transients (IPST2013), Vancouver, 2013.

[37] L. He, "Effects of pre-insertion resistor on energization of MMC-HVDC stations," IEEE Power \& Energy Society General Meeting, Chicago, 2017.

[38] H. Saad, S. Dennetière, J. Mahseredjian, T. Ould-Bachir and J.-P. David, "Chapter 9: Simulation of Transients for VSC-HVDC Transmission Systems Based on Modular Multilevel Converters," in Transient Analysis of Power Systems: Solution Techniques, Tools and Applications, John Wiley \& Sons, Ltd., 2015, pp. 317 - 359.

[39] S. Debnath, J. Qin, B. Bahrani, M. Saeedifard and P. Barbosa, "Operation, Control, and Applications of the Modular Multilevel Converter: A Review," IEEE Transactions on Power Electronics, vol. 30, no. 1, pp. 37 - 53, 2015.

[40] A. Beddard and M. Barnes, "Modelling of MMC-HVDC Systems - An Overview," Energy Procedia, vol. 80, pp. 201-212, 2015.

[41] C.-K. Kim, V. K. Sood, G.-S. Jang, S.-J. Lim and S.-J. Lee, "Chapter 8: Insulation Coordination of HVDC," in HVf)C Transmission: Power Conversion Applications ;n Power Systems , John Wiley \& Sons (Asia) Pte Ltd., 2009, pp. 279 - 293.

[42] Siemens AG, "High-voltage surge arresters (Product guide)," Energy Sector, Erlangen - Berlin, 2014.

[43] J. C. Garcia and F. Mosallat, "Webinar: MMC- Technologies," Manitoba-HVDC Research Centre, 2015.

[44] H. A. Saad, "Modélisation et simulation d'un liason hvdc de type vsc-mmc.," École Polytechnique de Montréal, 2015. 
[45] Q. Tu, Z. Xu and L. Xu, "Reduced Switching-Frequency Modulation and Circulating Current Suppression for Modular Multilevel Converters," IEEE Transactions on Power Delivery, vol. 26, no. 3, pp. 2009 - 2017, 2011.

[46] M. A. Perez, S. Bernet, J. Rodriguez, S. Kouro and R. Lizana, "Circuit Topologies, Modeling, Control Schemes, and Applications of Modular Multilevel Converters," IEEE Transactions on Power Electronics, vol. 30, no. 1, pp. $4-17,2015$.

[47] CIGRE Working Group B4.38, "Modelling and Simulation Studies to be performed during the lifecycle of HVDC Systems, Technical Brochure 563," 2013.

[48] PSCAD, "Type-4 Wind Turbine Model," Manitoba Hydro International, Winnipeg, 2018.

[49] A. Küchler, High Voltage Engineering, Schweinfurt: Springer-Verlag GmbH, 2018. 